\begin{tabular}{|l|c|}
\hline STA. 3048 & Page 1 of $\frac{1}{}$ \\
JAN 191999 & ENGINEERING DATA TRANSMITTAL No 611031 \\
\hline
\end{tabular}

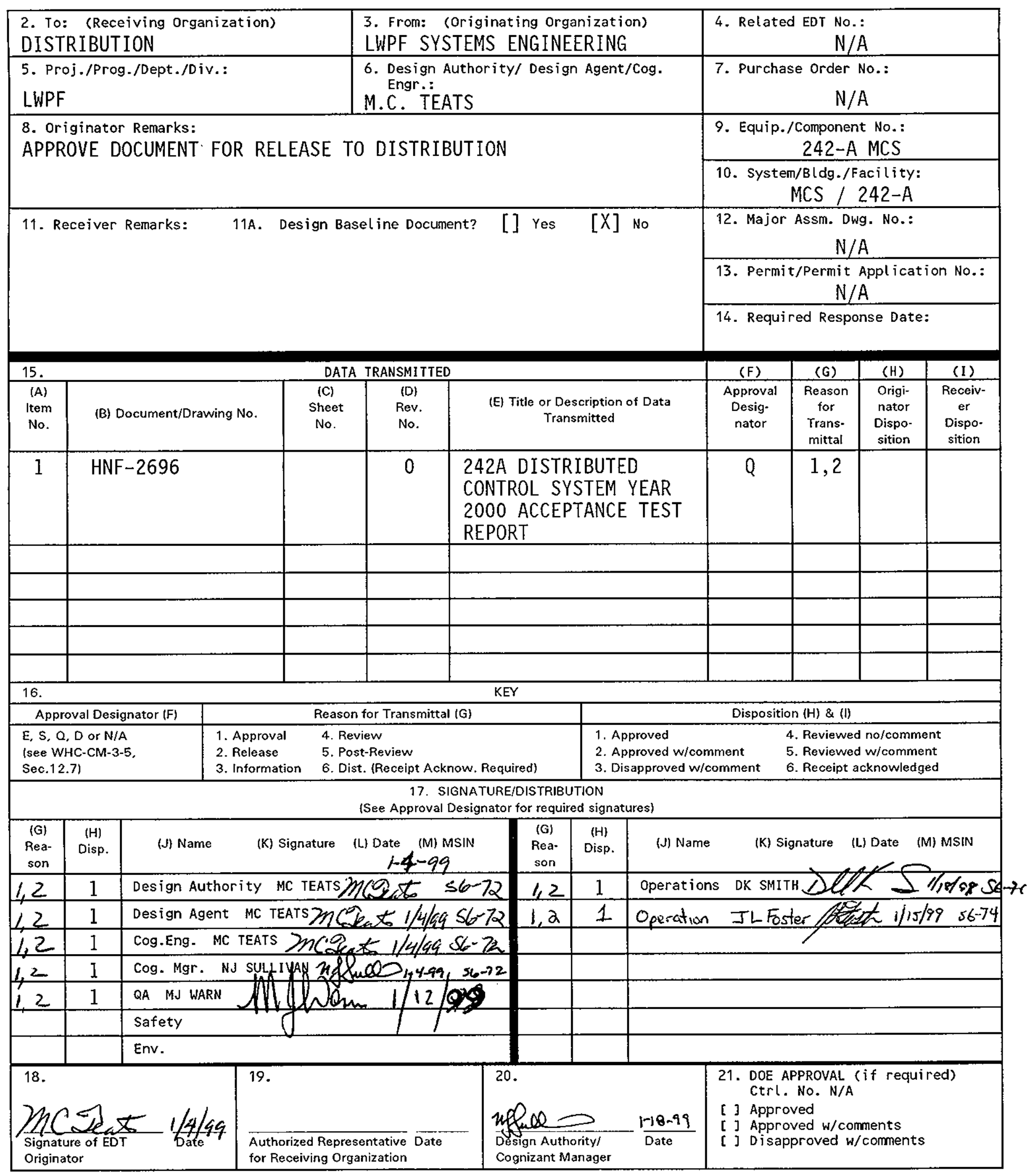

BD-7400-172-2 (05/96) GEF097 


\title{
242A DISTRIBUTED CONTROL SYSTEM YEAR 2000 ACCEPTANCE TEST REPORT
}

\section{M.C. TEATS}

WASTE MANAGEMENT HANFORD, Richland, WA 99352

U.S. Department of Energy Contract DE-AC06-96RL13200

\author{
EDT/ECN: 611031 \\ UC: 2030 \\ Org Code: 32230 \\ Charge Code: 101624 / AJ10 \\ B\&R Code: EW3120071 \\ Total Pages: 159
}

Key Words: Distributive Control System, 242-A, MCS, Year 2000

Abstract: This report documents acceptance test results for the 242-A Evaporator distributive control system upgrade to $D / 3$ version $9.0-2$ for year 2000 compliance.

TRADEMARK DISCLAIMER. Reference herein to any specific commercial product, process, or service by trade name, trademark, manufacturer, or otherwise, does not necessarily constitute or imply its endorsement, recommendation, or favoring by the United States Government or any agency thereof or its contractors or subcontractors.

Printed in the United States of America. To obtain copies of this document, contact: Document Control Services, P.0. Box 950, Mailstop 46-08, Richland WA 99352, Phone (509) 372-2420;

Fax (509) 376-4989.
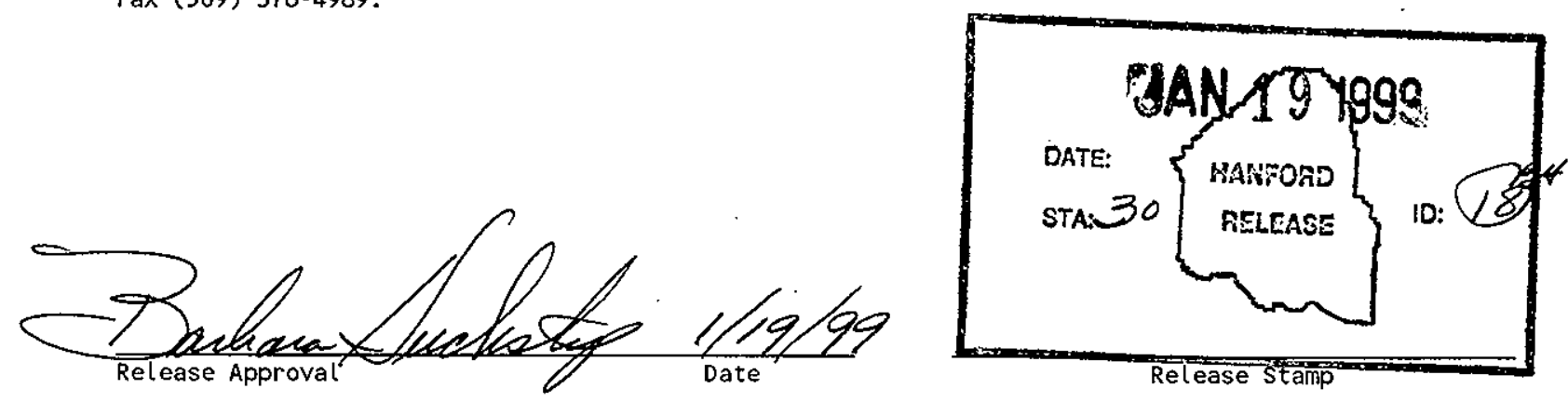
HNF-2696 REV 0.

\section{A DISTRIBUTED CONTROL SYSTEM}

YEAR 2000

ACCEPTANCE TEST REPORT 


\section{TABLE OF CONTENTS}

ACCEPTANCE TEST REPORT SUMMARY

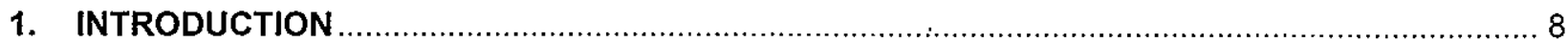

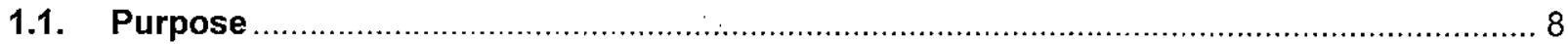

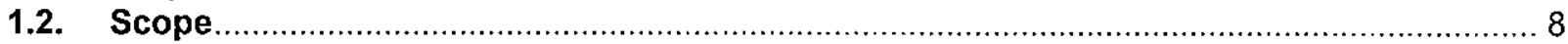

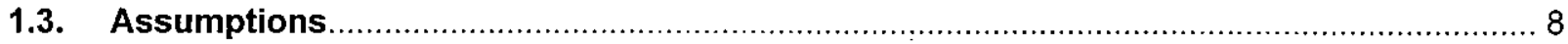

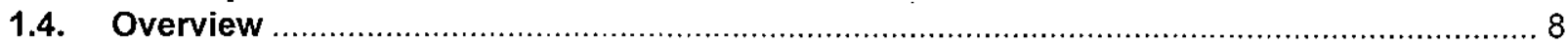

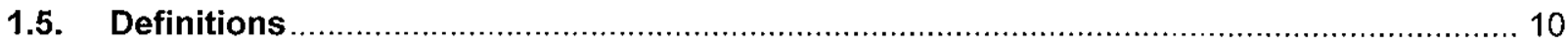

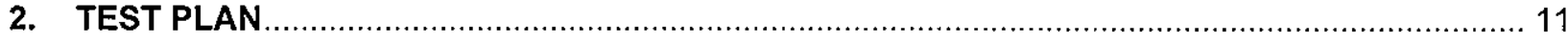

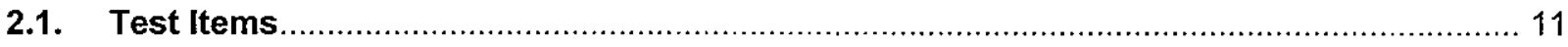

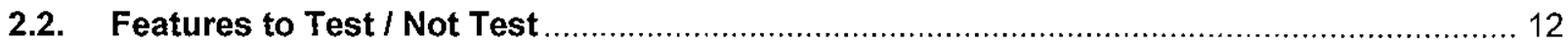

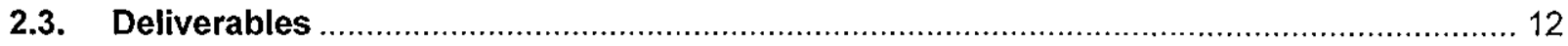

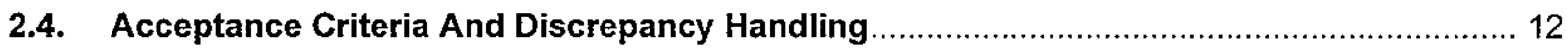

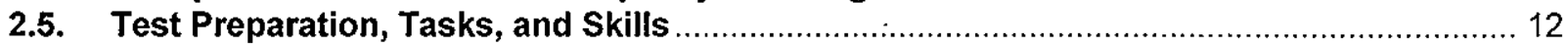

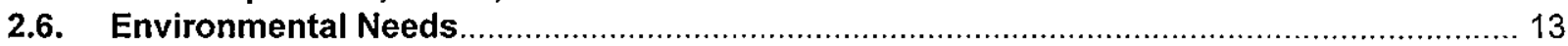

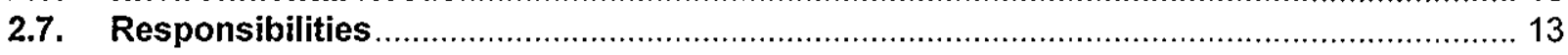

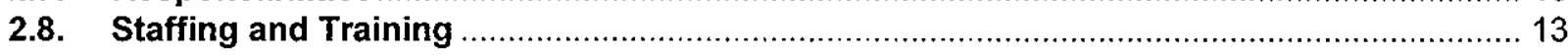

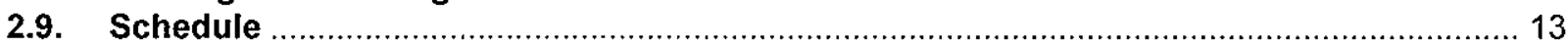

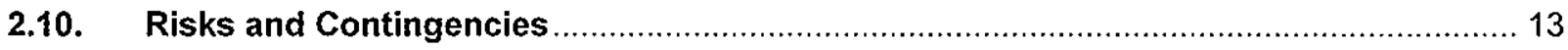

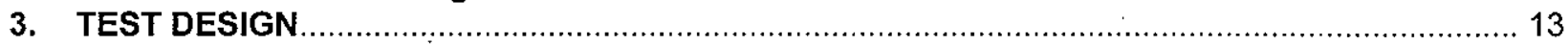

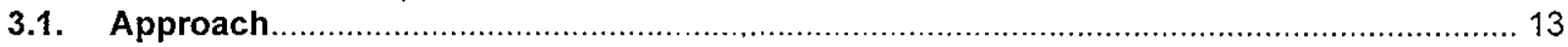

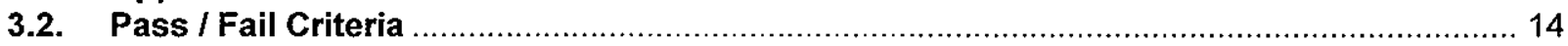

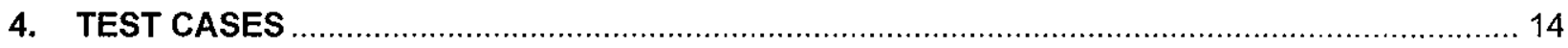

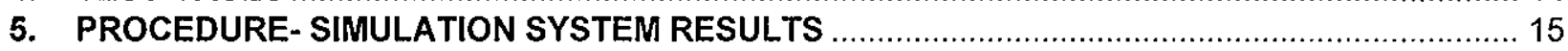

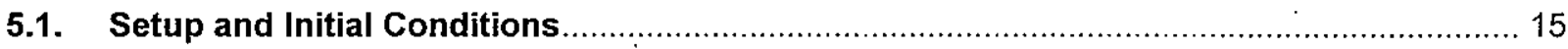

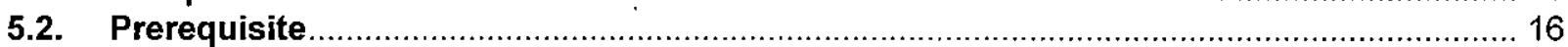

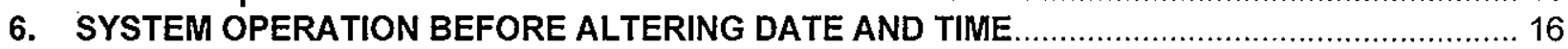

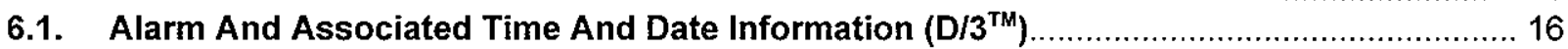

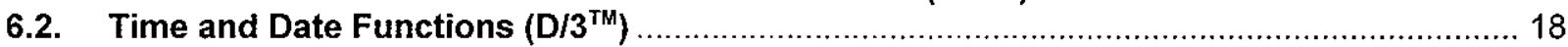

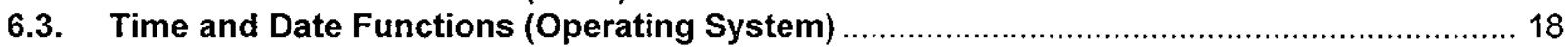

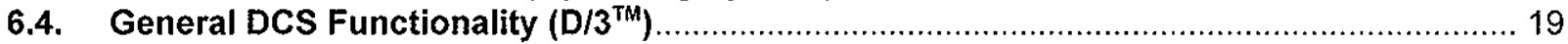

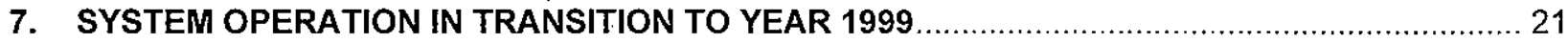

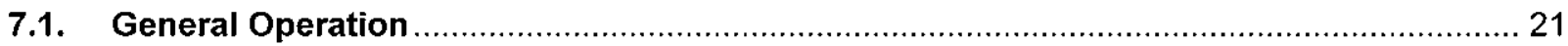

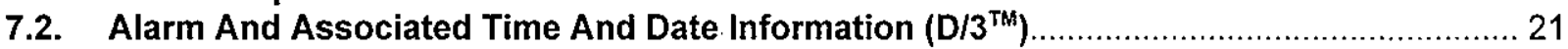

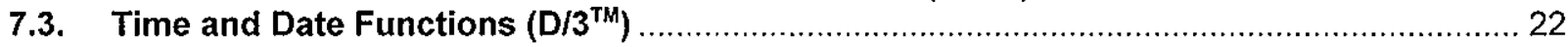

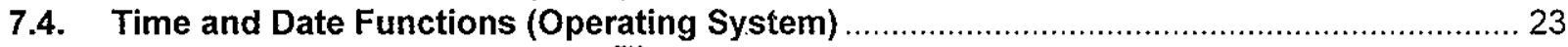

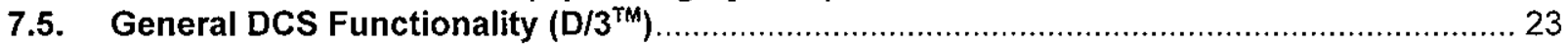

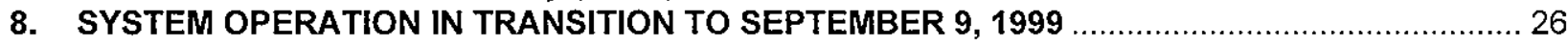

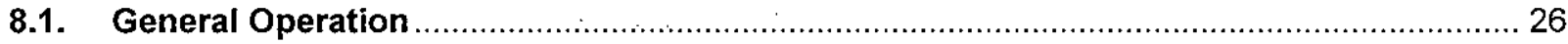

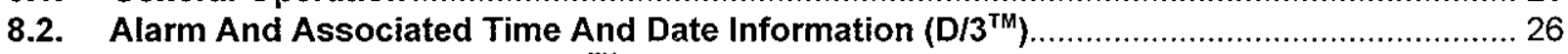

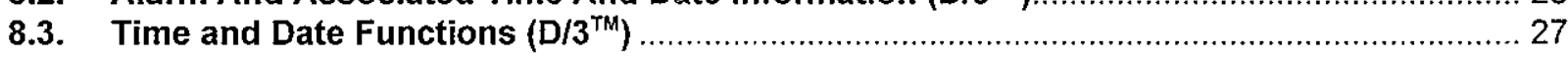

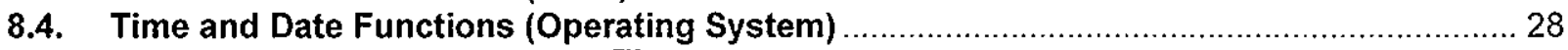

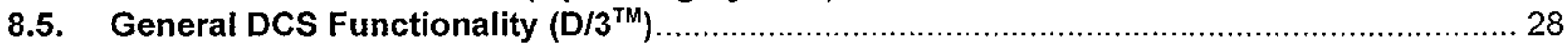

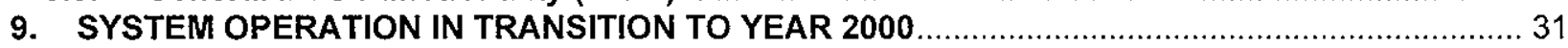

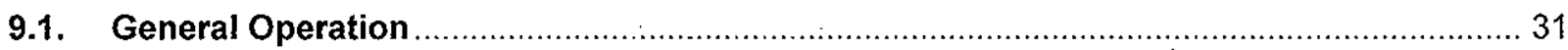

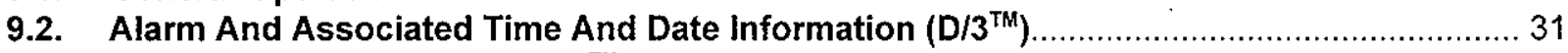

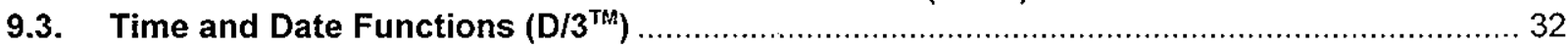

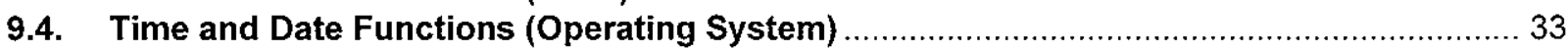

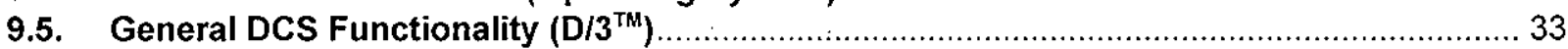


10. SYSTEM OPERATION DURING INITIAL LEAP YEAR RECOGNITION ............................... 36

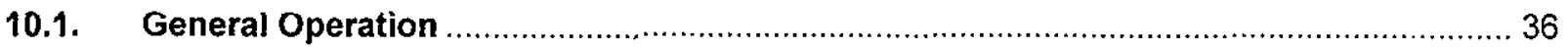

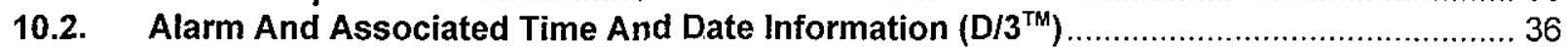

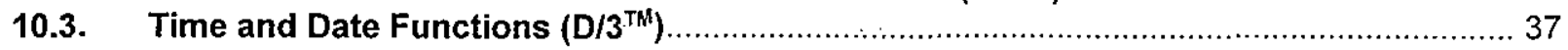

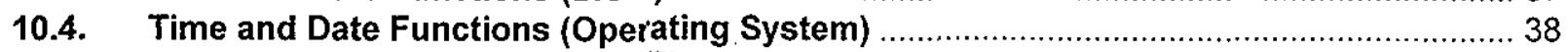

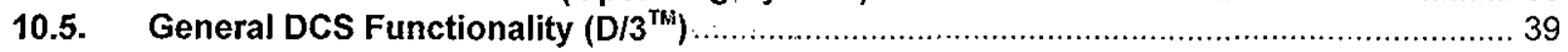

11. SYSTEM OPERATION FOLLOWING FEBRUARY 29, 2000 RECOGNITION ......................... 41

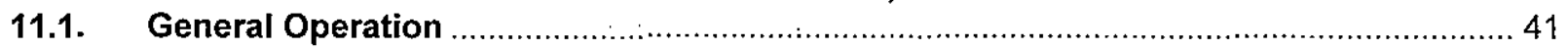

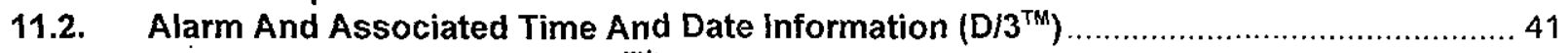

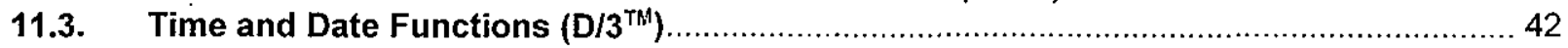

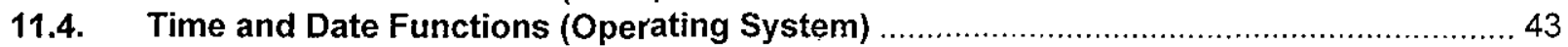

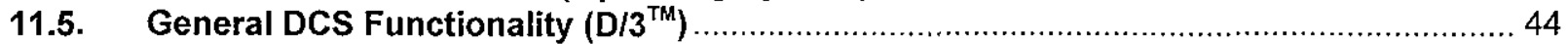

12. SYSTEM OPERATION TO EXPOSE BAD LEAP YEAR CALCULATION (<366 DAYS) ............46

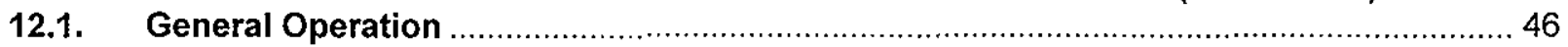

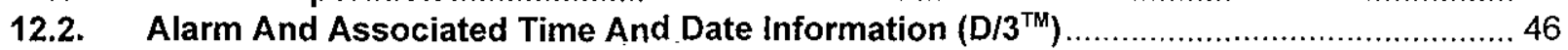

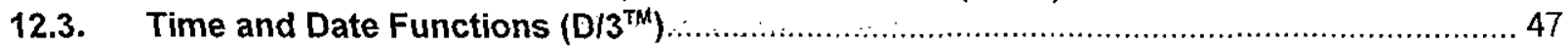

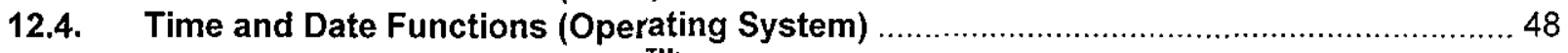

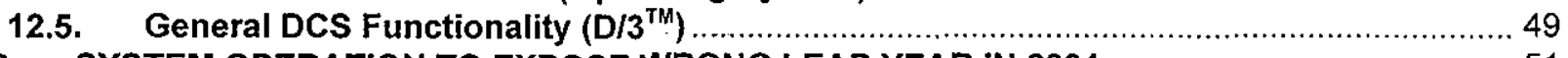

13. SYSTEM OPERATION TO EXPOSE WRONG LEAP YEAR IN 2001............................... 51

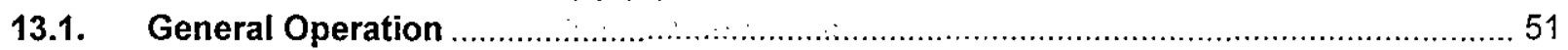

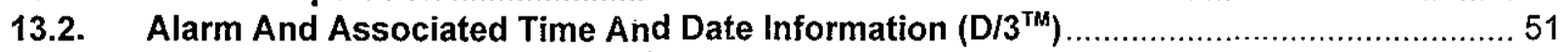

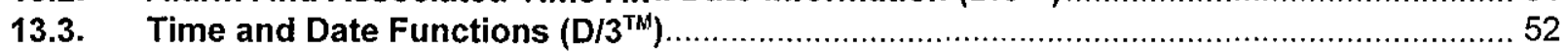

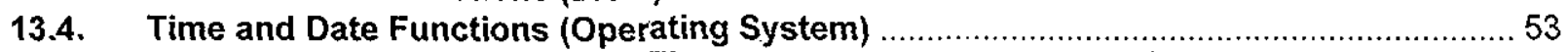

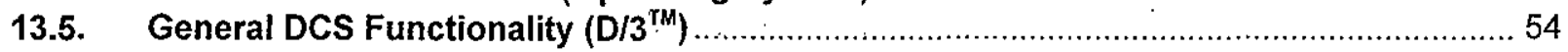

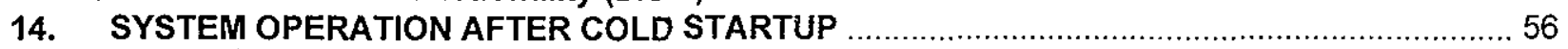

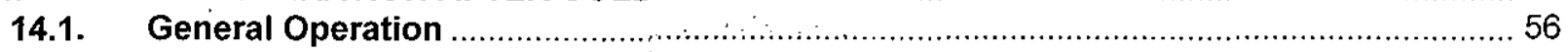

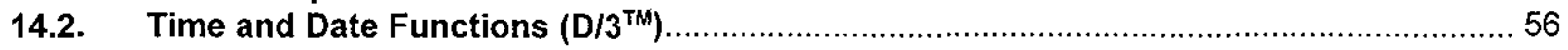

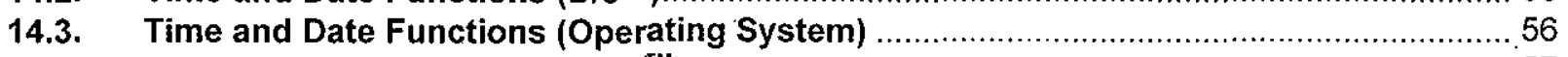

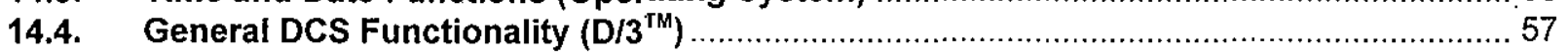

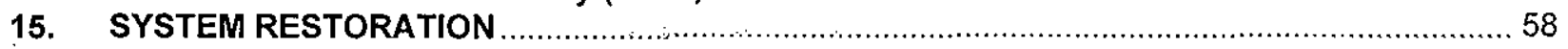

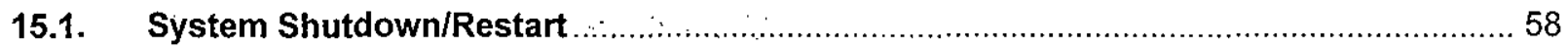

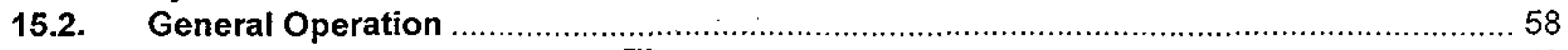

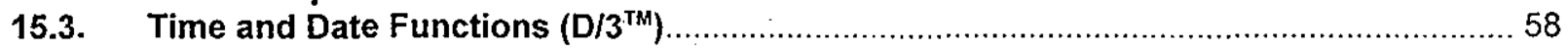

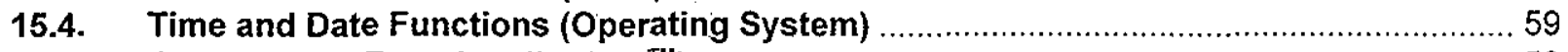

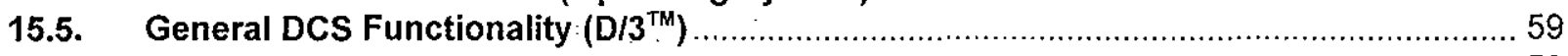

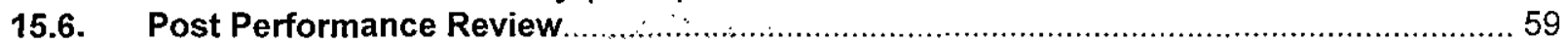

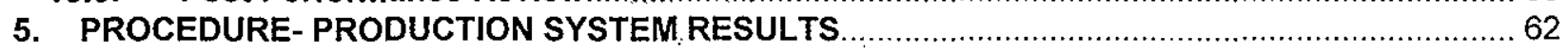

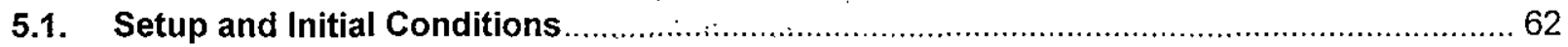

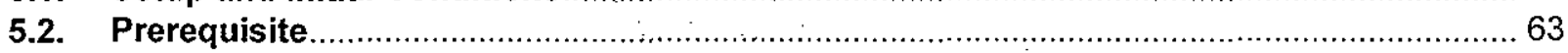

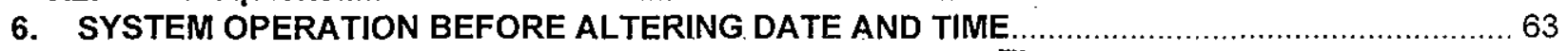

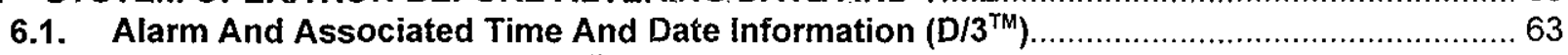

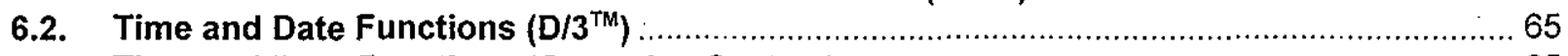

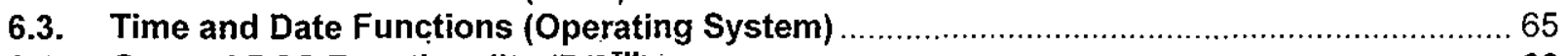

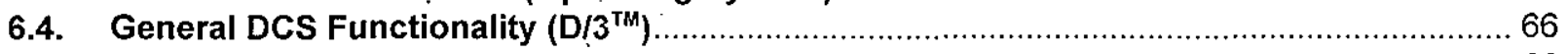

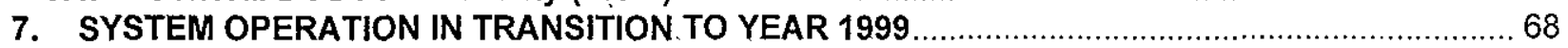

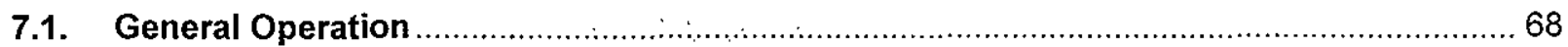

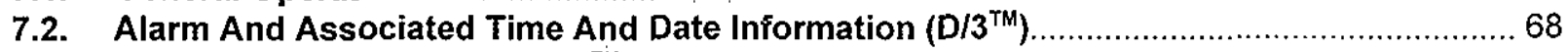

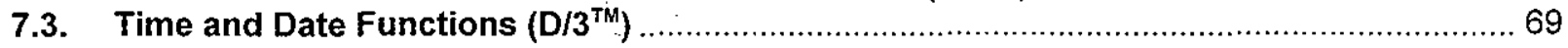

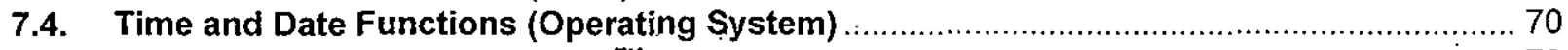

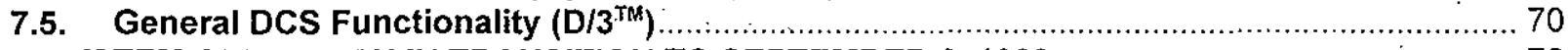

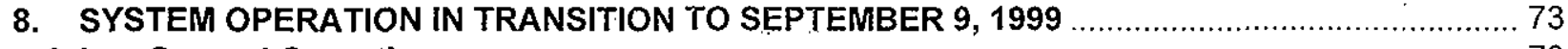

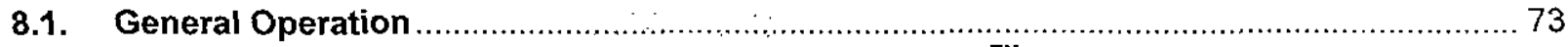

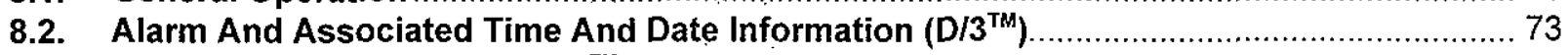

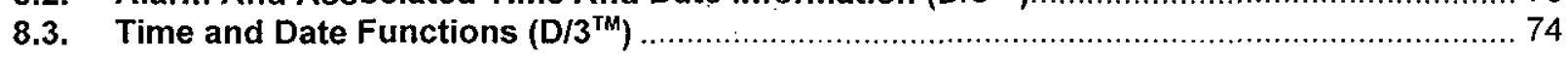


8.4. Time and Date Functions (Operating System) ….................................................. 75

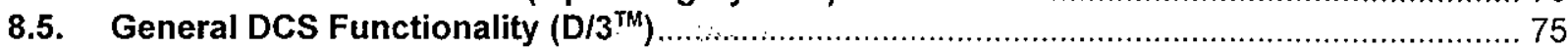

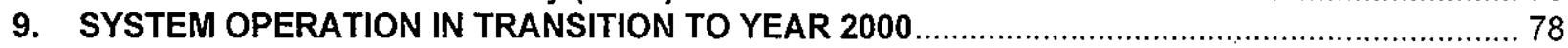

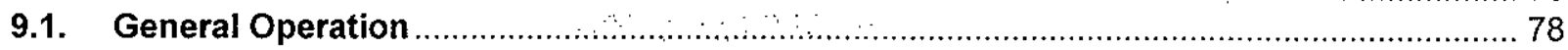

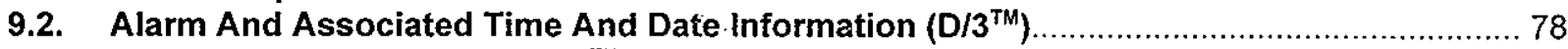

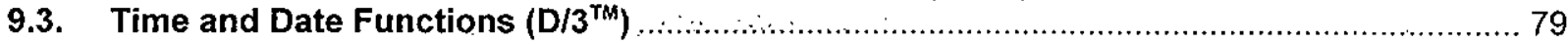

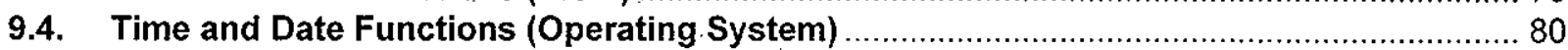

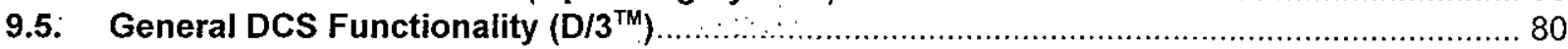

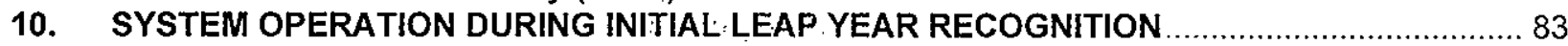

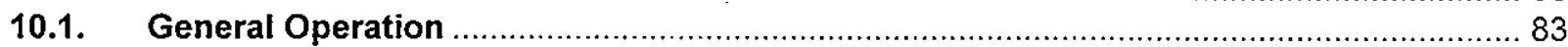

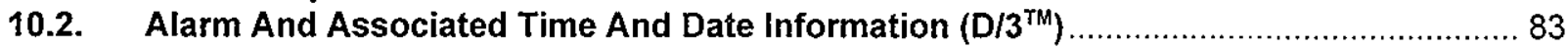

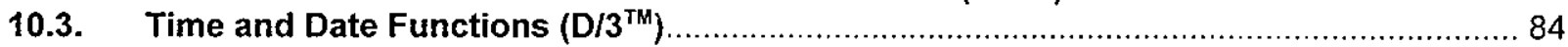

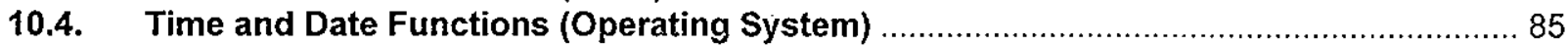

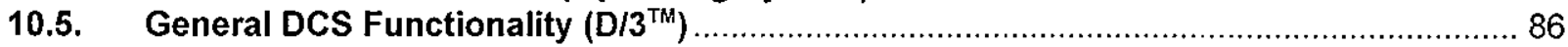

11. SYSTEM OPERATION FOLLOWING FEBRUARY 29, 2000 RECOGNITION …................... 88

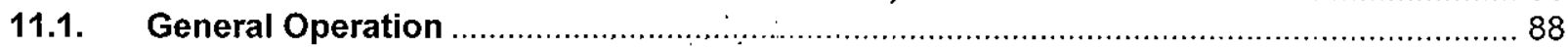

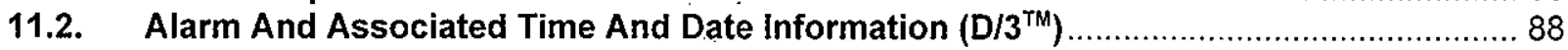

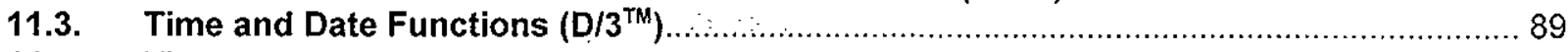

11.4. Time and Date Functions (Operating System) ................................................... 90

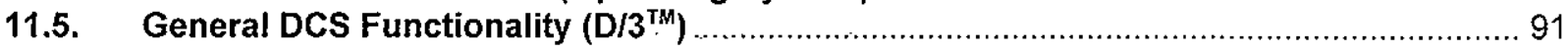

12. SYSTEM OPERATION TO EXPOSE BAD LEAP YEAR CALCULATION (<366 DAYS) .............93

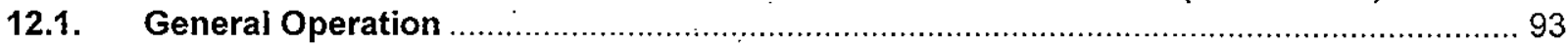

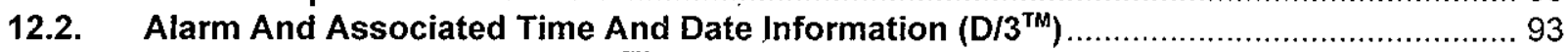

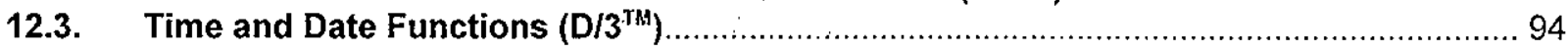

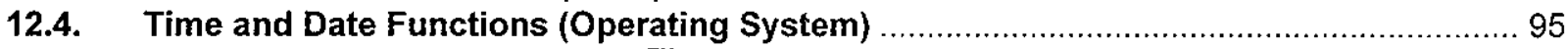

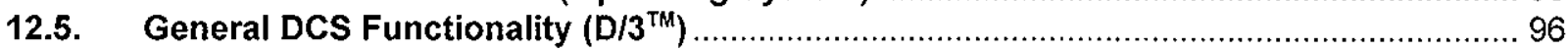

13. SYSTEM OPERATION TO EXPOSE WRONG LEAP YEAR IN $2001 \ldots \ldots \ldots \ldots \ldots \ldots \ldots \ldots \ldots \ldots . . \ldots 8$

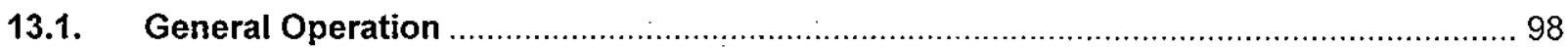

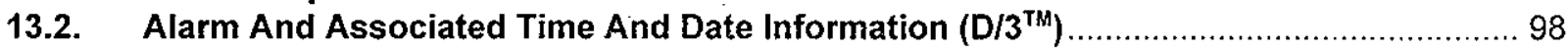

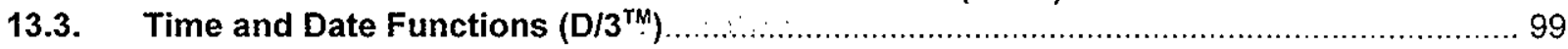

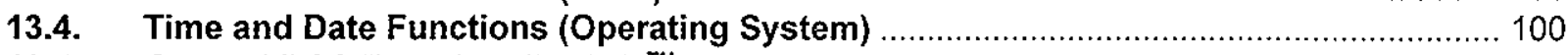

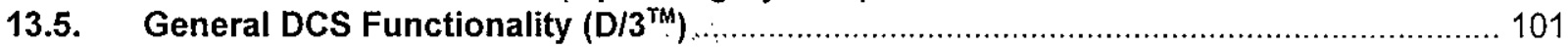

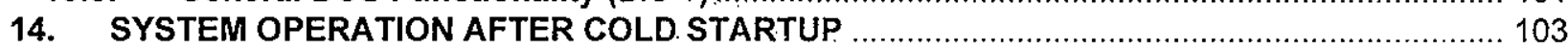

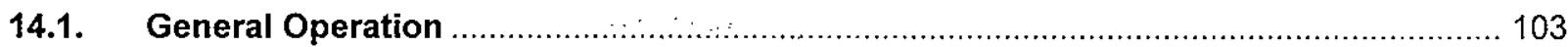

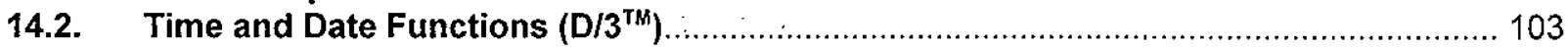

14.3. Time and Date Functions (Operating System) …............................................. 103

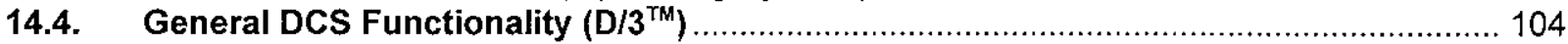

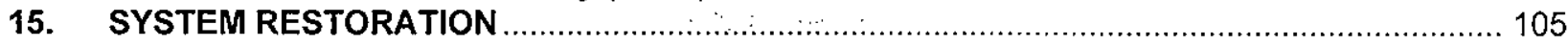

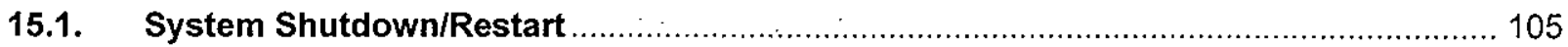

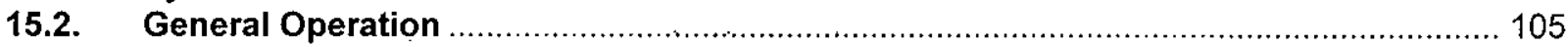

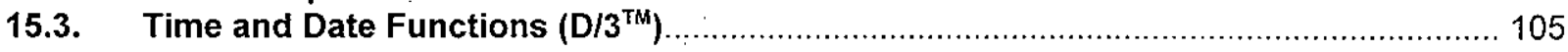

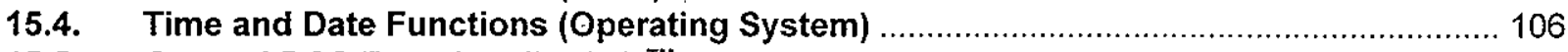

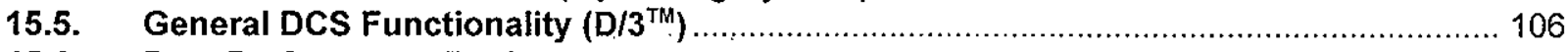

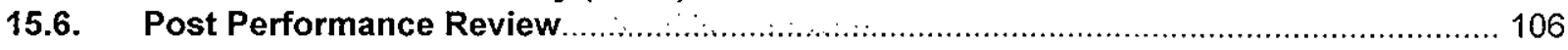


HNF-2696 REV 0

\section{TABLE:OF ATTACHMENTS}

ATTACHMENT 1: D/3 ${ }^{\text {TM }}$ DCS YEAR 2000 TEST CRITERIA 60

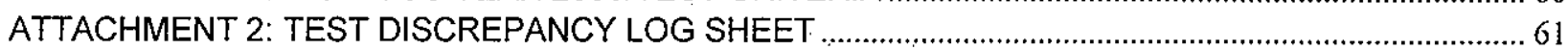

ATTACHMENT 3: TEST DISCREPANCIES BEFORE UPGRADE …….................................................. 107

ATTACHMENT 4: TEST DISCREPANCIES AFTER UPGRADE........................................................ 111

ATTACHMENT 5: SAMPLE TEST RESULTS ON SYSTEM UPGRADED FOR Y2K COMPLIANCE 
HNF-2696 REV 0

\section{TABLE OF FIGURES}

FIGURE 1: SYSTEM ARCHITECTURE .. 


\section{ACCEPTANCE TEST REPORT SUMMARY}

This test was performed per HNF-2695, 242A DISTRIBUTED CONTROL SYSTEM YEAR 2000 ACCEPTANCE TEST PROCEDURE. Two tests were performed; one on the original non-compliant system to provide baseline data, and the second on a system that was upgraded to be Year 2000 compliant.

Results of the baseline testing of the non-compliant system are documented on pages 15 through 59 and exceptions are documented in Attachment 3 (pages 107 to 110). All of these exceptions were resolved by the upgrade to the Year 2000 compliant system.

Results of the testing of the upgraded system are documented on pages 62 through 106 . Samples of the system data are documented in Attachment 5 (pages 113 to 158). There were no Year 2000 related exceptions exposed during testing. All displays, data, directories, and file contents correctly depicted the dates and times. All archived alarm and historical data files were created correctly, and the display of archived data performed without flaw. All systems functioned normally.

During testing of the upgraded system, two minor exceptions (see Attachment 4, pages 111 to 112) were exposed that are not related to the time/ date issue. These are not detrimental to the system operation. The first of these exceptions has already been fixed. The second exception involves the display of tag names and their descriptions to operators when running the $C$ program that generates a list of inhibited alarms. The tag names are correctly displayed, but not all descriptions are displayed correctly. The resolution is to accept this as-is for the procurement, but resolve the programming problem as time permits after installation at the 242-A Evaporator.

ACCEPTANCE TEST PROCEDURE APPROVALS:
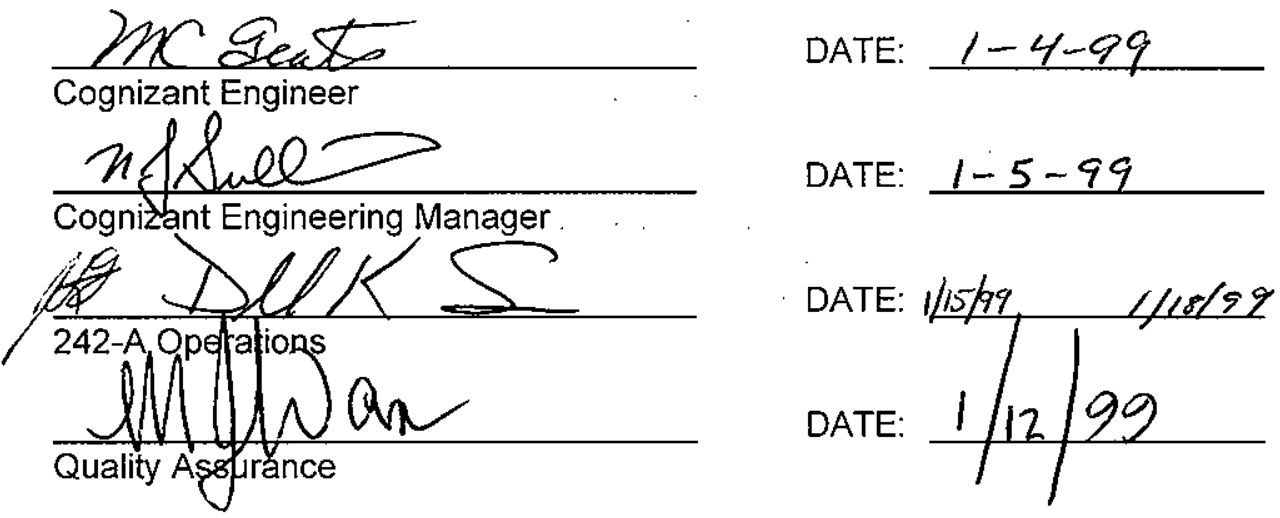


\section{INTRODUCTION}

\subsection{Purpose}

This report documents the test results obtained by acceptance testing as directed by procedure HNF-2695. This verification procedure will document the initial testing and evaluation of the potential 242-A Distributed Control System (DCS) operating difficulties across the year 2000 boundary and the calendar adjustments needed for the leap year. Baseline system performance data will be recorded using current, as-is operating system software. Data will also be collected for operating system software that has been modified to correct year 2000 problems.

\subsection{Scope}

This verification procedure is intended to be generic such that it may be performed on any $D / 3^{\mathrm{TM}}$ (GSE Process Solutions, Inc.) distributed control system that runs with the VMS ${ }^{\mathrm{TM}}$ (Digital Equipment Corporation) operating system. This test may be run on simulation or production systems depending upon facility status. On production systems, DCS outages will occur nine times throughout performance of the test. These outages are expected to last about 10 minutes each.

\subsection{Assumptions}

If adverse symptoms are observed when the test is executed on a simulation system, it will be assumed that these same symptoms will occur on the corresponding production system.

\subsection{Overview}

This document addresses testing of the vendor software for the 242-A Evaporator DCS. The evaporator concentrates low-heat-generating liquid wastes, reducing the volume and the number of double-shell tanks required to store the liquid wastes. This facility is monitored and controlled by a $D / 3^{\mathrm{TM}} \mathrm{DCS}$. The facility production system consists of the following hardware devices (see Figure 1).

- 2 Display Control Modules (DCMs), CDCM and DCM

- 21 Gigabyte hard drives, one for each DCM

- 2800 Megabyte hard drives, one for each DCM

- 4 Process Control Modules (PCMs); PCMOA, PCMOB, PCM1A, and PCM1B

- 11 Multiplexer cabinets for input and output

- 4 operator control stations (CDCM OCM 0, CDCM OCM 1, DCM OCM 1)

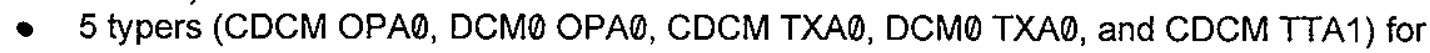
alarm and report documentation

- 1 to 3 VT-220 Programming Terminals and Keyboards

- 1 PC (PC TERM) for building graphics 0

- 1 Color Printer (CP) for color copying displays

- 1 Versatec $^{\mathrm{TM}}$ (Versatec Corp.) color copier and controller

- 1 Vaxstation 4000-60 Engineers terminal. (VAX TERM)

The simulation system runs the same software versions as the production system, but with fewer hardware components. 


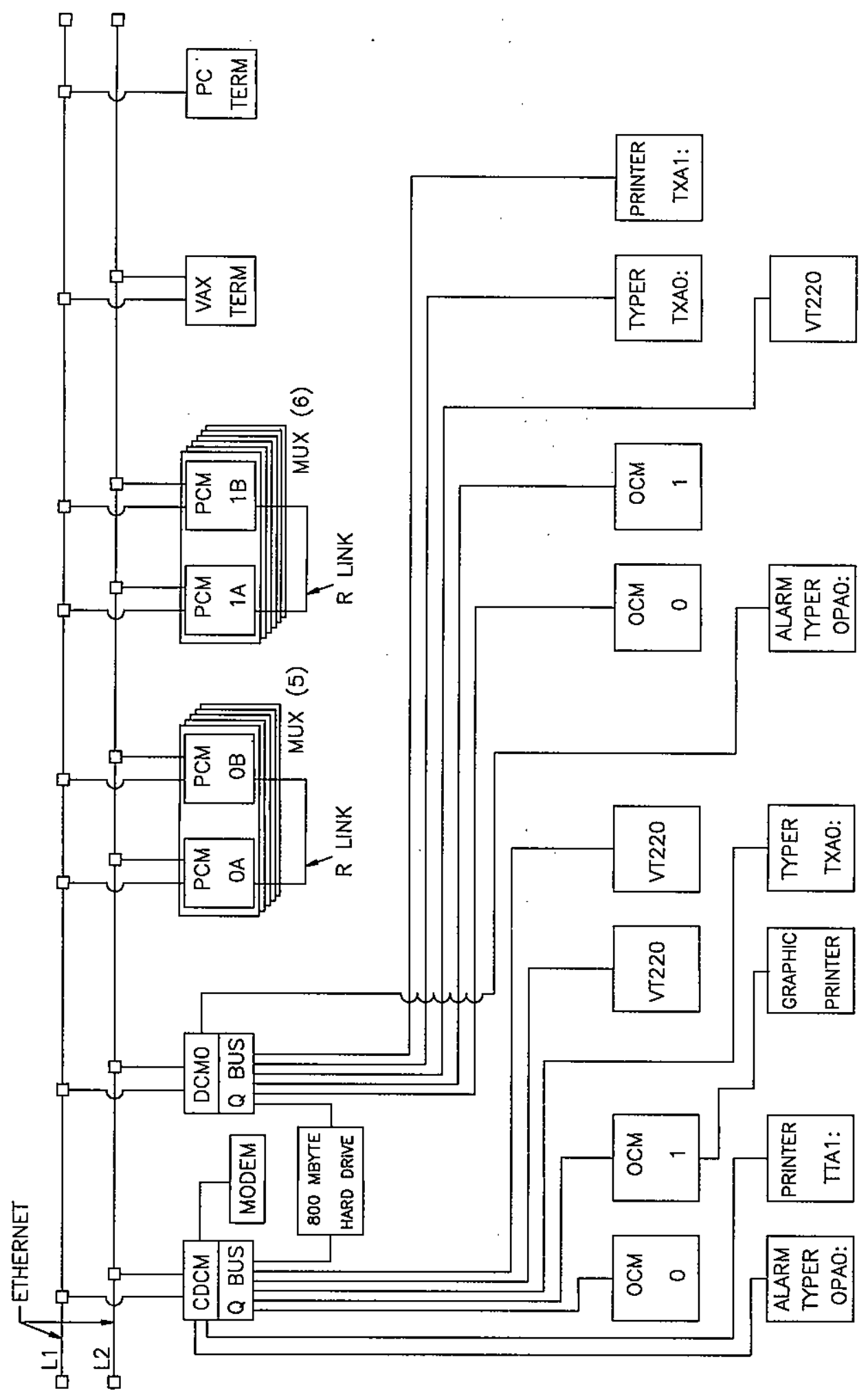

FIGURE 1: SYSTEM ARCHITECTURE 


\section{HNF-2696 REV 0}

The two display control modules (DCMs), CDCM and DCMO, are VAX 4000-105A computers with $\mathrm{VMS}^{\mathrm{TM}}$ as the operating system. These computers also run numerous $\mathrm{D} / 3^{\mathrm{TM}}$ tasks required for overall system functionality. The CDCM normally provides the system wide time and date used by the other processors. This function defaults to the backup processors, DCM0 followed by the Process Control Modules (PCMs), when the $\mathrm{CDCM} D / 3^{\mathrm{TM}}$ software is not running.

The PCMs are microprocessors that contain the D/3 ${ }^{\mathrm{TM}}$ tasks that execute facility controls based on the 242-A Evaporator databases, programs, and operator actions. There are two PCMO microprocessors, $\mathrm{PCM} O \mathrm{~A}$ and $\mathrm{PCM} \mathrm{B}$, which are configured as redundant units and have identical capabilities. Both microprocessors run continuously, with one performing the process control functions while the other is held in reserve as the backup. In the event that the controlling microprocessor fails, the backup takes over control of the process without loss of control continuity. Likewise, there are two redundant PCM1 microprocessors, PCM1A and PCM1B. The PCMs provide time and date stamps on messages they generate, but this time and date is normally obtained from the CDCM or another polling master if the CDCM's D/3 ${ }^{\mathrm{TM}}$ software is not running.

Field input and output (I/O) signals are connected to the system in the PCM multiplexer (MUX) cabinets. There are a total of 11 MUX cabinets. Two of these cabinets contain the PCMs and some of the $1 / O$ terminations. The other 9 cabinets contain the remaining $1 / O$ hardware and signal terminations. The multiplexers provide signal scanning and conditioning functions.

The Operator Console Modules (OCMs) and Vaxstation are the human interface with the plant equipment. They provide the operator with system, faceplate, graphic, trend, and alarm summary displays. They permit password protected access to control and alarm functions. Two OCMs are connected to each DCM. The displays and databases for each work station are generic in nature so that facility information can be obtained at any station.

\subsection{Definitions}

The following terms used within this document are defined as follows.

Acceptance Test - Formal testing conducted to determine whether or not a system satisfies its acceptance criteria and to enable the customer to determine whether or not to accept the system. (IEEE Std. 610.12-1990).

Configurator Display Control Module (CDCM) - VAX computer system designated for configuration of the control system databases on the network. Contains all software and source code needed to run the 242-A process. Drives Operator Console Modules and supports alarm typers. Provides graphic displays and processes operator issued commands for all functions within the network containing the CDCM.

Display Control Module 0 (DCMO) - VAX computer system. Drives Operator Console Modules and supports alarm typers. Provides graphic displays and processes operator issued commands for all functions within the network containing DCMO.

MCS cognizant engineer - The engineer responsible for the 242-A control system who is assigned the principal responsibility for the development of new or changes to existing computer software. 
Multiplexer (MUX) - The device that routes multiple process instrumentation signals to the microcomputer unit of the PCM and sends control signals from the PCM microcomputer unit to multiple process control elements.

Operator Console Module (OCM) - The operator interface to the process.

Process Control Module (PCM) - Performs all process control and data acquisition functions as specified in the application software. The PCM is capable of reading input signals, providing outputs, processing data, performing continuous control and logic functions, performing batch control, and executing user-generated $\mathrm{C}$-language programs.

Q Bus - The bus backplane structure and control card for a minicomputer system that interfaces the processor to the communications network.

VAX - Computers manufactured by Digital Equipment Corporation that are used as host computers on the $\mathrm{D} / 3^{\mathrm{TM}}$ network.

VMS - Virtual Memory operating System. The operating system used on the VAX.

\section{TEST PLAN}

\subsection{Test Items}

Hardware and software items will be tested. Hardware items tested will include all DCM and PCM processors. This hardware is tested by virtue of the fact that they are running the software to be tested. In general, software items tested include portions of the $\mathrm{VMS}^{\mathrm{TM}}$ and $\mathrm{D} / 3^{\mathrm{TM}}$ systems that use time and date information.

Specific operating system items to be tested include:

- $\mathrm{VMS}^{\mathrm{TM}}$ login time and date stamp

- Creation date and time on newly created software files

- Scheduled task execution (totalizer reset)

- Time clock on DCMs

- Authorize Utility time and date stamp

- C-compiler listing time and date stamp

The $D / 3^{T M}$ alarm items to be tested includes:

- Historical file time and date stamps

- Historical file names

- Time and date stamp on alarm printouts

- Time and date stamp in alarm history file

- Time and date stamp on alarm summary pages

- Chronological presentation on alarm summary pages

- Alarm acknowledgment

- Clearing of alarms

Other $D / 3^{\mathrm{TM}}$ time and date functions to be tested includes:

- Presentation of time and date on OCM screens

- SABL timing functions (fhold)

- Collection and display of current and historical trend information

- Operation of historical data archive task

- Operation of report programs 
Other general DCS functions that will be tested includes:

- Sequence programs

- Device logic

- Alarm inhibit C-program

- MCS operation via system status and P3 displays

- Operator keyboard display of old historical data

- Shutdown of DCMs

- Reboot of DCMs

- COD Utility time and date stamp

- MOD Utility time stamp

- MTS Utility time and date stamp

- SIC Compiler listing time and date stamp

- MEAT Utility time and date stamp

- Serial number from complete applications rebuild

\subsection{Features to Test / Not Test}

All features to be tested involve the time and date stamp that the $D / 3^{\mathrm{TM}}$ and $\mathrm{VMS} \mathrm{S}^{\mathrm{TM}}$ systems attach to various displays, data, and data files. In most cases, this will be verified by viewing this information for correctness. Other methods of verification include system and module functionality.

\subsection{Deliverables}

All test data will be incorporated into an acceptance test report and released as a supporting document in accordance with engineering procedures. Test data will include the signed procedure steps in this document, all test discrepancy log sheets (Attachment 2), and where possible any test results which can be captured from screen displays or data files.

\subsection{Acceptance Criteria And Discrepancy Handling}

Test acceptance criteria is provided in Attachment 1. Testing shall be $100 \%$ qualitative.

All test discrepancies that are observed during the performance of procedures in this document shall be logged using Attachment 2 .

\subsection{Test Preparation, Tasks, and Skills}

Baseline testing activities shall be conducted on the simulation system. In preparation for these activities, the Evaporator simulation program shall be stopped. No other special preparations are necessary for testing to commence on this system.

Testing on the production system requires that applicable vendor supplied code be modified and built prior to performing the test. A prerequisite for modifying vendor programs is that vendor services be obtained to identify all software that must be modified, and that system backup media be prepared or verified in place. No other DCS preparations are necessary.

Any Unreviewed Safety Question (USQ) documentation must be completed before testing on the production system can begin. Testing will be coordinated with Shift Operation Managers.

The following is a summary of tasks that must be completed for testing to commence:

- Simulation program stopped (baseline testing on simulator only) 
- Obtain vendor services to identify modification software (production system only)

- Prepare or verify backup media of all effected hard drives (production system only)

- Modify applicable software (production system only)

- Compile applicable software (production system only)

- Load new software (production and/or simulator systems)

- Complete any USQ documentation (production system only)

All test and test preparation activities identified in this procedure shall be conducted and documented by engineers and/or computer specialists experienced in the operation and maintenance of the $\mathrm{D} / 3^{\mathrm{TM}} \mathrm{DCS}$.

\subsection{Environmental Needs}

The time required to complete testing is about one shift for the simulation system and one to two shifts for the production system. Testing on the simulator will be done using the current baseline versions of the operating systems. Testing on the production system will require operating systems that have been modified to resolve the year 2000 problem. There are no other special personnel, equipment, or configuration requirements.

\subsection{Responsibilities}

The MCS cognizant engineer is responsible for documenting, managing, designing, preparing, and executing the tests, and resolving test-related issues.

\subsection{Staffing and Training}

This procedure shall be conducted and documented by engineers and/or computer specialists experienced in the operation and maintenance of the D/3 ${ }^{\mathrm{TM}}$ DCS. There are no other special staffing and training requirements other than those provided by the MCS cognizant engineer.

\subsection{Schedule}

Test plans and procedures contained in this document shall be issued by June 15,1998 . Testing will take place shortly thereafter and is contingent upon the completion of the vendor's evaluation of the 242-A control system to define the year-2000 software modifications that are required. It is expected that the vendor assessment will be completed in June. Testing will take about one day for the simulator system and one day for the production system. There are no milestones associated with these activities.

\subsection{Risks and Contingencies}

There are no high risk assumptions in the test plan. A low risk assumption is that vendor-supplied software, which was previously tested at the factory by vendor personnel, can be successfully compiled and executed on the 242-A DCS. If the new vendor software is determined to be inadequate or inferior to the former version, the contingency plan is to restore the original software, which is maintained on backup media.

\section{TEST DESIGN}

\subsection{Approach}




\section{HNF-2696 REV 0}

Testing shall be completely qualitative using the criteria in Attachment 1 . The systems shall be found to either pass verification of correctness or not pass verification of correctness on each of the items tested. Baseline testing shall be used a) to define any unacceptable anomalies before proceeding with testing on the production system, b) for comparing the performances of original and modified software, and c) as a method to refine estimated outages of the production system. Testing on the production system shall be used to verify the adequacy of vendor-supplied software modifications and overall system performance.

\subsection{Pass / Fail Criteria}

Other than the criteria defined in Attachment 1, there are no other criteria that may be used to accept or reject the new software version. Overall system performance and acceptability is the responsibility of the MCS cognizant engineer.

\section{TEST CASES}

Systems will be tested with the following minimal sets of dates to provide pre-year-2000 data, post-year-2000 data, and ensure the systems function properly. Fiscal year dates will not be tested on the 242-A control systems because these systems do not run applications that require fiscal year dates or data.

TEST DATES

Current Date in 1998

$12 / 31 / 98$ to $1 / 1 / 99$

$9 / 8 / 99$ to $9 / 9 / 99$

$12 / 31 / 99$ to $1 / 1 / 2000$

$2 / 28 / 2000$ to $2 / 29 / 2000$

$2 / 29 / 2000$ to $3 / 1 / 2000$

$12 / 30 / 2000$ to $12 / 31 / 2000$

$2 / 28 / 2001$ to $3 / 1 / 2001$

Any date after 2000

Current Date in 1998

\section{PURPOSE}

pre-year-2000 operation

pre-year-2000 transition

tests 9999

tests change of millennium

tests recognition of leap year

verify does not go to February 30,31

verify year 2000 has 366 days

verify does not go to February 29

cold startup operation

system restoration

\begin{tabular}{l} 
SECTION \\
\hline 6 \\
7 \\
8 \\
9 \\
10 \\
11 \\
12 \\
13 \\
14 \\
15
\end{tabular}

In addition, one baseline test run will be conducted on the simulation system using current, unmodified operating system software. Another test run will be made on the production or simulation system using modified operating system software. 


\section{HNF-2696 REV 0}

\section{PROCEDURE- SIMULATION SYSTEM RESULTS}

\subsection{Setup and Initial Conditions}

5.1.1. For simulation system, VERIFY simulation program stopped. Write N/A if production system shall be tested at this time.

Initials: $m T \quad 6-10-98$

5.1.2. For production system, VERIFY the following (Write N/A if simulation system shall be tested at this time):

5.1.2.1. Backup CDCM and DCMO before vendor software changed

5.1.2.2. Modify vendor software

Initials: $\frac{N / A M T}{6-10-98}$

Initials: $\frac{N / A M T}{6-10-98}$

5.1.2.3. Compile vendor software

Initials: $\frac{N / A M T}{6-10-98}$

5.1.2.4. Load new software to CDCM and DCMO

Initials: $\frac{N / A M T}{6-10-98}$

5.1.2.5. Complete any USQ documentation

Initials: $\frac{N / A \quad M T}{6-10-98}$ 


\subsection{Prerequisite}

Document the DCS system by recording the following information:

SYSTEM (Check One): $\quad$ Simulator I ] Production

D/3 ${ }^{\mathrm{TM}}$ VERSION: $6.3-3$

DATE OF TEST: $\quad 6-10-98$

CHECK ONE OF THE FOLLOWING SYSTEM STATUSES:

Original, Unmodified D/3 ${ }^{\mathrm{TM}}$ Version (BASELINE)

[ ] $D / 3^{\text {TM }}$ Version With Modified GSE System Patches

LIST OF GSE PATCH NUMBERS (N/A If None): $N / A \quad m r$

FILL IN THE FOLLOWING SYSTEM INFORMATION:

\begin{tabular}{|l|l|l|l|}
\hline & HARDWARE & $\begin{array}{l}\text { OPERATING } \\
\text { SYSTEM \& VERSION }\end{array}$ & $\begin{array}{l}\text { OPERATOR DISPLAY } \\
\text { AVAILABLE (Y/N) }\end{array}$ \\
\hline CDCM & VAX 4000-105 & VMS 5.5-2AH D & OCM IT /VXT 2000 \\
\hline DCM & $N / A$ & $N / A$ & $N / A$ \\
\hline WORKSTATIONS & $N / A$ & $N / A$ & $N / A$ \\
\hline PCM & PCM1OO-TI 505 & $D / 36.3-3$ & N/A \\
\hline NETWORK & ETHERNET-DENET N/A & N/A \\
\hline
\end{tabular}

NOTE: Throughout the test if possible, capture all terminal output to a printer or a file in order to document events. Also, when possible, print a screen copy of the operator console display to document operation of the system each time a display is checked as part of the test. (1) With $\triangle$ TIME LIMT PATCH

\section{SYSTEM OPERATION BEFORE ALTERING DATE AND TIME}

\subsection{Alarm And Associated Time And Date Information (D/3 $\left.{ }^{\mathrm{TM}}\right)$}

6.1.1. COPY as necessary alarm history files and historical data files into SAVE directories.

Initials: $m T 6-10-98$

6.1.2. VERIFY creation of alarm history files with name format "ALddmmmyy 000 ".

$$
\text { Initials: } \operatorname{mr} 6-10-98
$$

6.1.3. VERIFY date and time stamps are accurate for alarm history file contents (alarm messages) and have format "dd-mmm-yy 00:00:00".

Initials: $M T-6-10-98$

6.1.4. GENERATE a critical P1 (RED) process alarm, SILENCE it, but do NOT ACKNOWLEDGE it at this time. 
Alarm description:

RSH-VVALP

Initials: $m$ T $6-10-98$

6.1.5. GENERATE a non-critical P2 (YELLOW) process alarm, SILENCE it, but do NOT ACKNOWLEDGE it at this time.

Alarm description:

WFI-E 102

Initials: $M T 6-10-98$

6.1.6. GENERATE a non-critical WHITE process alarm, SILENCE it, but do NOT ACKNOWLEDGE it at this time.

Alarm description:

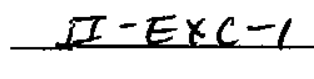

Initials:

$M T 6-10-98$

6.1.7. GENERATE a P3 SYSTEM ALARM (suggest network error)

Alarm description:

PCMD STATUS OFFLINE

Initials: $m \sigma \quad 6-10-98$

6.1.8. CHECK alarm printer functions correctly upon receipt of an alarm, including correct date and time stamp that has format "dd-mmm-yy 00:00:00".

Initials: $M T 6-10-98$

6.1.9. CHECK alarm history files are updated correctly upon receipt of an alarm, including correct alarm message date and time stamp that has format "dd-mmm-yy 00:00:00".

Initials: $M T 6-10-98$

6.1.10. CHECK alarms recorded above displayed correctly on P1 ALARM SUMMARY, including correct date and time stamp that has format "dd-mmm 00:00:00".

Initials: $M T 6-10-98$

6.1.11. CHECK alarms recorded above displayed correctly on P2 ALARM SUMMARY, including correct date and time stamp that has format "dd-mmm 00:00:00".

Initials: $M T 6-10-98$

6.1.12. CHECK alarms recorded above displayed correctly on WHITE ALARM SUMMARY, including correct date and time stamp that has format "dd-mmm-yy 00:00:00".

Initials: $M T 6-10-98$

6.1.13. CHECK system alarm recorded above displayed correctly on P3 ALARM SUMMARY, including correct date and time stamp that has format "dd-mmm-yy 00:00:00".

Initials: $M T 6-10-98$

6.1.14. CHECK alarms displayed in chronological order on alarm summary pages (newest at top).

Initials: $\underline{\mu T} 6-10-98$

6.1.15. ACKNOWLEDGE alarms and VERIFY they can be acknowledged.

Initials: $M T \quad 6-10-98$

6.1.16. RESTORE alarm conditions and VERIFY they clear from alarm summaries.

Initials: $M T$ 6-10-98 


\subsection{Time and Date Functions $\left(D / 3^{\mathrm{TM}}\right)$}

6.2.1. CHECK standard date and time on OCM screens (lower right corner) is accurate and has format of "dd-mmm-yy 00:00:00".

\section{Initials: $m T 6-10-98$}

6.2.2. CHECK Sequence And Batch Language timing functions work properly by observing FHOLD flag on Program Diagnostics graphic \#133 and VERIFY that FHOLD rolls over between 30 and 45 seconds.

Initials: $m$ T $6-10-98$

6.2.3. CHECK date and time function for FHOLD on Program Diagnostic graphic \#133 is accurate and has format "dd-mmm-yy 00:00:00". CHECKS GETDATE, GETTIME, Dalo
NOTE: $\triangle A Y$ OF WEEK $=3$ (WED)
Initials: $M T$ 6-10-98

6.2.4. RUN inhibit C-program from SKID panel and VERIFY date and time on graphic \#80 is correct and has format "dd-mmm-yy 00:00:00".

Initials: $M T \quad 6-10-98$

6.2.5. CHECK current trends operate correctly on OCMs and VERIFY correct time stamp that has format "00:00:00".

Initials: MT $6-10-98$

6.2.6. CHECK historical trends operate correctly on OCMs and VERIFY correct date and time stamp that has format "dd-mmm-yy 00:00:00".

Initials: $M T 6-10-98$

6.2.7. VERIFY Archiver has created archive file for previous day's historical data in the format "UNITymm.ddD" at about 23:55 hours on a DCM; and VERIFY Archiver has also created historical reference files for the next day's data in the format "UNITymm.ddC", "UNITymm.ddH", and "UNITymm.ddX" at about 00:01 hours.

$$
\text { Initials: } M T(6-10-98
$$

6.2.8. RUN the following reports and VERIFY they can be generated with correct date and time (suggest TFBA, REPOR $6-10-98$, and HISTDAT, HISTMON, or HISTMAX).

Report Name:

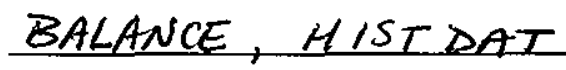

(1) Not Available on Simulator

Initials: $M T 6-10-98$ USE BALANCE.C INSTEAD

\subsection{Time and Date Functions (Operating System)}

6.3.1. LOGIN to a terminal (VT type) and VERIFY previous VMS ${ }^{\mathrm{TM}}$ login date and time stamp.

Initials: $M T Q-10-98$

6.3.2. LOGOUT from the terminal.

Initials: $M T \quad 6-10-98$ 
6.3.3. LOGIN to an engineering workstation and VERIFY previous VMS ${ }^{T M}$ Iogin date and time stamp.

$$
\text { Initials: MT } 6-10-98
$$

6.3.4. VERIFY VMS ${ }^{\mathrm{TM}}$ date and time stamps are accurate for newly created DCM files.

$$
\text { Initials: } M T 6-10-98
$$

6.3.5. SUBMIT a batch job (suggest FQIRESET) to the batch queue and VERIFY EXECUTION ON CDCM.

$$
\text { Initials: } M T 6-10-98
$$

6.3.6. VERIFY date and time correct on DCM ( $\$$ SHOW TIME or $>$ TIM commands).

$$
\text { List Systems verified: } \vee V A X C D C M
$$

Initials: $M T 6-10-98$

6.3.7. RUN the Authorize Utility and VERIFY date and time stamp is correct and has format "dd-mmm-yyyy 00:00".

initials: $M T 6-10-98$

6.3.8. COMPILE a dummy C-program and VERIFY the content of the compiler list file (*.LIS) date and time stamp is correct and has format "dd-mmm-yyyy 00:00:00".

Initials: $M T 6-10-98$

6.3.9. LOGOUT from the engineering workstation.

Initials: $M T 6-0-98$

\subsection{General DCS Functionality $\left(D / 3^{\mathrm{TM}}\right)$}

6.4.1. VERIFY Sequence and Batch Language programs are running by observing Program Status graphic \#43.

Initials: $M T 6-10-98$

6.4.2. CHECK Device Logic functions properly (suggest interlock bypass or simple valve such as 207-A basins).

Initials: $M T 6-10-98$

6.4.3. EXECUTE alarm inhibit C-program from the SKID panel and VERIFY proper operation.

Initials: $m \sigma 6-10-98$

6.4.4. INHIBIT an alarm and VERIFY removal from alarm summary display.

Initials: $M T 6-10-98$

6.4.5. REMOVE the inhibit from the alarm in previous step and VERIFY the alarm returns to the alarm summary display.

Initials: $M T 6-10-48$

6.4.6. VERIFY System Status AND P3 displays show no unexpected system alarm conditions.

Initials: Mr $6-10-98$ 
6.4.7. VERIFY OCM keyboard is able to access data that is more than 24 hours old.

Initials: $M T$ 6 $6-10-98$

6.4.8. VERIFY COD Utility date and time stamp is correct and has format "dd-mmm-yy 00:00:00".

Initials: $M T 6-10.98$

6.4.9. VERIFY MOD Utility time stamp is correct and has format "00:00:00".

Initials: $M T 6-10-98$

6.4.10. VERIFY MTS Utility date and time stamp is correct and has format "dd-mmm-yy 00:00:00".

Initials: $M T 6-10-98$

6.4.11. COMPILE a dummy Sequence and Batch Language program and VERIFY SIC Utility listing $\left({ }^{*}\right.$.LST) date and time stamp is correct and has format "dd-mmm-yy 00:00:00".

Initials: $M T 6-10-98$

6.4.12. VERIFY MEAT Utility date and time stamp is correct and has format "dd-mmm-yy 00:00:00".
NOTE: USE 'EN' SLOITCH.
Initials: $M T 6-10-98$

6.4.13. RUN D3DOWN on all nodes on the network and VERIFY smooth shut down. NOTE: Do first on non-CDCM.

Initials: $M T$ T $6-10-98$

6.4.14. STOP tasks FQIRESET and WATCH if applicable (STOP/ID=[\# FROM SHOW SYSTEM]).

NOTE: Prepares DCS for restart.

Initials: $m$ r $6-10-98$

6.4.15. SET TIME forward on the CDCM to December 31, 1998 23:45:00.00 hours. NOTE: This allows 10 minutes for restart before data is archived and prepares for verification of year 1999 operation.

Initials: $\operatorname{mr} 6-10-98$

6.4.16. COPY historical data files to dummy test files of format "UNITymm.30C", "UNITymm.30D", "UNITymm.30H", and "UNITymm.30X" for December 31, 1998, where "UNIT" may be CDCM and/or DCMO.

NOTE: Prepares for verification of year 1999 operation. 10:20

Initials: $m T 6-10-98$

6.4.17. RUN D3UP on all nodes on the network (CDCM first) and VERIFY smooth start up.

NOTE: This completes System Operation Before Altering Date and Time.

Initials: $m T 6-10-88$ $10 \div 21$ 
HNF-2696 REV 0

\section{SYSTEM OPERATION IN TRANSITION TO YEAR 1999}

\subsection{General Operation}

7.1.1. OBSERVE system functional throughout the transition to the year 1999 .

Initials: $\frac{M T 6-10-98}{10: 32}$

\subsection{Alarm And Associated Time And Date Information (D/3 $3^{\mathrm{TM}}$ )}

7.2.1. VERIFY creation of alarm history files with name format "ALddmmmyy .000 ".

$$
\text { Initials: } m T 6-10-98
$$

7.2.2. VERIFY date and time stamps are accurate for alarm history file contents (alarm messages) and have format "dd-mmm-yy 00:00:00".

Initials: mo $6-10-98$

7.2.3. GENERATE a critical P1 (RED) process alarm, SILENCE it, but do NOT ACKNOWLEDGE it at this time.

Alarm description: $\quad$ RSH $V V A L P$

$$
\text { Initials: } M T 6-10-98
$$

7.2.4. GENERATE a non-critical P2 (YELLOW) process alarm, SILENCE it, but do NOT ACKNOWLEDGE it at this time.

Alarm description: $-W F I-E \mid O I$

Initials: $m v \quad 6-10-98$

7.2.5. GENERATE a non-critical WHITE process alarm, SILENCE it, but do NOT ACKNOWLEDGE it at this time.

Alarm description: $\quad$ WFI-E 102

Initials: $m \pi 6-10-98$

7.2.6. GENERATE a P3 SYSTEM ALARM (suggest network error)

Alarm description: PCMQ STATKS OFFLINE

$$
\text { Initials: } M T 6-10-98
$$

7.2.7. CHECK alarm printer functions correctly upon receipt of an alarm, including correct date and time stamp that has format "dd-mmm-yy 00:00:00".

Initials: $M T 6-10-98$

7.2.8. CHECK alarm history files are updated correctly upon receipt of an alarm, including correct alarm message date and time stamp that has format "dd-mmm-yy 00:00:00".

Initials: MT $6-10-98$

7.2.9. CHECK alarms recorded above displayed correctly on P1 ALARM SUMMARY, including correct date and time stamp that has format "dd-mmm 00:00:00".

Initials: MT $6-10-98$ 
7.2.10. CHECK alarms recorded above displayed correctly on P2 ALARM SUMMARY, including correct date and time stamp that has format "dd-mmm 00:00:00".

$$
\text { Initials: } m \sigma 6-10-98
$$

7.2.11. CHECK alarms recorded above displayed correctly on WHITE ALARM SUMMARY, including correct date and time stamp that has format "dd-mmm-yy 00:00:00".

$$
\text { Initials: } M T 6-10-98
$$

7.2.12. CHECK system alarm recorded above displayed correctly on P3 ALARM SUMMARY, including correct date and time stamp that has format "dd-mmm-yy 00:00:00".

$$
\text { Initials: } M T 6-10-28
$$

7.2.13. CHECK alarms displayed in chronological order on alarm summary pages (newest at top).

Initials: $M 7 \&-10-98$

7.2.14. ACKNOWLEDGE alarms and VERIFY they can be acknowledged.

Initials: $M T 6-10-98$

7.2.15. RESTORE alarm conditions and VERIFY they clear from alarm summaries.

$$
\text { Initials: } \frac{m r \quad 6-10-98}{10: 52}
$$

\subsection{Time and Date Functions (D/3 $\left.{ }^{\mathrm{TM}}\right)$}

7.3.1. CHECK standard date and time on OCM screens (lower right corner) is accurate and has format of "dd-mmm-yy 00:00:00".

$$
\text { Initials: } M T \quad 6-10-88
$$

7.3.2. CHECK Sequence And Batch Language timing functions work properly by observing FHOLD flag on Program Diagnostics graphic \#133 and VERIFY that FHOLD rolls over between 30 and 45 seconds.

Initials: MT $6-10-98$

7.3.3. CHECK date and time function for FHOLD on Program Diagnostic graphic \#133 is accurate and has format "dd-mmm-yy 00:00:00".
NOTE: DAY OF WEEK $=5$ (FRF) FOR 1-JAN-99
Initials: $M T 6-10-98$

7.3.4. RUN inhibit C-program from SKID panel and VERIFY date and time on graphic \#80 is correct and has format "dd-mmm-yy 00:00:00".

Initials: $M T$ r $-0-98$

7.3.5. CHECK current trends operate correctly on OCMMs and VERIFY correct time stamp that has format "00:00:00".

$$
\text { Initials: MT 6-10-98 }
$$

7.3.6. CHECK historical trends operate correctly on OCMs and VERIFY correct date and time stamp that has format "dd-mmm-yy 00:00:00".

$$
\text { Initials: } M T \quad 6-10-98
$$

7.3.7. VERIFY Archiver has created archive file for previous day's historical data in the format "UNITymm.ddD" at about 23:55 hours on a DCM; and VERIFY Archiver has 
also created historical reference files for the next day's data in the format

"UNITymm.ddC", "UNITymm.ddH", and "UNITymm.ddX" at about 00:01 hours.

Initials: $M T 6-10-98$

7.3.8. RUN the following reports and VERIFY they can be generated with correct date and time (suggest HPAL, REPORT, and HISTDAT, HISTMON, or HISTMAX). (1) MT $6-10-98$

Report Name: $\quad B A \angle A N C E$

$\frac{H I S T D A T}{\text { (1) NOT AUALABLE ON SIAMLATOR. }}$
USE BALANCE INSTEAD

\subsection{Time and Date Functions (Operating System)}

7.4.1. LOGIN to a terminal (VT type) and VERIFY previous VMS ${ }^{\text {TM }}$ login date and time stamp.

Initials: $M T 6-10-98$

7.4.2. LOGOUT from the terminal.

Initials: $M T$ T $6-10-98$

7.4.3. LOGIN to an engineering workstation and VERIFY previous VMS ${ }^{\mathrm{TM}}$ login date and time stamp.

Initials: $M T \cdot 6-10-98$

7.4.4. VERIFY VMS ${ }^{\mathrm{TM}}$ date and time stamps are accurate for newly created DCM files.

initials: $M T$ 6-10.98

7.4.5. SUBMIT a batch job (suggest FQIRESET) to the batch queue and VERIFY EXECUTION on CDCM.

$$
\begin{gathered}
11: 25 \\
\text { Initials: MT } \quad 6-10-98
\end{gathered}
$$

7.4.6. VERIFY date and time correct on DCM (\$SHOW TIME or > TIM commands).

List Systems verified:

Initials: MT $6-10-98$

7.4.7. RUN the Authorize Utility and VERIFY date and time stamp is correct and has format "dd-mmm-yyyy 00:00".

Initials: $M T 6-10-98$

7.4.8. COMPILE a dummy C-program and VERIFY the content of the compiler list file (*.LIS) date and time stamp is correct and has format "dd-mmm-yyyy 00:00:00".

$$
\text { Initials: } M T 6-10-98
$$

7.4.9. LOGOUT from the engineering workstation.

Initials: MT $6-10-98$

\subsection{General DCS Functionality $\left(\mathrm{D} / 3^{\mathrm{TM}}\right)$}




\section{HNF-2696 REV 0}

7.5.1. VERIFY Sequence And Batch Language programs are running by observing Program Status graphic \#43.

Initials: $m T \quad 6-10-98$

7.5.2. CHECK Device Logic functions properly (suggest interlock bypass or simple valve such as 207-A basins).

Initials: $M T$ T-10-98

7.5.3. EXECUTE alarm inhibit C-program from the SKID panel and VERIFY proper operation.

Initials: $M T 6-10-48$

7.5.4. INHIBIT an alarm and VERIFY removal from alarm summary display.

Initials: $M T 6-10-98$

7.5.5. REMOVE the inhibit from the alarm in previous step and VERIFY the alarm returns to the alarm summary display.

Initials: $M T 6-10-98$

7.5.6. VERIFY System Status AND P3 displays show no unexpected system alarm conditions.

Initials: $M T 6-10-98$

7.5.7. VERIFY OCM keyboard is able to access data that is more than 24 hours old.

Initials: $M T \quad 6-10-98$

7.5.8. VERIFY COD Utility date and time stamp is correct and has format "dd-mmm-yy 00:00:00".

Initials: $M \pi-10-98$

7.5.9. VERIFY MOD Utility time stamp is correct and has format "00:00:00".

Initials: $M 76-10-98$

7.5.10. VERIFY MTS Utility date and time stamp is correct and has format "dd-mmm-yy 00:00:00".

Initials: $M T$ T $6-10-98$

7.5.11. COMPILE a dummy Sequence and Batch Language program and VERIFY SIC Utility listing ( $\left.{ }^{*} . \mathrm{LST}\right)$ date and time stamp is correct and has format "dd-mmm-yy 00:00:00".

Initials: $M r 6-10-98$

7.5.12. VERIFY MEAT Utility date and time stamp is correct and has format "dd-mmm-yy 00:00:00".

NOTE: USE "EN" SWITCH Initials: MT 6-10-98

7.5.13. RUN D3DOWN on all nodes on the network and VERIFY smooth shut down. NOTE: Do first on non-CDCM.

Initials: $M T \quad 6-10-98$

7.5.14. STOP tasks FQIRESET and WATCH if applicable (STOP/ID=[\# FROM SHOW SYSTEM]).

NOTE: Prepares DCS for restart.

Initials: MT 6-10-98 
7.5.15. SET TIME forward on the CDCM to September 8, 1999 23:45:00.00 hours. NOTE: This allows 10 minutes for restart before data is archived and prepares for verification of four-nines operation.

Initials: $M T 6-10-98$

7.5.16. COPY historical data files to dummy test files of format "UNITymm.07C", "UNITymm.07D", "UNITymm.07H", and "UNITymm.07X" for September 8, 1999, where "UNIT" may be CDCM and/or DCMO.

NOTE: Prepares for verification of four-nines operation.

Initials: Mr $6-10-98$

7.5.17. RUN D3UP on all nodes on the network (CDCM first) and VERIFY smooth start up. NOTE: This completes Transition to 1999.

Initials: $\frac{M T 6-10-98}{11: 51}$ 
HNF-2696 REV 0

\section{SYSTEM OPERATION IN TRANSITION TO SEPTEMBER 9, 1999}

\subsection{General Operation}

8.1.1. OBSERVE system functional throughout the transition to September 9, 1999.

$$
\text { Initials: } \frac{M T-6-10-98}{12: 10}
$$

\subsection{Alarm And Associated Time And Date Information (D/3 $\left.{ }^{T M}\right)$}

8.2.1. VERIFY creation of alarm history files with name format "ALddmmmyy.000". Initials: $M T 6-10-88$

8.2.2. VERIFY date and time stamps are accurate for alarm history file contents (alarm messages) and have format "dd-mmm-yy 00:00:00".

Initials: $M T 6-10-98$

8.2.3. GENERATE a critical P1 (RED) process alarm, SILENCE it, but do NOT ACKNOWLEDGE it at this time.

Alarm description:

RSH: VVALP

Initials: MT $6-10-98$

8.2.4. GENERATE a non-critical P2 (YELLOW) process alarm, SILENCE it, but do NOT ACKNOWLEDGE it at this time.

Alarm description: $W F I-E / Q 2 \quad(H I)$

Initials: $m \mathrm{~m}$ 6-10-98

8.2.5. GENERATE a non-critical WHITE process alarm, SILENCE it, but do NOT ACKNOWLEDGE it at this time.

Alarm description:

$W F I-E|\Phi|$ (Lo) Initials: $m Y \quad 6-10-98$

8.2.6. GENERATE a P3 SYSTEM ALARM (suggest network error) Alarm description: PCMQ STATUS OFFLINE

Initials: $M T 6-10-98$

8.2.7. CHECK alarm printer functions correctly upon receipt of an alarm, including correct date and time stamp that has format "dd-mmm-yy 00:00:00".

Initials: $M T \quad 6-10^{\circ} 98$

8.2.8. CHECK alarm history files are updated correctly upon receipt of an alarm, including correct alarm message date and time stamp that has format "dd-mmm-yy 00:00:00".

Initials: $M T 6-10-98$

8.2.9. CHECK alarms recorded above displayed correctly on P1 ALARM SUMMARY, including correct date and time stamp that has format "dd-mmm 00:00:00".

Initials: $m \nabla C-10-98$ 
8.2.10. CHECK alarms recorded above displayed correctly on P2 ALARM SUMMARY, including correct date and time stamp that has format "dd-mmm 00:00:00".

Initials: $M T 6-10-98$

8.2.11. CHECK alarms recorded above displayed correctly on WHITE ALARM SUMMARY, including correct date and time stamp that has format "dd-mmm-yy 00:00:00".

Initials: MT 6-10-98

8.2.12. CHECK system alarm recorded above displayed correctly on P3 ALARM SUMMARY, including correct date and time stamp that has format "dd-mmm-yy 00:00:00".

initials: $M T 6-10-98$

8.2.13. CHECK alarms displayed in chronological order on alarm summary pages (newest at top).

Initials: $M T 6-10-98$

8.2.14. ACKNOWLEDGE alarms and VERIFY they can be acknowledged.

Initials: $M T 6-10-98$

8.2.15. RESTORE alarm conditions and VERIFY they clear from alarm summaries.

Initials: $\frac{M T 6-0-88}{12: 57}$

\subsection{Time and Date Functions $\left(D / 3^{\mathrm{TM}}\right)$}

8.3.1. CHECK standard date and time on OCM screens (lower right corner) is accurate and has format of "dd-mmm-yy 00:00:00".

Initials: $M T \quad 6-10-98$

8.3.2. CHECK Sequence And Batch Language timing functions work properly by observing FHOLD flag on Program Diagnostics graphic \#133 and VERIFY that FHOLD rolls over between 30 and 45 seconds.

\section{Initials: MT $6-10-98$}

8.3.3. CHECK date and time function for FHOLD on Program Diagnostic graphic \#133 is accurate and has format "dd-mmm-yy 00:00:00".

NOTE: DAY OF WEEK $=4$ (THUR) For $9 / 9 / 99$ Initials: $M T 6-10-98$

8.3.4. RUN inhibit C-program from SKID panel and VERIFY date and time on graphic \#80 is correct and has format "dd-mmm-yy 00:00:00".

Initials: $\mathrm{Mr} 6-10-98$

8.3.5. CHECK current trends operate correctly on OCMs and VERIFY correct time stamp that has format "00:00:00".

Initials: $M T$ G-10-98

8.3.6. CHECK historical trends operate correctly on OCMs and VERIFY correct date and time stamp that has format "dd-mmm-yy 00:00:00".

Initials: $M T 6-10-98$

8.3.7. VERIFY Archiver has created archive file for previous day's historical data in the format "UNITymm.ddD" at about 23:55 hours on a DCM; and VERIFY Archiver has 
also created historical reference files for the next day's data in the format

"UNITymm.ddC", "UNITymm.ddH", and "UNITymm.ddX" at about 00:01 hours.

Initials: inT $6-10-98$

8.3.8. RUN the following reports and VERIFY they can be generated with correct date and time (suggest TFBAt, REPORT WRITER; and HISTDAT, HISTMON, or HISTMAX). (1) $M T 6-10-98$

Report Name:

BALANCE

HISTDAT

(1) Unavailable. Use BALANCE instead.

Initials: $\frac{M T 6-10-98}{1: 27}$

\subsection{Time and Date Functions (Operating System)}

8.4.1. LOGIN to a terminal (VT type) and VERIFY previous VMS ${ }^{\mathrm{TM}}$ login date and time stamp.

8.4.2. LOGOUT from the terminal.

$$
\text { Initials: } \frac{M T 6-10-98}{1: 28}
$$

Initials: $M T$ 6-10-98

8.4.3. LOGIN to an engineering workstation and VERIFY previous VMS ${ }^{\mathrm{TM}}$ login date and time stamp.

Initials: MT $6-10-98$

8.4.4. VERIFY VMS ${ }^{\mathrm{TM}}$ date and time stamps are accurate for newly created DCM files.

Initials: MT $6-10-98$

8.4.5. SUBMIT a batch job (suggest FQIRESET) to the batch queue and VERIFY EXECUTION on CDCM.

Initials: $M T \quad 6-10-98$

8.4.6. VERIFY date and time correct on DCM (\$SHOW TIME or > TIM commands).

List Systems verified:

$\checkmark A \times C D C M$

Initials: $M T$ G $-10-98$

8.4.7. RUN the Authorize Utility and VERIFY date and time stamp is correct and has format "dd-mmm-yyyy 00:00".

Initials: $M T-6-10.98$

8.4.8. COMPILE a dummy C-program and VERIFY the content of the compiler list file (* ${ }^{*}$ LIS) date and time stamp is correct and has format "dd-mmm-yyyy 00:00:00".

Initials: $m T \quad b-10-98$

8.4.9. LOGOUT from the engineering workstation.

Initials: $\frac{M T-10-98}{1: 35}$

8.5. General DCS Functionality $\left(D / 3^{T M}\right)$ 
8.5.1. VERIFY Sequence And Batch Language programs are running by observing Program Status graphic \#43.

Initials: $M T \quad 6-10-98$

8.5.2. CHECK Device Logic functions properly (suggest interlock bypass or simple valve such as 207-A basins).

Initials: MT 6-10-88

8.5.3. EXECUTE alarm inhibit C-program from the SKID panel and VERIFY proper operation.

Initials: MT 6-10-98

8.5.4. INHIBIT an alarm and VERIFY removal from alarm summary display.

Initials: $M T 6-10-98$

8.5.5. REMOVE the inhibit from the alarm in previous step and VERIFY the alarm returns to the alarm summary display.

Initials: $M T \quad 6-10-98$

8.5.6. VERIFY System Status AND P3 displays show no unexpected system alarm conditions.

Initials: $M T 6-10-98$

8.5.7. VERIFY OCM keyboard is able to access data that is more than 24 hours old.

Initials: $M T G 10-98$

8.5.8. VERIFY COD Utility date and time stamp is correct and has format "dd-mmm-yy 00:00:00".

Initials: MT $6-10-98$

8.5.9. VERIFY MOD Utility time stamp is correct and has format "00:00:00".

Initials: $M T<-10-98$

8.5.10. VERIFY MTS Utility date and time stamp is correct and has format "dd-mmm-yy 00:00:00".

Initials: $376-10-98$

8.5.11. COMPILE a dummy Sequence and Batch Language program and VERIFY SIC Utility listing $\left({ }^{*}\right.$.LST) date and time stamp is correct and has format "dd-mmm-yy 00:00:00".

Initials: $m$ r $6-10-98$

8.5.12. VERIFY MEAT Utility date and time stamp is correct and has format "dd-mmm-yy 00:00:00".

Initials: $m=6-10-98$

8.5.13. RUN D3DOWN on all nodes on the network and VERIFY smooth shut down. NOTE: Do first on non-CDCM.

Initials: $m \mathrm{~m}^{6}-10-98$

8.5.14. STOP tasks FQIRESET and WATCH if applicable (STOPIID=[\# FROM SHOW SYSTEM]).

NOTE: Prepares DCS for restart.

Initials: $2 m \pi-10-98$ 
8.5.15. SET TIME forward on the CDCM to December 31, 1999 23:45:00.00 hours. NOTE: This allows 10 minutes for restart before data is archived and prepares for verification of year $\mathbf{2 0 0 0}$ operation.

\section{Initials: $M T 6-10-98$}

8.5.16. COPY historical data files to dummy test files of format "UNITymm.30C", "UNITymm.30D", "UNITymm.30H", and "UNITymm.30X" for December 31, 1999, where "UNIT" may be CDCM and/or DCMO.

NOTE: Prepares for verification of year 2000 operation.

Initials: mit $6-10-98$

8.5.17. RUN D3UP on all nodes on the network (CDCM first) and VERIFY smooth start up. NOTE: This completes four-nines verification.

Initials: $\frac{m \pi}{2: 10}-10-98$ 


\section{SYSTEM OPERATION IN TRANSITION TO YEAR 2000}

\subsection{General Operation}

9.1.1. OBSERVE system functional throughout the transition to January 1, 1999.

$$
\text { Initials: } \frac{M r}{2: 14} 6 / 10 / 98
$$

\subsection{Alarm And Associated Time And Date Information (D/3 ${ }^{\mathrm{TM}}$ )}

9.2.1. VERIFY creation of alarm history files with name format "ALddmmmyy 000 ".

9.2.2. VERIFY date and time stamps are accurate for alarm history file contents (alarm messages) and have format "dd-mmm-yy 00:00:00".

Initials: EXCEPTION $=\frac{92}{2.2}$

9.2.3. GENERATE a critical P1 (RED) process alarm, SILENCE it, but do NOT mo ofro/98 ACKNOWLEDGE it at this time.

Alarm description: RSHAAL RSH-UVALP Initials: $m$ Clis/ar 2329

9.2.4. GENERATE a non-critical P2 (YELLOW) process alarm, SILENCE it, but do NOT ACKNOWLEDGE it at this time.

Alarm description: WFI E E $\quad$ W2

\section{Initials: $220 \mathrm{r}$ / $/ 4 / 48$}

9.2.5. GENERATE a non-critical WHITE process alarm, SILENCE it, but do NOT ACKNOWLEDGE it at this time.

Alarm description: $\quad \omega F I-E / Q I$

$$
\text { Initials: } 2 M \frac{M T}{6 / 10 / 98}
$$

9.2.6. GENERATE a P3 SYSTEM ALARM (suggest network error)

Alarm description:

PCMQ STATUS

OFFLINE

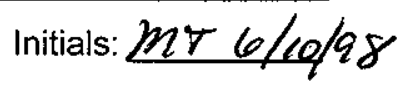

9.2.7. CHECK alarm printer functions correctly upon receipt of an alarm, including correct date and time stamp that has format "dd-mmm-yy 00:00:00".

$$
\text { Initials: EXCEPTION\#Z }
$$

9.2.8. CHECK alarm history files are updated correctly upon receipt of an alarm, including correct alarm message date and time stamp that has format "dd-mmm-yy 00:00:00".

$$
\text { Initials: EXCEPTIN }
$$

9.2.9. CHECK alarms recorded above displayed correctly on P1 ALARM SUMMARY, including correct date and time stamp that has format "dd-mmm 00:00:00".

$$
\text { Initials: } \frac{m 4 / 10 / 98}{2: 47}
$$


9.2.10. CHECK alarms recorded above displayed correctly on P2 ALARM SUMMARY, including correct date and time stamp that has format "dd-mmm 00:00:00".

$$
\text { Initials: } M T \text { 6/10/98 }
$$

9.2.11. CHECK alarms recorded above displayed correctly on WHITE ALARM SUMMARY, including correct date and time stamp that has format "dd-mmm-yy 00:00:00".

$$
\text { Initials: EXCEPTION \#2 }
$$

9.2.12. CHECK system alarm recorded above displayed correctly on P3 ALARM SUMMARY, including correct date and time stamp that has format "dd-mmm-yy 00:00:00".

$$
\text { Initials: EXCEPTION } 42
$$

9.2.13. CHECK alarms displayed in chronological order on alarm summary pages (newest at top).

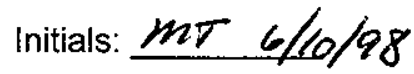

9.2.14. ACKNOWLEDGE alarms and VERIFY they can be acknowledged.

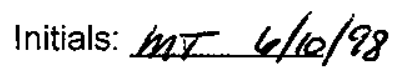

9.2.15. RESTORE alarm conditions and VERIFY they clear from alarm summaries.

$$
\text { Initials: } \frac{m}{2: 54} 6 / \mathrm{log} \text {. }
$$

\subsection{Time and Date Functions $\left(D / 3^{\mathrm{TM}}\right)$}

9.3.1. CHECK standard date and time on OCM screens (lower right corner) is accurate and has format of "dd-mmm-yy 00:00:00".
NOTE! IS "YY" OF "DQ", NOT"??"
Initials: $m \% 6 / 10 / 48$

9.3.2. CHECK Sequence And Batch Language timing functions work properly by observing FHOLD flag on Program Diagnostics graphic \#133 and VERIFY that FHOLD rolls over between 30 and 45 seconds.

Initials: $m r</ 10 / 98$

9.3.3. CHECK date and time function for FHOLD on Program Diagnostic graphic \#133 is accurate and has format "dd-mmm-yy 00:00:00".
NOTE: DAY OF WEEK IS $=6$ (SAT)
Initials: EXCEPTION $N^{*} 3$

9.3.4. RUN inhibit C-program from SKID panel and VERIFY date and time on graphic \#80 is correct and has format "dd-mmm-yy 00:00:00".

Initials: EXCEPTION \#2

9.3.5. CHECK current trends operate correctly on OCMs and VERIFY correct time stamp that has format "00:00:00".

Initials: $\operatorname{mr} 6 / 6 / 88$

9.3.6. CHECK historical trends operate correctly on OCMs and VERIFY correct date and time stamp that has format "dd-mmm-yy 00:00:00".

NOTE: AFTER 24 HR WILL BE EXCEPTNN \#2 (?? For YY)

Initials: $20 / 10 / 98$

9.3.7. VERIFY Árchiver has created archive file for previous day's historical data in the format "UNITymm.ddD" at about 23:55 hours on a DCM; and VERIFY Archiver has 
also created historical reference files for the next day's data in the format "UNITymm.ddC", "UNITymm.ddH", and "UNITymm.ddX" at about 00:01 hours.

NOTE: TIME PERMITING WILL GET EXCEPTION.

Initials: $m r 6 / 10 / 98$

9.3.8. RUN the following reports and VERIFY they can be generated with correct date and time (suggest FFAL, REPORF WRITER; and HISTDAT, HISTMON, or HISTMAX).

(1) $m_{T}$ G/10/a 8

Report Name: BALANCE (GLES "QQ")

HISTDAT (COCLECT FROM 12/31/9G)

(1) Not Adailable on Simulator.

Initials: $\operatorname{mo} 6 / 10 / 98$

\subsection{Time and Date Functions (Operating System)}

9.4.1. LOGIN to a terminal (VT type) and VERIFY previous VMS ${ }^{\mathrm{TM}}$ login date and time stamp.

HAS 4 DIGIT YEAR 2000

9.4.2. LOGOUT from the terminal.

Initials: $\frac{m T^{6} 6 / 10 / 98}{3: 16}$

Initials: $m \sigma 6 / 10 / 98$

9.4.3. LOGIN to an engineering workstation and VERIFY previous VMS ${ }^{\mathrm{TM}}$ login date and time stamp.

NOTE: HAS 2000 AS 4 DIGIT YEAR Initials: $M T 6 / 10 / 48$

9.4.4. VERIFY VMS ${ }^{\mathrm{TM}}$ date and time stamps are accurate for newly created DCM files.

Initials: $m-6 / 20 / 98$

9.4.5. SUBMIT a batch job (suggest FQIRESET) to the batch queue and VERIFY EXECUTION on CDCM:

Initials: $\operatorname{mT} 6 / 10 / 98$

9.4.6. VERIFY date and time correct on DCM (\$SHOW TIME or > TIM commands).

List Systems verified: $V A X C D C M$

HAS 4 DIGIT YEAR 2000 Initials: in $6 /$ Lo/98

9.4.7. RUN the Authorize Utility and VERIFY date and time stamp is correct and has format "dd-mmm-yyyy 00:00".

Initials: $2 m+6 / 10 / 98$

9.4.8. COMPILE a dummy C-program and VERIFY the content of the compiler list file ( ${ }^{*}$.LIS) date and time stamp is correct and has format "dd-mmm-yyyy 00:00:00".

Initials: $m \pi 6 / 10 / 98$

9.4.9. LOGOUT from the engineering workstation.

9.5. General DCS Functionality (D/3 $\left.{ }^{\mathrm{TM}}\right)$

Initials: $\frac{m T 6 / 10 / 98}{3: 30}$ 
9.5.1. VERIFY Sequence And Batch Language programs are running by observing Program Status graphic \#43.

$3: 32$ Initials: $m$ r $6 / 120 / 98$

9.5.2. CHECK Device Logic functions properly (suggest interlock bypass or simple valve such as 207-A basins).

Initials: $\operatorname{mo} 6 / 10 / 98$

9.5.3. EXECUTE alarm inhibit C-program from the SKID panel and VERIFY proper operation.

Initials: $\mathrm{mr} 6 / 10 / 98$

9.5.4. INHIBIT an alarm and VERIFY removal from alarm summary display.

Initials: $\mathrm{mr} 6 / 10 / 98$

9.5.5. REMOVE the inhibit from the alarm in previous step and VERIFY the alarm returns to the alarm summary display:

Initials: $M T 6 / 10 / 98$

9.5.6. VERIFY System Status AND P3 displays show no unexpected system alarm conditions.

Initials: $M T 6 / 10 / 98$

9.5.7. VERIFY OCM keyboard is able to access data that is more than 24 hours old.

9.5.8. VERIFY COD Utility date and time stamp is correct and has format "dd-mmm-yy 00:00:00".

$$
\text { NOTE: HAS "QQ" FOR "YY" }
$$

Initials: $M T$ b/10/98

9.5.9. VERIFY MOD Utility time stamp is correct and has format "00:00:00".

Initials: $M T 6 / 10 / 98$

9.5.10. VERIFY MTS Utility date and time stamp is correct and has format "dd-mmm-yy 00:00:00".

Initials: EXCEPTION *2

9.5.11. COMPILE a dummy Sequence and Batch Language program and VERIFY SIC Utility listing ( ${ }^{*}$.LST) date and time stamp is correct and has format "dd-mmm-yy 00:00:00".

Initials: $M T 6 / 10 / 98$

9.5.12. VERIFY MEAT Utility date and time stamp is correct and has format "dd-mmm-yy 00:00:00".

$3: 52$

Initials: $M T$ le/10/98

9.5.13. If testing on production system, WRITE N/A in sign-off spaces below and SKIP this step. If testing on simulation system, COMPLETE this step, Applications Rebuild.
9.5.13.1.
REBUILD all applications.
START $3: 55,6110 / 98$
9.5.13.2.
RESET and RELOAD PCMs.

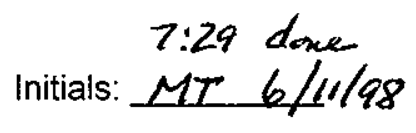

Initials: $M T 6 / 11 / 98$ 
9.5.14. RUN D3DOWN on all nodes on the network and VERIFY smooth shut down. NOTE: Do first on non-CDCM.

Initials: $M T \quad 6 / 11 / 98$

9.5.15. STOP tasks FQIRESET and WATCH if applicable (STOP/ID=[\# FROM SHOW SYSTEM]).

NOTE: Prepares DCS for restart.

Initials: $M 76 / 11 / 98$

9.5.16. SET TIME forward on the CDCM to February 28, $200023: 45: 00.00$ hours. NOTE: This allows 10 minutes for restart before data is archived and prepares for verification of initial leap year recognition.

$$
\text { Initials: } m T^{6 / 11 / 98}
$$

9.5.17. 'COPY historical data files to dummy test files of format "UNITymm.27C", "UNITymm.27D", "UNITymm.27H", and "UNITymm.27X" for February 28, 2000, where "UNIT" may be CDCM and/or DCMO.

NOTE: Prepares for verification of initial leap year recognition.

$$
\text { Initials: } M T 6 / 11 / 98
$$

9.5.18. RUN D3UP on all nodes on the network (CDCM first) and VERIFY smooth start up. NOTE: This completes year 2000 verification.

$$
\text { Initials: } \frac{m 76 / 11 / 98}{8: 57}
$$




\section{HNF-2696 REV 0}

\section{SYSTEM OPERATION DURING INITIAL LEAP YEAR RECOGNITION}

\subsection{General Operation}

10.1.1. VERIFY system recognizes February 29, 2000.

Initials: $M T 6 / 11 / 98$

10.1.2. VERIFY serial number (after complete applications rebuild) in MOD utility has correct format.

Initials: EXCEPT/ON $\# 2$

10.1.3. VERIFY general $D / 3^{T M}$ functionality following complete applications rebuild.

Initials: $M T 6 / 11 / 98$

10.1.4. OBSERVE system functional throughout the transition to February 29, 2000.

Initials: MT $6 / 11 / 98$

\subsection{Alarm And Associated Time And Date Information (D/3 ${ }^{\mathrm{TM}}$ )}

10.2.1. VERIFY creation of alarm history files with name format "ALddmmmyy.000". Initials: EXCEPTION

10.2.2. VERIFY date and time stamps are accurate for alarm history file contents (alarm messages) and have format "dd-mmm-yy 00:00:00".

$$
\text { Initials: EXCEPTION } 42
$$

10.2.3. GENERATE a critical P1 (RED) process alarm, SILENCE it, but do NOT ACKNOWLEDGE it at this time.

Alarm description: $\quad$ RSH-VUALP

$$
\text { Initials: } M T \text { C/u/as }
$$

10.2.4. GENERATE a non-critical P2 (YELLOW) process alarm, SILENCE it, but do NOT ACKNOWLEDGE it at this time.

Alarm description: WFI-EIDZ

$$
\text { Initials: } m \text { T } 6 / 11 / 98
$$

10.2.5. GENERATE a non-critical WHITE process alarm, SILENCE it, but do NOT ACKNOWLEDGE it at this time.

Alarm description: $\quad W F I-E / \phi /$

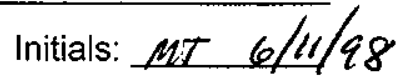

10.2.6. GENERATE a P3 SYSTEM ALARM (suggest network error)

Alarm description: PCMD STATUS OFFLINE

Initials: $m T 6 / 11 / 98$ 
10.2.7. CHECK alarm printer functions correctly upon receipt of an alarm, including correct date and time stamp that has format "dd-mmm-yy 00:00:00".

Initials: EXCEPTION \#Z

10.2.8. CHECK alarm history files are updated correctly upon receipt of an alarm, including correct alarm message date and time stamp that has format "dd-mmm-yy 00:00:00".

$$
\text { Initials: EXCEPTLON }
$$

10.2.9. CHECK alarms recorded above displayed correctly on P1 ALARM SUMMARY, including correct date and time stamp that has format "dd-mmm 00:00:00"1T 6/11/98

Initials: EXEETTON-z

10.2. 10. CHECK alarms recorded above displayed correctly on P2 ALARM SUMMARY, including correct date and time stamp that has format "dd-mmm 00:00:00".

$$
\text { Initials: } M T \quad 6 / 4 / 88
$$

10.2.11.CHECK alarms recorded above displayed correctly on WHITE ALARM SUMMARY, including correct date and time stamp that has format "dd-mmm-yy 00:00:00".

$$
\text { Initials: EXCEPTION \#Z }
$$

10.2.12. CHECK system alarm recorded above displayed correctly on P3 ALARM SUMMARY, including correct date and time stamp that has format "dd-mmm-yy 00:00:00".

initials: EXCEPTION

10.2.13. CHECK alarms displayed in chronological order on alarm summary pages (newest at top).

Initials: $M T$ G/11/98

10.2.14.ACKNOWLEDGE alarms and VERIFY they can be acknowledged.

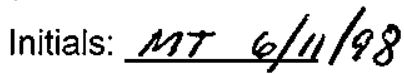

10.2.15.RESTORE alarm conditions and VERIFY they clear from alarm summaries.

Initials: $M T$ G/11/98

\subsection{Time and Date Functions $\left(\mathrm{D} / 3^{\mathrm{TM}}\right)$}

10.3.1. CHECK standard date and time on OCM screens (lower right corner) is accurate and has format of "dd-mmm-yy 00:00:00".

$$
\text { HAS "QQ" FOR YEAR "YY" }
$$

Initials: $M T 6 / 11 / 98$

10.3.2. CHECK Sequence And Batch Language timing functions work properly by observing FHOLD flag on Program Diagnostics graphic \#133 and VERIFY that FHOLD rolls over between 30 and 45 seconds.

\section{Initials: atT 6/1198}

10.3.3. CHECK date and time function for FHOLD on Program Diagnostic graphic \#133 is accurate and has format "dd-mmm-yy 00:00:00".

$$
\text { Initials: EXCEP TION \#3 }
$$

10.3.4. RUN inhibit C-program from SKID panel and VERIFY date and time on graphic \#80 is correct and has format "dd-mmm-yy 00:00:00".

Initials: EXCEPTION H2 
10.3.5. CHECK current trends operate correctly on OCMs and VERIFY correct time stamp that has format "00:00:00".

$$
\text { Initials: } M T 6 / 11 / 98
$$

10.3.6. CHECK historical trends operate correctly on OCMs and VERIFY correct date and time stamp that has format "dd-mmm-yy 00:00:00".

$$
\text { Initials: EXCEPT10al " } 2
$$

10.3.7. VERIFY Archiver has created archive file for previous day's historical data in the format "UNITymm.ddD" at about 23:55 hours on a DCM; and VERIFY Archiver has also created historical reference files for the next day's data in the format "UNITymm.ddC", "UNITymm.ddH", and "UNITymm.ddX" at about 00:01 hours.

initials: $M T 6 / 11 / 98$

10.3.8. RUN the following reports and VERIFY they can be generated with correct date and time (suggest FFAL, REPORT WRITER; and HISTDAT, HISTMON, or HISTMAX).

Report Name: BALANCE HISTDAT

(1) Not Available on Simulator. Use Initials: MT 6/11/98 Balance $\%$ Histdat instead.

\subsection{Time and Date Functions (Operating System)}

10.4.1. LOGIN to a terminal (VT type) and VERIFY previous VMS ${ }^{T M}$ login date and time stamp.

$$
\text { HAS } 4 \text { DIGIT YEAR }
$$

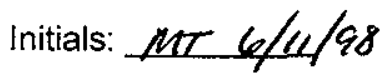

10.4.2. LOGOUT from the terminal.

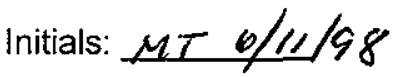

10.4.3. LOGIN to an engineering workstation and VERIFY previous VMS ${ }^{\mathrm{TM}}$ login date and time stamp.

$$
\text { HAS } 4 \text { DIGIT YEAR }
$$$$
\text { Initials: } M \pi \text { a } / 11 / 98
$$

10.4.4. VERIFY VMS $^{\text {TM }}$ date and time stamps are accurate for newly created DCM files.

Initials: MT $6 / 4 / 28$

10.4.5. SUBMIT a batch job (suggest FQIRESET) to the batch queue and VERIFY EXECUTION on CDCM.

Initials: $M T 6 / 1 / 98$

10.4.6. VERIFY date and time correct on DCM (\$SHOW TIME or $>$ TIM commands).

List Systems verified: $\cup A X C D C M$

$$
\text { HAS } 4 \text { DIGIT YEAR }
$$

Initials: $M T 6 / 11 / 98$

10.4.7. RUN the Authorize Utility and VERIFY date and time stamp is correct and has format "dd-mmm-yyyy 00:00".

$$
\text { Initials: } M T 6 / 1 / 98
$$


10.4.8. COMPILE a dummy C-program and VERIFY the content of the compiler list file (*.LIS) date and time stamp is correct and has format "dd-mmm-yyyy 00:00:00".

Initials: $M T 6 / 11 / 98$

10.4.9. LOGOUT from the engineering workstation.

$$
\text { Initials: } \frac{M T 6 / 11 / 98}{10: 02}
$$

\subsection{General DCS Functionality $\left(D / 3^{\mathrm{TM}}\right)$}

10.5.1. VERIFY Sequence And Batch Language programs are running by observing Program Status graphic \#43.

$$
\text { Initials: } 10: 03
$$

10.5.2. CHECK Device Logic functions properly (suggest interlock bypass or simple valve such as 207-A basins).

Initials: $\operatorname{AT} 6 / 10 / 98$

10.5.3. EXECUTE alarm inhibit C-program from the SKID panel and VERIFY proper operation.

Initials: EXCEPTION \#2

10.5.4. INHIBIT an alarm and VERIFY removal from alarm summary display.

$$
\text { Initials: } m \text { T } 6 / 11 / 98
$$

10.5.5. REMOVE the inhibit from the alarm in previous step and VERIFY the alarm returns to the alarm summary display.

Initials: $M T$ T $6 / 1 / 98$

10.5.6. VERIFY System Status AND P3 displays show no unexpected system alarm conditions.

Initials: $m r_{\text {G }} / 1 / 98$

10.5.7. VERIFY OCM keyboard is able to access data that is more than 24 hours old.

Initials: $M T 6 / 1 / 28$

10.5.8. VERIFY COD Utility date and time stamp is correct and has format "dd-mmm-yy 00:00:00".

$$
\text { HAS ' } \Phi Q^{\prime} \text { FOR YEAR }
$$

Initials: $\mu \mathrm{T}$ G/e1/28

10.5.9. VERIFY MOD Utility time stamp is correct and has format "00:00:00".

$$
\text { Initials: } M T 6 / 4 / 98
$$

10.5.10.VERIFY MTS Utility date and time stamp is correct and has format "dd-mmm-yy 00:00:00".

$$
\text { Initials: EXCEPY } 100^{* 2}
$$

10.5.11.COMPILE a dummy Sequence and Batch Language program and VERIFY SIC Utility listing (*.LST) date and time stamp is correct and has format "dd-mmm-yy 00:00:00".

Initials: $M T 6 / 11 / 98$ 
10.5.12.VERIFY MEAT Utility date and time stamp is correct and has format "dd-mmm-yy 00:00:00".

$$
\text { EN SWITCH }
$$

Initials: $\operatorname{mit} 6 / 11 / 98$

10.5.13. RUN D3DOWN on all nodes on the network and VERIFY smooth shut down. NOTE: Do first on non-CDCM.

$$
\text { Initials: } M T G / 11 / 98
$$

10.5.14.STOP tasks FQIRESET and WATCH if applicable (STOP/ID=[\# FROM SHOW SYSTEM]).

NOTE: Prepares DCS for restart.

$$
\text { Initials: } m T 6 / 11 / 98
$$

10.5.15.SET TIME forward on the CDCM to February 29, 2000 23:45:00.00 hours. NOTE: This allows 10 minutes for restart before data is archived and prepares for testing following February 29 recognition.

$$
\text { Initials: } M T 6 / 4 / 98
$$

10.5.16.RUN D3UP on all nodes on the network (CDCM first) and VERIFY smooth start up. NOTE: This completes initial recognition of leap year verification.

$$
\text { Initials: } \frac{m T}{10: 21} \text { b/11/98 }
$$


HNF-2696 REV 0

\section{SYSTEM OPERATION FOLLOWING FEBRUARY 29, 2000 RECOGNITION}

\subsection{General Operation}

11.1.1. VERIFY system recognizes that March 1, 2000 follows February 29,2000 , and that system does not roll over to February 30 or 31, 2000.

Initials: $M 76 / 11 / 28$

11.1.2. OBSERVE system functional throughout the transition to March 1, 2000.

Initials: $M T$ 6/11/98

\subsection{Alarm And Associated Time And Date Information (D/3 ${ }^{\mathrm{TM}}$ )}

11.2.1. VERIFY creation of alarm history files with name format "ALddmmmyy.000".

Initials: ExCEPTION \#/

11.2.2. VERIFY date and time stamps are accurate for alarm history file contents (alarm messages) and have format "dd-mmm-yy 00:00:00".

Initials: EXCEPT/OW $\# 2$

11.2.3. GENERATE a critical P1 (RED) process alarm, SILENCE it, but do NOT ACKNOWLEDGE it at this time.

Alarm description: $R S H-V V A<P$

$$
\text { Initials: } m \frac{6}{6} / 1 / 28
$$

11.2.4. GENERATE a non-critical P2 (YELLOW) process alarm, SILENCE it, but do NOT ACKNOWLEDGE it at this time.

Alarm description: $\quad$ WLEI-E $1 \$ 2$

$$
\text { Initials: } m 5 \text { 6/11/98 }
$$

11.2.5. GENERATE a non-critical WHITE process alarm, SILENCE it, but do NOT ACKNOWLEDGE it at this time.

Alarm description:

$$
W F I-E|D|
$$

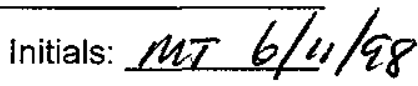

11.2.6. GENERATE a P3 SYSTEM ALARM (suggest network error)

Alarm description:

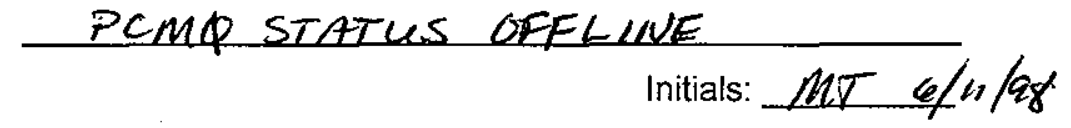

11.2.7. CHECK alarm printer functions correctly upon receipt of an alarm, including correct date and time stamp that has format "dd-mmm-yy 00:00:00".

Initials: EXCEPTEN $4 Z$

11.2.8. CHECK alarm history files are updated correctly upon receipt of an alarm, including correct alarm message date and time stamp that has format "dd-mmm-yy 00:00:00". Initials: EXCEPTION \#2 
11.2.9. CHECK alarms recorded above displayed correctly on P1 ALARM SUMMARY, including correct date and time stamp that has format "dd-mmm 00:00:00".

Initials: $M T 6 / 11 / 98$

11.2.10. CHECK alarms recorded above displayed correctly on P2 ALARM SUMMARY, including correct date and time stamp that has format "dd-mmm 00:00:00".

$$
\text { Initials: } n T 6 / 1 / 98
$$

11.2.11.CHECK alarms recorded above displayed correctly on WHITE ALARM SUMMARY, including correct date and time stamp that has format "dd-mmm-yy 00:00:00".

$$
\text { Initials: EXCEPTION }{ }^{*} 2
$$

11.2.12. CHECK system alarm recorded above displayed correctly on P3 ALARM SUMMARY, including correct date and time stamp that has format "dd-mmm-yy 00:00:00".

Initials: ExcEPTION

11.2.13. CHECK alarms displayed in chronological order on alarm summary pages (newest at top).

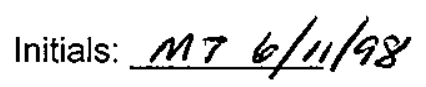

11.2.14.ACKNOWLEDGE alarms and VERIFY they can be acknowledged.

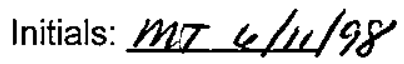

11.2.15.RESTORE alarm conditions and VERIFY they clear from alarm summaries.

Initials: $M T$ 6/11/98

\subsection{Time and Date Functions $\left(\mathrm{D} / 3^{\mathrm{T}}{ }^{\mathrm{M}}\right)$}

11.3.1. CHECK standard date and time on OCM screens (lower right corner) is accurate and has format of "dd-mmm-yy 00:00:00".

\section{Initials: $M T 6 / 11 / 98$}

11.3.2. CHECK Sequence And Batch Language timing functions work properly by observing FHOLD flag on Program Diagnostics graphic \# 133 and VERIFY that FHOLD rolls over between 30 and 45 seconds.

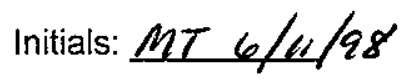

11.3.3. CHECK date and time function for FHOLD on Program Diagnostic graphic \# $\uparrow 33$ is accurate and has format "dd-mmm-yy 00:00:00".

Initials: EXCEPTION $\$$

11.3.4. RUN inhibit C-program from SKID panel and VERIFY date and time on graphic \#80 is correct and has format "dd-mmm-yy 00:00:00".

Initials: EXCEPTION WZ

11.3.5. CHECK current trends operate correctly on OCMs and VERIFY correct time stamp that has format "00:00:00".

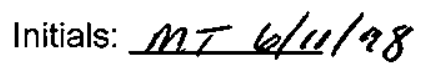

11.3.6. CHECK historical trends operate correctly on OCMs and VERIFY correct date and time stamp that has format "dd-mmm-yy 00:00:00".

Initials: EXCEPTION \#Z 
11.3.7. VERIFY Archiver has created archive file for previous day's historical data in the format "UNITymm.ddD" at about 23:55 hours on a DCM; and VERIFY Archiver has also created historical reference files for the next day's data in the format "UNITymm.ddC", "UNITymm.ddH", and "UNITymm.ddX" at about 00:01 hours.

Initials: $m T 6 / 11 / 98$

11.3.8. RUN the following reports and VERIFY they can be generated with correct date and time (suggest REPOAR; and HISTDAT, HISTMON, or HISTMAX). (1) $M \nabla$ 6-11-98

Report Name:

BALANCE

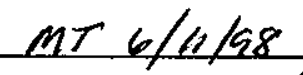

MISTDAT EXCEPTION 44

(1) Unavailable on Sincilator. Uloe Balance \& Histdat instead.

Initials: EXCEPTION \#4 $11: 30$

\subsection{Time and Date Functions (Operating System)}

11.4.1. LOGIN to a terminal (VT type) and VERIFY previous VMS ${ }^{T M}$ login date and time stamp.

Initials: $m \pi 6 / 11 / 98$

11.4.2. LOGOUT from the terminal.

Initials: $m \sigma \quad b / 1 / 98$

11.4.3. LOGIN to an engineering workstation and VERIFY previous VMS ${ }^{\mathrm{TM}}$ login date and time stamp.

Initials: $M T 6 / 4 / 98$

11.4.4. VERIFY VMS ${ }^{\top M}$ date and time stamps are accurate for newly created DCM files.

Initials: $M T 6 / \mathrm{H} / 98$

11.4.5. SUBMIT a batch job (suggest FQIRESET) to the batch queue and VERIFY EXECUTION on CDCM.

Initials: $M T 6 / 1 / 98$

11.4.6. VERIFY date and time correct on DCM (\$SHOW TIME or > TIM commands).

List Systems verified: $\vee A X \triangle \triangle C M$

Initials: $M T \& / 1 / 28$

11.4.7. RUN the Authorize Utility and VERIFY date and time stamp is correct and has format "dd-mmm-yyyy 00:00".

initials: $M T G / 11 / 98$

11.4.8. COMPILE a dummy C-program and VERIFY the content of the compiler list file ( ${ }^{*}$.LIS) date and time stamp is correct and has format "dd-mmm-yyyy 00:00:00".

Initials: $M T$ \& $/ 1 / 98$

11.4.9. LOGOUT from the engineering workstation.

Initials: MT $6 / 11 / 98$ 


\subsection{General DCS Functionality $\left(D / 3^{\mathrm{TM}}\right)$}

11.5.1. VERIFY Sequence And Batch Language programs are running by observing Program Status graphic \#43.

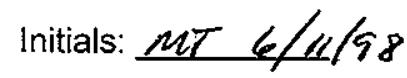

11.5.2. CHECK Device Logic functions properly (suggest interlock bypass or simple valve such as $207-\mathrm{A}$ basins).

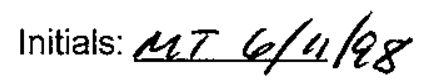

11.5.3. EXECUTE alarm inhibit C-program from the SKID panel and VERIFY proper operation.

$$
\begin{aligned}
& \text { ul1198 mT EXCEPTION } 42 \\
& \text { Initials: } 4 F \text { G/H/98 }
\end{aligned}
$$

11.5.4. INHIBIT an alarm and VERIFY removal from alarm summary display.

$$
\text { Initials: } M T 6 / 11 / 98
$$

11.5.5. REMOVE the inhibit from the alarm in previous step and VERIFY the alarm returns to the alarm summary display.

Initials: $M T 6 / 11 / 98$

11.5.6. VERIFY System Status AND P3 displays show no unexpected system alarm conditions.

$$
\text { Initials: } M T 6 / 11 / 88
$$

11.5.7. VERIFY OCM keyboard is able to access data that is more than 24 hours old.

$$
\text { Initials: } M T 6 / 11 / 98
$$

11.5.8. VERIFY COD Utility date.and time stamp is correct and has format "dd-mmm-yy 00:00:00".

$$
\text { HAS ' } Q Q^{\prime} \text { 'FOR 'YY' }
$$

Initials: $m T$ T/11/98

11.5.9. VERIFY MOD Utility time stamp is correct and has format "00:00:00".

$$
\text { Initials: } m \sigma \quad 6 / 4 / 98
$$

11.5.10.VERIFY MTS Utility date and time stamp is correct and has format "dd-mmm-yy 00:00:00".

$$
\text { Initials: EXCEPTION }
$$

11.5.11.COMPILE a dummy Sequence and Batch Language program and VERIFY SIC Utility listing $\left({ }^{*}\right.$.LST) date and time stamp is correct and has format "dd-mmm-yy 00:00:00".

$$
\text { Initials: } M T 6 / 11 / 98
$$

11.5.12.VERIFY MEAT Utility date and time stamp is correct and has format "dd-mmm-yy 00:00:00".

$$
\text { Initials: } M T 6 / 4 / 98
$$

11.5.13.RUN D3DOWN on all nodes on the network and VERIFY smooth shut down. NOTE: Do first on non-CDCM.

$$
\text { Initials: } \frac{M T 6 / 11 / 98}{12 ! 00}
$$


HNF-2696 REV 0

11.5.14. STOP tasks FQIRESET and WATCH if applicable (STOP/ID=[\# FROM SHOW SYSTEM]).

NOTE: Prepares DCS for restart.

Initials: $M T$ b/11/98

11.5.15. SET TIME forward on the CDCM to December 30, $200023: 45: 00.00$ hours.

NOTE: This allows 10 minutes for restart before data is archived and prepares for verification that year 2000 has 366 days.

Initials: $m T 6 / m / 98$

11.5.16. COPY historical data files to dummy test files of format "UNITymm. $29 \mathrm{C}$ ", "UNITymm.29D", "UNITymm.29H", and "UNITymm.29X" for December 30, 2000, where "UNIT" may be CDCM and/or DCMO.

NOTE: Prepares for verification that year 2000 has 366 days.

Initials: $m T 6 / m / 98$

11.5.17. RUN D3UP on all nodes on the network (CDCM first) and VERIFY. smooth start up. NOTE: This completes February $30 / 31$ verification.

Initials: $\frac{M T 6 / 11 / 98}{12: 16}$

45 


\section{SYSTEM OPERATION TO EXPOSE BAD LEAP YEAR CALCULATION (<366 DAYS)}

\subsection{General Operation}

12.1.1. VERIFY system recognizes that December 31, 2000 follows December 30,2000 , and that system does not transition to January 1, 2001 directly from December 30, 2000.

$$
\text { Initials: } M T \text { 6/11/98 }
$$

12.1.2. OBSERVE system functional throughout the transition to December $31,2000$.

$$
\text { Initials: } \frac{M T}{12: 39} 6 / 11 / 98
$$

\subsection{Alarm And Associated Time And Date Information (D/3 $\left.{ }^{\mathrm{TM}}\right)$}

12.2.1. VERIFY creation of alarm history files with name format "ALddmmmyy.000".

$$
\text { Initials: ExCEPTION \#/ }
$$

12.2.2. VERIFY date and time stamps are accurate for alarm history file contents (alarm messages) and have format "dd-mmm-yy 00:00:00".

$$
\text { Initials: EXCEPTION }{ }^{*} Z
$$

12.2.3. GENERATE a critical P1 (RED) process alarm, SILENCE it, but do NOT ACKNOWLEDGE it at this time.

Alarm description: $\quad R S H-V \vee A L \rho$

$$
\text { Initials: } m \pi \quad 6 / 11 / 98
$$

12.2.4. GENERATE a non-critical P2 (YELLOW) process alarm, SILENCE it, but do NOT ACKNOWLEDGE it at this time.

Alarm description:

$$
\text { WFI-E/Q2 }
$$

$$
\text { Initials: } m \nabla \operatorname{co} / 1 / 88
$$

12.2.5. GENERATE a non-critical WHITE process alarm, SILENCE it, but do NOT ACKNOWLEDGE it at this time.

Alarm description: $W F I-E|Q|$

$$
\text { Initials: } m 76 / k^{\prime} / 98
$$

12.2.6. GENERATE a P3 SYSTEM ALARM (suggest network error) Alarm description: PCMD STATUS OFFLINE Initials: $m T$ b/1/98

12.2.7. CHECK alarm printer functions correctly upon receipt of an alarm, including correct date and time stamp that has format "dd-mmm-yy 00:00:00".

Initials: EXCEPTION $\$ 2$

12.2.8. CHECK alarm history files are updated correctly upon receipt of an alarm, including correct alarm message date and time stamp that has format "dd-mmm-yy 00:00:00".

$$
\text { Initials: EXCEPTION \#2 }
$$


12.2.9. CHECK alarms recorded above displayed correctly on P1 ALARM SUMMARY, including correct date and time stamp that has format "dd-mmm 00:00:00".

\section{Initials: $M T$ G/11/98}

12.2.10.CHECK alarms recorded above displayed correctly on P2 ALARM SUMMARY, including correct date and time stamp that has format "dd-mmm 00:00:00".

$$
\text { Initials: } M T \text { G/11/98 }
$$

12.2.11. CHECK alarms recorded above displayed correctly on WHITE ALARM SUMMARY, including correct date and time stamp that has format "dd-mmm-yy 00:00:00".

$$
\text { Initials: EXCEPTION \#2 }
$$

12.2.12. CHECK system alarm recorded above displayed correctly on P3 ALARM SUMMARY, including correct date and time stamp that has format "dd-mmm-yy 00:00:00".

Initials: EXCEPTION \#/

12.2.13. CHECK alarms displayed in chronological order on alarm summary pages (newest at top).

Initials: $m T$ 6/11/98

12.2.14.ACKNOWLEDGE alarms and VERIFY they can be acknowledged.

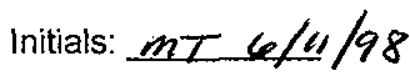

12.2.15.RESTORE alarm conditions and VERIFY they clear from alarm summaries.

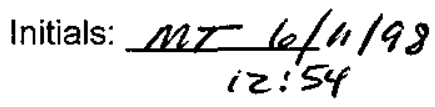

\subsection{Time and Date Functions $\left(\mathrm{D} / 3^{\mathrm{TM}}\right)$}

12.3.1. CHECK standard date and time on OCM screens (lower right corner) is accurate and has format of "dd-mmm-yy 00:00:00".

$$
\text { HAS "QQ" FOR YEAR Initials: MT } 6 / 11 / 98
$$

12.3.2. CHECK Sequence And Batch Language timing functions work properly by observing FHOLD flag on Program Diagnostics graphic \#133 and VERIFY that FHOLD rolls over between 30 and 45 seconds.

$$
\text { Initials: MT 6/11/98 }
$$

12.3.3. CHECK date and time function for FHOLD on Program Diagnostic graphic \#133 is accurate and has format "dd-mmm-yy 00:00:00".

$$
\text { Initials: EXCEPTION \#3 }
$$

12.3.4. RUN inhibit C-program from SKID panel and VERIFY date and time on graphic \#80 is correct and has format "dd-mmm-yy 00:00:00".

Initials: EXCEPTION ${ }^{\text {Ht }} 2$

12.3.5. CHECK current trends operate correctly on OCMs and VERIFY correct time stamp that has format "00:00:00".

$$
\text { Initials: MT } 6 / 14 / 98
$$

12.3.6. CHECK historical trends operate correctly on OCMs and VERIFY correct date and time stamp that has format "dd-mmm-yy 00:00:00".

$$
\text { Initials: EXCEPTION \#2 }
$$


12.3.7. VERIFY Archiver has created archive file for previous day's historical data in the format "UNITymm.ddD" at about 23:55 hours on a DCM; and VERIFY Archiver has also created historical reference files for the next day's data in the format "UNITymm.ddC", "UNITymm.ddH", and "UNITymm.ddX" at about 00:01 hours.

$$
\text { Initials: } M T \text { 6/11/98 }
$$

12.3.8. RUN the following reports and VERIFY they can be generated with correct date and time (suggest TFBAL, REPF WRITER; and HISTDAT, HISTMON, or HISTMAX). O MT 6-11-98
Report Name:

$$
\text { BALANCE }
$$$$
\text { MT } 6 / 11 / 58
$$$$
\text { HISTDAT }
$$$$
\text { EXCEPTIOW }
$$
(O) Unavailable On Simulator. Use
BALANCE instead.
Initials: EXCEPTION ${ }^{4} 4$

$$
1: 10
$$

\subsection{Time and Date Functions (Operating System)}

12.4.1. LOGIN to a terminal (VT type) and VERIFY previous VMS ${ }^{\mathrm{TM}}$ login date and time stamp.

\section{$1: 11$}

Initials: $M T 6 / 11 / 98$

12.4.2. LOGOUT from the terminal.

$$
\text { Initials: } M T 6 / 11 / 98
$$

12.4.3. LOGIN to an engineering workstation and VERIFY previous $\mathrm{VMS}^{\mathrm{TM}}$ login date and time stamp.

$$
\text { Initials: } M T \text { G/4/98 }
$$

12.4.4. VERIFY VMS ${ }^{\top M}$ date and time stamps are accurate for newly created DCM files.

$$
\text { Initials: } M T \text { G/u/a } / 8
$$

12.4.5. SUBMIT a batch job (suggest FQIRESET) to the batch queue and VERIFY EXECUTION on CDCM.

$$
\text { Initials: } m T 6 / 11 / 98
$$

12.4.6. VERIFY date and time correct on DCM ( $\$$ SHOW TIME or > TIM commands).

List Systems verified:

$$
\text { - VAX CDCM }
$$

$$
\text { Initials: } m \text { T } 10 / 4 / 98
$$

12.4.7. RUN the Authorize Utility and VERIFY date and time stamp is correct and has format "dd-mmm-yyyy 00:00".

$$
\text { Initials: } M T \text { G/4/98 }
$$

12.4.8. COMPILE a dummy C-program and VERIFY the content of the compiler list file ( ${ }^{*}$.LIS) date and time stamp is correct and has format "dd-mmm-yyyy 00:00:00".

Initials: $M T 6 / 11 / 98$

12.4.9. LOGOUT from the engineering workstation.

Initials: $M T$ 6/11/98

$$
1: 20
$$




\section{HNF-2696 REV 0}

\subsection{General DCS Functionality $\left(D / 3^{\mathrm{TM}}\right)$}

12.5.1. VERIFY Sequence And Batch Language programs are running by observing Program Status graphic \#43.

12.5.2. CHECK Device Logic functions properly (suggest interlock bypass or simple valve such as $207-A$ basins).

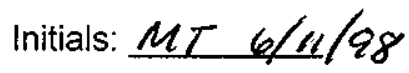

12.5.3. EXECUTE alarm inhibit C-program from the SKID panel and VERIFY proper operation.

Initials: EXCEPTION ${ }^{*} Z$

12.5.4. INHIBIT an alarm and VERIFY removal from alarm summary display.

Initials: $m T 6 / 11 / 98$

12.5.5. REMOVE the inhibit from the alarm in previous step and VERIFY the alarm returns to the alarm summary display.

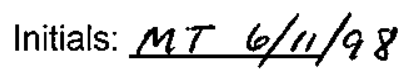

12.5.6. VERIFY System Status AND.P3 displays show no unexpected system alarm conditions.

Initials: $M$ T b/ll/ $/ 98$

12.5.7. VERIFY OCM keyboard is able to access data that is more than 24 hours old.

Initials: $M T$ co/11/98

12.5.8. VERIFY COD Utility date and time stamp is correct and has format "dd-mmm-yy 00:00:00".

Initials: $M T$ lo/ $/ 1 / 98$

12.5.9. VERIFY MOD Utility time stamp is correct and has format "00:00:00".

\section{Initials: $M T 6 / 11 / 98$}

12.5.10.VERIFY MTS Utility date and time stamp is correct and has format "dd-mmm-yy 00:00:00".

Initials: EXCEPTION \#Z

12.5.11.COMPILE a dummy Sequence and Batch Language program and VERIFY SIC Utility listing (".LST) date and time stamp is correct and has format "dd-mmm-yy 00:00:00".

$$
\text { Initials: } M T 6 / 11 / 98
$$

12.5.12.VERIFY MEAT Utility date and time stamp is correct and has format "dd-mmm-yy 00:00:00".

Initials: MT $6 / 11 / 98$

12.5.13.RUN D3DOWN on all nodes on the network and VERIFY smooth shut down. NOTE: Do first on non-CDCM.

Initials: MT $6 / 11 / 98$

$1: 35$ 
12.5.14.STOP tasks FQIRESET and WATCH if applicable (STOP/ID=[\# FROM SHOW SYSTEM]).

NOTE: Prepares DCS for restart.

Initials: $M T 6 / 11 / 98$

12.5.15.SET TIME forward on the CDCM to February $28,200123: 45: 00.00$ hours. NOTE: This allows 10 minutes for restart before data is archived and prepares for to verify no leap year in 2001.

Initials: $M T 6 / 11 / 98$

12.5.16. COPY historical data files to dummy test files of format "UNITymm. $27 \mathrm{C}$ ", "UNITymm.27D", "UNITymm.27H", and "UNITymm.27X" for February 28, 2001, where "UNIT" may be CDCM and/or DCM0.

NOTE: Prepares to verify no leap year in 2001.

\section{$1: 42$}

Initials: MT $6 / 14 / 98$

12.5.17.RUN D3UP on all nodes on the network (CDCM first) and VERIFY smooth start up. NOTE: This completes testing for bad leap year calculation ( $<366$ days).

Initials: $\frac{m \pi \cdot 6 / 11 / 98}{1: 47}$ 


\section{SYSTEM OPERATION TO EXPOSE WRONG LEAP YEAR IN 2001}

\subsection{General Operation}

13.1.1. VERIFY system recognizes that March 1, 2001 follows February 28, 2001, and that system does not transition to February 29, 2001 directly from February 28, 2001.

$$
\text { Initials: } m T 6 / 11 / 98
$$

13.1.2. OBSERVE system functional throughout the transition to March 1, 2001.

$$
\text { Initials: } \frac{M T 6 / 11 / 88}{2: 03}
$$

\subsection{Alarm And Associated Time And Date Information (D/3 ${ }^{\mathrm{TM}}$ )}

13.2.1. VERIFY creation of alarm history files with name format "ALddmmmyy 000 ".

$$
\text { Initials: EXCEPTION \#/ }
$$

13.2.2. VERIFY date and time stamps are accurate for alarm history file contents (alarm messages) and have format "dd-mmm-yy 00:00:00".

$$
\text { Initials: EXCEPT } 10 \mathrm{~N}^{4} \mathrm{Z}
$$

13.2.3. GENERATE a critical P1 (RED) process alarm, SILENCE it, but do NOT ACKNOWLEDGE it at this time:

Alarm description: RSH-VVALP

$$
\text { Initials: } m \text { r } 6 / 11 / 98
$$

13.2.4. GENERATE a non-critical P2 (YELLOW) process alarm, SILENCE it, but do NOT ACKNOWLEDGE it at this time.

Alarm description: WFI-E 102

$$
\text { Initials: } m \pi \quad 6 / 11 / 98
$$

13.2.5. GENERATE a non-critical WHITE process alarm, SILENCE it, but do NOT ACKNOWLEDGE it at this time.

Alarm description: WFI-E101

$$
\text { Initials: } m T 6 / 4 / 98
$$

13.2.6. GENERATE a P3 SYSTEM ALARM (suggest network error)

Alarm description: PCMD STATUS

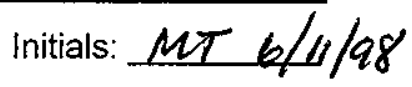

13.2.7. CHECK alarm printer functions correctly upon receipt of an alarm, including correct date and time stamp that has format "dd-mmm-yy 00:00:00".

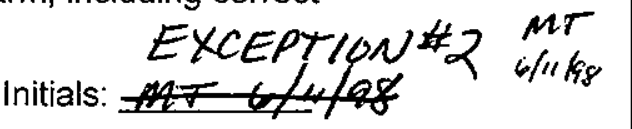

13.2.8. CHECK alarm history files are updated correctly upon receipt of an alarm, including correct alarm message date and time stamp that has format "dd-mmm-yy 00:00:00".

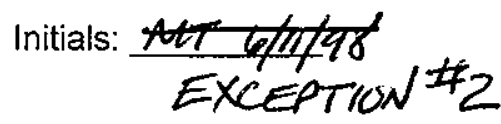


13.2.9. CHECK alarms recorded above displayed correctly on P1 ALARM SUMMARY, including correct date and time stamp that has format "dd-mmm 00:00:00".

Initials: $M T$ C $/ 4 / 98$

13.2.10.CHECK alarms recorded above displayed correctly on P2 ALARM SUMMARY, including correct date and time stamp that has format "dd-mmm 00:00:00".

\section{Initials: $M T 6 / 11 / 98$}

13.2.11. CHECK alarms recorded above displayed correctly on WHITE ALARM SUMMARY, including correct date and time stamp that has format "dd-mmm-yy 00:00:00".

Initials: EXCEPTION \#Z

13.2.12.CHECK system alarm recorded above displayed correctly on P3 ALARM SUMMARY, including correct date and time stamp that has format "dd-mmm-yy 00:00:00".

Initials: EXCEPTION 42

13.2.13. CHECK alarms displayed in chronological order on alarm summary pages (newest at top).

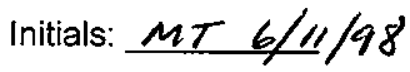

13.2.14.ACKNOWLEDGE alarms and VERIFY they can be acknowledged.

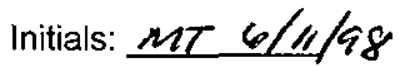

13.2.15.RESTORE alarm conditions and VERIFY they clear from alarm summaries.

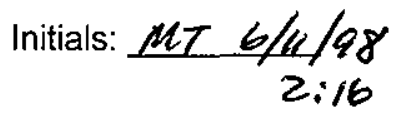

\subsection{Time and Date Functions $\left(D / 3^{\mathrm{TM}}\right)$}

13.3.1. CHECK standard date and time on OCM screens (lower right corner) is accurate and has format of "dd-mmm-yy 00:00:00".

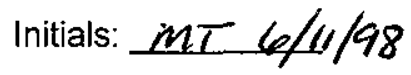

13.3.2. CHECK Sequence And Batch Language timing functions work properly by observing FHOLD flag on Program Diagnostics graphic \#133 and VERIFY that FHOLD rolls over between 30 and 45 seconds.

Initials: $M T 6 / 11 / 88$

13.3.3. CHECK date and time function for FHOLD on Program Diagnostic graphic \#133 is accurate and has format "dd-mmm-yy 00:00:00".

$$
\text { Dow }=4
$$

Initials: EXCEPTION

13.3.4. RUN inhibit C-program from SKID panel and VERIFY date and time on graphic $\# 80$ is correct and has format "dd-mmm-yy 00:00:00".

Initials: EXCEPTION $\mathbb{Z}_{2}$

13.3.5. CHECK current trends operate correctly on OCMs and VERIFY correct time stamp that has format "00:00:00".

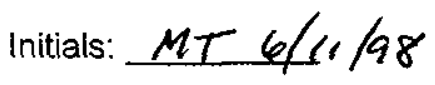

13.3.6. CHECK historical trends operate correctly on OCMs and VERIFY correct date and time stamp that has format "dd-mmm-yy 00:00:00". 
13.3.7. VERIFY Archiver has created archive file for previous day's historical data in the format "UNITymm.ddD" at about 23:55 hours on a DCM; and VERIFY Archiver has also created historical reference files for the next day's data in the format "UNITymm.ddC", "UNITymm.ddH", and "UNITymm.ddX" at about 00:01 hours.

Initials: $M T$ G $/ 4 / 98$

13.3.8. RUN the following reports and VERIFY they can be generated with correct date and time (suggest FFBAt, REPORT WRITER; and HISTDAT, HISTMON, or HISTMAX). (1) MT 6-11-98

Report Name:

BALANCE MT $6 / 11 / 98$

HISTDAT EXCEPTION H4

(1) Unavailable on Simulator. Use Balance instead.

Initials: EXCEPT/ON $\# 4$

$2: 28$

\subsection{Time and Date Functions (Operating System)}

13.4.1. LOGIN to a terminal (VT type) and VERIFY previous VMS ${ }^{\mathrm{TM}}$ login date and time stamp.

13.4.2. LOGOUT from the terminal.

$$
\text { Initials: } M T 6 / 11 / 98
$$

Initials: $M T$ ofu/g8

13.4.3. LOGIN to an engineering workstation and VERIFY previous VMS ${ }^{\mathrm{TM}}$ login date and time stamp.

Initials: $M T 6 / 11 / 98$

13.4.4. VERIFY VMS ${ }^{\mathrm{TM}}$ date and time stamps are accurate for newly created DCM files.

Initials: $M T$ lefilas

13.4.5. SUBMIT a batch job (suggest FQIRESET) to the batch queue and VERIFY EXECUTION on CDCM.

Initials: $M T 6 / 1 / 98$.

13.4.6. VERIFY date and time correct on DCM (\$SHOW TIME or >TIM commands).

List Systems verified: $\quad \checkmark A \times C D C M$

Initials: $M T-6 / 4 / 98$

13.4.7. RUN the Authorize Utility and VERIFY date and time stamp is correct and has format "dd-mmm-yyyy 00:00".

Initials: $M T 6 / 4 / 98$

13.4.8. COMPILE a dummy C-program and VERIFY the content of the compiler list file (*.LIS) date and time stamp is correct and has format "dd-mmm-yyyy 00:00:00".

Initials: $M T 6 / 1 / 98$

13.4.9. LOGOUT from the engineering workstation.

$$
\text { Initials: } \frac{M T \cdot 6 / 4 / 98}{2: 42}
$$




\subsection{General DCS Functionality $\left(\mathrm{D} / 3^{\mathrm{TM}}\right)$}

13.5.1. VERIFY Sequence And Batch Language programs are running by observing Program Status graphic \#43.

$$
2: 42
$$

Initials: $M T 6 / 11 / 98$

13.5.2. CHECK Device Logic functions properly (suggest interlock bypass or simple valve such as 207-A basins).

Initials: $M T$ ef/11/8

13.5.3. EXECUTE alarm inhibit C-program from the SKID panel and VERIFY proper operation.

Initials: EXCEPTION

13.5.4. INHIBIT an alarm and VERIFY removal from alarm summary display.

$$
\text { Initials: } m \text { T } 6 / 11 / 98
$$

13.5.5. REMOVE the inhibit from the alarm in previous step and VERIFY the alarm returns to the alarm summary display.

$$
\text { Initials: } M T 6 / 14 / 98
$$

13.5.6. VERIFY System Status AND P3 displays show no unexpected system alarm conditions.

$$
\text { Initials: } M T \text { b/ulas }
$$

13.5.7. VERIFY OCM keyboard is able to access data that is more than 24 hours old.

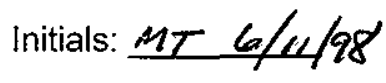

13.5.8. VERIFY COD Utility date and time stamp is correct and has format "dd-mmm-yy 00:00:00".

$$
\text { initials: } M T \text { b/e/ } / 98
$$

13.5.9. VERIFY MOD Utility time stamp is correct and has format "00:00:00".

$$
\text { Initials: } m T \text { oft/198 }
$$

13.5.10.VERIFY MTS Utility date and time stamp is correct and has format "dd-mmm-yy 00:00:00".

$$
\text { Initials: EXCEPTION \#2. }
$$

13.5.11.COMPILE a dummy Sequence and Batch Language program and VERIFY SIC Utility listing (*.LST) date and time stamp is correct and has format "dd-mmm-yy 00:00:00".

$$
\text { Initials: } M T 6 / 4 / 98
$$

13.5.12. VERIFY MEAT Utility date and time stamp is correct and has format "dd-mmm-yy 00:00:00".

$$
\text { Initials: } M T 6 / 4 / 9^{8}
$$

13.5.13.RUN D3DOWN on all nodes on the network and VERIFY smooth shut down. NOTE: Do first on non-CDCM.

$$
\text { Initials: } M T \& / 11 / 98
$$


13.5.14.STOP tasks FQIRESET and WATCH if applicable (STOP/ID $=[\#$ FROM SHOW SYSTEM]).

NOTE: Prepares DCS to verify cold startup after year 2000. $13: 01$

Initials: $M T$ $6 / 1 / 98$

13.5.15. On all nodes on the network, SHUT DOWN the operating system, POWER DOWN, and RESTART the operating system.

NOTE: Multiple nodes may be done simultaneously. Prepares DCS to verify cold startup after year 2000.

$$
\text { Initials: } m \text { T } 6 / 11 / 98
$$

13.5.16.WAIT until restart of operating system is completed on all nodes before continuing.

$$
\text { Initials: } m+6 / 11 / 98
$$

13.5.17. RUN D3UP on all nodes on the network (CDCM first) and VERIFY smooth start up. NOTE: Prepares DCS to verify cold startup after year 2000.

$$
\text { Initials: } \frac{m T 6 / 11 / 98}{3: 18}
$$




\section{SYSTEM OPERATION AFTER COLD STARTUP}

\subsection{General Operation}

14.1.1. OBSERVE system functional following cold startup.

$$
\text { Initials: } \frac{M T 6 / 11 / 98}{3: 19}
$$

\subsection{Time and Date Functions $\left(D / 3^{\mathrm{TM}}\right)$}

14.2.1. CHECK standard date and time on OCM screens (lower right corner) is accurate and has format of "dd-mmm-yy 00:00:00".

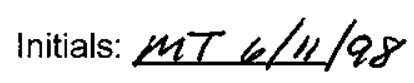

14.2.2. CHECK Sequence And Batch Language timing functions work properly by observing FHOLD flag on Program Diagnostics graphic \#133 and VERIFY that FHOLD rolls over between 30 and 45 seconds.

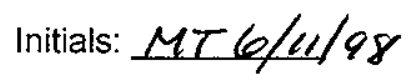

14.2.3. CHECK date and time function for FHOLD on Program Diagnostic graphic \#133 is accurate and has format "dd-mmm-yy 00:00:00".

Initials: EXCEPTION

14.2.4. RUN inhibit C-program from SKID panel and VERIFY date and time on graphic \#80 is correct and has format "dd-mmm-yy 00:00:00".

$$
\text { Initials: EXCEPTION \#Z }
$$

14.2.5. CHECK current trends operate correctly on OCMs and VERIFY correct time stamp that has format "00:00:00".

$$
\text { Initials: } m T \text { G/11/98 }
$$

14.2.6. CHECK historical trends operate correctly on OCMs and VERIFY correct date and time stamp that has format "dd-mmm-yy 00:00:00".

Initials: EXCEPTION $\# 2$

\subsection{Time and Date Functions (Operating System)}

14.3.1. LOGIN to a terminal (VT type) and VERIFY previous VMS ${ }^{T M}$ login date and time stamp.

$$
\text { Initials: } m \text { T } 6 / 11 / 98
$$

14.3.2. LOGOUT from the terminal.

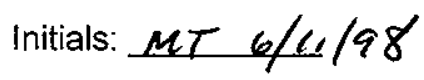

14.3.3. LOGIN to an engineering workstation and VERIFY previous VMS ${ }^{\mathrm{TM}}$ login date and time stamp.

14.3.4. LOGOUT from the engineering workstation.

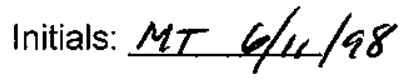

Initials: $M T \quad 6 / 11 / 98$ 
14.4. General DCS Functionality $\left(D / 3^{\mathrm{TM}}\right)$

14.4.1. VERIFY Sequence And Batch Language programs are running by observing Program Status graphic \#43.

Initials: $M T$. $/ 11 / 98$

14.4.2. VERIFY System Status AND P3 displays show no unexpected system alarm conditions.

NOTE: This completes verification of cold startup. THIS COMPLETES YEAR 2000 TESTING. Prepare for reset of system date/time and system restart.

Initials: $M T 6 / 11 / 98$

$3: 26$ 


\section{SYSTEM RESTORATION}

\subsection{System Shutdown/Restart}

15.1.1. RUN D3DOWN.

NOTE: Do all nodes on the network and first on non-CDCM.

15.1.2. STOP Tasks FQIRESET And WATCH.

Initials: MT $6 / 14 / 98$

NOTE: STOP/ID=[\# From Show System $]$ ).

Initials: $M T$ G/11/98

15.1.3. SET TIME On CDCM To Current Date/Time.

Initials: $M T 6 / 11 / 98$

15.1.4. On all nodes on the network, SHUT DOWN the operating system, POWER DOWN, and RESTART the operating system.

NOTE: Multiple nodes may be done simultaneously.

Initials: MT $6 / 11 / 98$

15.1.5. WAIT until restart of operating system is completed on all nodes before continuing.

Initials: $M T 6 / 11 / 98$

15.1.6. RUN D3UP.

NOTE: Do for all applicable nodes on the network, CDCM first.

Initials: $M T 6 / 11 / 98$

15.1.7. After all nodes are running, RUN GENERAL FUNCTION 14 on CDCM to regenerate all alarms.

initials: $M T 6 / 11 / 98$

\subsection{General Operation}

15.2.1. OBSERVE system functional following system startup.

15.3. Time and Date Functions $\left(D / 3^{T M}\right)$

Initials: $M T 6 / 4 / 98$

15.3.1. CHECK standard date and time on OCM screens (lower right corner) is accurate and has format of "dd-mmm-yy 00:00:00".

Initials: $M T 6 / 11 / 98$

15.3.2. RUN inhibit C-program from SKID panel and VERIFY date and time on graphic \#80 is correct and has format "dd-mmm-yy 00:00:00".

Initials: $M T$ G/11/98

15.3.3. CHECK current trends operate correctly on OCMs and VERIFY correct time stamp that has format "00:00:00".

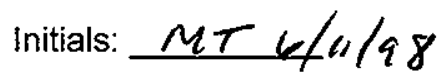


15.3.4. CHECK historical trends operate correctly on OCMs and VERIFY correct date and time stamp that has format "dd-mmm-yy 00:00:00".

\section{Initials: $M T$ T/15/98}

\subsection{Time and Date Functions (Operating System)}

15.4.1. LOGIN to a terminal (VT type) and VERIFY previous VMS ${ }^{\mathrm{TM}}$ login date and time stamp.

Initials: $\operatorname{mr} 6 / 4 / 98$

15.4.2. LOGOUT from the terminal.

Initials: MT G/11/a8

15.4.3. LOGIN to an engineering workstation and VERIFY previous VMS ${ }^{\mathrm{TM}}$ login date and time stamp.

initials: $M T 6 / 11 / 88$

15.4.4. LOGOUT from the engineering workstation.

Initials: $M T$ G/11/98

\subsection{General DCS Functionality $\left(D / 3^{\mathrm{TM}}\right)$}

15.5.1. VERIFY Sequence And Batch Language programs are running by observing Program Status graphic \#43.

$$
\text { Initials: } m T 6 / 11 / 98
$$

15.5.2. VERIFY System Status AND P3 displays show no unexpected system alarm conditions.

NOTE: This completes verification of system restoration.

Initials: MT $6 / 11 / 98$

\subsection{Post Performance Review}

15.6.1. This procedure's testing has been completed.

Initials: $M T 6 / 15 / 98$

15.6.2. The system's date and time have been restored to the current date and time and all systems have been verified functional.

Initials: $M T 6 / 15 / 28$ 
HNF-2696 REV 0

ATTACHMENT 1: D/3 ${ }^{\text {TM }}$ DCS YEAR 2000 TEST CRITERIA

ALARM INFORMATION $\left(D / 3^{\text {rM }}\right)$

HISTORICAL. FILES' TIME AND DATE STAMPS

HISTORICAL FILES' NAMES (INCORPORATES DATE)

PROPER TIME AND DATE STAMP ON THE ALARM TYPER PRINTOUTS

PROPER TIME AND DATE STAMP IN ALARM HISTORY FILE

TIME AND DATE STAMP ON THE ALARM SUMMARY PAGES (CRITICAL, NON-CRITICAL, WHITE, AND SYSTEM)

CHRONOLOGICAL PRESENTATION ON THE ALARM SUMMARY PAGES

ENSURE ALARM ACKNOWLEDGMENT FUNCTIONS PROPERLY ALARMS

ENSURE CLEARING OF ALARMS FUNCTIONS PROPERLY

TIME AND DATE FUNCTIONS (D/3 $\left.{ }^{\mathrm{TM}}\right)$

PRESENTATION OF THE TIME AND DATE ON OCM SCREENS

SABL TIMING FUNCTIONS WORK PROPERLY (SUGGEST FHOLD)

PROPER COLLECTION AND DISPLAY OF CURRENT TREND INFORMATION

PROPER COLLECTION AND DISPLAY OF HISTORICAL TREND INFORMATION

PROPER OPERATION OF HISTORICAL DATA ARCHIVER

PROPER OPERATION OF REPORT PROGRAMS

TIME AND DATE FUNCTIONS (OPERATING SYSTEM)

VERIFY PREVIOUS VMS ${ }^{\text {TM }}$ LOGIN TIME AND DATE STAMP

CORRECT CREATION DATE AND TIME ON NEWLY CREATED SOFTWARE FILES

TOTALIZER RESET AT 01:03 WORKS PROPERLY

CORRECT TIME CLOCK FUNCTIONING ON CDCM AND DCM'S

VERIFY AUTHORIZE UTILITY TIME AND DATE STAMP

VERIFY C-COMPILER LISTING TIME AND DATE STAMP

GENERAL DCS FUNCTIONALITY (D/3 $\left.{ }^{\text {TM }}\right)$

ENSURE SEQUENCE PROGRAMS RUN

ENSURE DEVICE LOGIC WORKS PROPERLY (SUGGEST INTERLOCK BYPASS)

ENSURE ALARM INHIBIT C-PROGRAM AND FUNCTION WORKS PROPERLY

VERIFY PROPER MCS OPERATION VIA SYSTEM STATUS AND P3 DISPLAYS

VERIFY OPERATOR KEYBOARD WORKS (DISPLAY OF > 1 DAY-OLD HISTORICAL DATA)

VERIFY SMOOTH SHUTDOWN OF CDCM, DCM'S

VERIFY SMOOTH BOOT UP/REBOOT OF CDCM, DCM'S

VERIFY COD UTILITY TIME AND DATE STAMP

VERIFY MOD UTILITY TIME STAMP

VERIFY MTS UTILITY TIME AND DATE STAMP

VERIFY SIC COMPILER LISTING TIME AND DATE STAMP

VERIFY MEAT UTILITY TIME AND DATE STAMP

VERIFY SERIAL NUMBER FROM COMPLETE APPLICATIONS REBUILD

VERIFY D/3 ${ }^{\text {TM }}$ FUNCTIONALITY FOLLOWING COMPLETE APPLICATIONS REBUILD 
HNF-2696 REV 0

ATTACHMENT 2: TEST DISCREPANCY LOG SHEET

Page of

TEST

STEP

NUMBER

DESCRIPTION

RESOLUTION

CLOSED
DATE

CLOSED
DATE 


\section{HNF-2696 REV 0}

\section{PROCEDURE-PRODUCTION SYSTEM RESULTS}

\subsection{Setup and Initial Conditions}

5.1.1. For simulation system, VERIFY simulation program stopped. Write N/A if production * system shall be tested at this time.

$$
\text { Initials: } N / A \text { m } 12 / 16 / 98
$$

5.1.2. For production system, VERIFY the following (Write N/A if simulation system shall be tested at this time):

5.1.2.1. Backup CDCM and DCMO before vendor software changed

$$
\text { Initials: } N / A \text { m } 12 / 16 / 98
$$

5.1.2.2. Modify vendor software

Initials: $N / A$ m $12 / 16 / 48$

5.1.2.3. Compile vendor software

5.1.2.4. Load new software to CDCM and DCMO

Initials: $N / A m$ m $12 / 16 / 98$

Initials: N/AMT $12 / 16 / 98$

5.1.2.5. Complete any USQ documentation

Initials: N/A MT $12 / 16 / 98$

* Production system for this ATP is new $D / 3$ version instead of 242A $6-3-3 \quad D B$. 
HNF-2696 REV 0

\subsection{Prerequisite}

Document the DCS system by recording the following information:

SYSTEM (Check One): [ ] Simulator X] Production (Procurement $D / 3$ )

D/3 TMVRSION: $9.0 .2-2$

DATE OF TEST: $12-16-98$

CHECK ONE OF THE FOLLOWING SYSTEM STATUSES:

[ ] Original, Unmodified D/3 ${ }^{T M}$ Version (BASELINE)

[ ] $D / 3^{\mathrm{TM}}$ Version With Modified GSE System Patches

$[X]$ New $D / 3$ version as noted above

LIST OF GSE PATCH NUMBERS (N/A If None):

$N / A$

FILL IN THE FOLLOWING SYSTEM INFORMATION:

\begin{tabular}{|c|c|c|c|}
\hline & HARDWARE & \begin{tabular}{|l|} 
OPERATING \\
SYSTEM \& VERSION
\end{tabular} & $\begin{array}{l}\text { OPERATOR DISPLAY } \\
\text { AVAILABLE (Y/N) }\end{array}$ \\
\hline CDCM & DEC ALPHA 433 & VMS $7.1-1 \mathrm{H}_{2}$ & YES (2) \\
\hline DCM & DEC ALPHA 433 & vans $7.1-1+12$ & YES (2) \\
\hline WORKSTATIONS & $V A X 4000-60$ (1) & vms $7.1-1 \mathrm{Mz}$ & YES $(1)$ \\
\hline$\frac{\text { PCM }}{\text { NETY }}$ & 386 PCM TI & $\frac{D / 3}{N / A} \cdot 0.2-2$ & $\frac{N / A}{N / A}$ \\
\hline
\end{tabular}

NOTE: Throughout the test if possible, capture all terminal output to a printer or a file in order to document events. Also, when possible, print a screen copy of the operator console display to document operation of the system each time a display is checked as part of the test.

(1) ALSO $9.0 .2-2$ NT PC

\section{SYSTEM OPERATION BEFORE ALTERING DATE AND TIME}

\subsection{Alarm And Associated Time And Date Information (D/3 $\left.{ }^{\mathrm{TM}}\right)$}

6.1.1. COPY as necessary alarm history files and historical data files into SAVE directories.

Initials: $M T$ 12/16/98 asis

6.1.2. VERIFY creation of alarm history files with name format "ALddmmmyy.000".

Initials: $m$ T $12 / 11 / 98$ ogk

6.1.3. VERIFY date and time stamps are accurate for alarm history file contents (alarm messages) and have format "dd-mmm-yy 00:00:00".

(2)

Initials: MT $12 / 16 / 980916$

6.1.4. GENERATE a critical P1 (RED) process alarm, SHENEE it, but do NOT ACKNOWLEDGE it at this time.

mT 12/16/98

(2) No alarm printer or horn on F.A.T. 
Alarm description: PI-IA-1 IBAD ALARM Initials: $M T \quad 092012 / 16 / 98$

6.1.5. GENERATE a non-critical P2 (YELLOW) process alarm, SHENEE it, but do NOT ACKNOWLEDGE it at this time. MT $12 / 16 / 48$

Alarm description: PI-PA-1 LO ALARM

Initials: $M T \quad 0922 \quad 12 / 16 / 98$

6.1.6. GENERATE a non-critical WHITE process alarm, SHENEE it, but do NOT ACKNOWLEDGE it at this time. $M T 12 / 16 / 48$

Alarm description: TI-AMBS-1 COLD IUNC SENSOR LO Initials: $M T$ o924 $12 / 16 / 98$

6.1.7. GENERATE a P3 SYSTEM ALARM (suggest network error)

Alarm description: PCMNA GINK STATUS CMANGE Initials: $M T$ O929 12/16/98

8.1.8. GHEGK-atarm primter functions: correcty upon receipt of an alarm, inctuding correct date-and the-stamp that has format"dd-mmm-yy 00:00:00". NIA NO Printer on F.A.T. initials: N/A
USE AHF INSTEAD

6.1.9. CHECK alarm history files are updated correctly upon receipt of an alarm, including correct alarm message date and time stamp that has format "dd-mmm-yy 00:00:00". Initials: $M r \quad 12 / 16 / 98$

6.1.10. CHECK alarms recorded above displayed correctly on P1 ALARM SUMMARY, including correct date and time stamp that has format "dd-mmm 00:00:00".

Initials: $n T \quad 12 / 16 / a 8$

6.1.11. CHECK alarms recorded above displayed correctly on P2 ALARM SUMMARY, including correct date and time stamp that has format "dd-mmm 00:00:00".

Initials: $M T$ 12/16/98

6.1.12. CHECK alarms recorded above displayed correctly on WHITE ALARM SUMMARY, including correct date and time stamp that has format "dd-mmm-yy 00:00:00".

Initials: $M T 12 / 16 / 98$

6.1.13. CHECK system alarm recorded above displayed correctly on P3 ALARM SUMMARY, including correct date and time stamp that has format "dd-mmm-yy 00:00:00".

Initials: $M T \quad 12 / 16 / 98$

6.1.14. CHECK alarms displayed in chronological order on alarm summary pages (newest at top).

Initials: NT $12 / 16 / 98$

6.1.15. ACKNOWLEDGE alarms and VERIFY they can be acknowledged. Initials: MT 12/16/98

6.1.16. RESTORE alarm conditions and VERIFY they clear from alarm summaries.

Initials: $M T$ 12/10/98 


\subsection{Time and Date Functions $\left(D / 3^{T M}\right)$}

6.2.1. CHECK standard date and time on OCM screens (lower right corner) is accurate and has format of "dd-mmm-yy 00:00:00".

$$
\text { Initials: } m \nabla / 2 / 46 / 98
$$

6.2.2. CHECK Sequence And Batch Language timing functions work properly by observing FHOLD flag on Program Diagnostics graphic \#133 and VERIFY that FHOLD rolls over between 30 and 45 seconds.

$$
\text { Initials: } M 212 / 17 / 981536
$$

6.2.3. CHECK date and time function for FHOLD on Program Diagnostic graphic \#133 is accurate and has format "dd-mmm-yy 00:00:00".

$$
\text { Initials: } \underline{\mu T} 12 / 17 \quad 1536
$$

6.2.4. RUN inhibit C-program from SKID panel and VERIFY date and time on graphic \#80 is correct and has format "dd-mmm-yy 00:00:00".
EXCEPTION \#/Reso/ved /2/12/4g
Initials: MT $12 / 17 / 981926$

6.2.5. CHECK current trends operate correctly on OCMs and VERIFY correct time stamp that has format "00:00:00".

$$
\text { Initials: } M T, 2 / 171610
$$

6.2.6. CHECK historical trends operate correctly on OCMs and VERIFY correct date and time stamp that has format "dd-mmm-yy 00:00:00".

$$
\text { Initials: MT } 12 / 17 \quad 1611
$$

6.2.7. VERIFY Archiver has created archive file for previous day's historical data in the format "UNITymm.ddD" at about 23:55 hours on a DCM; and VERIFY Archiver has also created historical reference files for the next day's data in the format "UNITymm.ddC", "UNITymm.ddH", and "UNITymm.ddX" at about 00:01 hours.

$$
[d 3 H I S,[H T D]
$$

Initials: $M T 12 / 1716 / 4$

6.2.8. RUN the following reports and VERIFY they can be generated with correct date and time (suggest TFBAL, REPORTWWRITER; and HISTDAT) HISTMON, or HISTMAX).

Report Name: HISTDAT

$$
\begin{aligned}
& \text { RuN D3EXE: HISTDAT } \\
& \text { (Nite: Reports are generated with corred } \\
& \text { date/time but data Looks wrong) initials: } M T 12 / 171619
\end{aligned}
$$

\subsection{Time and Date Functions (Operating System)}

6.3.1. LOGIN to a terminal (VT type) and VERIFY previous VMS ${ }^{\mathrm{TM}}$ login date and time stamp. DECTERM / SHOWTIME

$$
\text { Initials: MT } 12 / 171620
$$

6.3.2. LOGOUT from the terminal.

Initials: $M T, 2 / 17$ 
6.3.3. LOGIN to an engineering workstation and VERIFY previous VMS ${ }^{\mathrm{TM}}$ login date and time stamp. SET HOST WHCDCM

Initials: $M \nabla \quad 12 / 17 / 98$

6.3.4. VERIFY VMS ${ }^{\mathrm{TM}}$ date and time stamps are accurate for newly created DCM files.

Initials: MN $12 / 17 / 98$

6.3.5. SUBMIT a batch job (suggest FQIRESET) to the batch queue and VERIFY EXECUTION on CDCM.

Initials: $M T \quad 12 / 17 / 98$

6.3.6. VERIFY date and time correct on DCM (\$SHOW TIME of $>$ TMands). mTi2/17/48

List Systems verified: WHENGR, WHDCMd, WGCDCM initials: $M T$ T2/17/98

6.3.7. RUN the Authorize Utility and VERIFY date and time stamp is correct and has format "dd-mmm-yyyy 00:00".

Initials: $M T \quad 12 / 17 / 98$

6.3.8. COMPILE a dummy C-program and VERIFY the content of the compiler list file (*.LIS) date and time stamp is correct and has format "dd-mmm-yyyy 00:00:00".
$B L D-C$ WATCH.C - LIS
initials: $M T \quad 12 / 17 / 98$

6.3.9. LOGOUT from the engineering workstation.

Initials: $M T \quad 12 / 7 / 48$

\subsection{General DCS Functionality $\left(\mathrm{D} / 3^{\mathrm{TM}}\right)$}

6.4.1. VERIFY Sequence and Batch Language programs are running by observing Program Status graphic \#43.

Initials: 15 12/,7/98

6.4.2. CHECK Device Logic functions properly (suggest interlock bypass or simple valve such as 207-A basins).

initials: $M T \quad 12 / 171649$

6.4.3. EXECUTE alarm inhibit C-program from the SKID panel and VERIFY proper operation.

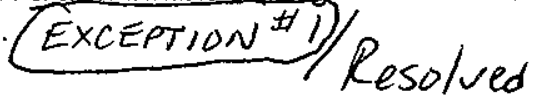

Initials: $M T / 2 / 17 / 981927$

6.4.4. INHIBIT an alarm and VERIFY removal from alarm summary display.

Initials: MT $1652 \quad 12 / 17 / 98$

6.4.5. REMOVE the inhibit from the alarm in previous step and VERIFY the alarm returns to the alarm summary display.

Initials: $M T \quad 165312 / 17 / 98$

6.4.6. VERIFY System Status AND P3 displays show no unexpected system alarm conditions.

Initials: $M T \quad 12 / n / 98$ 
6.4.7. VERIFY OCM keyboard is able to access data that is more than 24 hours old.

$$
\text { Initials: } M T \quad 12 / 17 / 98
$$

6.4.8. VERIFY COD Utility date and time stamp is correct and has format "dd-mmm-yy 00:00:00".

$$
\text { Initials: } \mu T \quad 12 / 17 / 58
$$

6.4.9. VERIFY MOD Utility time stamp is correct and has format "00:00:00".

$$
\text { Initials: } m T \quad 12 / 17 / 98
$$

6.4.10. VERIFY MTS Utility date and time stamp is correct and has format "dd-mmm-yy 00:00:00".

$$
\text { Initials: } M T \quad 12 / 17 / 98
$$

6.4.11. COMPILE a dummy Sequence and Batch Language program and VERIFY SIC Utility listing $\left({ }^{*}\right.$.LST) date and time stamp is correct and has format "dd-mmm-yy 00:00:00".

Initials: $M T \quad 12 / 17 / 98<200$

6.4.12. VERIFY MEAT Utility date and time stamp is correct and has format "dd-mmm-yy 00:00:00".

Initials: MT $170,12 / 17 / 98$

6.4.13. RUN D3DOWN on all nodes on the network and VERIFY smooth shut down.

NOTE:-DOfirston-non-CDCM. - mT $12 / 17 / 98$

Initials: $M T \quad / 2 / 17 / 98$

6.4.14. STOP tasks FQIRESET and WATCH if applicable (STOP/ID=[\# FROM SHOW SYSTEM)).

NOTE: Prepares DCS for restart.

6.4.15. SET TIME forward on the CDCM to December 31, 1998 23:45:00.00 hours.

50 Initials: $M T \quad 12 / 17 / 98$

NOTE: This allows 10 minutes for restart before data is archived and prepares for verification of year 1999 operation. $m \tau / 2 / 17 / 98$

$$
\text { Initials: } M T \quad 12 / 17 / 98
$$

6.4.46. COPYhistorical data files to dummy test files of format "UNITymm.30C", "UNITymm.30D", "UNHTymm.30H", and "UNITymm.30X" for December 31, 1998, where "UNIT" may be CDCM and/OrDGAM.

NOTE: Prepares for verification of year 1999 operation. $N / A$ MT $12 / 17 / 98$ Initials: $M T \quad 12 / 17 / 48$

6.4.17. RUN D3UP on all nodes on the network (CDCM first) and VERIFY smooth start up. NOTE: This completes System Operation Before Altering Date and Time.

Initials: $M T \quad 12 / 17 / 98$ 
HNF-2696 REV 0

\section{SYSTEM OPERATION IN TRANSITION TO YEAR 1999}

\subsection{General Operation}

7.1.1. OBSERVE system functional throughout the transition to the year 1999.

Initials: $M T / 2 / 17 / 98$

\subsection{Alarm And Associated Time And Date Information (D/3 ${ }^{\mathrm{TM}}$ )}

7.2.1. VERIFY creation of alarm history files with name format "ALddmmmyy.000".

$$
\text { initials: } M T \quad 12 / 17 / 98
$$

7.2.2. VERIFY date and time stamps are accurate for alarm history file contents (alarm messages) and have format "dd-mmm-yy 00:00:00".

$$
\text { Initials: } M T / 2 / 17 / 98
$$

7.2.3. GENERATE a critical P1 (RED) process alarm,-SHENEE it but do NOT ACKNOWLEDGE it at this time.

$$
\text { mo } 12 / 17 / 88
$$

Alarm description: WFI-E Initials: $M T / 2 / 17 / 98$ cos 38

7.2.4. GENERATE a non-critical P2 (YELLOW) process alarm, SHENCE it, but do NOT ACKNOWLEDGE it at this time. m. $12 / 17 / 98$

Alarm description: WFI-E/OZ HI

Initials: $M T / 2 / 17 / 280045$

7.2.5. GENERATE a non-critical WHITE process alarm, SHENGE-it, but do NOT ACKNOWLEDGE it at this time. MT $12 / 17 / 98$

Alarm description: WFI-EIOM LO

$$
\text { Initials: } M T / 2 / 17 / 98
$$

7.2.6. GENERATE a P3 SYSTEM ALARM (suggest network error)

Alarm description:

$$
\frac{\text { PCMQA LINK STATUS CMANGE }}{\text { Initials: MT 12/17/98 }}
$$
0049

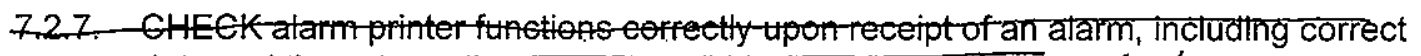
date and time-stamp that has format"dd-mmm-yy 00:00:00'

$$
\text { No Printer For F.A.T. use AHF }
$$

7.2.8. CHECK alarm history files are updated correctly upon receipt of an alarm, including correct alarm message date and time stamp that has format "dd-mmm-yy 00:00:00".

$$
\text { initials: MT 12/17/98 }
$$

7.2.9. CHECK alarms recorded above displayed correctly on P1 ALARM SUMMARY, including correct date and time stamp that has format "dd-mmm 00:00:00".

Initials: $M T .12 / 17 / 98$ 
7.2.10. CHECK alarms recorded above displayed correctly on P2 ALARM SUMMARY, including correct date and time stamp that has format "dd-mmm 00:00:00".

$$
\text { Initials: } M T \text { 12/17/98 } 0100
$$

7.2.11. CHECK alarms recorded above displayed correctly on WHITE ALARM SUMMARY, including correct date and time stamp that has format "dd-mmm-yy 00:00:00".

$$
\text { Initials: } M T \quad 12 / 17 / 98
$$

7.2.12. CHECK system alarm recorded above displayed correctly on P3 ALARM SUMMARY, including correct date and time stamp that has format "dd-mmm-yy 00:00:00".

$$
\text { Initials: } M T \quad 12 / 17 / 98
$$

7.2.13. CHECK alarms displayed in chronological order on alarm summary pages (newest at top).

Initials: $M T / 2 / 17 / 48$

7.2.14. ACKNOWLEDGE alarms and VERIFY they can be acknowledged.

$$
\text { Initials: } M T \quad 12 / 17 / 98
$$

7.2.15. RESTORE alarm conditions and VERIFY they clear from alarm summaries.

$$
\text { Initials: } M T \text { T } 12 / 17 / 98
$$

\subsection{Time and Date Functions $\left(D / 3^{T M}\right)$}

7.3.1. CHECK standard date and time on OCM screens (lower right corner) is accurate and has format of "dd-mmm-yy 00:00:00".

$$
\text { Initials: } M \sigma, 2 / 17 / 28
$$

7.3.2. CHECK Sequence And Batch Language timing functions work properly by observing FHOLD flag on Program Diagnostics graphic \#133 and VERIFY that FHOLD rolls over between 30 and 45 seconds.

$$
\text { Initials: } M T 12 / 17 / 98
$$

7.3.3. CHECK date and time function for FHOLD on Program Diagnostic graphic \#133 is accurate and has format "dd-mmm-yy 00:00:00".

$$
\text { initials: } m \nabla / 2 / 17 / 98
$$

7.3.4. RUN inhibit C-program from SKID panel and VERIFY date and time on graphic \#80 is correct and has format "dd-mmmi-yy 00:00:00".

$$
\text { Initials: } M T \quad 2 / 17 / 98
$$

7.3.5. CHECK current trends operate correctly on OCMs and VERIFY correct time stamp that has format "00:00:00".

$$
\text { Initials: MY } 12 / 17 / 98
$$

7.3.6. CHECK historical trends operate correctly on OCMs and VERIFY correct date and time stamp that has format "dd-mmm-yy 00:00:00".

$$
\text { Initials: } \ln \pi / 2 / 17 / 98
$$

7.3.7. VERIFY Archiver has created archive file for previous day's historical data in the format "UNITymm.ddD" at about 23:55 hours on a DCM; and VERIFY Archiver has 
also created historical reference files for the next day's data in the format

"UNITymm.ddC", "UNITymm.ddH", and "UNITymm.ddX" at about 00:01 hours.

Initials: $M T / 2 / 17 / 28$

7.3.8. RUN the following reports and VERIFY they can be generated with correct date and time (suggest TFBAL, REPORF WRTFER; and (HISTDAT, HISTMON, or HISTMAX). $M T 12 / 17 / 98$

Report Name:

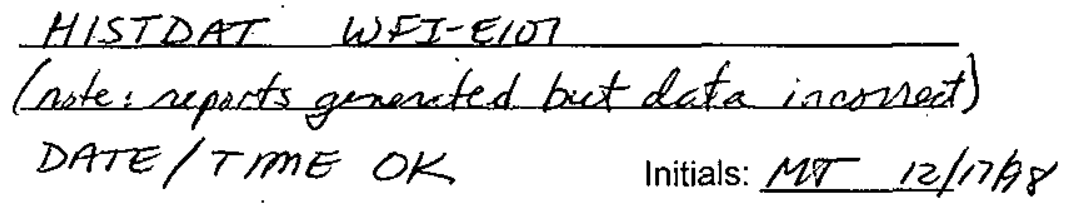

\subsection{Time and Date Functions (Operating System)}

7.4.1. LOGIN to a terminal (VT type) and VERIFY previous VMS ${ }^{T M}$ login date and time stamp.

Initials: $M T, 2 / 17 / 58$

7.4.2. LOGOUT from the terminal.

Initials: hT $12 / 17 k 8$

7.4.3. LOGIN to an engineering workstation and VERIFY previous VMS ${ }^{\mathrm{TM}}$ login date and time stamp.

Initials: $M T \quad 12 / 17 / 98$

7.4.4. VERIFY VMS ${ }^{\mathrm{TM}}$ date and time stamps are accurate for newly created DCM files.

7.4.5. SUBMIT a batch job (suggest FQIRESET) to the batch queue and VERIFY

Initials: $M T / 2 / 17 / 98$ EXECUTION on CDCM.

Initials: $M T / 2 / 12 / 98$

7.4.6. VERIFY date and time correct on DCM (\$SHOW TIME or >TIM commands).

List Systems verified: $D C m D, D C M /, C D C M$

initials: $M Z \quad 12 / 17 / 98$

7.4.7. RUN the Authorize Utility and VERIFY date and time stamp is correct and has format "dd-mmm-yyyy 00:00".

Initials: $M T / 2 / 17 / 98$

7.4.8. COMPILE a dummy C-program and VERIFY the content of the compiler list file ( ${ }^{*}$.LIS) date and time stamp is correct and has format "dd-mmm-yyyy 00:00:00".

Initials: $M T / 2 / 17 / 98$

7.4.9. LOGOUT from the engineering workstation.

Initials: $m T \quad 12 / 17 / 98$

\subsection{General DCS Functionality $\left(D / 3^{\top M}\right)$}


7.5.1. VERIFY Sequence And Batch Language programs are running by observing Program Status graphic \#43.

$$
\text { Initials: } M T 12 / 17 / 98
$$

7.5.2. CHECK Device Logic functions properly (suggest interlock bypass or simple valve such as 207-A basins).

$$
\text { Initials: } M T \quad 12 / 17 / 98
$$

7.5.3. EXECUTE alarm inhibit C-program from the SKID panel and VERIFY proper operation.

$$
\text { Initials: } M T .12 / 17 / 98
$$

7.5.4. INHIBIT an alarm and VERIFY removal from alarm summary display.

- Initials: $M T \quad 12 / 17 / 98$

7.5.5. REMOVE the inhibit from the alarm in previous step and VERIFY the alarm returns to the alarm summary display.

$$
\text { Initials: } M T \quad 12 / 17 / 98
$$

7.5.6. VERIFY System Status AND P3 displays show no unexpected system alarm conditions.

$$
\text { Initials: } M T \quad 12 / 17 / 98
$$

7.5.7. VERIFY OCM keyboard is able to access data that is more than 24 hours old.

$$
\text { Initials: MT } 12 / 17 / 98
$$

7.5.8. VERIFY COD Utility date and time stamp is correct and has format "dd-mmm-yy 00:00:00".

$$
\text { Initials: } M T 12 / 17 / 98
$$

7.5.9. VERIFY MOD Utility time stamp is correct and has format "00:00:00".

7.5.10. VERIFY MTS Utility date and time stamp is correct and has format "dd-mmm-yy

$$
\text { Initials: } M T 12 / 17 / 98
$$
00:00:00".

$$
\text { Initials: } M T \text { 12/17/98 }
$$

7.5.11. COMPILE a dummy Sequence and Batch Language program and VERIFY SIC Utility listing ( ${ }^{*}$.LST) date and time stamp is correct and has format "dd-mmm-yy 00:00:00".

$$
\text { Initials: } m T 12 / 17 / 98
$$

7.5.12. VERIFY MEAT Utility date and time stamp is correct and has format "dd-mmm-yy 00:00:00".

$$
\text { Initials: } M T 12 / 17 / 98
$$

7.5.13. RUN D3DOWN on all nodes on the network and VERIFY smooth shut down. NOTE: Do first on non-CDCM.

Initials: $M T 12 / 17 / 98$

7.5.14. STOP tasks FQIRESET and WATCH if applicable (STOP/ID=[\# FROM SHOW SYSTEM]). NOTE: Prepares DCS for restart.

Initials: $M T \quad 12 / 17 / 98$ 


\section{HNF-2696 REV 0}

7.5.15. SET TIME forward on the CDCM to September 8, $199923: 45: 00$

NOTE: This allows 10 minutes for restart before data is archived and prepares for verification of four-nines operation.

Initials: MT 12/12/48

7.5.16 COPY historical data files to dummy test files of format "UNITymm.07C",

"UNITymm.078", "UNLTymm.07H", and "UNITymm.07X" for September 8, 1999, where "UNIT" may be CDCM and/or DCMO.

NOTE: Prepares for verification of four-nines operation.

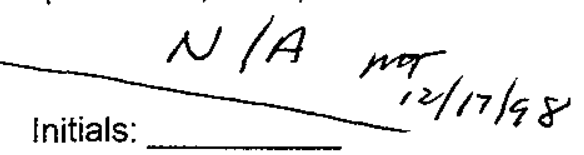

7.5.17. RUN D3UP on all nodes on the network (CDCM first) and VERIFY smooth start up. NOTE: This completes Transition to 1999.

Initials: $\mu T, 2 / 17 / 98$ 


\section{HNF-2696 REV 0}

\section{SYSTEM OPERATION IN TRANSITION TO SEPTEMBER 9, 1999}

\subsection{General Operation}

8.1.1. OBSERVE system functional throughout the transition to September $9,1999$.

$$
\text { Initials: } M T / 2 / 17 / 98
$$

\subsection{Alarm And Associated Time And Date information $\left(D / 3^{\mathrm{TM}}\right)$}

8.2.1. VERIFY creation of alarm history files with name format "ALddmmmyy.000".

$$
\text { Initials: } M T 12 / 17 / 98
$$

8.2.2. VERIFY date and time stamps are accurate for alarm history file contents (alarm messages) and have format "dd-mmm-yy 00:00:00".

$$
\text { Initials: } M T / 2 / 10 / 98
$$

8.2.3. GENERATE a critical P1 (RED) process alarm, SHENGE i but do NOT ACKNOWLEDGE it at this time. $m r / 2 / 17 / 98$

Alarm description: WFI-EIOL HCMI Initials: MT 12/17/98 0005

8.2.4. GENERATE a non-critical P2 (YELLOW) process alarm, SHENGEit, but do NOT ACKNOWLEDGE it at this time. mT $12 / 17 / 48$

Alarm description:

WEE-EIOI HT

$$
\text { Initials: MT } 12 / 170005
$$

8.2.5. GENERATE a non-critical WHITE process alarm, SHENGE if, but do NOT ACKNOWLEDGE it at this time.

Alarm description:

WFI-E $104 \quad \angle 0$

\section{Initials: $M T 12 / 17 / 98$}

8.2.6. GENERATE a P3 SYSTEM ALARM (suggest rietwork error)

Alarm description: DCMOLINKSTATUS CMANGE

Initials: MT $000812 / 7$

8.2.7. CHECK alarm printer functions correctly upon recelpt of an alarm, including correct -date and time stamp that has format" dd-mmm-yy 00:00:00".

$$
\text { No Printer at F. A.T. }
$$

Initials:

8.2.8. CHECK alarm history files are updated correctly upon receipt of an alarm, including correct alarm message date and time stamp that has format "dd-mmm-yy 00:00:00".

$$
\text { Initials: } M T 12 / 17 / 28
$$

8.2.9. CHECK alarms recorded above displayed correctly on P1 ALARM SUMMARY, including correct date and time stamp that has format "dd-mmm 00:00:00".

$$
\text { Initials: } M T 12 / 17 / 98
$$


8.2.10. CHECK alarms recorded above displayed correctly on P2 ALARM SUMMARY, including correct date and time stamp that has format "dd-mmm 00:00:00".

Initials: $M T / 2 / 17 / 98$

8.2.11. CHECK alarms recorded above displayed correctly on WHITE ALARM SUMMARY, including correct date and time stamp that has format "dd-mmm-yy 00:00:00".

Initials: $M T \quad 12 / 17 / 98$

8.2.12. CHECK system alarm recorded above displayed correctly on P3 ALARM SUMMARY, including correct date and time stamp that has format "dd-mmm-yy 00:00:00".

Initials: $M T, 2 / 17 / 98$

8.2.13. CHECK alarms displayed in chronological order on alarm summary pages (newest at top).

Initials: $M T \quad 12 / 12 / 48$

8.2.14. ACKNOWLEDGE alarms and VERIFY they can be acknowledged.

Initials: $\mu$ T $12 / 2 / 98$

8.2.15. RESTORE alarm conditions and VERIFY they clear from alarm summaries.

Initials: $M T 12 / 0198$

\subsection{Time and Date Functions $\left(D / 3^{T M}\right)$}

8.3.1. CHECK standard date and time on OCM screens (lower right corner) is accurate and has format of "dd-mmm-yy 00:00:00".

Initials: $M T / 2 / 17 / 98$

8.3.2. CHECK Sequence And Batch Language timing functions work properly by observing FHOLD flag on Program Diagnostics graphic \#133 and VERIFY that FHOLD rolls over between 30 and 45 seconds.

Initials: $M T 12 / 17 / 98$

8.3.3. CHECK date and time function for FHOLD on Program Diagnostic graphic \#133 is accurate and has format "dd-mmm-yy 00:00:00".

Initials: $M T / 2 / 17 / 98^{\prime}$

8.3.4. RUN inhibit C-program from SKID panel and VERIFY date and time on graphic \#80 is correct and has format "dd-mmni-yy 00:00:00".

Initials: $M T r / 17 / 98$

8.3.5. CHECK current trends operate correctly on OCMs and VERIFY correct time stamp that has format "00:00:00".

Initials: $M T / 2 / 17 / 98$

8.3.6. CHECK historical trends operate correctly on OCMs and VERIFY correct date and time stamp that has format "dd-mmm-yy 00:00:00".

Initials: $M T \quad 12 / 17 / 98$

8.3.7. VERIFY Archiver has created archive file for previous day's historical data in the format "UNITymm.ddD" at about 23:55 hours on a DCM; and VERIFY Archiver has 
also created historical reference files for the next day's data in the format "UNITymm.ddC", "UNITymm.ddH", and "UNITymm.ddX" at about 00:01 hours.

Initials: $\operatorname{nn} T 12 / 17 / 98$

8.3.8. RUN the following reports and VERIFY they can be generated with correct date and time (suggest FFBAt, REPQRT WRITER; and HISTDAT) HISTMON, or HISTMAX).

Report Name:

HISTDAT WFE-EIOZ

(wote: reports generated but data looks incorrect)

DATE/TIME OK

Initials: $M T / 2 / 1 / 98$

\subsection{Time and Date Functions (Operating System)}

8.4.1. LOGIN to a terminal (VT type) and VERIFY previous VMS ${ }^{T M}$ login date and time stamp.

Initials: $M T \quad 12 / 17 / 98$

8.4.2. LOGOUT from the terminal.

Initials: $M T \quad 12 / / 7 / 58$

8.4.3. LOGIN to an engineering workstation and VERIFY previous VMS ${ }^{\mathrm{TM}}$ login date and time stamp.

Initials: $M T \quad 2 / / 2 / 98$

8.4.4. VERIFY VMS ${ }^{\mathrm{TM}}$ date and time stamps are accurate for newly created DCM files.

Initials: $M T / 2 / 17 / 98$

8.4.5. SUBMIT a batch job (suggest FQIRESET) to the batch queue and VERIFY EXECUTION on CDCM.

Initials: $M T, 12 / 17 / 48$

8.4.6. VERIFY date and time correct on DCM (\$SHOW TIME or $>$ TIM commands).

List Systems verified: $W H C D C M$

Initials: MT $12 / 17 / 48$

8.4.7. RUN the Authorize Utility and VERIFY date and time stamp is correct and has format "dd-mmm-yyyy 00:00".

Initials: $M T, 2 / 17 / 98$

8.4.8. COMPILE a dummy C-program and VERIFY the content of the compiler list file ( ${ }^{*}$.LIS) date and time stamp is correct and has format "dd-mmm-yyyy 00:00:00".

Initials: $M T 12 / 17 / 98$

8.4.9. LOGOUT from the engineering workstation.

Initials: $M T \quad 12 / 17 / 98$

\subsection{General DCS Functionality $\left(\mathrm{D} / 3^{\mathrm{TM}}\right)$}


8.5.1. VERIFY Sequence And Batch Language programs are running by observing Program Status graphic \#43.

$$
\text { Initials: } 12 / 17 / 98
$$

8.5.2. CHECK Device Logic functions properly (suggest interlock bypass or simple valve such as 207-A basins).

$$
\text { Initials: } \stackrel{M T}{12 / 17 / 98}
$$

8.5.3. EXECUTE alarm inhibit C-program from the SKID panel and VERIFY proper operation.

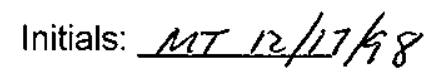

8.5.4. INHIBIT an alarm and VERIFY removal from alarm summary display.

Initials: $M T / 2 / 17 / 98$

8.5.5. REMOVE the inhibit from the alarm in previous step and VERIFY the alarm returns to the alarm summary display.

Initials: aTT $12 / 17 / 88$

8.5.6. VERIFY System Status AND P3 displays show no unexpected system alarm conditions.

Initials: MT $12 / 17 k 8$

8.5.7. VERIFY OCM keyboard is able to access data that is more than 24 hours old.

Initials: $M F, 2 / 17 / 98$

8.5.8. VERIFY COD Utility date and time stamp is correct and has format "dd-mmm-yy 00:00:00".

$$
\text { d3cfg: config, rep }
$$

Initials: MT 12/12/98

8.5.9. VERIFY MOD Utility time stamp is correct and has format "00:00:00".

$$
\text { Initials: } M T / 2 / 12 / 98
$$

8.5.10. VERIFY MTS Utility date and time stamp is correct and has format "dd-mmm-yy 00:00:00".

Initials: $M T / 2 / 17 / 98$

8.5.11. COMPILE a dummy Sequence and Batch Language program and VERIFY SIC Utility listing (*.LST) date and time stamp is correct and has format "dd-mmm-yy 00:00:00".

$$
\text { Dummys.LSt Initials: } M T / 2 / 12 / 98
$$

8.5.12. VERIFY MEAT Utility date and time stamp is correct and has format "dd-mmm-yy 00:00:00".

$$
\text { Initials: } M T 12 / 17 / 98
$$

8.5.13. RUN D3DOWN on all nodes on the network and VERIFY smooth shut down. NOTE: Do first on non-CDCM.

Initials: $M 1$ 12/17/98

8.5.14. STOP tasks FQIRESET and WATCH if applicable (STOP/ID=[\# FROM SHOW SYSTEM]). NOTE: Prepares DCS for restarí. 
8.5.15. SET TIME forward on the CDCM to December 31, 1999 23:45:00.00 hours.

$$
\text { mor } 12 / 17 / 98 \quad 50
$$

NOTE: This allows to minutes for restart before data is archived and prepares for verification of year $\mathbf{2 0 0 0}$ operation.

Initials: $m v$ i2/17/98

8.5.16. GOPY historiealdata files to dummy test files of format "UNITymm.30C",

"UNITymm.30D", "UNITymm.30H", and "UNITymm.30X" for December 31, 1999, where "UNIT" may be CDCM and/or DCMO.

NOTE: Prepares for verification of year 2000 operation.

Initials:

$m T, 2 / 12 / 48$

8.5.17. RUN D3UP on all nodes on the network (CDCM first) and VERIFY smooth start up. NOTE: This completes four-nines verification.

Initials: $M T, 2 / 17 / 98$ 


\section{HNF-2696 REV 0}

\section{SYSTEM OPERATION IN TRANSITION TO YEAR 2000}

\subsection{General Operation}

9.1.1. OBSERVE system functional throughout the transition to January 1, 1999.

Initials: $N T, 2 / 17 / 98$

\subsection{Alarm And Associated Time And Date Information $\left(\mathrm{D} / 3^{\mathrm{TM}}\right)$}

9.2.1. VERIFY creation of alarm history files with name format "ALddmmmyy 000 ". Initials: $/ M T / 2 / 18 / 98$

9.2.2. VERIFY date and time stamps are accurate for alarm history file contents (alarm messages) and have format "dd-mmm-yy 00:00:00".

9.2.3. GENERATE a critical P1 (RED) process alarm, StLENEE but do NOT i2/18/48 Initials: $m, 12 / 18 / 98$ ACKNOWLEDGE it at this time.

Alarm description: WLEI-EIOI HIHI i2/18/4g Initials: $M \vec{V} / 2 / 8 / 98$

9.2.4. GENERATE a non-critical P2 (YELLOW) process alarm, SHENEE it, but do NOT ACKNOWLEDGE it at this time.

Alarm description: WFI-EIOIHI $12 / 18 / 98$ Initials: $M T \cdot 12 / 18 / 98$

9.2.5. GENERATE a non-critical WHITE process alarm, SUEEAGE it, but do NOT ACKNOWLEDGE it at this time.

Alarm description: COFI-EIOU $\angle 0$ Initials: $M T, 2 / 18 / 98$

9.2.6. GENERATE a P3 SYSTEM ALARM (suggest network error) Alarm description: PCMQA LINK STATUS CMANGE OOLS Initials: $M T \quad 12 / 18 / 98$

9.2.7. CHECK alarm printor funtions-corroty-upen receiptofan-atam, inctuding correct date-and the-stamp thas format"ctd-mmm-yy 00:00:00"

$$
\text { No Printer for F.A.T. mV iz/18/as Initials: N N }
$$

9.2.8. CHECK alarm history files are updated correctly upon receipt of an alarm, including correct alarm message date and time stamp that has format "dd-mmm-yy 00:00:00". Initials: $M T r 2 / 8 / 98$

9.2.9. CHECK alarms recorded above displayed correctly on P1 ALARM SUMMARY, including correct date and time stamp that has format "dd-mmm 00:00:00".

Initials: $M T / 2 / 8 / 98$ 
9.2.10. CHECK alarms recorded above displayed correctly on P2 ALARM SUMMARY, including correct date and time stamp that has format "dd-mmm 00:00:00".

Initials: $M T, 2 / 18 / 98$

9.2.11. CHECK alarms recorded above displayed correctly on WHITE ALARM SUMMARY, including correct date and time stamp that has format "dd-mmm-yy 00:00:00".

Initials: $M T \quad 12 / 17 / 98$

9.2.12. CHECK system alarm recorded above displayed correctly on P3 ALARM SUMMARY, including correct date and time stamp that has format "dd-mmm-yy 00:00:00".

Initials: $M T / 2 / 18 / 98$

9.2.13. CHECK alarms displayed in chronological order on alarm summary pages (newest at top).

Initials: $M T 12 / 18 / 48$

9.2.14. ACKNOWLEDGE alarms and VERIFY they can be acknowledged.

Initials: $M / 2 / 18 / 98$

9.2.15. RESTORE alarm conditions and VERIFY they clear from alarm summaries.

Initials: $M \quad 12 / 18 / 98$

\subsection{Time and Date Functions $\left(D / 3^{T M}\right)$}

9.3.1. CHECK standard date and time on OCM screens (lower right corner) is accurate and has format of "dd-mmm-yy 00:00:00".

Initials: $M T 12 / 8 / 98$

9.3.2. CHECK Sequence And Batch Language timing functions work properly by observing FHOLD flag on Program Diagnostics graphic \#133 and VERIFY that FHOLD rolls over between 30 and 45 seconds.

Initials: $M T$ T2/18/98

9.3.3. CHECK date and time function for FHOLD on Program Diagnostic graphic \#133 is accurate and has format "dd-mmm-yy 00:00:00".

Initials: $M T / 2 / 18 / 98$

9.3.4. RUN inhibit C-program from SKID panel and VERIFY date and time on graphic \#80 is correct and has format "dd-mmm-yy 00:00:00".

Initials: $M T 12 / 18 / 98$

9.3.5. CHECK current trends operate correctly on OCMs and VERIFY correct time stamp that has format "00:00:00".

Initials: $M T, 2 / 18 / 98$

9.3.6. CHECK historical trends operate correctly on OCMs and VERIFY correct date and time stamp that has format "dd-mmm-yy 00:00:00".

Initials: $M T 12 / 18 / 98$

9.3.7. VERIFY Archiver has created archive file for previous day's historical data in the format "UNITymm.ddD" at about 23:55 hours on a DCM; and VERIFY Archiver has 
also created historical reference files for the next day's data in the format

"UNITymm.ddC", "UNITymm.ddH",, and "UNITymm.ddX" at about 00:01 hours.

Initials: $\mu \tau / 2 / 18 / 98$

9.3.8. RUN the following reports and VERIFY they can be generated with correct date and time (suggest FFBAL,REPORF WFRIFER, and HISTDAT)HISTMON, or HISTMAX).

Report Name:

$$
\text { MT } 12 / 18 / 98
$$

$$
\begin{aligned}
& \text { HISTDAT } \\
& \text { (nte: reports geneanted but data inconect) } \\
& \text { DATE/TIME OK Initials: MT } 12 / 18 / 98
\end{aligned}
$$

\subsection{Time and Date Functions (Operating System)}

9.4.1. LOGIN to a terminal (VT type) and VERIFY previous VMS ${ }^{T M}$ login date and time stamp.

Initials: $M T 12 / 18 / 98$

9.4.2. LOGOUT from the terminal.

Initials: $m_{T} / 2 / 18 / 98$

9.4.3. LOGIN to an engineering workstation and VERIFY previous VMS ${ }^{\mathrm{TM}}$ login date and time stamp.

Initials: $M T 12 / 18 / 98$

9.4.4. VERIFY VMS ${ }^{\top M}$ date and time stamps are accurate for newly created DCM files.

Initials: $12 / 18 / 98$

9.4.5. SUBMIT a batch job (suggest FQIRESET) to the batch queue and VERIFY EXECUTION ON CDCM.

Initials: $M T 12 / 18 / 98$

9.4.6. VERIFY date and time correct on DCM (\$SHOW TIME or >TIM commands).

List Systems verified: WHCDCM

Initials: $m$ T $12 / 18 / 98$

9.4.7. RUN the Authorize Utility and VERIFY date and time stamp is correct and has format "dd-mmm-yyyy 00:00".

Initials: $M T / 2 / 8 / 98$

9.4.8. COMPILE a dummy C-program and VERIFY the content of the compiler list file (*.LIS) date and time stamp is correct and has format "dd-mmm-yyyy 00:00:00".

Initials: MT $12 / 18 / 98$

9.4.9. LOGOUT from the engineering workstation.

Initials: $M T R / 18 / 98$

\subsection{General DCS Functionality $\left(\mathrm{D} / 3^{\mathrm{TM}}\right)$}




\section{HNF-2696 REV 0}

9.5.1. VERIFY Sequence And Batch Language programs are running by observing Program Status graphic \#43.

Initials: $n T \quad 12 / 8 / 98$

9.5.2. CHECK Device Logic functions properly (suggest interlock bypass or simple valve such as 207-A basins).

nitials: MT 12/18/98

9.5.3. EXECUTE alarm inhibit C-program from the SKID panel and VERIFY proper EXCEPTION 42 Initials: $M T / 2 / 18 / 98$

9.5.4. INHIBIT an alarm and VERIFY removal from alarm summary display.

Initials: $M T / 2 / 18 / 98$

9.5.5. REMOVE the inhibit from the alarm in previous step and VERIFY the alarm returns to the alarm summary display.

Initials: $\mu$ 12/18/98

9.5.6. VERIFY System Status AND P3 displays show no unexpected system alarm conditions.

Initials: MT 12/18/98

9.5.7. VERIFY OCM keyboard is able to access data that is more than 24 hours old.

Initials: MT $12 / 8 / 98$

9.5.8. VERIFY COD Utility date and time stamp is correct and has format "dd-mmm-yy 00:00:00".

Initials: MT $12 / 18 / 98$

9.5.9. VERIFY MOD Utility time stamp is correct and has format "00:00:00".

Initials: $M T \quad 12 / 18 / 98$

9.5.10. VERIFY MTS Utility date and time stamp is correct and has format "dd-mmm-yy 00:00:00".

Initials: MT 12/18/98

9.5.11. COMPILE a dummy Sequence and Batch Language program and VERIFY SIC Utility listing $\left({ }^{*}\right.$.LST) date and time stamp is correct and has format "dd-mmm-yy 00:00:00".

Initials: $M T / 2 / 18 / 98$

9.5.12. VERIFY MEAT Utility date and time stamp is correct and has format "dd-mmm-yy 00:00:00".

Initials: MT 12/18/98

9.5.13. If testing on production system, WRITE N/A in sign-off spaces below and SKIP this step. If testing on simulation system, COMPLETE this step, Applications Rebuild.

9.5.13.1. REBUILD all applications.

Initials: $N / A$

9.5.13.2. RESET and RELOAD PCMs.

Rebuild already done. mo $12 / 18 / 98$

Initials: $N / A$ 
9.5.14. RUN D3DOWN on all nodes on the network and VERIFY smooth shut down. NOTE: Do first on non-CDCM.

Initials: $12 \pi / 18 / 28$

9.5.15. STOP tasks FQIRESET and WATCH if,applicable (STOP/ID=[\# FROM SHOW SYSTEM]).

NOTE: Prepares DCS for restart.

$$
\text { (3) m } 12 / 18 / 48 \quad 52^{\text {Initials: } M T 12 / 18 / 98}
$$

9.5.16. SET TIME forward on the CDCM to February 28, $200023: 45.00 .00$ hours.

NOTE: This allows $(10)$ minutes for restart before data is archived and prepares for verification of initial leap year recognition.

$$
\text { Initials: MT } 12 / 18 / 98
$$

9.5.17. GORY historical data files to dummy test files of format "UNITymm.27C", "UNITymm.27D", "UNITymm.27H", and "UNITymm.27X" for February 28, 2000, where "UNIT" may be CDCM and/OP DGMO.

NOTE: Prepares for verification of initial leap-year recognition.

$$
N / A
$$

Initials: mor $12 / 18 / 98$

9.5.18. RUN D3UP on all nodes on the network (CDCM first) and VERIFY smooth start up. NOTE: This completes year 2000 verification.

Initials: $M T / 2 / 18 / 98$ 


\section{SYSTEM OPERATION DURING INITIAL LEAP YEAR RECOGNITION}

\subsection{General Operation}

10.1.1. VERIFY system recognizes February 29, 2000.

Initials: $M T$ I2/18/98

10.1.2. VERIFY seriat number (afteremplete applications rebuild) in MOD utility has correct format.

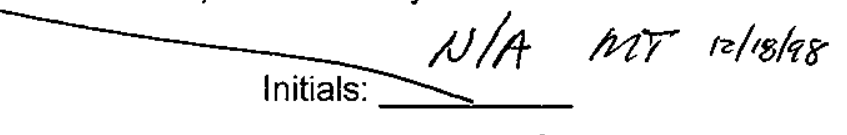

10.1.3. VERIFY general $D / 3^{T M}$ functionality folltim Initials: MT /2/18/98

10.1.4. OBSERVE system functional throughout the transition to February $29,2000$.

Initials: MT $12 / 18 / 98$

\subsection{Alarm And Associated Time And Date Information (D/3 $\left.{ }^{\mathrm{TM}}\right)$}

10.2.1. VERIFY creation of alarm history files with name format "ALddmmmyy.000". Initials: $M T 12 / 18 / 48$

10.2.2. VERIFY date and time stamps are accurate for alarm history file contents (alarm messages) and have format "dd-mmm-yy 00:00:00".

12-18-18 Initials: $M T 12 / 18 / 98$

10.2.3. GENERATE a critical P1 (RED) process alarm, SHENEE it, but do NOT ACKNOWLEDGE it at this time.

Alarm description: WEI-EIOI HIHI

iz-18-48 Initials: $\mu \mathrm{MT} / 2 / 18 / 98$

10.2.4. GENERATE a non-critical P2 (YELLOW) process alarm, SHTEAGE it, but do NOT ACKNOWLEDGE it at this time.

Alarm description:

WFI-E $101 \quad H I$ 12-18-98 Initials: $M T 12 / 18 / 98$

$>$ 10.2.5. GENERATE a non-critical WHITE process alarm, SHENEE it, but do NOT ACKNOWLEDGE it at this time:

Alarm description: WFI-E104 $L$ initials: $M T \quad 12 / 18 / 98$

10.2.6. GENERATE a P3 SYSTEM ALARM (suggest network error) Alarm description: SEQ PGM NOT LOADEP initials: $M \nabla / 2 / 18 / 98$ 


\section{HNF-2696 REV 0}

10.2.7. CHECK-atarm printer functions corroctly upen receipt of antarm, ineluding correct date and time stamp that has format "dd-mnmy $00: 00: 00 "$

$$
\text { No Printer For F. A.T. }
$$

$$
\text { Initials: } 12 / 18 / 98
$$

10.2.8. CHECK alarm history files are updated correctly upon receipt of an alarm, including correct alarm message date and time stamp that has format "dd-mmm-yy 00:00:00".

$$
\text { Initials: } M T \quad 12 / 18 / 98
$$

10.2.9. CHECK alarms recorded above displayed correctly on P1 ALARM SUMMARY, including correct date and time stamp that has format "dd-mmm 00:00:00".

$$
\text { Initials: } M T 12 / 18 / 98
$$

10.2.10.CHECK alarms recorded above displayed correctly on P2 ALARM SUMMARY, including correct date and time stamp that has format "dd-mmm 00:00:00".

$$
\text { Initials: } M T / 2 / 18 / 98
$$

10.2.11.CHECK alarms recorded above displayed correctly on WHITE ALARM SUMMARY, including correct date and time stamp that has format "dd-mmm-yy 00:00:00".

$$
\text { Initials: } M T, 2 / 18 / 98
$$

10.2.12. CHECK system alarm recorded above displayed correctly on P3 ALARM SUMMARY, including correct date and time stamp that has format "dd-mmm-yy 00:00:00".

$$
\text { Initials: } M T 12 / 18 / 98
$$

10.2.13. CHECK alarms displayed in chronological order on alarm summary pages (newest at top).

$$
\text { Initials: } M T, 2 / 18 / 98
$$

10.2.14.ACKNOWLEDGE alarms and VERIFY they can be acknowledged.

$$
\text { Initials: } M T 12 / 18 / 98
$$

10.2.15.RESTORE alarm conditions and VERIFY they clear from alarm summaries.

$$
\text { Initials: } m \nabla / 2 / 18 / 98
$$

\subsection{Time and Date Functions (D/3 $\left.{ }^{\mathrm{TM}}\right)$}

10.3.1. CHECK standard date and time on OCM screens (lower right corner) is accurate and has format of "dd-mmm-yy 00:00:00".

$$
\text { Initials: } M F 12 / 18 / 98
$$

10.3.2. CHECK Sequence And Batch Language timing functions work properly by observing FHOLD flag on Program Diagnostics graphic \#133 and VERIFY that FHOLD rolls over between 30 and 45 seconds.

$$
\text { Initials: } M T 12 / 18 / 98
$$

10.3.3. CHECK date and time function for FHOLD on Program Diagnostic graphic \#133 is accurate and has format "dd-mmm-yy 00:00:00".

$$
\text { Initials: } M T / 2 / 18 / 98
$$

10.3.4. RUN inhibit C-program from SKID panel and VERIFY date and time on graphic \#80 is correct and has format "dd-mmm-yy 00:00:00".

$$
\text { EXCEPTION"2 }
$$

Initials: MT r/18/98 
10.3.5. CHECK current trends operate correctly on OCMs and VERIFY correct time stamp that has format "00:00:00".

$$
\text { Initials: } M T 12 / 18 / 98
$$

10.3.6. CHECK historical trends operate correctly on OCMs and VERIFY correct date and time stamp that has format "dd-mmm-yy 00:00:00".

$$
\text { Initials: } M T 12 / 18 / 98
$$

10.3.7. VERIFY Archiver has created archive file for previous day's historical data in the format "UNITymm.ddD" at about 23:55 hours on a DCM; and VERIFY Archiver has also created historical reference files for the next day's data in the format "UNITymm.ddC", "UNITymm.ddH", and "UNITymm.ddX" at about 00:01 hours.

Initials: $M T / 2 / 18 / 98$

10.3.8. RUN the following reports and VERIFY they can be generated with correct date and time (suggest TFBAL-REPORT WRTTER; and HISTDAT) HISTMON, or HISTMAX).

Report Name:

$$
\begin{aligned}
& \text { HISTDAT } \\
& \text { (noter repats generated but data in aonect) } \\
& \text { DATE/TIME is oK Initials: } M T, 2 / 18 / 98
\end{aligned}
$$

\subsection{Time and Date Functions (Operating System)}

10.4.1. LOGIN to a terminal (VT type) and VERIFY previous VMS ${ }^{\mathrm{TM}}$ login date and time stamp.

Initials: $M T \quad 12 / 18 / 58$

10.4.2. LOGOUT from the terminal.

Initials: MT 12/18/48

10.4.3. LOGIN to an engineering workstation and VERIFY previous VMS ${ }^{\mathrm{TM}}$ login date and time stamp.

Initials: $M T 12 / 18 / 98$

10.4.4. VERIFY VMS ${ }^{T M}$ date and time stamps are accurate for newly created DCM files.

Initials: $M T$ I2/18/98

10.4.5. SUBMIT a batch job (suggest FQIRESET) to the batch queue and VERIFY EXECUTION on CDCM.

Initials: $M \sigma 12 / 18 / 98$

10.4.6. VERIFY date and time correct on DCM (\$SHOW TIME or > TIM commands).

List Systems verified: WHCDCM

Initials: $M T 12 / 18 / 98$

10.4.7. RUN the Authorize Utility and VERIFY date and time stamp is correct and has format "dd-mmm-yyyy 00:00".

Initials: $M T 12 / 18 / 98$ 
10.4.8. COMPILE a dummy C-program and VERIFY the content of the compiler list file (*.LIS) date and time stamp is correct and has format "dd-mmm-yyyy 00:00:00".

10.4.9. LOGOUT from the engineering workstation.

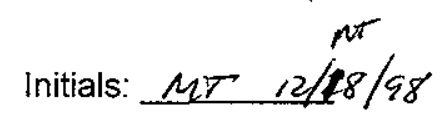

\subsection{General DCS Functionality $\left(D / 3^{\mathrm{TM}}\right)$}

10.5.1. VERIFY Sequence And Batch Language programs are running by observing Program Status graphic \#43.

$$
\text { Initials: MT } 12 / 28 / 98
$$

10.5.2. CHECK Device Logic functions properly (suggest interlock bypass or simple valve such as 207-A basins).

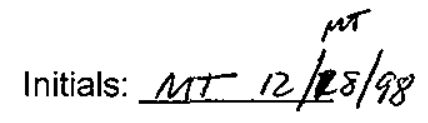

10.5.3. EXECUTE alarm inhibit C-program from the SKID panel and VERIFY proper operation.

$$
\text { Initials: } M T 12 / 18 / 48
$$

10.5.4. INHIBIT an alarm and VERIFY removal from alarm summary display.

$$
\text { Initials: } M T \quad 12 / 18 / 98
$$

10.5.5. REMOVE the inhibit from the alarm in previous step and VERIFY the alarm returns to the alarm summary display.

Initials: $M T 12 / 18 / 98$

10.5.6. VERIFY System Status AND P3 displays show no unexpected system alarm conditions.

Initials: $m T / 2 / 18 / 98$

10.5.7. VERIFY OCM keyboard is able to access data that is more than 24 hours old.

$$
\text { Dec 31, } 1999 \text { used }
$$

Initials: $M T$ 12/18/98

10.5.8. VERIFY COD Utility date and time stamp is correct and has format "dd-mmm-yy 00:00:00".

Initials: $M \pi 12 / 18 / 98$

10.5.9. VERIFY MOD Utility time stamp is correct and has format "00:00:00".

Initials: $M T 12 / 18 / 78$

10.5.10.VERIFY MTS Utility date and time stamp is correct and has format "dd-mmm-yy 00:00:00".

Initials: $m+12 / 18 / 98$

10.5.11.COMPILE a dummy Sequence and Batch Language program and VERIFY SIC Utility listing ( ${ }^{*}$.LST) date and time stamp is correct and has format "dd-mmm-yy 00:00:00". Initials: $m T 12 / 18 / 98$ 
10.5.12.VERIFY MEAT Utility date and time stamp is correct and has format "dd-mmm-yy 00:00:00".

Initials: $m=12 / 18 / 98$

10.5.13.RUN D3DOWN on all nodes on the network and VERIFY smooth shut down. NOTE: Do first on non-CDCM.

Initials: $M T / 2 / 18 / \varepsilon 8$

10.5.14.STOP tasks FQIRESET and WATCH if applicable (STOP/ID=[\# FROM SHOW SYSTEM]).

NOTE: Prepares DCS for restart.

$$
\text { (3) m i2/18/98 m } 52^{\text {Initials: } M \pi \quad 12 / 18 / 98}
$$

10.5.15.SET TIME forward on the CDCM to February 29, 2000 23:48:00.00 hours. NOTE: This allows (10) minutes for restart before data is archived and prepares for testing following February 29 recognition.

Initials: $M T 12 / 8 / 98$

10.5.16. RUN D3UP on all nodes on the network (CDCM first) and VERIFY smooth start up. NOTE: This completes initial recognition of leap year verification.

Initials: $M T 2 / 18 / 98$ 


\section{HNF-2696 REV 0}

\section{SYSTEM OPERATION FOLLOWING FEBRUARY 29, 2000 RECOGNITION}

\subsection{General Operation}

11.1.1. VERIFY system recognizes that March 1, 2000 follows February 29, 2000, and that system does not roll over to February 30 or $31,2000$.

Initials: $M \frac{M i}{2} / 18 / 98$

11.1.2. OBSERVE system functional throughout the transition to March 1, 2000.

Initials: mo $12 / 18 / 98$

\subsection{Alarm And Associated Time And Date Information (D/3 ${ }^{\mathrm{TM}}$ )}

11.2.1. VERIFY creation of alarm history files with name format "ALddmmmyy.000".

Initials: $m T / 2 / 18 / 98$

11.2.2. VERIFY date and time stamps are accurate for alarm history file contents (alarm messages) and have format "dd-mmm-yy 00:00:00".

$m$ Initials: $m T \quad 12 / 18 / 98$

11.2.3. GENERATE a critical P1 (RED) process alarm, SULENEE it, but do NOT ACKNOWLEDGE it at this time.

$12 / 18 / 98$

Alarm description: WFI-E101 MIHI

11.2.4. GENERATE a non-critical P2 (YELLOW) process alarm, SHENEE it, but do NOT ACKNOWLEDGE it at this time.

Alarm description: WFI-EIOL HI

Initials: $M T 12 / 18 / 48$

11.2.5. GENERATE a non-critical WHITE process alarm, SHENEE it, but do NOT ACKNOWLEDGE it at this time.

$12 / 18 / 48$

Alarm description: WFI-E104 $\angle 0$

Initials: $M T / 2 / 18 / 98$

11.2.6. GENERATE a P3 SYSTEM ALARM (suggest network error)

Alarm description: $D C M Q$ LINK STATUS CHANGE Initials: $M T 12 / 18 / 98$

41.2.7. GHEGK-atarm printer funetions correetly upon reeeipt of an alarm, imcluding corTect date and time-stamp that has format"dd-mmm-yy 00:00:00"

$$
\text { No Printer for FA.T. Initials: N/A MT }
$$

11.2.8. CHECK alarm history files are updated correctly upon receipt of an alarm, including correct alarm message date and time stamp that has format "dd-mmm-yy 00:00:00".

Initials: $M T \quad 12 / 18 / 98$ 
11.2.9. CHECK alarms recorded above displayed correctly on P1 ALARM SUMMARY, including correct date and time stamp that has format "dd-mmm 00:00:00".

Initials: $M T 12 / 18 / 98$

11.2.10.CHECK alarms recorded above displayed correctly on P2 ALARM SUMMARY, including correct date and time stamp that has format "dd-mmm 00:00:00".

initials: $m \bar{T} / 2 / 18 / 98$

11.2.11. CHECK alarms recorded above displayed correctly on WHITE ALARM SUMMARY, including correct date and time stamp that has format "dd-mmm-yy 00:00:00".

Initials: $M T / 2 / 18 / 98$

11.2.12. CHECK system alarm recorded above displayed correctly on P3 ALARM SUMMARY, including correct date and time stamp that has format "dd-mmm-yy 00:00:00".

Initials: $m \nabla 12 / 18 / 88$

11.2.13.CHECK alarms displayed in chronological order on alarm summary pages (newest at top).

Initials: $m T / 2 / 18 / 98$

11.2.14.ACKNOWLEDGE alarms and VERIFY they can be acknowledged.

Initials: $n \pi 12 / 18 / 98$

11.2.15.RESTORE alarm conditions and VERIFY they clear from alarm summaries.

Initials: $m \sigma / 2 / 8 / 98$

\subsection{Time and Date Functions $\left(\mathrm{D} / 3^{\mathrm{TM}}{ }^{\mathrm{M}}\right)$}

11.3.1. CHECK standard date and time on OCM screens (lower right corner) is accurate and has format of "dd-mmm-yy 00:00:00".

Initials: MT $12 / 18 / 98$

11.3.2. CHECK Sequence And Batch Language timing functions work properly by observing FHOLD flag on Program Diagnostics graphic \#133 and VERIFY that FHOLD rolls over between 30 and 45 seconds.

Initials: $M T / 2 / 18 / 98$

11.3.3. CHECK date and time function for FHOLD on Program Diagnostic graphic \#133 is accurate and has format "dd-mmm-yy 00:00:00".

Initials: $m T 12 / 18 / 98$

11.3.4. RUN inhibit C-program from SKID panel and VERIFY date and time on graphic \#80 is correct and has format "dd-mmm-yy 00:00:00".
EXCEPTION
Initials: $m T / 2 / 18 / 98$

11.3.5. CHECK current trends operate correctly on OCMs and VERIFY correct time stamp that has format "00:00:00".

Initials: $m \tau-12 / 18 / 98$

11.3.6. CHECK historical trends operate correctly on OCMS and VERIFY correct date and time stamp that has format "dd-mmm-yy 00:00:00".

Initials: $m \pi / 2 / 18 / 98$ 


\section{HNF-2696 REV 0}

11.3.7. VERIFY Archiver has created archive file for previous day's historical data in the format "UNITymm.ddD" at about 23:55 hours on a DCM; and VERIFY Archiver has also created historical reference files for the next day's data in the format

"UNITymm.ddC", "UNITymm.ddH"; and "UNITymm.ddX" at about 00:01 hours.

Initials: $m$ T $12 / 18 / 98$

11.3.8. RUN the following reports and VERIFY they can be generated with correct date and time (suggest TFBAL, REPORT HRITER; and HISTDAT HISTMON, or HISTMAX).

Report Name:

$$
\text { MT 12/18/98: }
$$

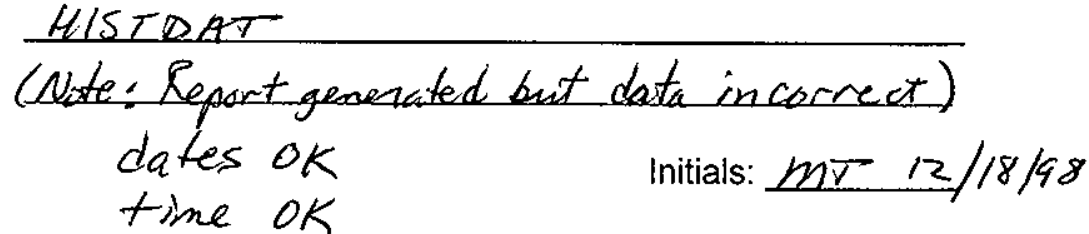

\subsection{Time and Date Functions (Operating System)}

11.4.1. LOGIN to a terminal (VT type) and VERIFY previous VMS ${ }^{\mathrm{TM}}$ login date and time stamp.

11.4.2. LOGOUT from the terminal.

Initials: $m$ r $12 / 18 / 98$

Initials: MT $12 / 18 / 98$

11.4.3. LOGIN to an engineering workstation and VERIFY previous VMS ${ }^{\mathrm{TM}}$ login date and time stamp.

Initials: $m \mathrm{~T} / 2 / 18 / 98$

11.4.4. VERIFY VMS ${ }^{\mathrm{TM}}$ date and time stamps are accurate for newly created DCM files.

Initials: 2 NT $12 / 18 / 98$

11.4.5. SUBMIT a batch job (suggest FQIRESET) to the batch queue and VERIFY EXECUTION on CDCM.

Initials: $m+12 / 18 / 98$

11.4.6. VERIFY date and time correct on DCM (\$SHOW TIME or >TIM commands).

List Systems verified: WHCDCM, WHDCMф, WHENGR Initials: $M T / 2 / 18 / 98$

11.4.7. RUN the Authorize Utility and VERIFY date and time stamp is correct and has format "dd-mmm-yyyy 00:00".

Initials: $M T 12 / 18 / 98$

11.4.8. COMPILE a dummy C-program and VERIFY the content of the compiler list file ( ${ }^{*}$.LIS) date and time stamp is correct and has format "dd-mmm-yyyy 00:00:00".

Initials: $m T 12 / 18 / 98$

11.4.9. LOGOUT from the engineering workstation.

Initials: $m \pi 12 / 8 / 98$ 


\subsection{General DCS Functionality $\left(D / 3^{\mathrm{TM}}\right)$}

11.5.1. VERIFY Sequence And Batch Language programs are running by observing Program Status graphic \#43.

\section{Initials: $m=12 / 18 / 98$}

11.5.2. CHECK Device Logic functions properly (suggest interlock bypass or simple valve such as 207-A basins).

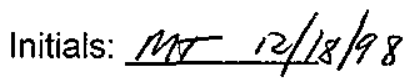

11.5.3. EXECUTE alarm inhibit C-program from the SKID panel and VERIFY proper operation. EX-C-1 4 HV-ECH-1 using

$$
\text { PDSH-FCSI INLK Initials: }
$$

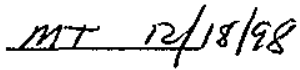

11.5.4. INHIBIT an alarm and VERIFY removal from alarm summary display.

Initials: $m T / 2 / 8 / 98$

11.5.5. REMOVE the inhibit from the alarm in previous step and VERIFY the alarm returns to the alarm summary display.

Initials: $M T, 2 / 18 / 98$

11.5.6. VERIFY System Status AND P3 displays show no unexpected system alarm conditions.

Initials: $M T \quad 2 / 18 / 98$

11.5.7. VERIFY OCM keyboard is abie to access data that is more than 24 hours old.

$$
\text { DeC 31, } 1999 \quad \mathrm{HT}^{\mathbb{H}_{48}}
$$

Initials: $M r \quad 2 / 18 / 48$

11.5.8. VERIFY COD Utility date and time stamp is correct and has format "dd-mmm-yy 00:00:00".

Initials: $M T / 2 / 18 / 98$

11.5.9. VERIFY MOD Utility time stamp is correct and has format "00:00:00".

Initials: $M T 12 / 18 / 98$

11.5.10.VERIFY MTS Utility date and time stamp is correct and has format "dd-mmm-yy 00:00:00".

Initials: $m v 12 / 18 / 98$

11.5.11. COMPILE a dummy Sequence and Batch Language program and VERIFY SIC Utility listing (*.LST) date and time stamp is correct and has format "dd-mmm-yy 00:00:00".

initials: $m$ T /2/18/98

11.5.12.VERIFY MEAT Utility date and time stamp is correct and has format "dd-mmm-yy 00:00:00".

initials: $m T 12 / 18 / 98$

11.5.13.RUN D3DOWN on all nodes on the network and VERIFY smooth shut down. NOTE: Do first on non-CDCM.

Initials: $M T$ 12/18/98 
11.5.14.STOP tasks FQIRESET and WATCH if applicable (STOP/ID=[\# FROM SHOW SYSTEM]).

NOTE: Prepares DCS for restart.

11.5.15.SET TIME forward on the CDCM to December 30, $200023.45: 00.00$ hours.

(3) MA i2/10ke mor $(52)^{\text {nitials: } M T R / 18 / 98}$ NOTE: This allows 10 minutes for restart before data is archived and prepares for verification that year 2000 has 366 days.

Initials: $M T / 2 / 18 / 98$

41.5.16. COPY historical data files to dummy test files of format "UNITymm.29C",

"UNITymm.298", "UNITYmm.29H", and "UNITymm.29X" for December 30, 2000, where "UNIT" may be CDCM andtor DGMO.

NOTE: Prepares for verification that year 2000 has 366 days

$N / A$ m.

Initials:

11.5.17. RUN D3UP on all nodes on the network (CDCM first) and VERIFY smooth start up. NOTE: This completes February $30 / 31$ verification.

Initials: $M V \quad 12 / 18 / 98$ 
HNF-2696 REV 0

\section{SYSTEM OPERATION TO EXPOSE BAD LEAP YEAR CALCULATION (<366 DAYS)}

\subsection{General Operation}

12.1.1. VERIFY system recognizes that December 31,2000 follows December 30,2000 , and that system does not transition to January 1, 2001 directly from December 30, 2000.

Initials: $M T \cdot 12 / 18 / 98$

12.1.2. OBSERVE system functional throughout the transition to December $31,2000$.

Initials: $M T 12 / 18 / 98$

\subsection{Alarm And Associated Time And Date Information (D/3 ${ }^{\mathrm{TM}}$ )}

12.2.1. VERIFY creation of alarm history files with name format "ALddmmmyy 000 ".

Initials: $\ln T / 2 / 18 / 48$

12.2.2. VERIFY date and time stamps are accurate for alarm history file contents (alarm messages) and have format "dd-mmm-yy 00:00:00".

$$
12 / 18 / 98 \text { Initials: } M T \quad 12 / 18 / 98
$$

12.2.3. GENERATE a critical P1 (RED) process alarm, SHENGE it, but do NOT ACKNOWLEDGE it at this time.

Alarm description: WFI-EIO/ HIHI

12/18/48 Initials: $\mathrm{Mr} 12 / 18 / 98$

12.2.4. GENERATE a non-critical P2 (YELLOW) process alarm, SHENEE but do NOT ACKNOWLEDGE it at this time.

Alarm description: WFI-EIO/ HI

$$
12 / 18 / 98 \text { MT Initials: } M T, 12 / 18 / 98
$$

$>$ 12.2.5. GENERATE a non-critical WHITE process alarm, \&HENEE it, but do NOT ACKNOWLEDGE it at this time.

Alarm description: WFI-E104 LO

$$
\text { Initials: } M T / 2 / 18 / 98
$$

12.2.6. GENERATE a P3 SYSTEM ALARM (suggest network error)

Alarm description: PCMQA LINK STATUS CHANGE 0006 Initials: $M T, 2 / 18 / 98$

12.2.7. CHECK alarm printer functions correctly upon receipt of an atam, including correct date and time stamp that has format "dd-mmm-yy 00:00:00"

$$
\text { No Printer for F.A.T. }
$$

12.2.8. CHECK alarm history files are updated correctly upon receipt of an alarm, including correct alarm message date and time stamp that has format "dd-mmm-yy 00:00:00".

$$
\text { Initials: } M T / 2 / 18 / 98
$$


12.2.9. CHECK alarms recorded above displayed correctly on P1 ALARM SUMMARY, including correct date and time stamp that has format "dd-mmm 00:00:00".

Initials: $M T 12 / 18 / 98$

12.2.10.CHECK alarms recorded above dișplayed correctly on P2 ALARM SUMMARY, including correct date and time stamp that has format "dd-mmm 00:00:00".

$$
\text { Initials: } M T / 2 / 18 / 98
$$

$>$ 12.2.11.CHECK alarms recorded above displayed correctly on WHITE ALARM SUMMARY, including correct date and time stamp that has format "dd-mmm-yy 00:00:00".

$$
\text { Initials: } M T / 2 / 18 / 98
$$

12.2.12.CHECK system alarm recorded above displayed correctly on P3 ALARM SUMMARY, including correct date and time stamp that has format "dd-mmm-yy 00:00:00".

$$
\text { Initials: } m \text { T } 12 / 18 / 28
$$

12.2.13. CHECK alarms displayed in chronological order on alarm summary pages (newest at top).

Initials: $m \mathrm{~mL} / 2 / 18 / 98$

12.2.14.ACKNOWLEDGE alarms and VERIFY they can be acknowledged.

Initials: $M T 12 / 18 / 98$

12.2.15. RESTORE alarm conditions and VERIFY they clear from alarm summaries.

$$
\text { Initials: } m \quad 12 / 18 / 98
$$

\subsection{Time and Date Functions $\left(D / 3^{T M}\right)$}

12.3.1. CHECK standard date and time on OCM screens (lower right corner) is accurate and has format of "dd-mmm-yy 00:00:00".

$$
\text { Initials: } M T 12 / 18 \% 8
$$

12.3.2. CHECK Sequence And Batch Language timing functions work properly by observing FHOLD flag on Program Diagnostics graphic \#133 and VERIFY that FHOLD rolls over between 30 and 45 seconds.

$$
\text { Initials: } M T 12 / 18 / 98
$$

12.3.3. CHECK date and time function for FHOLD on Program Diagnostic graphic \#133 is accurate and has format "dd-mmm-yy 00:00:00".

Initials: $M T, 2 / 18 / 98$

12.3.4. RUN inhibit C-program from SKID panel and VERIFY date and time on graphic \#80 is correct and has format "dd-mmm-yy 00:00:00".
EXEXPTION \#2
Initials: $M T / 2 / 18 / 98$

12.3.5. CHECK current trends operate correctly on OCMs and VERIFY correct time stamp that has format "00:00:00".

$$
\text { Initials: } m_{T}(2 / 18 / 98
$$

12.3.6. CHECK historical trends operate correctly on OCMs and VERIFY correct date and time stamp that has format "dd-mmm-yy 00:00:00".

Initials: $m T 12 / 18 / 98$ 


\section{HNF-2696 REV 0}

12.3.7. VERIFY Archiver has created archive file for previous day's historical data in the format "UNITymm.ddD" at about 23:55 hours on a DCM; and VERIFY Archiver has also created historical reference files for the next day's data in the format

"UNITymm.ddC", "UNITymm.ddH", and "UNITymm.ddX" at about 00:01 hours.

$$
\text { Initials: } m T / 2 / 18 / 98
$$

12.3.8. RUN the following reports and VERIFY they can be generated with correct date and time (suggest TFBAL, REPORF $M$ MRIFER; and HISTDAT, BISTMON, or HISTMAX).

Report Name:

$$
\begin{aligned}
& \text { HISTDAT } \\
& \text { (Note: Genesates lepent with proper DATE } \\
& \text { TIME OKAY, but } \\
& \text { EPN valuex are wrong) initials: } m \overline{12} 18 / 98
\end{aligned}
$$

\subsection{Time and Date Functions (Operating System)}

12.4.1. LOGIN to a terminal (VT type) and VERIFY previous VMS ${ }^{\mathrm{TM}}$ login date and time stamp.

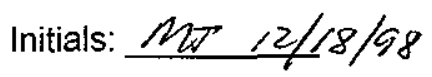

12.4.2. LOGOUT from the terminal.

Initials: $M T, 2 / 8 / 98$

12.4.3. LOGIN to an engineering workstation and VERIFY previous VMS ${ }^{\mathrm{TM}}$ login date and time stamp.

Initials: MT $12 / 18 / 98$

12.4.4. VERIFY VMS ${ }^{\top M}$ date and time stamps are accurate for newly created DCM files.

Initials: $M T<2 / 18 / 98$

12.4.5. SUBMIT a batch job (suggest FQIRESET) to the batch queue and VERIFY EXECUTION on CDCM.

Initials: Mr $12 / 18 / 98$

12.4.6. VERIFY date and time correct on DCM (\$SHOW TIME or >TIM commands).

List Systems verified:

$$
\text { WHENGR, WHDCMD, WHCDCm }
$$

12.4.7. RUN the Authorize Utility and VERIFY date and time stamp is correct and has format "dd-mmm-yyyy 00:00".

Initials: $M T / 2 / 18 / 98$

12.4.8. COMPILE a dummy C-program and VERIFY the content of the compiler list file $\left({ }^{*}\right.$.LIS) date and time stamp is correct and has format "dd-mmm-yyyy 00:00:00".

Initials: $M T 12 / 18 / 98$

12.4.9. LOGOUT from the engineering workstation.

Initials: $M T / 2 / 18 / 98$ 


\subsection{General DCS Functionality $\left(\mathrm{D} / 3^{\mathrm{TM}}\right)$}

12.5.1. VERIFY Sequence And Batch Language programs are running by observing Program Status graphic \#43.

Initials: nT $12 / 18 / 98$

12.5.2. CHECK Device Logic functions properly (suggest interlock bypass or simple valve such as 207-A basins). LERFILK

\section{a $\angle D S-A I I N L K$}

Initials: $1 \pi / 2 / 18 / 98$

12.5.3. EXECUTE alarm inhibit C-program from the SKID panel and VERIFY proper operation.

$$
\text { Initials: } M T / 2 / 18 / 98
$$

12.5.4. INHIBIT an alarm and VERIFY removal from alarm summary display.

$$
\text { Initials: } M T / 2 / 18 / 98
$$

12.5.5. REMOVE the inhibit from the alarm in previous step and VERIFY the alarm returns to the alarm summary display.

$$
\text { Initials: } M \nabla 12 / 18 / 98
$$

12.5.6. VERIFY System Status AND P3 displays show no unexpected system alarm conditions.

12.5.7. VERIFY OCM keyboard is able to access data that is more than 24 hours old.

$$
\text { Initials: } m \text { T } 12 / 18 / 98
$$

Initials: $M T / 2 / 18 / 98$

12.5.8. VERIFY COD Utility date and time stamp is correct and has format "dd-mmm-yy 00:00:00".

Initials: $M T / 2 / 18 / 98$

12.5.9. VERIFY MOD Utility time stamp is correct and has format "00:00:00".

$$
\text { Initials: } M T, 2 / 18 / 98
$$

12.5.10.VERIFY MTS Utility date and time stamp is correct and has format "dd-mmm-yy 00:00:00".

$$
\text { Initials: } M T^{-12 / 18 / 98}
$$

12.5.11.COMPILE a dummy Sequence and Batch Language program and VERIFY SIC Utility listing (*.LST) date and time stamp is correct and has format "dd-mmm-yy 00:00:00".

$$
\text { Initials: } 12 / 18 / 98 \quad m 5
$$

12.5.12.VERIFY MEAT Utility date and time stamp is correct and has format "dd-mmm-yy 00:00:00".

$$
\text { Initials: } M T / 2 / 18 / 98
$$

12.5.13.RUN D3DOWN on all nodes on the network and VERIFY smooth shut down. NOTE: Do first on non-CDCM.

Initials: MT $12 / 18 / 98$ 
12.5.14.STOP tasks FQIRESET and WATCH if applicable (STOP/ID=[\# FROM SHOW SYSTEM]).

NOTE: Prepares DCS for restart.

$$
\text { (3) } M r 12 / 18 / 98 \quad \text { (52) Initials: } M T 12 / 18 / 98
$$

12.5.15.SET TIME forward on the CDCM to February $28,200123.4800 .00$ hours.

NOTE: This allows 10 minutes for restart before data is archived and prepares for to verify no leap year in 2001 .

$$
\text { Initials: MT } 12 / 18 / 98
$$

12.5.16.COPY historicaldata files to dummy test files of format "UNITymm.27C",

"UNITymm.27D", "UNITymm.27H" and "UNITymm.27X" for February 28, 2001, where "UNIT" may be CDCM and/or DCMO.

NOTE: Prepares to verify no leap year in 2001.

$$
\text { N/A MT } 12 / 18 / 98
$$

Initials:

12.5.17.RUN D3UP on all nodes on the network (CDCM first) and VERIFY smooth start up. NOTE: This completes testing for bad leap year calculation (<366 days).

Initials: $M$ 12/18/98 


\title{
13. SYSTEM OPERATION TO EXPOSE WRONG LEAP YEAR IN 2001
}

\subsection{General Operation}

13.1.1. VERIFY system recognizes that March 1, 2001 follows February 28,2001 , and that system does not transition to February 29, 2001 directly from February 28, 2001.

\section{Initials: $M T 12 / 18 / 98$}

13.1.2. OBSERVE system functional throughout the transition to March 1, 2001.

\author{
Initials: $2012 / 18 / 48$
}

\subsection{Alarm And Associated Time And Date Information (D/3 ${ }^{\mathrm{TM}}$ )}

13.2.1. VERIFY creation of alarm history files with name format "ALddmmmyy.000".

$$
\text { Initials: MT } 12 / 18 / 98
$$

13.2.2. VERIFY date and time stamps are accurate for alarm history file contents (alarm messages) and have format "dd-mmm-yy 00:00:00".

$$
\text { 12/18/48 Initials: } M T / 2 / 18 / 48
$$

13.2.3. GENERATE a critical P1 (RED) process alarm, EHENEE it, but do NOT ACKNOWLEDGE it at this time.

Alarm description: WFI-E/O/ HItI

$$
12 / 15 / 48 \text { Initials: Not } 12 / 18 / 98
$$

13.2.4. GENERATE a non-critical P2 (YELLOW) process alarm, SHENGE-it, but do NOT ACKNOWLEDGE it at this time.

Alarm description: WFI-EIOL HI

$$
\text { 12/18/98 Initials: } M T \text { 12/18/98 }
$$

13.2.5. GENERATE a non-critical WHITE process alarm, EHEENCE it, but do NOT ACKNOWLEDGE it at this time.

Alarm description: WFI-EN4<O

$$
\text { Initials: } M \sigma / 2 / 18 / 98
$$

13.2.6. GENERATE a P3 SYSTEM ALARM (suggest network error)

Alarm description: PCMDA LINK STATUS CHANGE Initials: $M T 12 / 18 / 98$

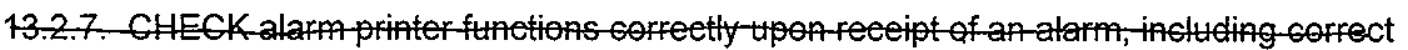
date and time stamp thathas format "det-m 00.00 .00 ".

$$
\text { No Printer for F. A, T. }
$$

13.2.8. CHECK alarm history files are updated correctly upon receipt of an alarm, including correct alarm message date and time stamp that has format "dd-mmm-yy 00:00:00".

$$
\text { Initials: } M T 12 / 18 / 98
$$


13.2.9. CHECK alarms recorded above displayed correctly on P1 ALARM SUMMARY, including correct date and time stamp that has format "dd-mmm 00:00:00".

Initials: $M T r / 18 / 98$

13.2. 10.CHECK alarms recorded above displayed correctly on P2 ALARM SUMMARY, including correct date and time stamp that has format "dd-mmm 00:00:00".

Initials: $M T \quad 12 / 18 / 98$

$>$ 13.2.11.CHECK alarms recorded above displayed correctly on WHITE ALARM SUMMARY, including correct date and time stamp that has format "dd-mmm-yy 00:00:00".

$$
\text { Initials: } M T \quad 12 / 19 / 98
$$

13.2.12. CHECK system alarm recorded above displayed correctly on P3 ALARM SUMMARY, including correct date and time stamp that has format "dd-mmm-yy 00:00:00".

Initials: $M \bar{\gamma}$ 12/18/98

13.2.13. CHECK alarms displayed in chronological order on alarm summary pages (newest at top).

Initials: $M T 12 / 18 / 98$

13.2.14.ACKNOWLEDGE alarms and VERIFY they can be acknowledged.

Initials: MT $12 / 18 / 98$

13.2.15.RESTORE alarm conditions and VERIFY they clear from alarm summaries.

Initials: $M T r / 18 / 98$

\subsection{Time and Date Functions $\left(D / 3^{\mathrm{TM}}\right)$}

13.3.1. CHECK standard date and time on OCM screens (lower right corner) is accurate and has format of "dd-mmm-yy 00:00:00".

\section{Initials: $M T, 2 / 18 / 98$}

13.3.2. CHECK Sequence And Batch Language timing functions work properly by observing FHOLD flag on Program Diagnostics graphic \#133 and VERIFY that FHOLD rolls over between 30 and 45 seconds.

Initials: $m$ T $12 / 18 / 98$

13.3.3. CHECK date and time function for FHOLD on Program Diagnostic graphic \#133 is accurate and has format "dd-mmm-yy 00:00:00".

Initials: $M T$, $2 / 18 / 98$

13.3.4. RUN inhibit C-program from SKID panel and VERIFY date and time on graphic \#80 is correct and has format "dd-mmm-yy 00:00:00".
EXCEPTION \#2
Initials: $M T$ 12/18/98

13.3.5. CHECK current trends operate correctly on OCMs and VERIFY correct time stamp that has format "00:00:00".

Initials: MT $12 / 18 / 98$

13.3.6. CHECK historical trends operate correctly on OCMS and VERIFY correct date and time stamp that has format "dd-mmm-yy 00:00:00".

Initials: $m T / 2 / 18 / 98$ 
13.3.7. VERIFY Archiver has created archive file for previous day's historical data in the format "UNITymm.ddD" at about 23:55 hours on a DCM; and VERIFY Archiver has also created historical reference files for the next day's data in the format "UNITymm.ddC", "UNITymm.ddH", and "UNITymm.ddX" at about 00:01 hours.

Initials: $M T 12 / 18 / 98$

13.3.8. RUN the following reports and VERIFY they can be generated with correct date and time (suggest FFBAL, REPERT HRTTER; and HISTDAD,HISTMON, or HISTMAX).

Report Name:

$$
\text { HISTDAO }
$$$$
\begin{aligned}
& \text { (Note: Genecates Report with peopen date } 4 \text { tine } \\
& \text { But collected values are initials: } M T \text { (2/18/98) } \\
& \text { wrong) }
\end{aligned}
$$

\subsection{Time and Date Functions (Operating System)}

13.4.1. LOGIN to a terminal (VT type) and VERIFY previous VMS ${ }^{\mathrm{TM}}$ login date and time stamp.

$$
\text { Initials: } M \pi, 2 / 18 / 98
$$

13.4.2. LOGOUT from the terminal.

Initials: $M T 12 / 18 / 98$

13.4.3. LOGIN to an engineering workstation and VERIFY previous VMS ${ }^{\mathrm{TM}}$ login date and time stamp.

Initials: $M T 12 / 18 / 98$

13.4.4. VERIFY VMS ${ }^{\top M}$ date and time stamps are accurate for newly created DCM files.

Initials: $M T / 2 / 18 / 98$

13.4.5. SUBMIT a batch job (suggest FQIRESET) to the batch queue and VERIFY EXECUTION on CDCM.

$$
\text { Initials: } M T 12 / 18 / 98
$$

13.4.6. VERIFY date and time correct on DCM (\$SHOW TIME or > TIM commands).

$$
\text { List Systems verified: WHDCMQ, WHENGR, WHCDCM }
$$

13.4.7. RUN the Authorize Utility and VERIFY date and time stamp is correct and has format "dd-mmm-yyyy 00:00".

$$
\text { Initials: } M T / 2 / 18 / 98
$$

13.4.8. COMPILE a dummy C-program and VERIFY the content of the compiler list file ( ${ }^{*}$.LIS) date and time stamp is correct and has format "dd-mmm-yyyy 00:00:00".

$$
\text { initials: } M T \text { 12/18/98 }
$$

13.4.9. LOGOUT from the engineering workstation.

$$
\text { Initials: } m T(2 / 18 / 98 \text {. }
$$




\subsection{General DCS Functionality (D/3 $\left.{ }^{\mathrm{TM}}\right)$}

13.5.1. VERIFY Sequence And Batch Language programs are running by observing Program Status graphic \#43.

$$
\text { Initials: } M-12 / 18 / 98
$$

13.5.2. CHECK Device Logic functions properly (suggest interlock bypass or simple valve such as 207-A basins). HV-CAI-2 + HV-CAI-6

$$
\text { Q INCK TO HV-CAT-6 FROM Initials: MT } 12 / 18 / 98
$$

13.5.3. EXECUTE alarm inhibit C-program from the SKID panel and VERIFY proper operation.

Initials: $M T 12 / 18 / 98$

13.5.4. INHIBIT an alarm and VERIFY removal from alarm summary display.

$$
\text { Initials: } M F<2 / 18 / 98
$$

13.5.5. REMOVE the inhibit from the alarm in previous step and VERIFY the alarm returns to the alarm summary display.

$$
\text { Initials: MT } 12 / 18 / 98
$$

13.5.6. VERIFY System Status AND P3 displays show no unexpected system alarm conditions.

$$
\text { Initials: } M T / 2 / 18 / 98
$$

13.5.7. VERIFY OCM keyboard is able to access data that is more than 24 hours old.

$$
\text { Initials: } M T \quad 12 / 18 / 98
$$

13.5.8. VERIFY COD Utility date and time stamp is correct and has format "dd-mmm-yy 00:00:00".

$$
\text { Initials: } M T / 2 / 18 / 98
$$

13.5.9. VERIFY MOD Utility time stamp is correct and has format "00:00:00".

$$
\text { Initials: } M T 12 / 18 / 98
$$

13.5.10.VERIFY MTS Utility date and time stamp is correct and has format "dd-mmm-yy 00:00:00".

$$
\text { Initials: } M T / 2 / 18 / 98
$$

13.5.11.COMPILE a dummy Sequence and Batch Language program and VERIFY SIC Utility listing $\left({ }^{*}\right.$.LST) date and time stamp is correct and has format "dd-mmm-yy 00:00:00".

$$
\text { Initials: } M T 12 / 18 / 98
$$

13.5.12.VERIFY MEAT Utility date and time stamp is correct and has format "dd-mmm-yy 00:00:00".

$$
\text { Initials: } M T 12 / 18 / 98
$$

13.5.13.RUN D3DOWN on all nodes on the network and VERIFY smooth shut down. NOTE: Do first on non-CDCM.

Initials: $M T 12 / 18 / 98$ 
13.5.14.STOP tasks FQIRESET and WATCH if applicable (STOP/ID=[\# FROM SHOW SYSTEM]).

NOTE: Prepares DCS to verify cold startup after year 2000.

Initials: $M T 12 / 18 / 98$

13.5.15. On all nodes on the network, SHUT DOWN the operating system, POWER DOWN, and RESTART the operating system.

NOTE: Multiple nodes may be done simultaneously. Prepares DCS to verify cold startup after year 2000 .

$$
\text { Initials: } M T / 2 / 18 / 98
$$

13.5.16. WAIT until restart of operating system is completed on all nodes before continuing.

Initials: $M T / 2 / 18 / 98$

13.5.17.RUN D3UP on all nodes on the network (CDCM first) and VERIFY smooth start up. NOTE: Prepares DCS to verify cold startup after year 2000.

Initials: $M T \quad 12 / 18 / 98$ 


\section{SYSTEM OPERATION AFTER COLD STARTUP}

\subsection{General Operation}

14.1.1. OBSERVE system functional following cold startup.

Initials: $m \pi / 2 / 18 / 98$

\subsection{Time and Date Functions $\left(D / 3^{\mathrm{TM}}\right)$}

14.2.1. CHECK standard date and time on OCM screens (lower right corner) is accurate and has format of "dd-mmm-yy 00:00:00".

$$
\text { Initials: } m T 2 / 18 / 98
$$

14.2.2. CHECK Sequence And Batch Language timing functions work properly by observing FHOLD flag on Program Diagnostics graphic \#133 and VERIFY that FHOLD rolls over between 30 and 45 seconds.

Initials: $M T 12 / 18 / 98$

14.2.3. CHECK date and time function for FHOLD on Program Diagnostic graphic \#133 is accurate and has format "dd-mmm-yy 00:00:00".

Initials: $m T / 2 / 18 / 58$

14.2.4. RUN inhibit C-program from SKID panel and VERIFY date and time on graphic \#80 is correct and has format "dd-mmm-yy 00:00:00".

$$
\text { EXCEPTION } 72 \text { Initials: } M T 12 / 18 / 98
$$

14.2.5. CHECK current trends operate correctly on OCMs and VERIFY correct time stamp that has format "00:00:00".

Initials: $M T 12 / 18 / 98$

14.2.6. CHECK historical trends operate correctly on OCMs and VERIFY correct date and time stamp that has format "dd-mmm-yy 00:00:00".

Initials: $M T / 2 / 18 / 98$

\subsection{Time and Date Functions (Operating System)}

14.3.1. LOGIN to a terminal (VT type) and VERIFY previous VMS ${ }^{\mathrm{TM}}$ login date and time stamp.

Initials: $M T / 2 / 18 / 98$

14.3.2. LOGOUT from the terminal.

Initials: $m T / 2 / 18 / 98$

14.3.3. LOGIN to an engineering workstation and VERIFY previous VMS ${ }^{\mathrm{TM}}$ login date and time stamp.

Initials: $m / 2 / 18 / 98$

14.3.4. LOGOUT from the engineering workstation.

Initials: $200 / 2 / 18 / 98$ 
HNF-2696 REV 0

14.4. General DCS Functionality $\left(D / 3^{\mathrm{TM}}\right)$

14.4.1. VERIFY Sequence And Batch Language programs are running by observing Program Status graphic \#43.

Initials: $M T 12 / 18 / 98$

14.4.2. VERIFY System Status AND'P3 displays show no unexpected system alarm conditions.

NOTE: This completes verification of cold startup. THIS COMPLETES YEAR 2000 TESTING. Prepare for reset of system date/time and system restart.

Initials: MT $12 / 18 / 98$ 


\section{HNF-2696 REV 0}

\section{SYSTEM RESTORATION}

\subsection{System Shutdown/Restart}

15.1.1. RUN D3DOWN.

NOTE: Do all nodes on the network and first on non-CDCM.

Initials: MCT $12 / 18 / 98$

15.1.2. STOP Tasks FQIRESET And WATCH.

NOTE: STOP/ID=[\# From Show System]).

Initials: $M V / 2 / 18 / 98$

15.1.3. SET TIME On CDCM To Current Date/Time, then do Dzup on all.

Initials: mr $12 / 18 / 98$

15.1.4. On all nodes on the network, SHUT DOWN the operating system, POWER DOWN, and RESTART the operating system.

NOTE: Multiple nodes may be done simultaneously.

Initials: Mr $2 / 18 / 98$

15.1.5. WAIT until restart of operating system is completed on all nodes before continuing.

15.1.6. RUN D3UP.

Initials: $\operatorname{mis} 12 / 18 / 98$

NOTE: Do for all applicable nodes on the network, CDCM first.

Initials: $12 \pi / 18 / 98$

45.4.7. After all nodes are running, RUNGENERALFUNCTION 140IT CDEM to regenetate

allatarms GF-14 WORKS FINE. NO NEEP

TO RETEST HERE.

Initials:

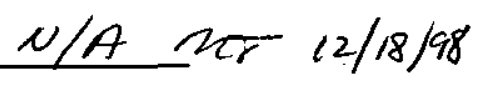

\subsection{General Operation}

15.2.1. OBSERVE system functional following system startup.

Initials: $M T \quad 12 / 18 / 98$

\subsection{Time and Date Functions $\left(\mathrm{D} / 3^{\mathrm{TM}}\right)$}

15.3.1. CHECK standard date and time on OCM screens (lower right corner) is accurate and has format of "dd-mmm-yy 00:00:00".

Initials: $M T$ 12/18/98

15.3.2. RUN inhibit C-program from SKID panel and VERIFY date and time on graphic \#80 is correct and has format "dd-mmm-yy 00:00:00".

$$
\text { Initials: MT } 12 / 18 / 98
$$

15.3.3. CHECK current trends operate correctly on OCMs and VERIFY correct time stamp that has format "00:00:00".

Initials: WT $12 / 18 / 98$ 
15.3.4. CHECK historical trends operate correctly on OCMs and VERIFY correct date and time stamp that has format "dd-mmm-yy 00:00:00".

Initials: $m \pi / 2 / 18 / 98$

\subsection{Time and Date Functions (Operating System)}

15.4.1. LOGIN to a terminal (VT type) and VERIFY previous VMS ${ }^{\mathrm{TM}}$ login date and time stamp.

Initials: MT 12/18/98

15.4.2. LOGOUT from the terminal.

Initials: $M T \quad 12 / 18 / 98$

15.4.3. LOGIN to an engineering workstation and VERIFY previous $\mathrm{VMS}^{\mathrm{TM}}$ login date and time stamp.

Initials: $M \sigma / 2 / 18 / 98$

15.4.4. LOGOUT from the engineering workstation.

Initials: MT/2/18/98

15.5. General DCS Functionality (D/3 $\left.{ }^{T M}\right)$

15.5.1. VERIFY Sequence And Batch Language programs are running by observing Program Status graphic \#43.

Initials: $M T$ 12/18/98

15.5.2. VERIFY System Status AND P3 displays show no unexpected system alarm conditions.

NOTE: This completes verification of system restoration.

Initials: $M T / 2 / 18 / 98$

\subsection{Post Performance Review}

15.6.1. This procedure's testing has been completed.

Initials: $M T \quad 12 / 18 / 98$

15.6.2. The system's date and time have been restored to the current date and time and all systems have been verified functional.

Get copies of AHF, HTD directories.

Examples of AHF contents. 
HNF-2696 REV 0

ATTACHMENT 2 : TEST DISCREPANCY LOG SHEET Page 1 of 4

EXCEPTION \#1 (JUNE 1998 TEST)

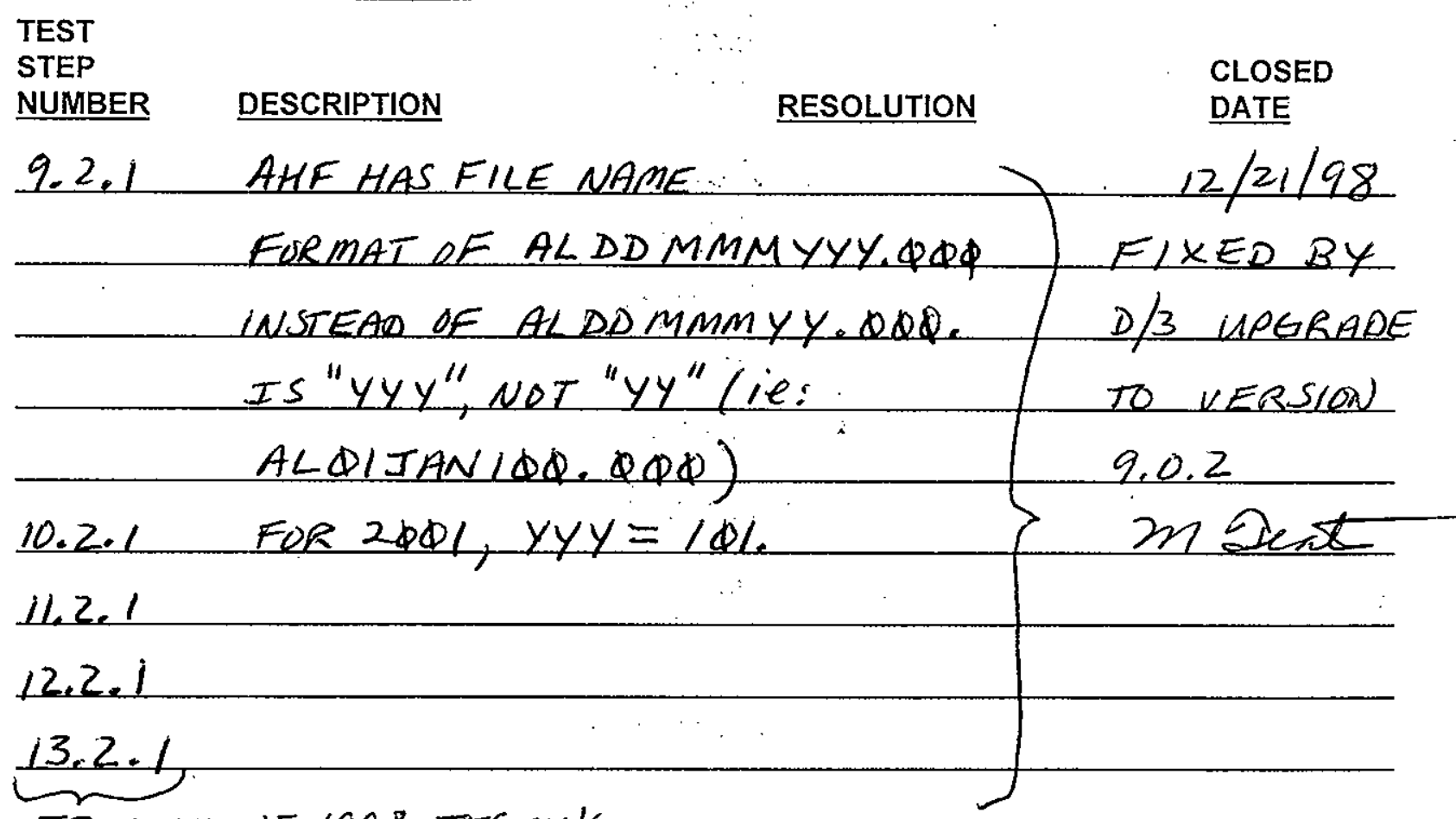

FROM TUNE 1998 TESTING

107 
HNF-2696 REV 0

ATTACHMENT $\frac{3}{2}$ : TEST DISCREPANCY LOG SHEET Page 2 of 4 EXCEPTION \# 2 (JUNE 1998 TEST)

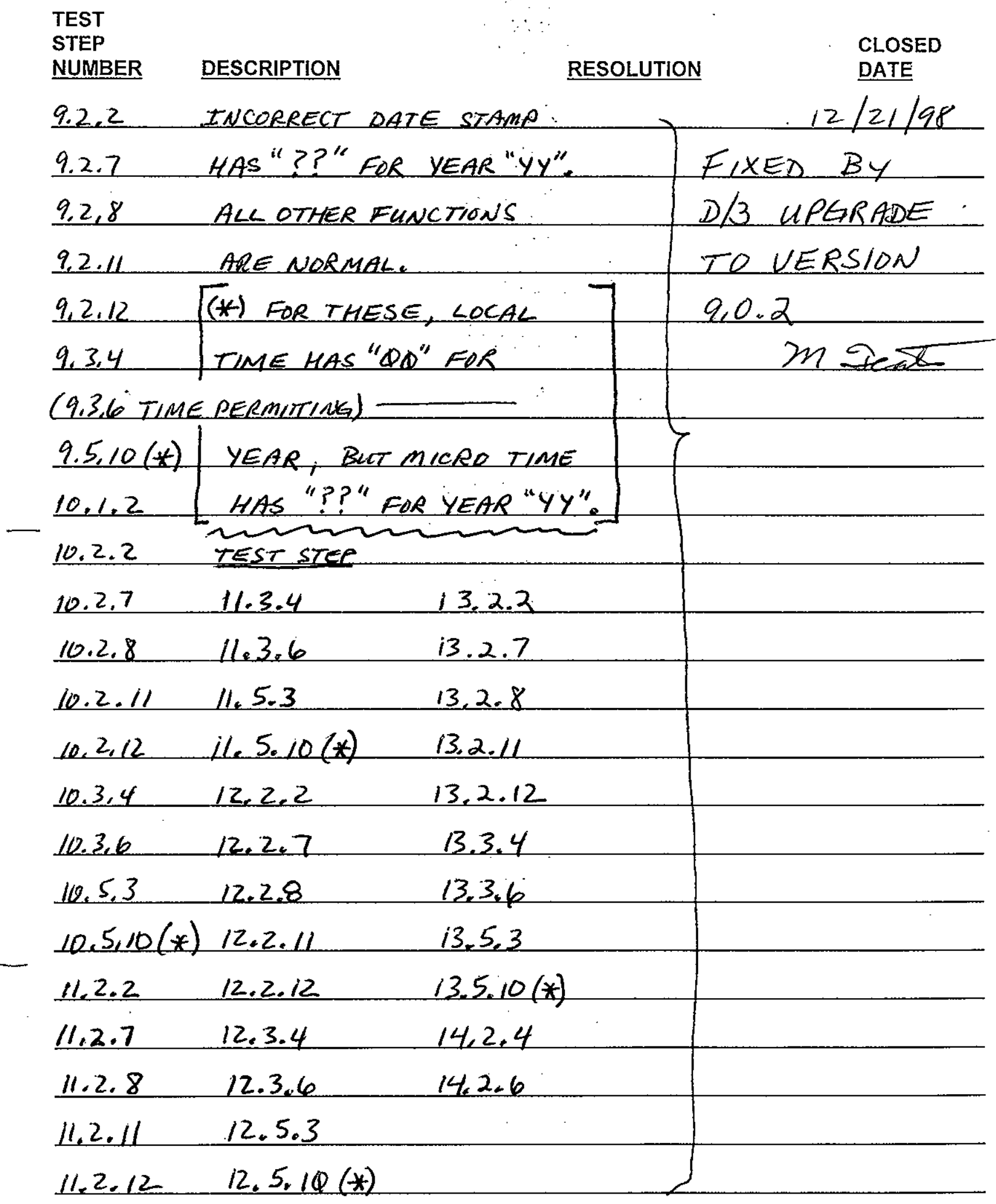

608 
HNF-2696 REV 0

ATTACHMENT $2 \frac{3}{2}$ TEST DISCREPANCY LOG SHEET Page 3 of 4 EXCEPTION \#3 (TUNE 1998 TEST)

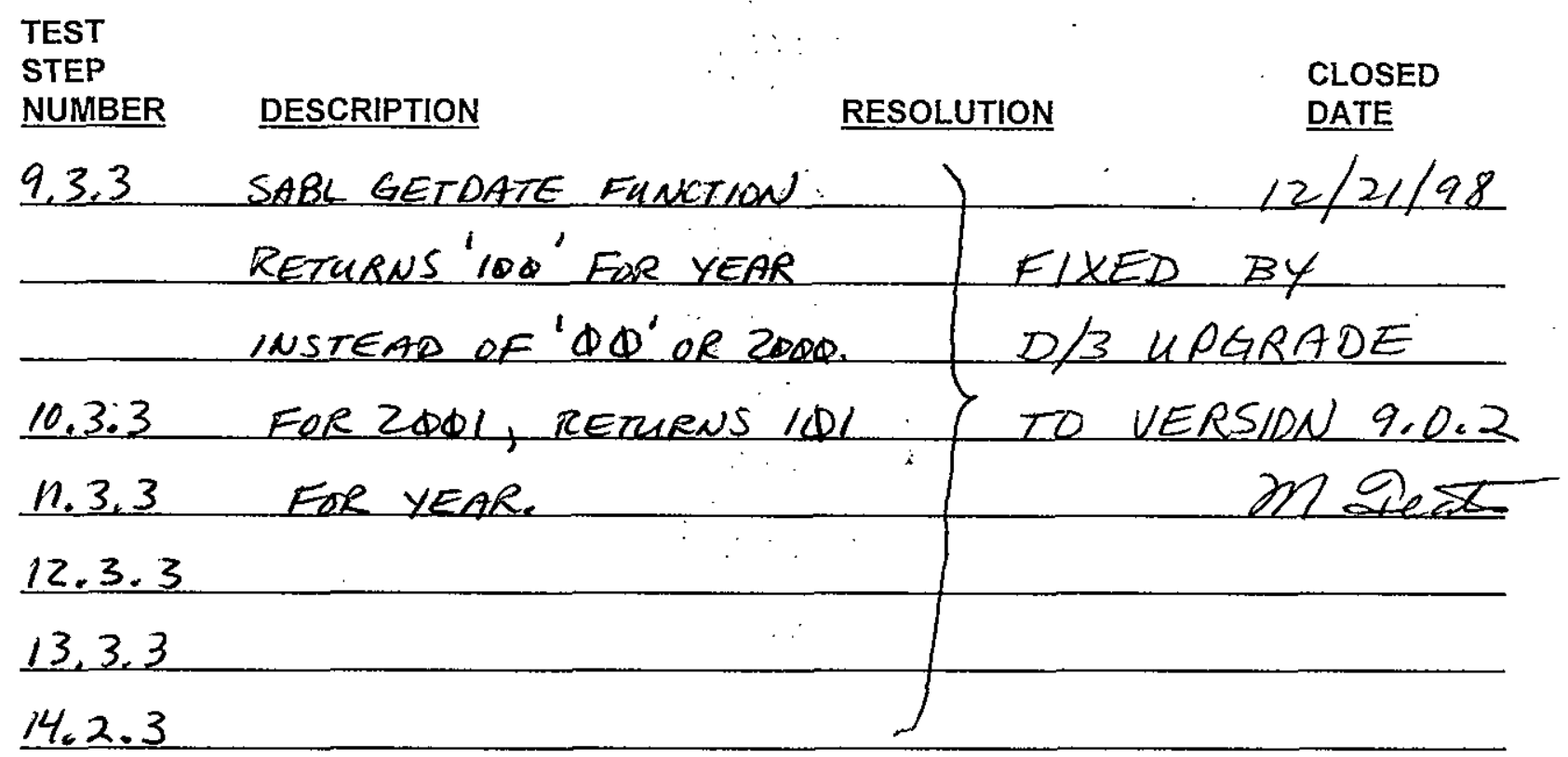

109 
HNF-2696 REV 0

ATTACHMENT $\stackrel{3}{2}$ : TEST DISCREPANCY LOG SHEET Page 4 of 4

EXCEPTION 4 (JUNE 1998 TEST)

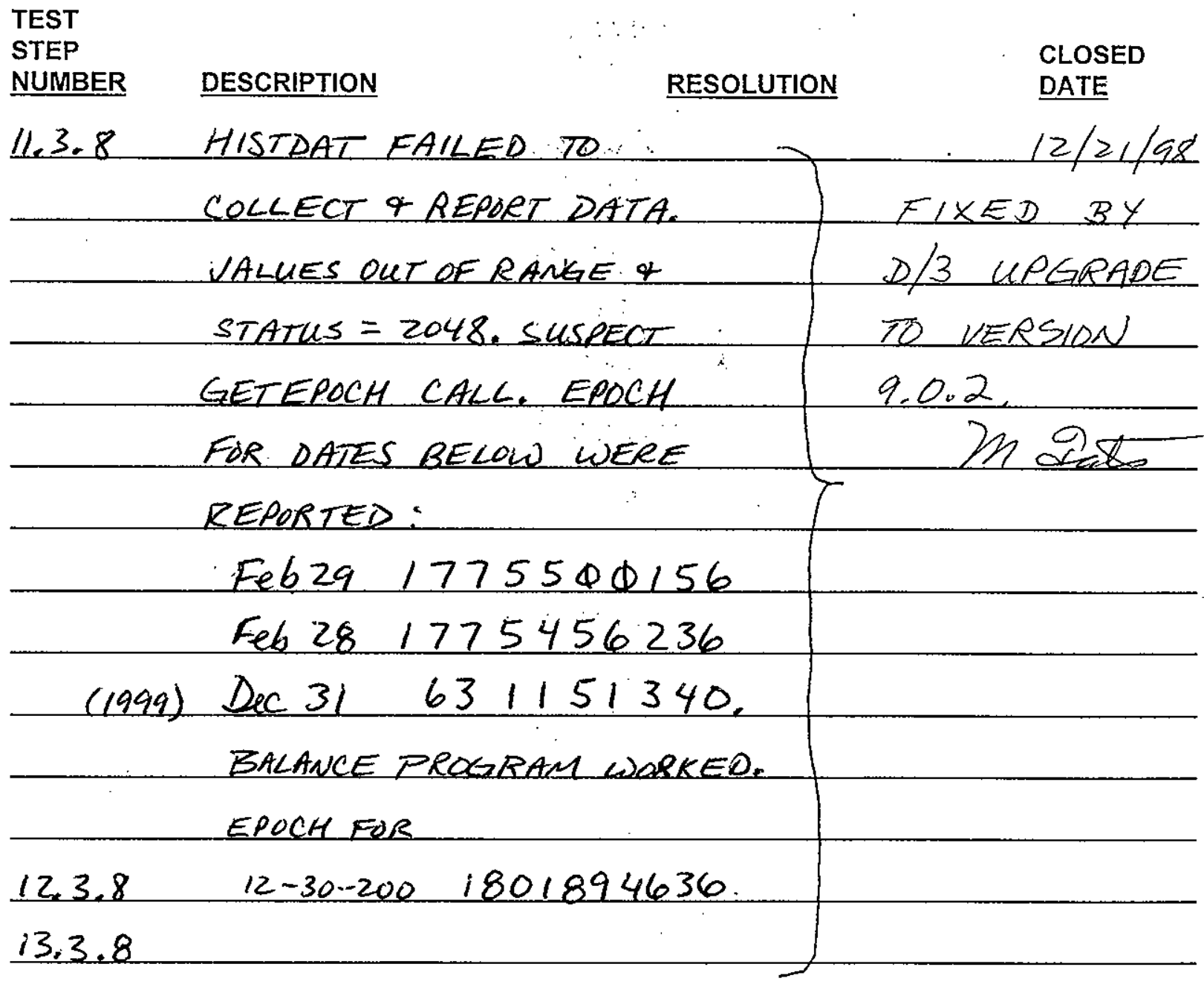

13.3 .8

80110 
HNF-2696 REV 0

ATTACHMENT 8: TEST DISCREPANCY LOG SHEET Page 1 of 2

YZK UPGRADE TEST (DEC: 1998) - TEST EXCEPTION \#

TEST

STEP

NUMBER DESCRIPTION

RESOLUTION

CLOSED

(1) 6.2.4 INHA.C did not work Fix by removing $12 / 17 / 98$

6.4 .3 due to Access Violation, "O9" from strings mast

tut time/date on Logical put into

graphic 80 worked. D3 SET: SITEASSIGN.COM

$\infty 8111$ 


\section{HNF-2696 REV 0}

4

ATTACHMENT \&: TEST DISCREPANCY LOG SHEET Page 2 of 2

YZK UPGRADE TEST (DEC. 1998):- TEST EXCEPTION \#Z

\section{TEST}

STEP

NUMBER DESCRIPTION

RESOLUTION

CLOSED

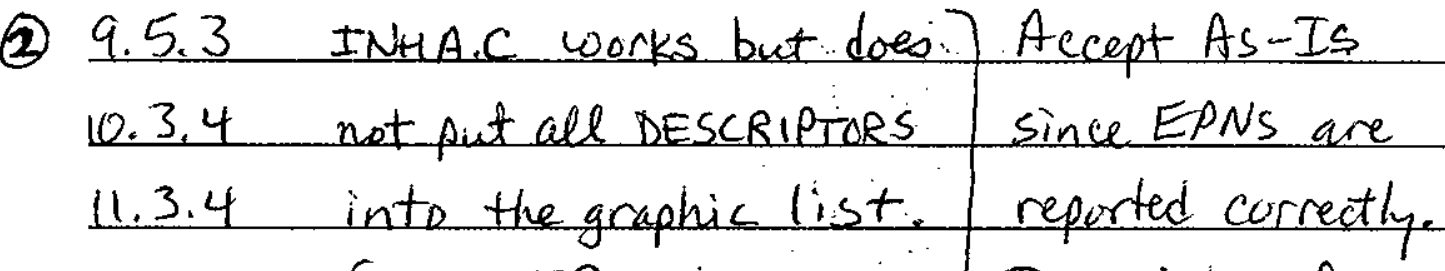

12.3.4 Some EPNs have all Descriptor fix

13.3.4 descriptors okay, sone can be worked

14.2.4 have less than they out after system

should. Use of 8 is delivered.

- character words

causes truncated.

Descriptors of 7

characters or less are okay.

DATE

$1 / 4 / 98$ $m V$ 
SYSTEM ALARM REVIEW PAGE $\square$ 09-SEP-99 00:10:22 CDCM DCMO LINK STATUS CHANGE: ETHERNET_O TO ONLTNE

O9-SEP-99 00:10:22 CDCH O9-SEP-99 00:08:19 CDCM 09-SEP-99 00:08:19 CDCH OB-SEP-99 23:59:02 CDCH 08-SEP-99 23:59:02 CDCH 08-SEP-99 23:59:00 CDCM 08-SEP-99 23:58:57 CDCM 08-SEP-99 23:58:57. CDCH Q8-SEP-99 23:58:55 CDCH 08-SEP-99 23:58:53 CDCH 08-SEP-99 23:58:53 CDCH O8-SEP-99 23:58:50 CDCH 08-SEP-99 23:58:48 CDCM O8-SEP-99 23:58:48 CDCH 08-SEP-99 23:58:45 CDCM Q8-SEP-99 23:58:43 CDCM O8-SEP-99 23:58:43 CDCM OB-SEP-99 23:58:41 CDCM 08-SEP-99 23:58:38 CDCM O8-SEP-99 23:58:38 CDCM 08-SEP-99 23:58:36 CDCH OB-SEP-99 23:58:33 CDCH 08-SEP-99 23:58:33 CDCM
DCHO STATUS CHANGE: STAADBY $\rightarrow$ RUNNING

DCHO LINK STATUS CHANGE: ETHERNET_O TO OFFLTNE DCMO STATUS CHANGE: RUNNING $\rightarrow$ STANDBY DCH1 LINK STATUS CHANGE: ETHERNET_O TO ONLINE DCM1 STATUS CHANGE: OFFLTNE $\rightarrow$ RUNNING DCM1 STATUS CHANGE: RUNNING $\rightarrow$ OFFLINE. DCH1 LINK STATUS CHANGE: ETHERNET_O TO ONLINE DCHI STATUS CHANGE: OFFLTNE $\rightarrow$ RUNNTNG DCHI STATUS CHANGE: RUNNING $\rightarrow$ OFFLINE DCH1 LINK STATUS CHANGE: ETHERNET_O TO ONLINE DCH1 STATUS CHANGE: OFFLINE $\rightarrow$ RUNNING DCM1 STATUS CHANGE: RUNNING $\rightarrow$ OFFLINE DCH1 LINK STATUS CHANGE: ETHERNET_O TO ONLINE DCH1 STATUS CHANGE: OFFLINE $\rightarrow$ RUNNING DCM1 STATUS CHANGE: RUNNTNG $\rightarrow$ OFFLINE DCM1 LINK STATUS CHANGE: ETHERNET_O TO ONLINE DCM1 STATUS CHANGE: OFFLINE $\rightarrow$ RUNNING DCM1 STATUS CHANGE: RUNNTNG $\rightarrow$ OFFLINE DCM1 LINK STATUS CHANGE: ETHERNET_O TO ONLINE DCM1 STATUS CHANGE: OFFLINE $\rightarrow$ RUNNING DCM1 STATUS CHANGE: RUNNING $\rightarrow$ OFFLINE DCMI LINK STATUS CHANGE: ETHERNET_O TO ONLINE DCH1 STATUS CHANGE: OFFLINE $\rightarrow$ RUNNTNG

O9-SEP-99 00:15:42 


$\begin{array}{ll}1 & \text { AR44 } \\ 2 & \text { HVC244 } \\ 3 & \text { WASTE } \\ 4 & \text { A3SO } \\ 5 & \text { FEED } \\ 6 & \text { CA1 } \\ 7 & \text { PB1 } \\ 8 & \text { PER } \\ 9 & \text { EA1 } \\ 10 & \text { EC1 } \\ 11 & \text { RWATER } \\ 12 & \text { URW } \\ 13 & \text { VVENT } \\ 14 & \text { PC } \\ 15 & \text { IX } \\ 15 & \text { SC } \\ 17 & \text { BASINS } \\ 18 & \text { UTIL } \\ 19 & \text { ROOMS } \\ 20 & \text { AMU } \\ 21 & \text { LERF } \\ \end{array}$

SHORTO 204 FALMON 207 ACK SHORTO 204 FALMON 207 ACK SHORTO 204 FALMON 207 ACK SHORTO 204 FALMON 207 ACK PRCESS 3E4 FALMON 367 ACK PRCESS 364 FALMON 367 ACK PRCESS 364 FALMON 367 ACK PRCES5 354 FALMON 367 ACK PRCESS 364 FALMON 367 ACK PRCESS 364 FALMON 367 ACK PRCESS 354 FALMON 357 ACK PRCESS 364 FALMON 357 ACK PRCESS 364 FALMON 367 ACK PRCESS 354 FALMON 357 ACK PRCESS 364 FALMON 367 ACK PRCESS 364 FALMON 367 ACK PRCESS 364 FALMON 367 ACK PRCESS 364 FALMON 367 ACK PRCESS 364 FALMON 367 ACK PRCESS 364 FALMON 367 ACK PRCESS 364 FALMON 367 ACK

244BATCH PGM STARTINE 2A4-A EXH STK FLO LO WSTXFR PGM STARTINE BSDBATCH PGM STARTING

\section{PRQGRAM DIAGNOSTIC} (133)

STEAM CNDSE DIVERTED TO IDRAW BASINEAT.SER START

TK-E-101 WT FACTOR LO-LO
TIME O 1739

HR MN SEC

APIOZ TNKFRM 452

AWHVC TNKFRM 495 450

AWVLV TNKFRM 449

AWPT1 TNKFRM 451

4 XYZFRM TNKFRM 492 447

AFRM TNKFRM 495 448

AYFRM TNKFRM 449

AY-AZFRM TNKFRM 450

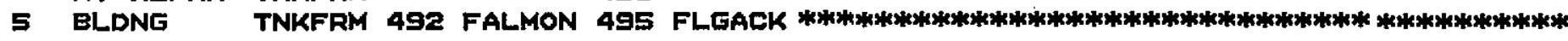

25 BLANKO BLANKK 168 FSLO FNK

E BLANK1 BLANKK $1 E 8$ ACK

Q9-SEP-99 00:17:36 
HNF-2696 REV 0

ATTACHMENT 5

$\underset{0}{\infty}$

$\underset{z}{\frac{x}{x}} \frac{0}{\frac{9}{7}}$

告

0

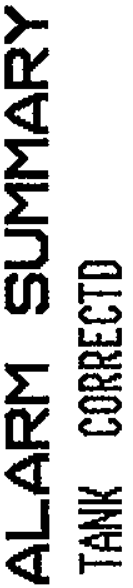

1 톨

$H$

m

본

$\rightarrow$ m 


$\begin{array}{ll}1 & \text { A244 } \\ 2 & \text { HVC244 } \\ 3 & \text { WASTE } \\ 4 & \text { A3Sם } \\ 5 & \text { FEED } \\ 6 & \text { CA1 } \\ 7 & \text { PE1 } \\ 8 & \text { PE2 } \\ 9 & \text { EA1 } \\ 10 & \text { EC1 } \\ 11 & \text { RWATER } \\ 12 & \text { URW } \\ 13 & \text { VVENT } \\ 14 & \text { PC } \\ 15 & \text { IX } \\ 16 & \text { SC } \\ 17 & \text { BASINS } \\ 18 & \text { UTIL } \\ 19 & \text { ROOMS } \\ 20 & \text { AMU } \\ 21 & \text { LERF }\end{array}$

SHORTO 2Q4 FALMON 207 ACK SHORTO 204 FALMON 207 ACK SHORTO 204 FALMON 207 ACK SHORTO 204 FALMON 207 ACK PRCESS 364 FALMON 367 ACK PRCESS 364 FALMON 367 ACK PRCESS 3E4 FALMON 3E7 ACK PRCESS 364 FALMON 357 ACK PRCESS 364 FALMON 367 ACK PRCESS 364 FALMON 367 ACK PRCESS 364 FALMON 367 ACK PRCESS 354 FALMON 367 ACK PRCESS 364 FALMON 367 ACK PRCESS 364 FALMON 367 ACK PRCESS 364 FALMON 367 ACK PRCESS 364 FALMON 367 ACK PRCESS 364 FALMON 36? ACK PRCESS 364 FALMON 367 ACK PRCESS 364 FALMON 367 ACK PRCESS 364 FALMON 367 ACK PRCESS 364 FALMON 367 ACK

244BATCH PGM STARTING 244 A EXH STK FLO LO WSTXFR PEM STARTINE

GSDBATCH PGM STARTING

\section{PROGRAM}

DIAGNOSTIC

(133)

STEAM CNDSB DIVERTED TO 10ZAW

BASINAAT , SEC START

TK-E-101 WT FACTOR LO-LO

\section{TNKFAM 492}

447

TNKFRM

449

447
TIME O 1733

HR MN SEC

DATE $\underset{90}{9} 9 \stackrel{9}{99}$

DAY OF WEEK 4

3 AWFARM

AWHVC

AWVLV

AWR71

4 XYZFRM

AFRM

AYFRM

AY-AZFRM

5 ELDNG

25 BLANKG

5 BLANK1

TNKFRM 495 450

TNKFRM 449

TNKFRM 451

$\begin{array}{ll}\text { TNKFRM } & 452 \\ \text { TNKFRM } 492 & 447\end{array}$

TNKFRM 495, 450

TNKFRM 449

TNKFRM

TNKFRM 492

TNKFRM 495

TNKFRM 449

TNKFRM

TNKFRM 492 FALMON 495 FLGACK ***************************************************

BLANKK 168 FSLO

RNK

BLANKK 168

ACK

O9-SEP-99 00:17:36 
HNF-2696 REV 0

ATTACHMENT 5

00
0
0
08
0

妾是

品

$\ddot{\nabla}$

哭凅

$\begin{array}{ll}0 & 0 \\ 11 & 1 \\ 1 & 0 \\ 1 & 0 \\ 0 & 0\end{array}$

品

$\frac{1}{2}$

10

$\sum$ 蓆

4

4 㘳

니놀

$H$

m

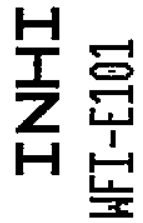

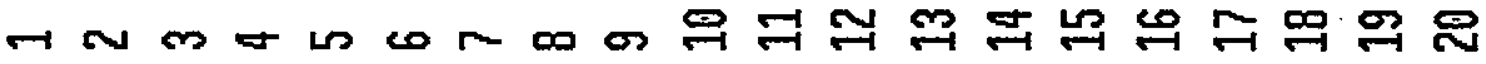




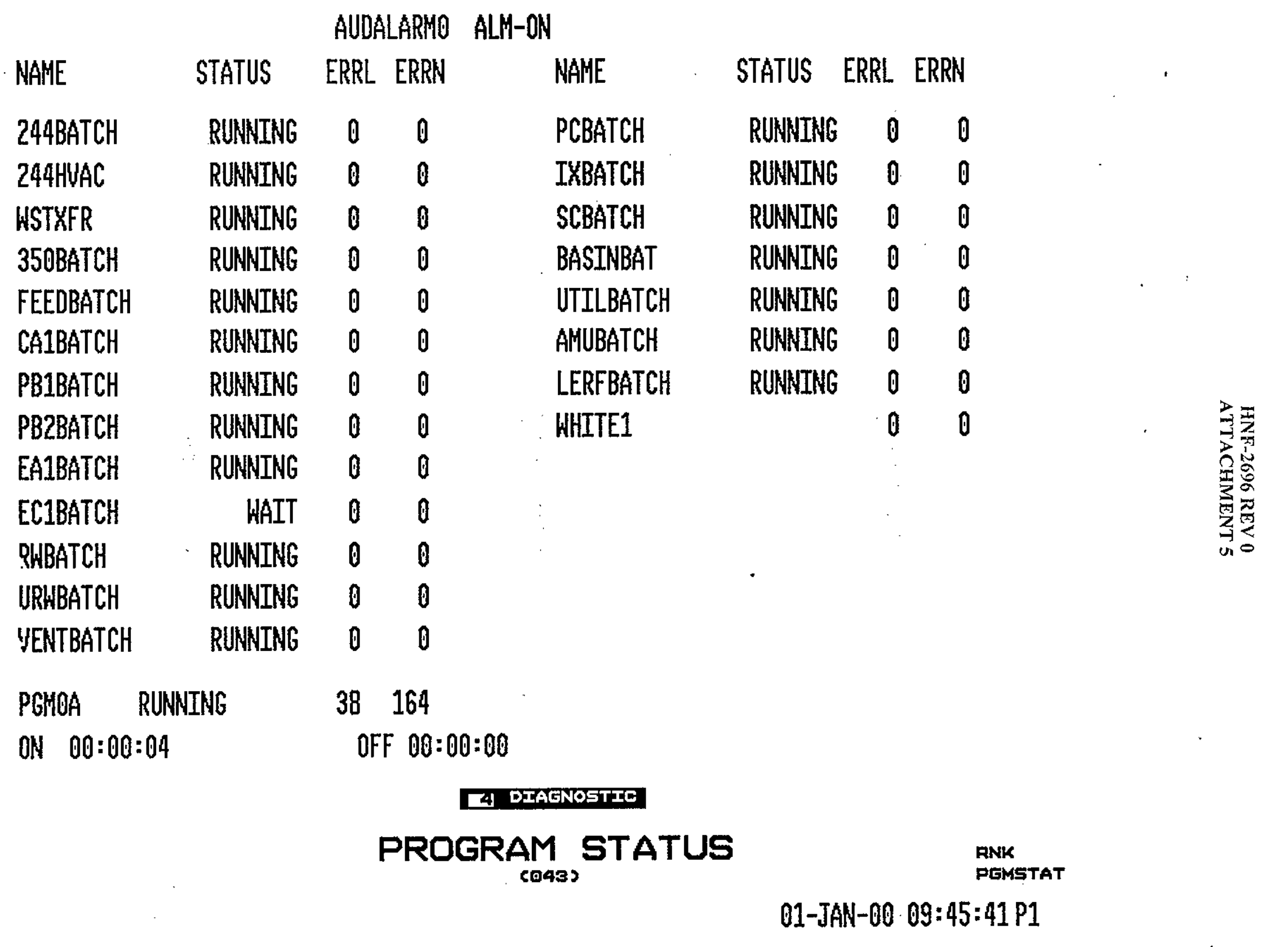




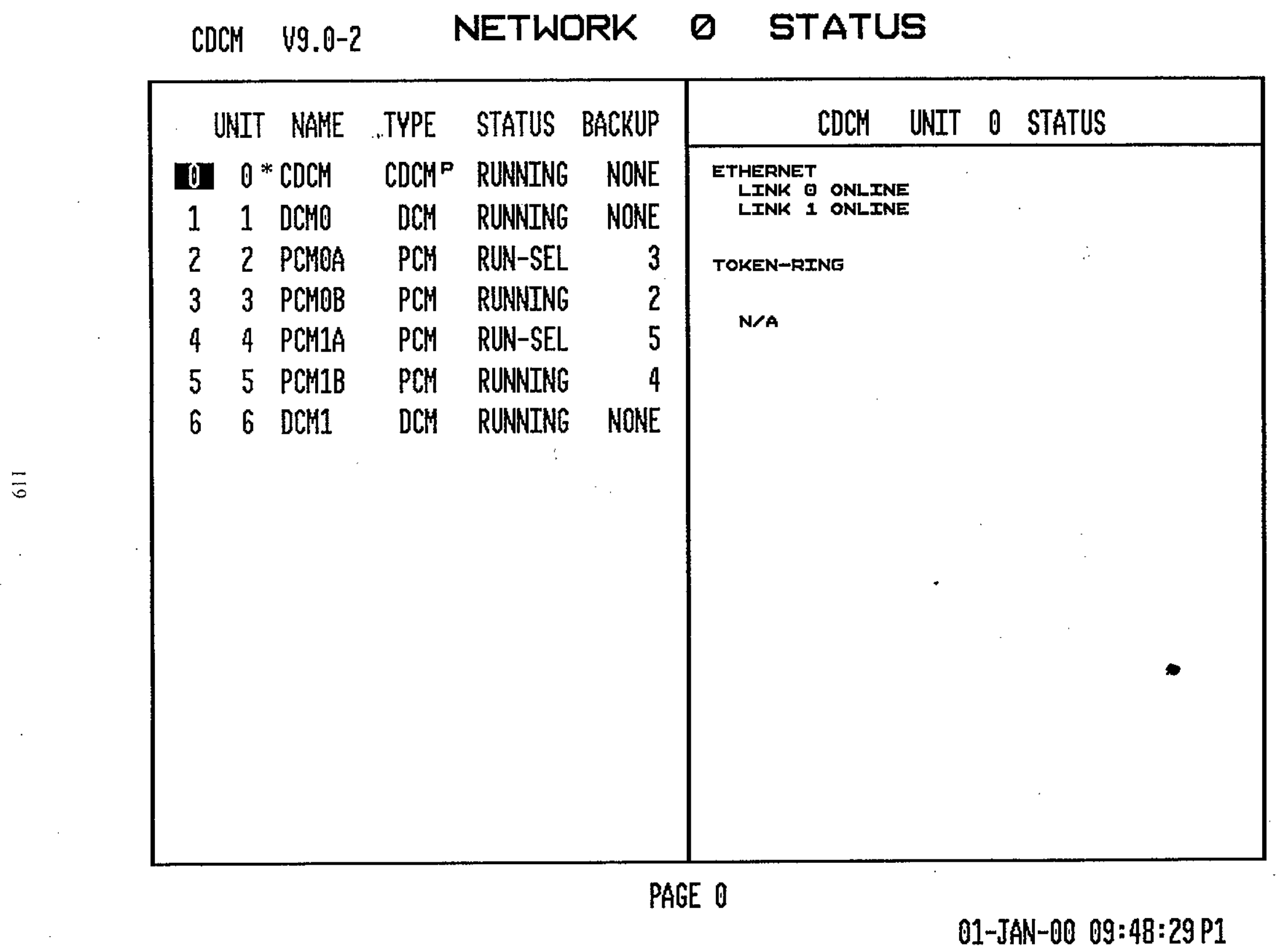




$\begin{array}{ll}1 & \text { A244 } \\ 2 & \text { HVC244 } \\ 3 & \text { NASTE } \\ 4 & \text { A350 } \\ 5 & \text { FEED } \\ 5 & \text { CA1 } \\ 7 & \text { PB1 } \\ 8 & \text { PE2 } \\ 9 & \text { EA1 } \\ 10 & \text { EC1 } \\ 11 & \text { RWATER } \\ 12 & \text { URW } \\ 13 & \text { VVENT } \\ 14 & \text { PC } \\ 15 & \text { IX } \\ 15 & \text { SC } \\ 17 & \text { BASINS } \\ 19 & \text { UTIL } \\ 19 & \text { ROOMS } \\ 20 & \text { AMU } \\ 21 & \text { LERF }\end{array}$

SHORTO 204 FALMON 207 ACK SHORTO 204 FALMON 207 ACK SHORTO 204 FALMON 207 ACK SHORTO 204 FALMON 207 ACK PRCESS 364 FALMON 367 ACK PRCESS 364 FALMON 367 ACK PRCESS 354 FALMON 367 ACK PRCESS 354 FALMON 367 ACK PRCESS 364 FALMON 367 ACK PRCESS 364 FALMON 367 ACK PRCESS 354 FALMON 357 ACK PRCESS 364 FALMON 357 ACK PRCESS 364 FALMON 367 ACK PRCESS 364 FALMON 367 ACK PRCESS 364 FALMON 357 ACK PRCESS 364 FALMON 367 ACK PRCESS 364 FALMON 367 ACK PRCESS 364 FALMON 367 ACK PRCESS 364 FALMON 367 ACK PRCESS 354 FALMON 367 ACK PRCESS 364 FALMON 367 ACK

244BATCH PEM STARTING 244-A EXH STK FLO LO WSTXFR PEM STARTINE

35DEATCH PGM STARTING

\section{PROGRAM \\ DIAGNOSTIC}

(135)

STEAM CNDSB DIVERTED TO 1D2AN

BASINBAT . SER START

START AMUBATCH PGM

FHOLD

450

449

451

447

450

449

451

452

447

450

449

451

447

448

449

AY-AZFRM TNKFRM
BLDNG TNKFRM 492 FALMON 495 FLEACK

25 BLANKO BLANKK 168 FSLO

6 BLANK1 BLANKK 168
ON . פ0:00:10

TIME $23 \quad 54 \quad 5$

DATE $\stackrel{2}{2}{ }^{2}{ }^{2}{ }^{\circ}$

DAY OF WEEK 6
RNK ACK 
SYSTEM ALARM REVIEW PAGE $\square$ 02-JAN-00 00:15:32 CDCH PCMOA LINK STATUS CHANGE: ETHERNET_1 TO ONLINE O2-JAN-00 00:15:32 CDCM PCMOA LINK STATUS CHANGE: ETHERNET_O TO ONLINE Q2-JAN-00 00:15:32 CDCM O2-JAN-OB 00:15:20 CDCH O2-JAN-00 00:15:20 CDCM O2-JAN-00 00:15:20 CDCH O2-JAN-00 00:15:20 CDCH O2-JAN-00 00:15:17 CDCH O2-JAN-OO 00:15:15 COCM O2-JAN-80 00:08:24 PCYOA O2-JAN-OO 00:08:23 PCHOA O2-JAN-00 00:08:23 PCMQA O1-JAN-OO O9:43:04 PCYOB 01-JAN-00 09:39:29 PCHOB 01-JAN-6日 09:34:43 PCYOB

PCHOA STATUS CHANGE: OFFLINE $\rightarrow$ RUNNING DCHO LINK STATUS CHANGE: ETHERNET_O TO ONLINE DCFO STATUS CHANGE: STANDBY $\rightarrow$ RUNNING DCMO LINK STATUS CHANGE: ETHERNET_O TO OFFLINE DCMO STATUS CHANGE: RUNNING $\rightarrow$ STANDBY PCMOA STATUS CHANGE: RUNNING $\rightarrow$ OFFLINE PCHOA LINK STATUS CHANGE: ETHERNET_O TO OFFLINE SEOUENCE PROGRAM NOT LOADED IN BOTH PCHS: RHBATCH SEOUENCE PROGRAM NOT LOADED IN BOTH PCHS: FEEDBATCH SEQUENCE PROGRAM NOT LOADED IN BOTH PCHS: PB2BATCH SEOUENCE PROGRAM SERIAL NUMBER MISMATCH: RHBATCH SEQUENCE PROGRAM SERIAL NUMBER MISMATCH: PBZBATCH SEQUENCE PROGRAM SERIAL NUMBER MISMATCH: FEEDBATCH

01-JAN-8O 09:26:18 PCH1B 01-JAN-00 09:26:03 PCM1A O1-JAN-OO 09:26:02 CDCH 01-JAN-00 09:26:00 PCM1B 01-JAN-BO 09:26:00 PCH1B 01-JAN-00 09:26:00 PCM1B 01-JAN-00 09:25:57 PCM1A
BACKUP STATUS CHANGE TO IN SYNCH BACKUP STATUS CHANGE TO IN SYNCH PCM1B STATUS CHANGE: AUTO-SYNC ENABLED BACKUP STATUS CHANGE TO INITIALIZING RSYNC - CROSS INIT REOUEST: DUQ386 RSYNC - CROSS INIT REQUEST: SEQ386 R-LINK STATUS CHANGED TO ONLINE 
$\Delta$

$\frac{11}{2}$ 볻

象

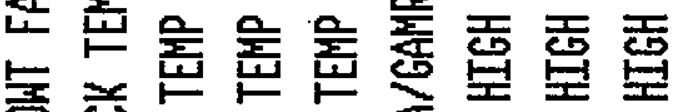

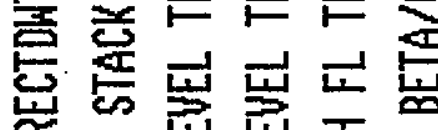

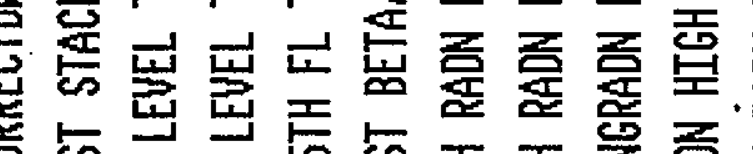

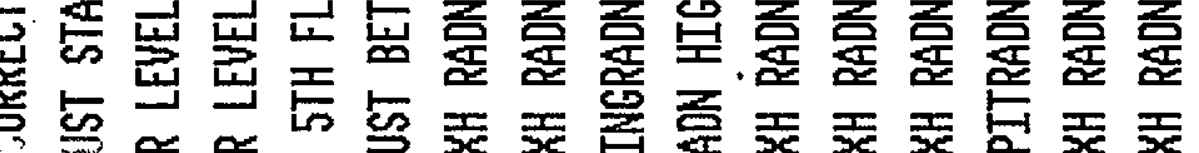

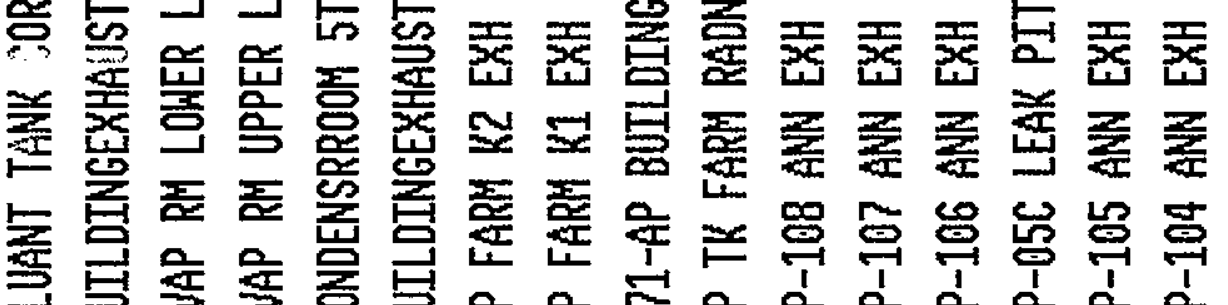

ק

$\frac{\sum_{1}}{4}$

$\frac{1}{4}$

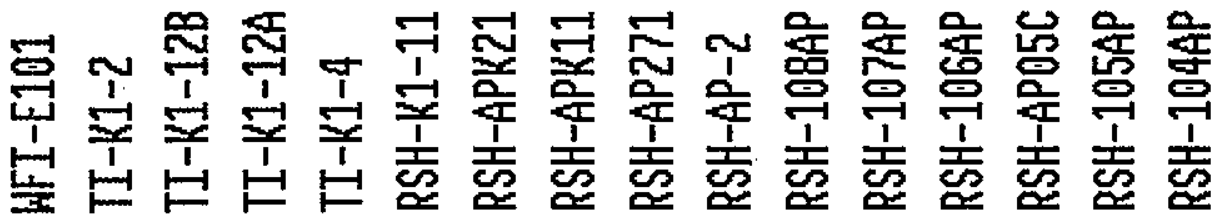

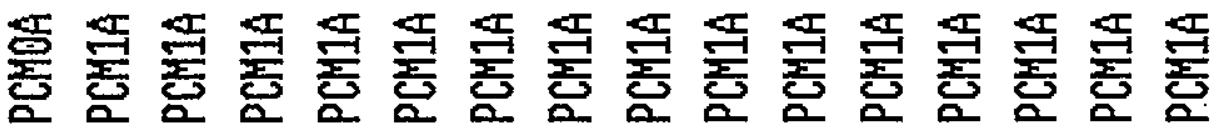

()

I

1

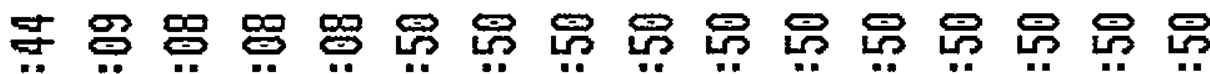

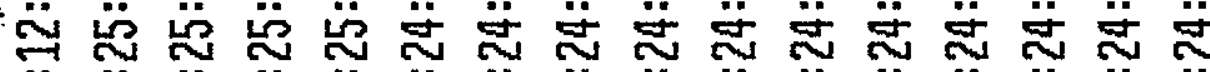

$\ddot{\sigma} \ddot{\sigma} \ddot{\sigma} \ddot{\sigma} \ddot{\sigma} \ddot{\sigma} \ddot{\sigma} \quad \ddot{\sigma} \ddot{\sigma} \ddot{\sigma} \ddot{\sigma} \ddot{\sigma} \ddot{\sigma} \ddot{\sigma} \ddot{\sigma} \ddot{\sigma}$

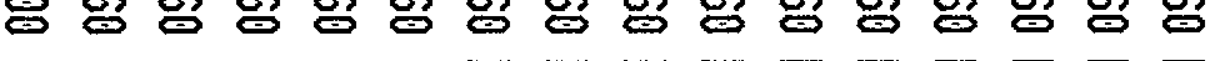

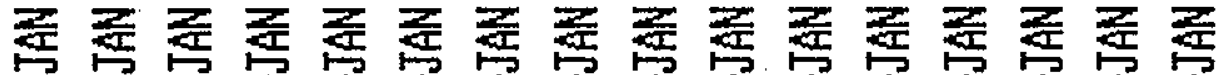

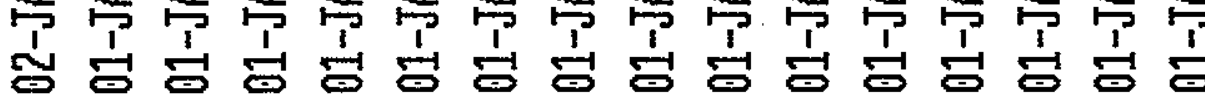

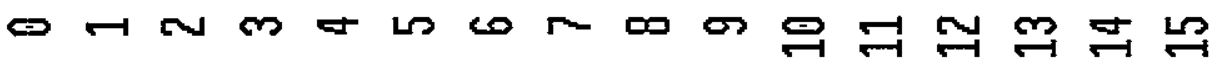




$\begin{array}{ll}1 & \text { A244 } \\ 2 & \text { HVC244 } \\ 3 & \text { WASTE } \\ 4 & \text { A3SE } \\ 5 & \text { FEED } \\ 6 & \text { CA1 } \\ 7 & \text { PB1 } \\ 9 & \text { PE2 } \\ 9 & \text { EA1 } \\ 10 & \text { EC1 } \\ 11 & \text { RHATER } \\ 12 & \text { URH } \\ 13 & \text { VVENT } \\ 14 & \text { PC } \\ 15 & \text { IX } \\ 16 & \text { SC } \\ 17 & \text { EASINS } \\ 19 & \text { UTIL } \\ 19 & \text { ROOMS } \\ 20 & \text { AMU } \\ 21 & \text { LERF }\end{array}$

1 ANFARM ANHVC

ANVLV ANETI

2 APFARM APHVC APVLV AP271 AP102

3 AHFARM AWHVC AWVLV AWR? 1

4 XYZFRM AFRM AYFRM

AY-AZFRM

5 BLDNG

25 BLANKO

5 BLANKI
5HORTD 204 FALMON 207 ACK SHORTO 204 FALMON 207 ACK SHORTG 204 FALMON 207 ACK SHORTO 204 FALMON 207 ACK PRCESS 354 FALMON 357 ACK PRCESS 964 FALMON 367 ACK PRCESS 354 FALMON 367 ACK PRCESS 364 FALMON 367 ACK PRCESS 364 FALMON 367 ACK PRCESS 354 FALMON 367 ACK PRCESS 354 FALMON 357 ACK PRCESS 354 FALMON 357 ACK PRCESS 354 FALMON 367 ACK PRCESS 364 FALMON 367 ACK PRCESS 364 FALMON 367 ACK PRCESS 364 FALMON 367 ACK PRCESS 354 FALMON 367 ACK PRCESS 354 FALMON 357 ACK PRCESS 364 FALMON 367 ACK PRCESS 354 FALMON BE7 ACK PRCESS 364 FALMON 367 ACK

294BATCH PEM STARTINE 244-A EXH STK FLO LO

WSTXFR PCM STARTING

35OEATCH PEM STARTINE

\section{PROGRAM \\ DIAGNOSTIC}

(13B)

STEAM CNDSE DIVERTED TO 10RAN

BASINBAT . SER START

START AMUBATCH PGM

TNKFRM 492

TNKFRM 495

TNKFRM 449

TNKFRM 451

TNKFRM 492

TNKFRM 495

TNKFRM 449

TNKFRM 459

TNKFRM 452

TNKFRM 492 447

TNKFRM 495

TNKFRM 449

TNKFRM

TNKFRM 497

TNKFRM 495 448

TNKFRM

450

TNKFRM 492 FALMON 495 FLGACK

BLANKK 158 FSLD

BLANKK 158
RNK

ACK 


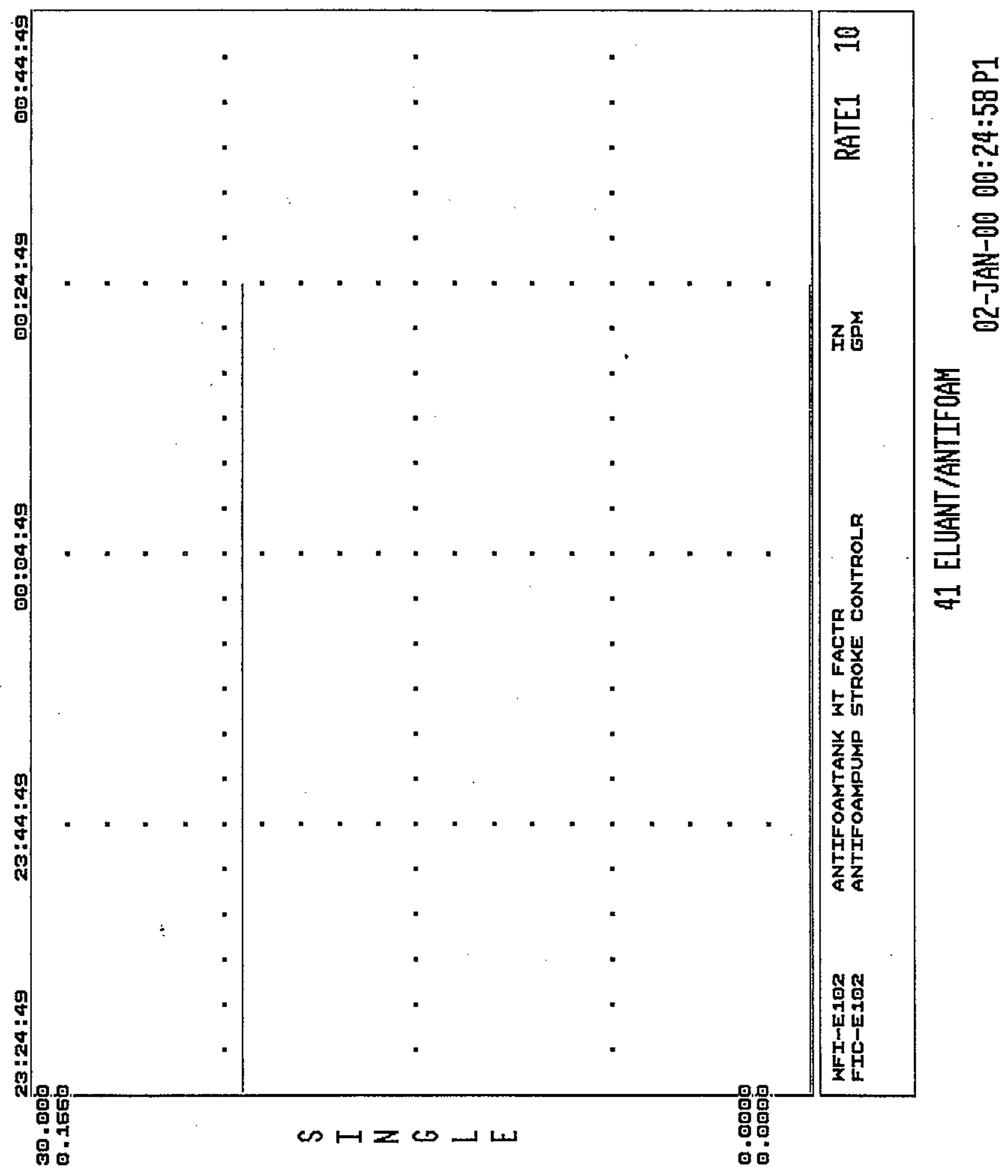


22:26:31 01-JAN-00 22:56:31

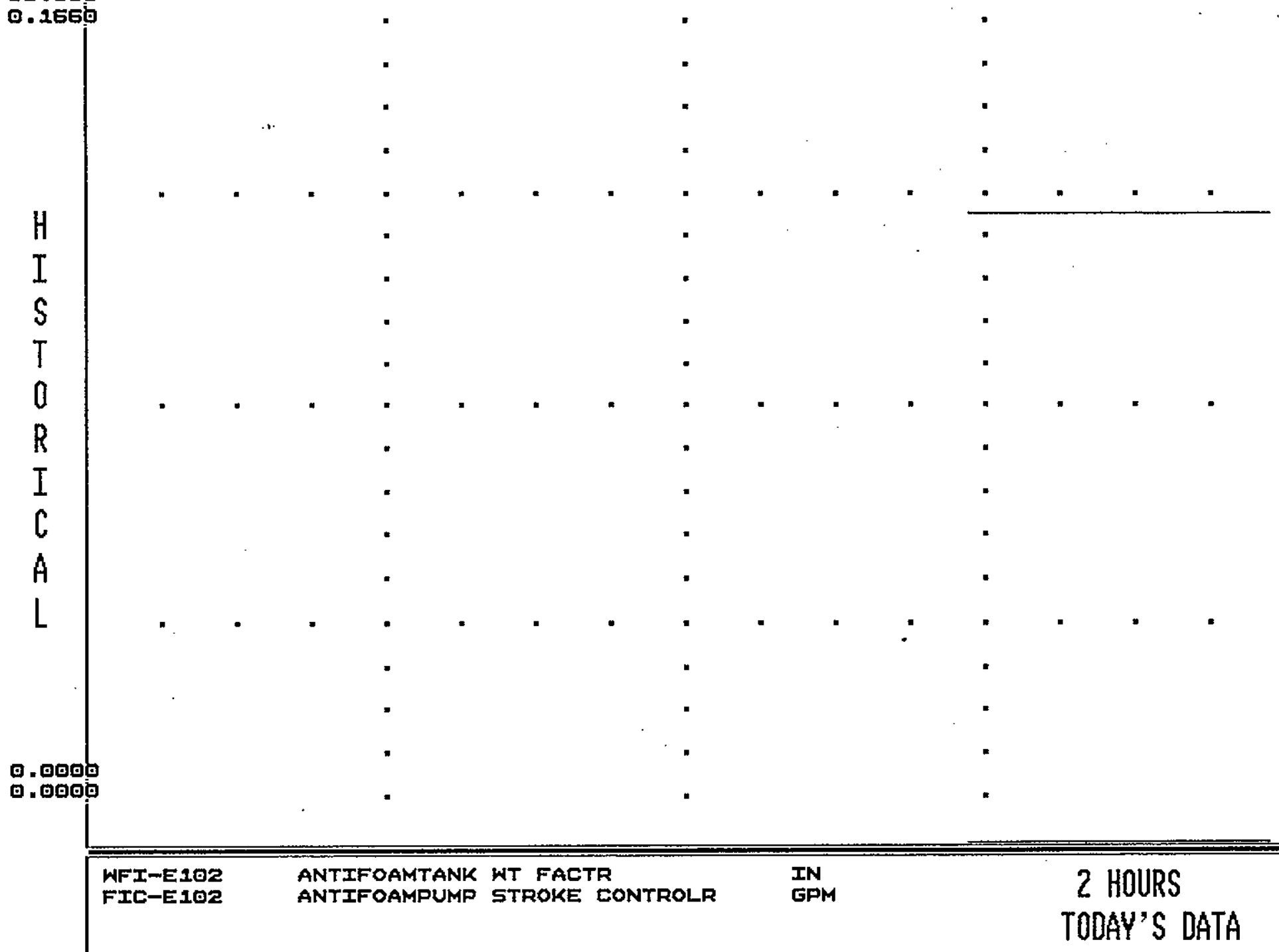

E EXPAND $c=$ CONTRACT

48 ELUANT/ANTIFOAM O2-JAN-00 00:27:27P1 


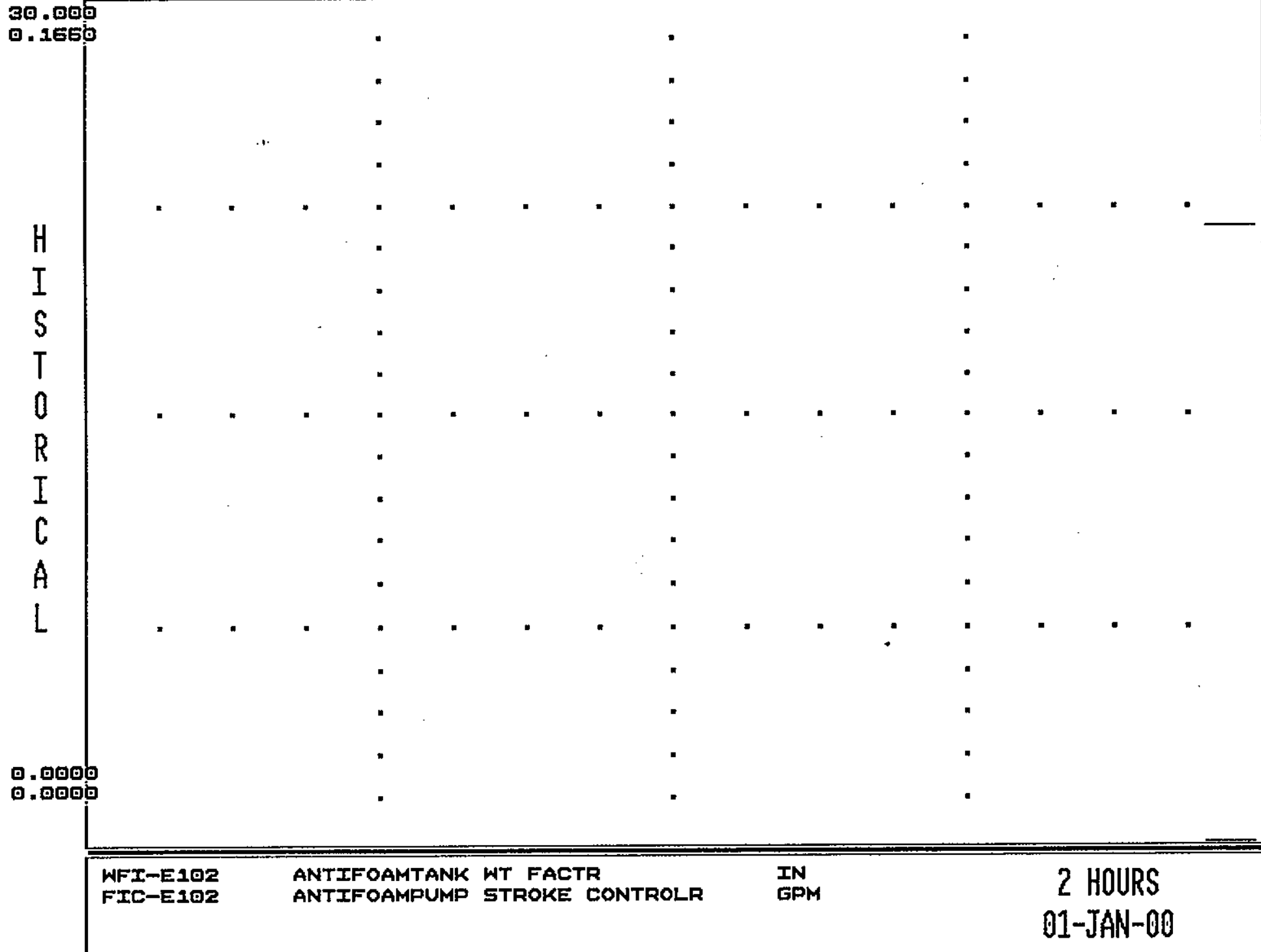

E E EXPAND C a CONTRACT

48 ELUANT/ANTIFOAM O2-JAN-60 01:04:54 P1 


\section{CDCH U9.0-2 NETWORK Ø STATUS}

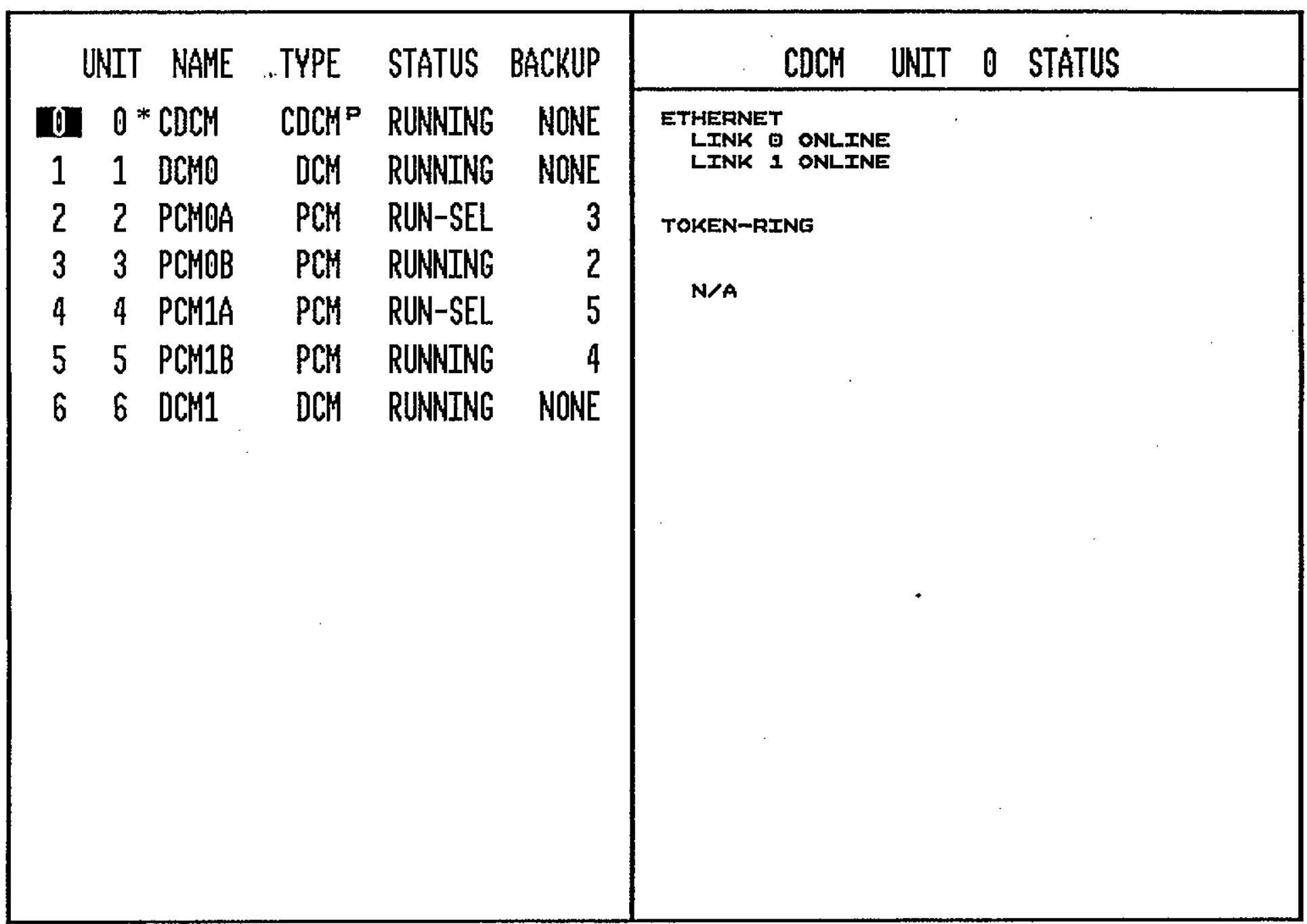

PAGE 0

28-FEB-00 23:58:49 


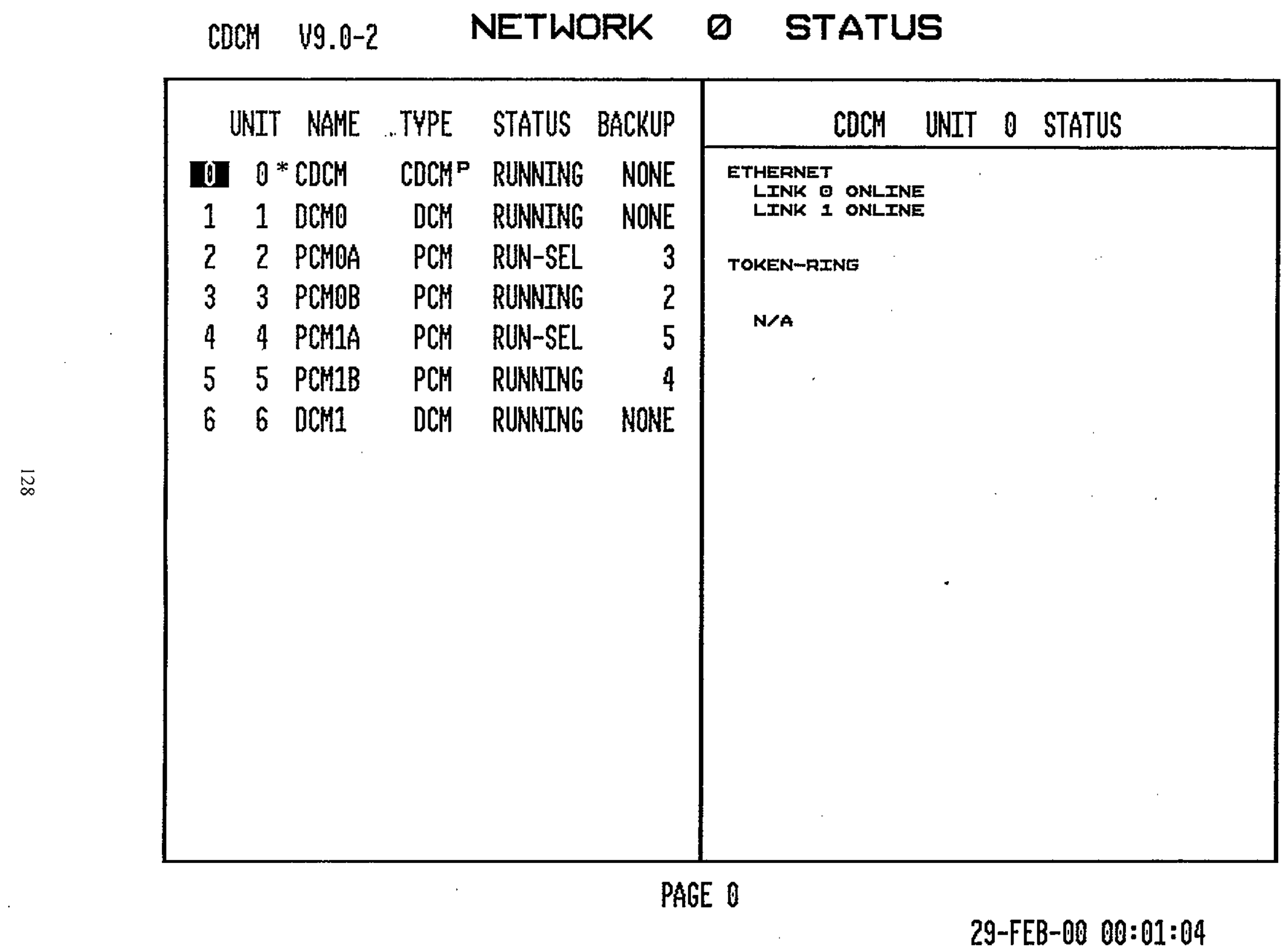

29-FEB-00 00:01:04 
HNF-2696 REV 0

ATTACHMENT 5

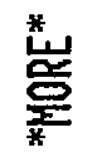

崖

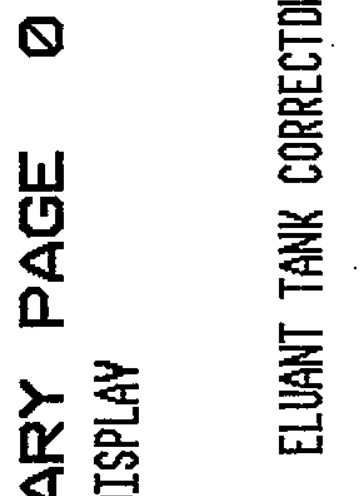

堇

보 이 의 워

$\underline{20}$

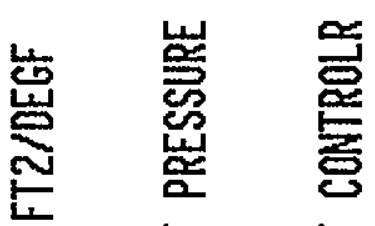

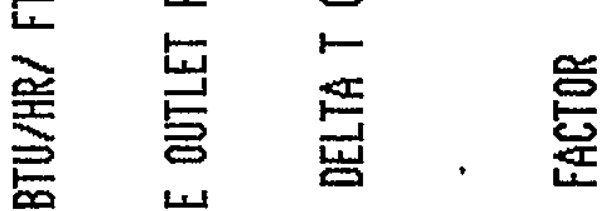

$\sum \underset{0}{0}$

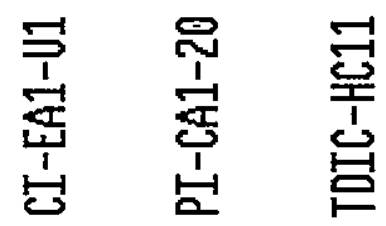

腒

$\sum_{1}^{0}$

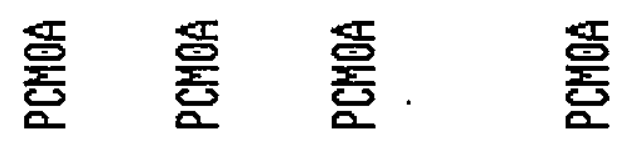

क

$\because$

I

要

بـ

لئيس

in

造

녿

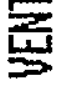

농

楸

도

焉

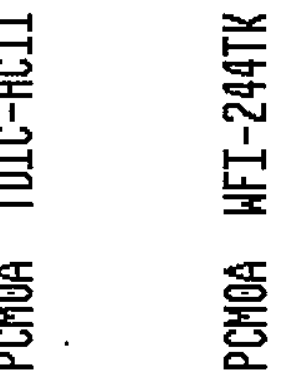

눈

की

品 品 哭

$\ddot{\sim} \quad \ddot{m}$

$\ddot{\theta} \quad \ddot{\theta}$

n

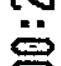

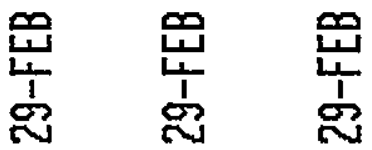

an

in

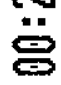

$\theta \rightarrow n$ m

$\infty$ の 마묨ㅁ 


\section{CRITICAL ALARM SUMMARY PAGE $\oslash$ *MORE* DYNAMIC DISPLAY}

8 29-FEB 00:54:30 PCMOA HFI-E101 ELLANT TANK CORRECTDHT FACTR HIHI

1 29-FEB 00:27:48 PCMOA CI-EA1-U1 HT XFER COEFF BTU/HR/ FT2/DEGF LOLO

2 29-FEB 00:27:29 PCMOA PI-CA1-20 CONDSATERECYCLE OUTLET PRESSURE LOLO

3 29-FEB 00:27:28 PCHOA TDIC-HC11 VES YENTHEATER DELTA T CONTROLR LOLO

4 29-FEB 00:27:27 PCMOA WFI-244TK TK-244-AWEIGHT FACTOR LOLO

5 29-FEB 00:27:26 PCMOA LI-CA1-3 EUAP CA1-3 CORRECTDHT FACTR LO

6 29-FEB 00:27:26 PCHOA FI-AS-5 UESSEL UENT EXHAUST FLOW LOLO

7 29-FEB 00:27:26

PCMOA FI-CA1-2 PB-2 SEAL HATER FLOW LOLO

8 29-FEB 00:27:26 PCMOA LIC-CA1-2 EVAP CA1-2 LEVEL CONTROLR LOLO

9 29-FEB 00:27:25 PCHOA FI-CA1-1 PB-1 SEAL HATER FLOW LOLO

10 29-FEB 00:27:25 PCMOA LIC-CA1-1 EUAP CA1-1 LEUEL CONTROLR LOLO

11 29-FEB 00:27:25 PCMOA WFIC-C100 TK-C-100HT FACTOR L L

12. 29-FEB 00:27:25 PCHOA HFI-SUMP1 PUMP RM SUMP CORRECTDHT FACTR LOLO

13 29-FEB 00:27:24 PCHOA PI-CAI-10 PB-2 SEAL HATER PRESSURE LOLO

14 29-FEB 00:27:24 PCMOA PI-CA1-9 PB-1 SEAL HATER PRESSURE LOLO

15 29-FEB 60:18:21 PCH1A TI-K1-2 BUILDTNGEXHAUST STACK TEMP IBAD

29-FEB-OB 01:01:49 P1 
SYSTEM ALARM REVIEW PAGE $\oslash$

29-FEB-00 00:46:37 PCMOA SEQUENCE PROGRAM NOT LOADED IN BOTH PCMS: FHOLD

29-FEB-0O 00:43:30 PCMOA SEQUENCE PROGRAM NOT LOADED IN BOTH PCHS: SCBATCH 29-FEB-00 00:43:30 PCHOA SEQUENCE PROGRAH NOT LOADED IN BOTH PCHS: RHBATCH 29-FEB-60 60:43:30̈ PCHOA SEOUENCE PROGRAM NOT LOADED IN BOTH PCHS: AMUBATCH 29-FEB-00 00:43:29 PCMOA SEOUENCE PROGRAM NOT LOADED IN BOTH PCMS: LERFBATCH 29-FEB-60 00:43:29 PCHOA 29-FEB-OO 00:43:29 PCMOA 29-FEB-00 00:43:29 PCMOA 29-FEB-00 00:43:28 PCHOA 29-FEB-00 00:43:28 PCMOA 29-FEB-00 00:43:28 PCHOA 29-FEB-00 00:43:27 PCHOA 29-FEB-00 00:43:27 PCHOA 29-FEB-0B 00:43:27 PCHOA 29-FEB-00 00:43:27 PCHOA 29-FEB-OO 00:43:26 PCMOA 29-FEB-00 00:43:26 PCHOA 29-FEB-OO 00:43:26 PCHOA 29-FEB-00 00:43:26 PCMOA 29-FEB-60 00:43:25 PCMOA 29-FEB-00 00:43:25 PCMOA 29-FEB-OO 00:43:25 PCMOA 29-FEB-00 00:43:25 PCMOA 29-FEB-OO 00:43:25 PCMOA SEQUENCE PROGRAM NOT LOADED IN BOTH PCMS: IXBATCH SEOUENCE PROGRAM NOT LOADED IN BOTH PCHS: PCBATCH SEQUENCE PROGRAM NOT LOADED IN BOTH PCHS: URHBATCH SEQUENCE PROGRAM NOT LOADED IN BOTH PCHS: VENTBATCH SEQUENCE PROGRAM NOT LOADED IN BOTH PCHS: FEEDBATCH SEOUENCE PROGRAM NOT LOADED IN BOTH PCMS: CA1BATCH SEQUENCE PROGRAM NOT LOADED IN BOTH PCHS: EA1BATCH SEOUENCE PROGRAM NOT LOADED IN BOTH PCMS: EC1BATCH SEOUENCE PROGRAM NOT LOADED IN BOTH PCMS: PBZBATCH SEQUENCE PROGRAM NOT LOADED IN BOTH PCMS: PB1BATCH SEOUENCE PROGRAM NOT LOADED IN BOTH PCHS: BASINBAT SEQUENCE PROGRAM NOT LOADED IN BOTH PCMS: UTILBATCH SEOUENCE PROGRAM NOT LOADED IN BOTH PCHS: WSTXFR SEOUENCE PROGRAM NOT LOADED IN BOTH PCMS: 35OBATCH SEOUENCE PROGRAM NOT LOADED IN BOTH PCMS: 244HUAC SEOUENCE PROGRAM NOT LOADED IN BOTH PCHS: 244BATCH SEOUENCE PROGRAM NOT LOADED IN BOTH PCHS: PGMOA SEQUENCE PROGRAM NOT LOADED IN BOTH PCHS: TAG SEOUENCE PROGRAM NOT LOADED IN BOTH PCHS: TIMEINHA 29-FEB-00 01:05:04 P1 


$\begin{array}{ll}1 & \text { AZ44 } \\ 2 & \text { HVC244 } \\ 3 & \text { WASTE } \\ 4 & \text { A3SO } \\ 5 & \text { FEED } \\ 6 & \text { CA1 } \\ 7 & \text { PB1 } \\ 8 & \text { PBI } \\ 9 & \text { EA1 } \\ 10 & \text { EC1 } \\ 11 & \text { RWATER } \\ 12 & \text { URW } \\ 13 & \text { VVENT } \\ 14 & \text { PC } \\ 15 & \text { IX } \\ 16 & \text { SC } \\ 17 & \text { BASINS } \\ 18 & \text { UTIL } \\ 19 & \text { ROOMS } \\ 20 & \text { AMU } \\ 21 & \text { LERF }\end{array}$

SHORTG 204 FALMON 207 ACK SHORTO 204 FALMON 207 ACK SHORTO 204 FALMON 207 ACK SHORTO 204 FALMON 207 ACK PRCESS 364 FALMON 367 ACK PRCESS 354 FALMON 367 ACK PRCESS 364 FALMON 367 ACK PRCESS 364 FALMON 367 ACK PRCESS 354 FALMON 367 ACK PRCESS 364 FALMON 367 ACK PRCESS 364 FALMON 357 ACK PRCESS 364 FALMON 367 ACK PRCESS 3E4 FALMON 3ET ACK PRCESS 364 FALMON 367 ACK PRCESS 364 FALMON 367 ACK PRCESS 364 FALMON 367 ACK PRCESS 364 FALMON 367 ACK PRCESS 364 FALMON 367 ACK PRCESS 354 FALMON 367 ACK PRCESS 354 FALMON 367 ACK PRCESS 3ES FALMON 367 ACK

24ABATCH PEM STARTINE 244-A EXH STK FLO LO

MSTXFR PGM STARTINE

GEDEATCH PGM STARTINE

\section{PROGRAM \\ DIAGNOSTIC}

(133)

STEAM CNDSE DIVERTEO TO IOZAN

BASINBAT . SER START

TK-E-104 WT FACTOR LO-LO

ANHVC TNKFRM 495 450

ANYLV TNKFRM 449

$\begin{array}{lll}\text { AN271 } & \text { TNKFRM } & 451\end{array}$

2 APFARM TNKFRM 492 447

APHVE TNKFRM 495 450

APVLV TNKFRM 449

AP271 TNKFRM 451

APLOZ TNKFRM 452

3 AWFARM TNKFRM 492 447

AWHVC TNKFRM 495 450

AWVLV TNKFRM 449

AW271 TNKFRM 451

4 XYZFRM TNKFRM 492 447

AFRM TNKFRM $495 \quad 448$

AYFRM TNKFRM 449

AY-AZFRM TNKFRM 45

5 BLDNE TNKFRM 492 FALMON 495 FLEACK

25 ELANKO BLANKK 158 FSLO

5 BLANK1 BLANKK 168

RNK

ACK 
INHIBITED ALARM SUMMARY PAGE $\square$ *MORE

\begin{tabular}{|c|c|c|c|c|}
\hline 1 & PI-CA1-11 & EUAP WACUUH O-30 IN HG & & \\
\hline 2 & PIC-CA1-7 & EUAP ABSOLUTE & $29-F E B-00$ & $01: 19: 18$ \\
\hline 3 & LIC-CA1-1 & EUAP CA1-1 LEUEL CONTROLR & & \\
\hline 4 & LIC-CA1-2 & EUAP CA1-2 LEUEL CONTROLR & & \\
\hline 5 & LI-CA1-3 & EUAP CA1-3 CORRECTD & & \\
\hline 6 & FIC-CA1-6 & UPPER DE-ENTRN & & \\
\hline 7 & FI-CA1-7 & PB-1 PUAP RECIRC FLOH & & \\
\hline 8 & UI-PB1-2A & PB-1 PUMP VERTICAL & & \\
\hline 9 & UI-PB1-1A & PB-1 PUMP HORIZONT & & \\
\hline 10 & UI-PB1-3A & PB-1 PUMP LATERAL & & \\
\hline 11 & FI-CA1-1 & PB-1 SEAL HATER FLOH & & \\
\hline 12 & PI-CA1-9 & PB-1 SEAL HATER PRESSURE & & \\
\hline 13 & FI-CA1-3 & RECIRC BYPASS SLURRY FLOW & & \\
\hline 14 & PI-CA1-20 & CONDSATE & & \\
\hline 15 & SIC-PB2-1 & SLURRY PUMAP SPEED CONTROLR & & \\
\hline 16 & UI-PB2-1A & PB-2 PUMAP LATERAL & - & \\
\hline 17 & FI-CA1-2 & PB-2 SEAL HATER FLOH & & \\
\hline 18 & PI-CA1-10 & PB-2 SEAL HATER PRESSURE & & \\
\hline 19 & FIC-CA1-4 & EUAP SLURRY FLOH & & \\
\hline 20 & PI-EA1-14 & 10 PSI STEAM TO DESUP & & INHAO \\
\hline & & & $29-\mathrm{FE}$ & $: 21: 13 P 1$ \\
\hline
\end{tabular}




\begin{tabular}{|c|c|c|c|c|c|c|c|c|}
\hline & & & AUDA & ARHO & ALM-ON & & & \\
\hline & NAME & STATUS & ERRL & ERRN & NAME & STATUS & ERRL & ERRN \\
\hline & 244BATCH & RUNNING & $\theta$ & 0 & PCBATCH & RUNBING & 0 & 0 \\
\hline & 244HUAC & RUNAING & 0 & 0 & IXBATCH & RUNNING & 0 & 0 \\
\hline & HSTYFR & RUNNING & 0 & 0 & SCBATCH & RUNNING & 0 & 0 \\
\hline & 350ВАТСН & WAIT & 0 & 0 & BASINBAT & RUNNING & 0 & 0 \\
\hline & FEEDBATCH & RUNNING & 0 & 0 & UTILBATCH & RUNNING & 0 & 0 \\
\hline & CA1BATCH & HAIT & 0 & 0 & AMUBATCH & RUNNING & 0 & 0 \\
\hline & PB1BATCH & RIINNING & 0 & 0 & LERFBATCH & RUNNING & 0 & $\theta$ \\
\hline & PBZBATCH & RUNANING & 0 & 0 & WHITE1 & & 0 & 0 \\
\hline & EA1BATCH & RUNNING & 0 & 0 & & & & \\
\hline & EC1BATCH & RUNBING & 0 & 0 & & & & \\
\hline & PHBATCH & RUNNTING & 0 & 0 & & & & \\
\hline & URHBATCH & RUNNING & 0 & 0 & & & & \\
\hline & YENTBATCH & RUNNING & 0 & 0 & & & & \\
\hline & PGHOA & & 0 & 0 & & & & \\
\hline & ON $00: 00:$ & & & 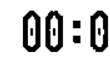 & .00 & & & \\
\hline
\end{tabular}

[4. DIAENOSTIC

PROGRAM STATUS

RNK

PEMSTAT

29-FEB-OO 01:32:20 P1 


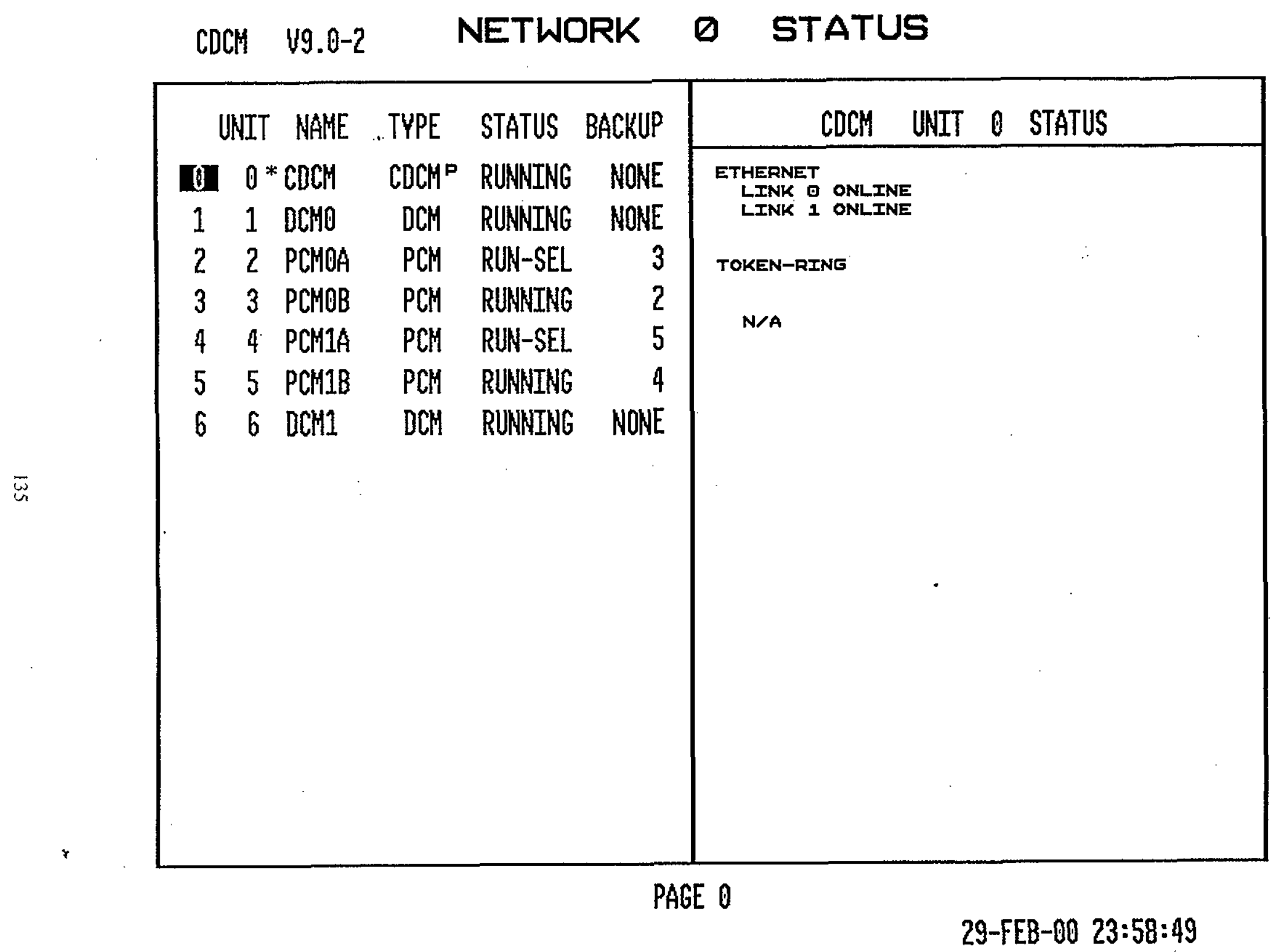




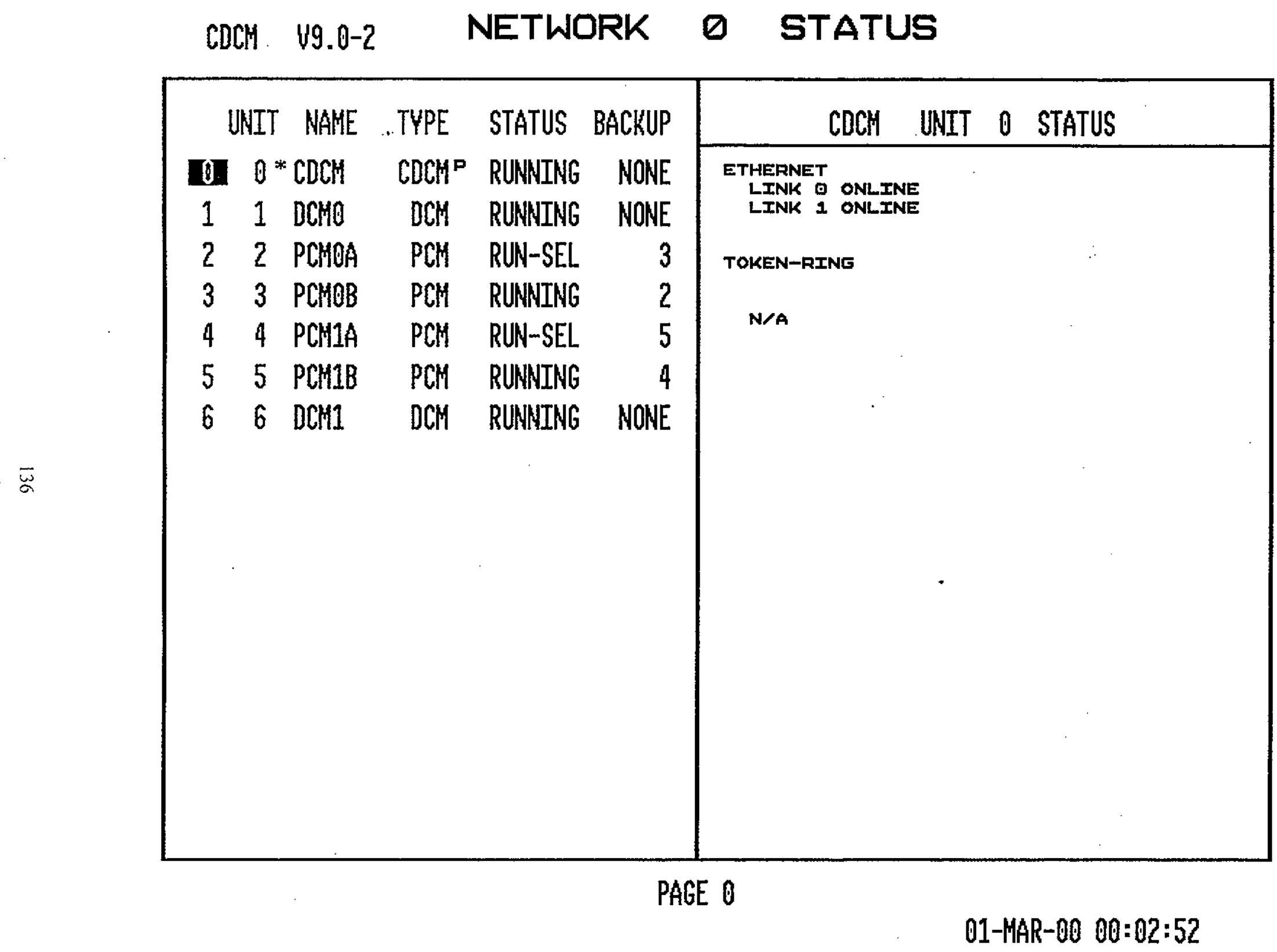




$\begin{array}{ll}1 & \text { A244 } \\ 2 & \text { HVC244 } \\ 3 & \text { NASTE } \\ 4 & \text { A3SG } \\ 5 & \text { FEED } \\ 6 & \text { CA1 } \\ 7 & \text { PBI } \\ 8 & \text { PB2 } \\ 9 & \text { EA1 } \\ 10 & \text { EC1 } \\ 11 & \text { RHATER } \\ 12 & \text { URW } \\ 13 & \text { VVENT } \\ 14 & \text { PC } \\ 15 & \text { IX } \\ 16 & \text { SC } \\ 17 & \text { BASINS } \\ 18 & \text { UTIL } \\ 19 & \text { ROOMS } \\ 20 & \text { AMU } \\ 21 & \text { LERF }\end{array}$

1 ANFARM ANHVE ANVLV AN271

2 APFARM APHVC APVLV AP271 AP 102

3 AWFARM ANHYC ANVLV Awe71

4 XYZFRM AFRM AYFRM AY-AZFRM 5 BLDNE

2S BLANKE

5 ELANK1
SHOR:G 204 FALMON 207 ACK SHORTa 204 FALMON 207 ACK SHORTO 204 FALMON 207 ACK 5HORTO 204 FALMON 207 ACK PREESS 364 FALMON 367 ACK PRCESS 354 FALMON 367 ACK PRCEES 364 FALMON 367 ACK PRCESS 354 FALMON 367 ACK PRCESS 354 FALMON 367 ACK PRCESS 364 FALMON 367 ACK PRCESS 364 FALMON 367 ACK PRCESS 364 FALMON 967 ACK PRCESS 364 FALMON 367 ACK PRCESS 364 FALMON 367 ACK PRCESS 364 FALMON 367 ACK PRCESS 964 FALMON 367 ACK PRCESS 364 FALMON 367 ACK PRCESS 364 FALMON 367 ACK PRCESS 364 FALMON 3ET ACK PRCE55 354 FALMON $3 E 7$ ACK PRCESS 364 FALMON 367 ACK

244BATCH PEM STARTING 244-A EXH STK FLO LO

MSTXFR PGM STARTINC

GSOEATCH PEM STARTINC

\section{PROGRAM \\ DIAGNOSTIC}

(133)

STEAM CNDSB DIVERTEO TO 102AN

EASINBAT , SER START

TK-E-104 WT FACTOR LO-LO

\begin{tabular}{|c|c|c|c|}
\hline & FHO & LLD & \\
\hline & & 0 & \\
\hline & ON & . $00: 0$ & :00:20 \\
\hline TIME & $\begin{array}{c}\text { D } \\
\text { HR }\end{array}$ & $\begin{array}{l}11 \\
M N\end{array}$ & $\begin{array}{l}16 \\
\text { SEC }\end{array}$ \\
\hline ATE & $\stackrel{1}{D D}$ & MMM & $Y_{Y Y^{\circ}}$ \\
\hline
\end{tabular}

RNK

ACK 


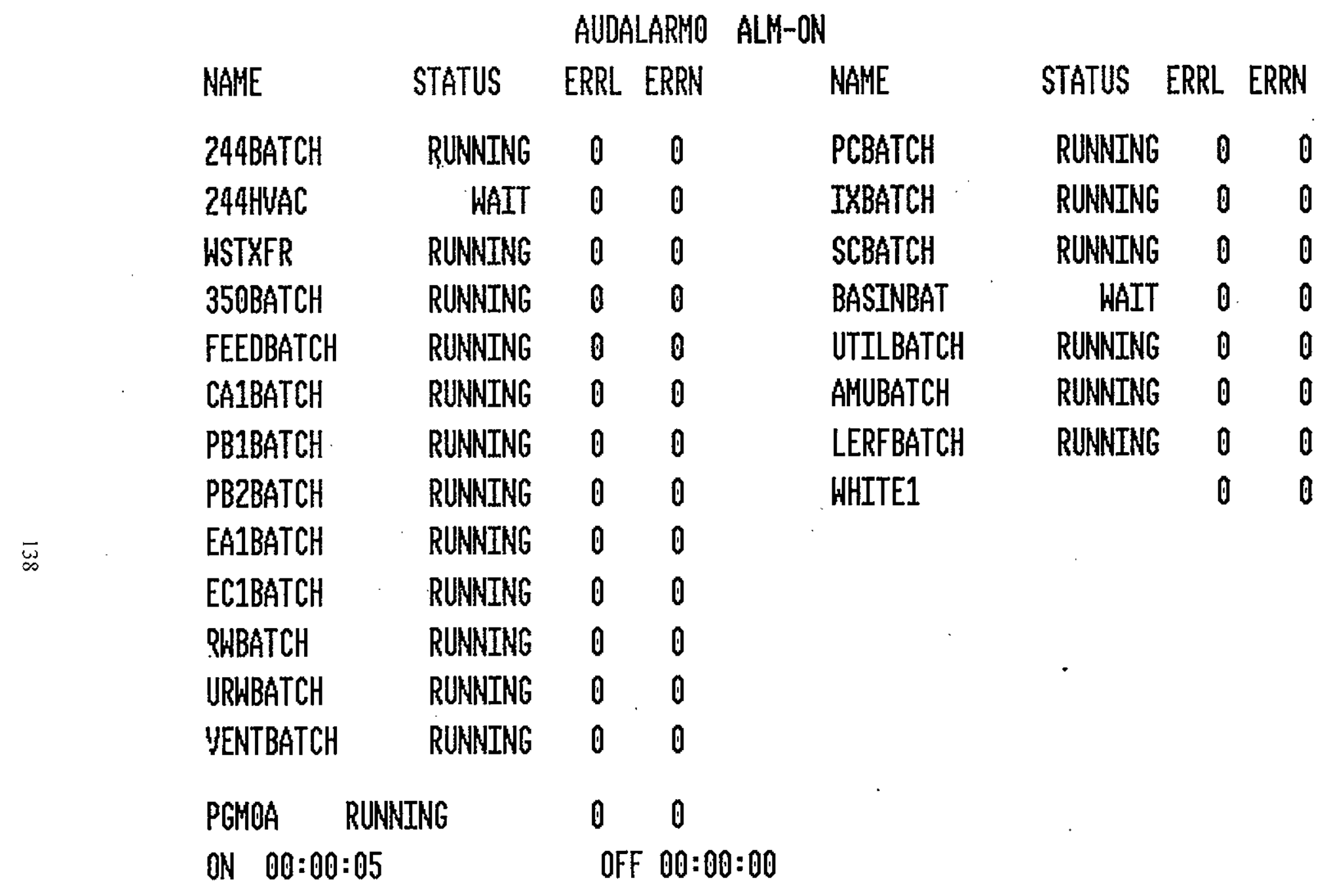

(4) DIAGNOSTIE

PROGRAM STATUS

RNK

PEMSTAT

(043)

01-MAR-00 00:26:58 


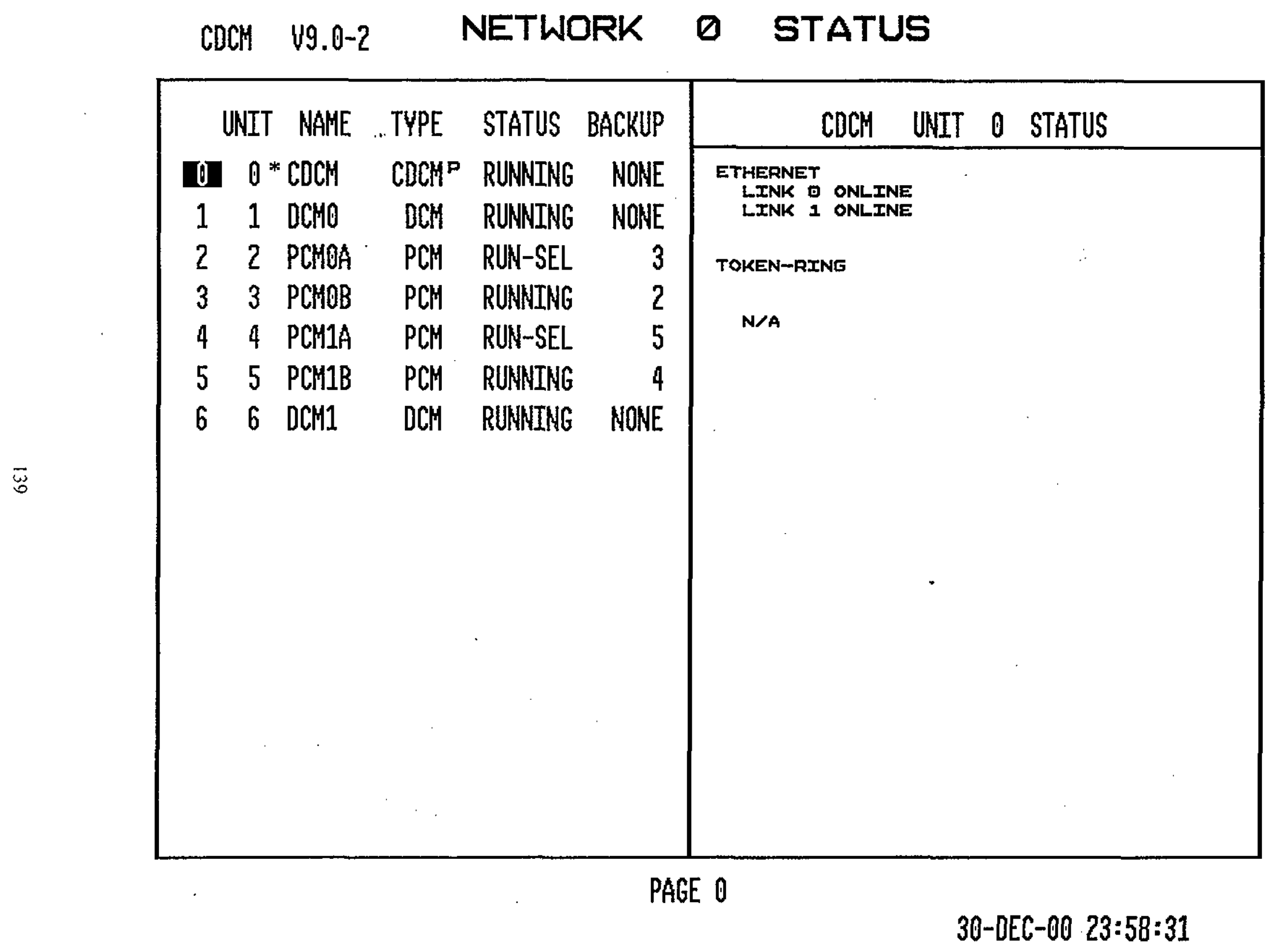




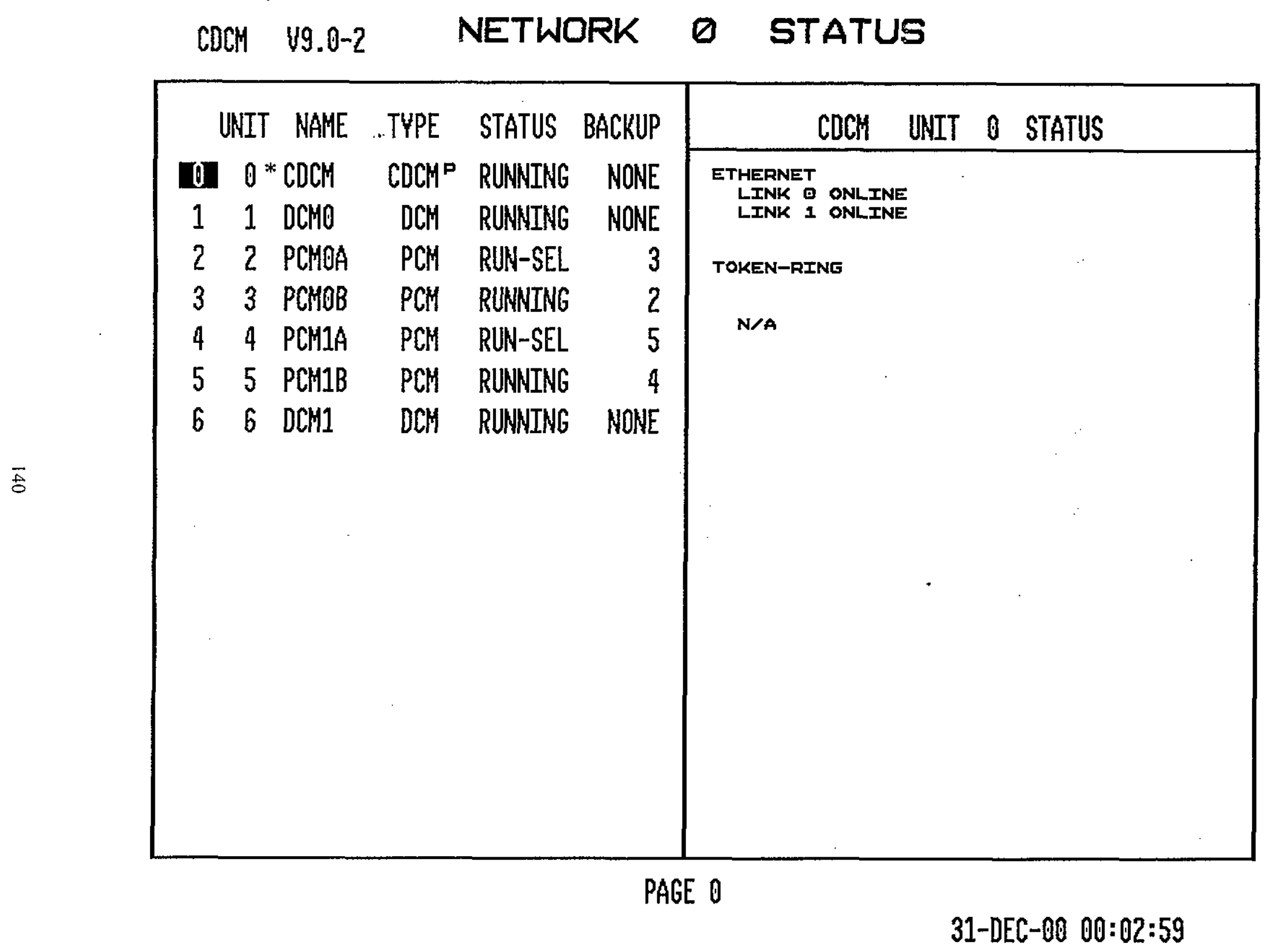


SYSTEM ALARM REVIEW PAGE $\square$ 31-DEC-00 00:06:41 CDCH PCHOA LINK STATUS CHANGE: ETHERNET_1 TO ONLINE 31-DEC-00 00:06:41 CDCH 31-DEC-OO 00:06:41 CDCH 31-DEC-60 00:06:36 CDCH 31-DEC-00 00:06:34 CDCH PCMOA LINK STATUS CHANGE: ETHERNET_O TO ONLINE PCMOA STATUS CHANGE: OFFLINE $\rightarrow$ RUNNING PCMOA STATUS CHANGE: RUNNING $\rightarrow$ OFFLINE PCMOA LINK STATUS CHANGE: ETHERNET_O TO OFFLINE

3Q-DEC-00 23:55:52 CDCM 30-DEC-00 23:55:52 CDCH 30-DEC-DO 23:52:45 CDCH 30-DEC-OO 23:52:45 CDCH 30-DEC-OB 23:52:45 CDCH 30-DEC-BO 23:52:42 CDCH 30-DEC-00 23:52:40 CDCH 30-DEC-OB 23:52:40 CDCH 30-DEC-60 23:52:40 CDCH

30-DEC-BO 23:52:37 CDCM 30-DEC-OB 23:52:37 CDCH 30-DEC-OB 23:52:37 CDCH $30-D E C-00 \quad 23: 52: 37$ CDCH
DCH1 LINK STATUS CHANGE: ETHERNET_O TO ONLINE DCH1 STATUS CHANGE: OFFLINE $\rightarrow$ RUNNING DCHO LINK STATUS CHANGE: ETHERNET_1 TO ONLTNE DCMO LINK STATUS CHANGE: ETHERNET_O TO ONLTHE DCHO STATUS CHANGE: OFFLINE $\rightarrow$ RUNNING DCHO STATUS CHANGE: RUNNING $\rightarrow$ OFFLINE DCMO LINK STATUS CHANGE: ETHERNET_1 TO ONLINE DCMO LINK STATUS CHANGE: ETHERNET_O TO ONLINE DCMO STATUS CHANGE: OFFLINE $\rightarrow$ RUNNING

DCMO STATUS CHANGE: RUNNING $\rightarrow$ OFFLINE DCHO LINK STATUS CHANGE: ETHERNET_1 TO ONLTNE DCMO LINK STATUS CHANGE: ETHERNET_O TO ONLINE DCMO STATUS CHANGE: OFFLINE $\rightarrow$ RUNNING 


$\begin{array}{ll}1 & \text { A244 } \\ 2 & \text { HVC244 } \\ 3 & \text { WASTE } \\ 4 & \text { ASSO } \\ 5 & \text { FEED } \\ 6 & \text { CA1 } \\ 7 & \text { PB1 } \\ 8 & \text { PB2 } \\ 9 & \text { EA1 } \\ 10 & \text { ECI } \\ 11 & \text { RWATER } \\ 12 & \text { URW } \\ 13 & \text { VVENT } \\ 14 & \text { PC } \\ 15 & \text { IX } \\ 16 & \text { SC } \\ 17 & \text { EASINS } \\ 18 & \text { UTIL } \\ 19 & \text { ROOMS } \\ 20 & \text { AMU } \\ 21 & \text { LERF } \\ \end{array}$

SHORTO 204 FALMON 207 ACK SHORTD 2D4 FALMON 207 ACK SHORTO 204 FALMON 207 ACK SHORTO 204 FALMON 207 ACK PRCESS 364 FALMON 367 ACK PRCESS 364 FALMON 367 ACK PRCESS 364 FALMON 367 ACK PRCESS 364 FALMON 367 ACK PRCESS 364 FALMON 367 ACK PRCESS 354 FALMON 367 ACK PRCESS 364 FALMON 367 ACK PRCESS 364 FALMON 367 ACK PRCESS 364 FALMON 367 ACK PRCESS 364 FALMON 367 ACK PRCESS 364 FALMON 367 ACK PRCESS 364 FALMON 367 ACK PRCESS 364 FALMON 367 ACK PRCESS 364 FALMON 367 ACK PRCESS 364 FALMON 367 ACK PRCESS 364 FALMON 367 ACK PRCESS 364 FALMON 367 ACK

244RATCH PGM STARTING 244-A EXH STK FLO LO WSTXFR PEM STARTING 35OEATCH PEM STARTINE

\section{PROGRAM DIAGNOSTIC}

(133)

STEAM CNDSE DIVERTED TO IORAW BASINEAT . SER START

TK-E-104 HT FACTOR LO-LO

$\begin{array}{llll}\text { TIME } & 0 & 17 & 20 \\ & \text { HR } & \text { MN } & \text { SEC } \\ \text { DATE } & 31 & 12 & 0 \\ & D D & M M M & Y Y\end{array}$

DAY OF WEEK D
RNK

ACK 


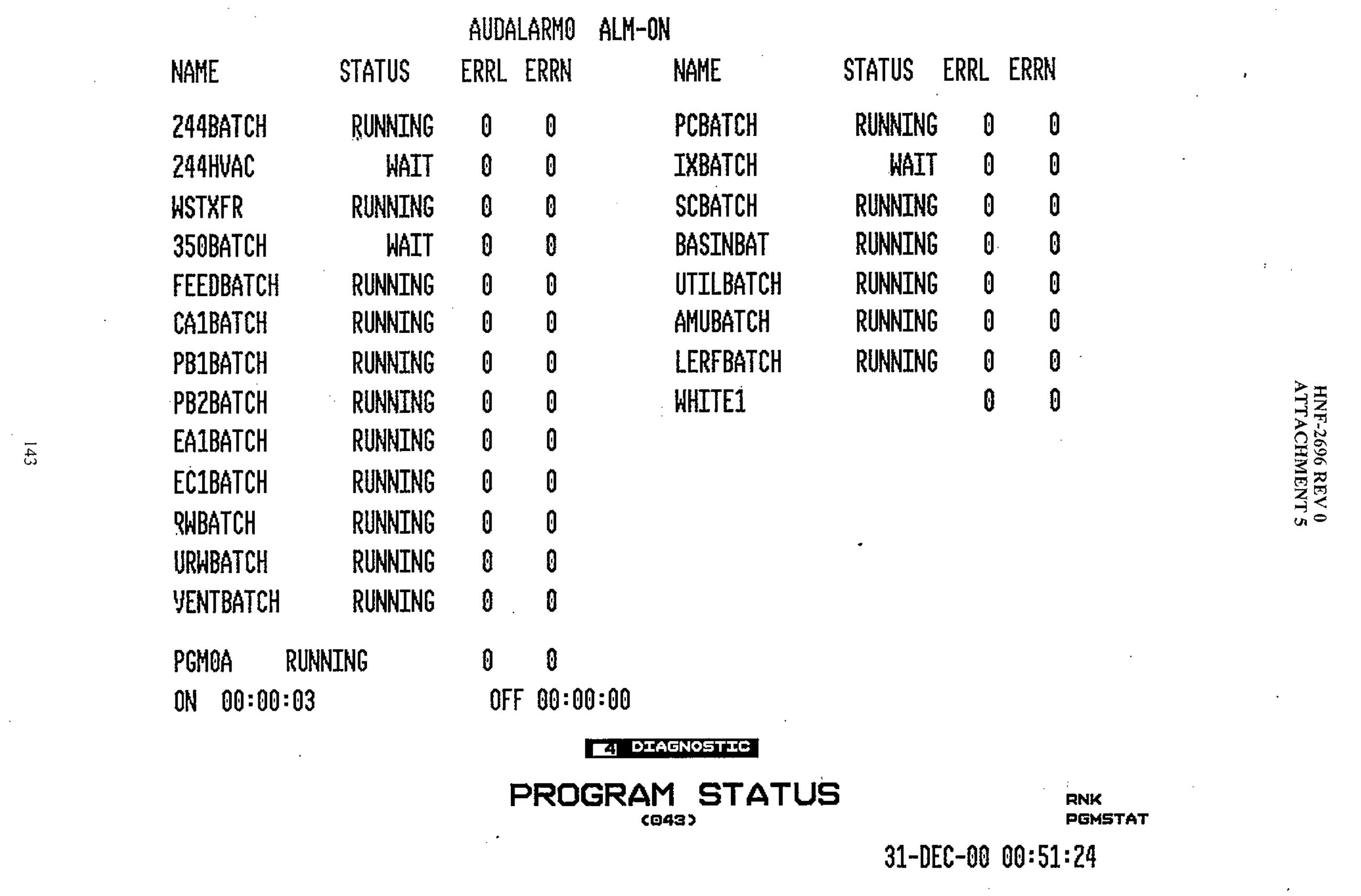




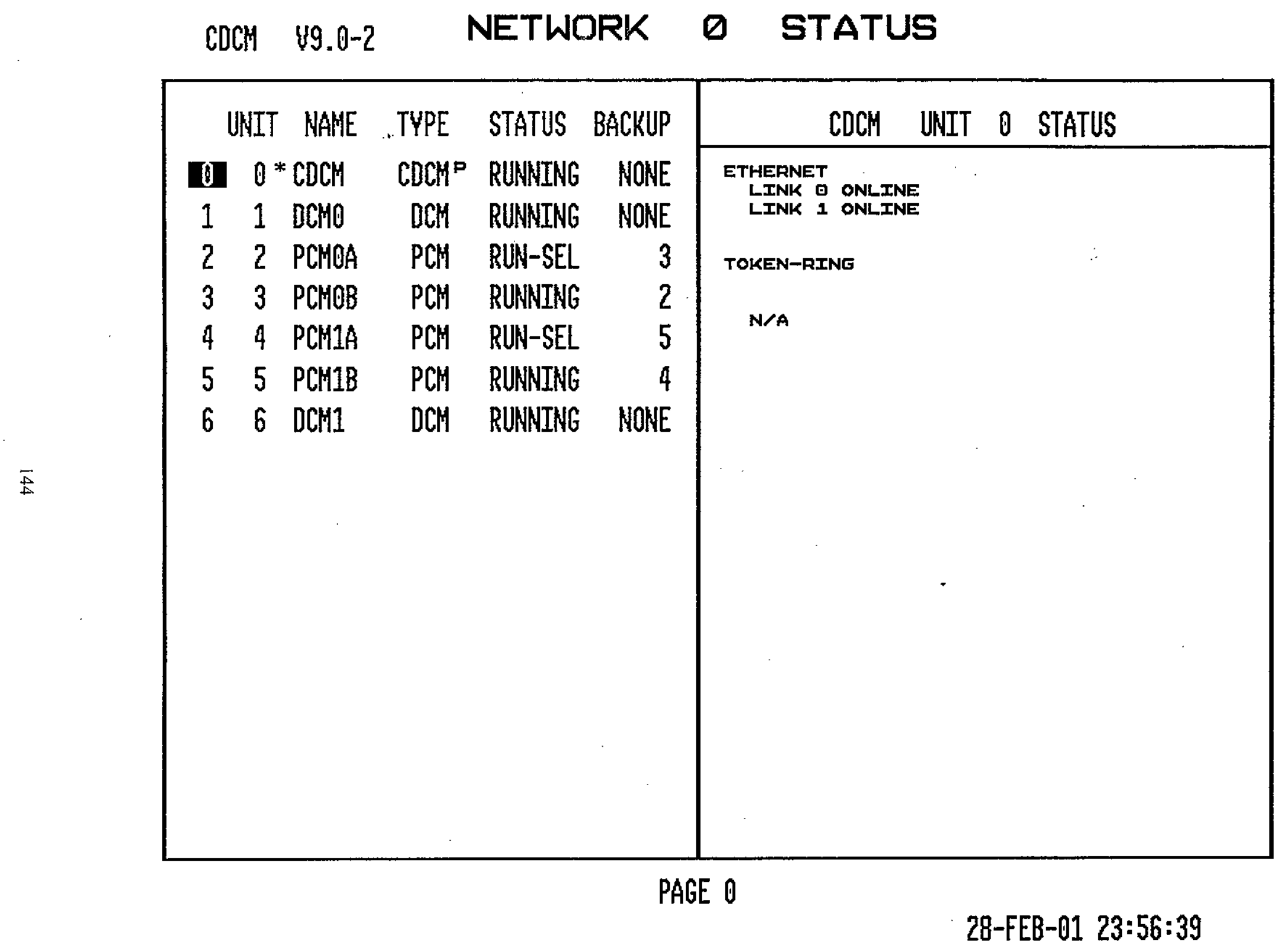




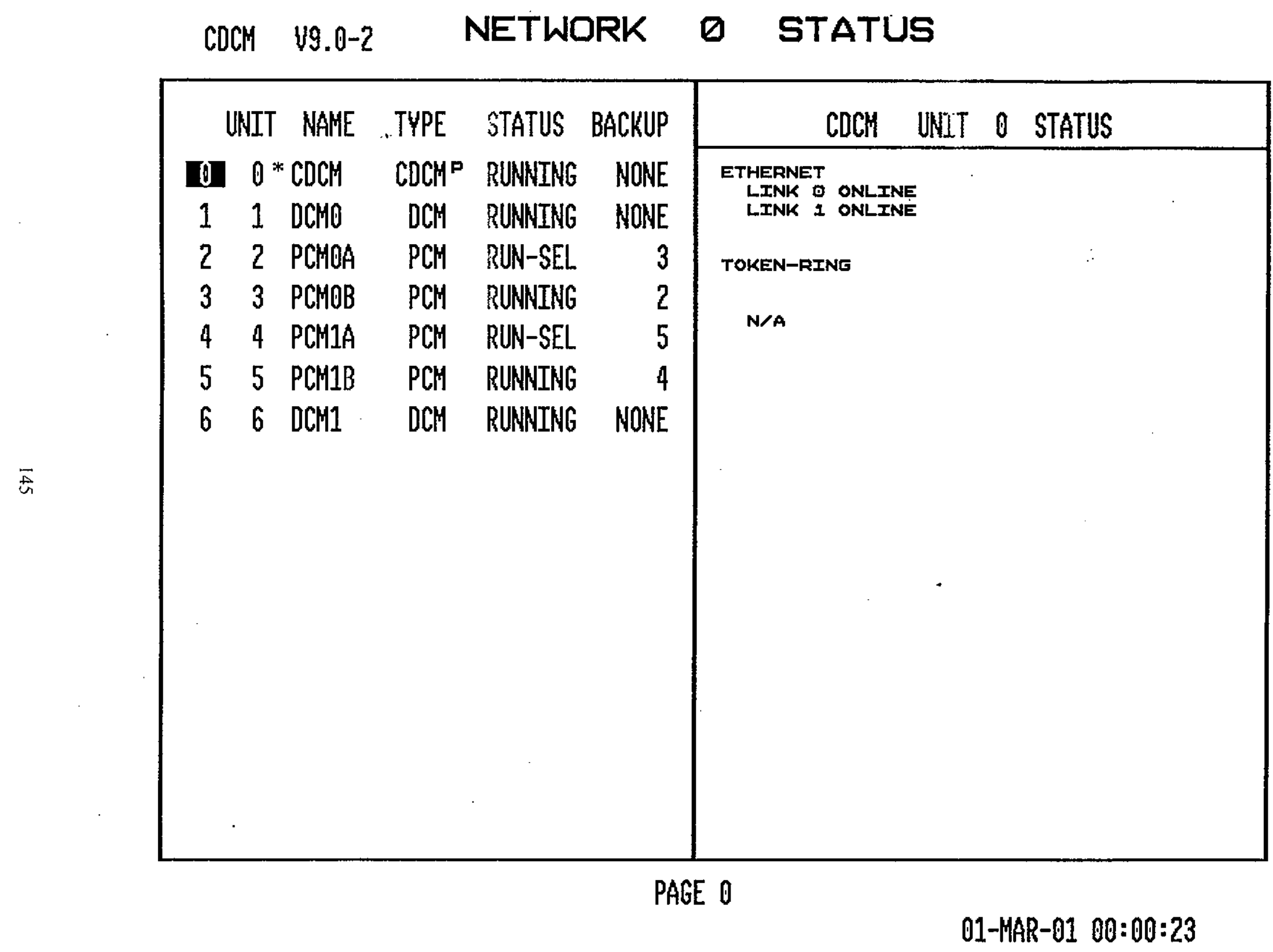




\section{ALARM SUMMARY PAGE $\oslash$}

DWNAMIC DISPLAY

O 01-MAR 00:19:13 PCMOA HFI-E104 DECON TANK CORRECTDAT FACTR HI

1 01- MAR 00:11:12 PCMOA WFI-E101 ELUANT TANK CORRECTDWT FACTR HI 


\section{CRITICAL ALARM SUMMARY PAGE $\square$}

DYNAMIC DISPLAY

O 01-MAR 00:19:13 PCMOA WFI-E104 DECON TANK CORRECTDHT FACTR HTHI

1 01-MAR 00:11:12 PCMOA WFI-E101 ELUANT TANK CORRECTOWT FACTR HIHI 
SYSTEM ALARM REVIEW PAGE $\square$ 01-MAR-01 00:12:58 CDCH PCMOA LINK STATUS CHANGE: ETHERNET_1 TO ONLINE 01-MAR-01 00:12:58 CDCH PCHOA LINK STATUS CHANGE: ETHERNET_O TO ONLINE 01-MAR-01 00:12:58 CDCM 01-MAR-01 00:12:54 CDCM 01-MAR-01 00:12:54 CDCM 01-MAR-01 00:12:54 CDCH 01-MAR-01 00:12:54 CDCM O1-MAR-01 00:12:51 CDCH 01-MAR-01 00:12:49 CDCM 01-MAR-01 00:07:57 CDCM 01-MAR-01 00:07:57 CDCH 01-MAR-01 00:07:57 CDCH 01-MAR-01 00:07:55 CDCM 01-MAR-01 00:07:52 CDCH

PCHOA STATUS CHANGE: OFFLINE $\rightarrow$ RLNNING DCHO LINK STATUS CHANGE: ETHERNET_O TO ONLINE DCHO STATUS CHANGE: STANDBY $\rightarrow$ RUNNING DCHO LINK STATUS CHANGE: ETHERNET_O TO OFFLINE DCHO STATUS CHANGE: RUNNING $\rightarrow$ STANDBY PCMOA STATUS CHANGE: RUNNING $\rightarrow$ OFFLINE PCMOA LINK STATUS CHANGE: ETHERNET_O TO OFFLINE PCMOA LINK STATUS CHANGE: ETHERNET_1 TO ONLINE PCHOA LINK STATUS CHANGE: ETHERNET_O TO ONLINE PCMOA STATUS CHANGE: OFFLINE $\rightarrow$ RUNNING PCHOA STATUS CHANGE: RUNNING $\rightarrow$ OFFLINE PCHOA LINK STATUS CHANGE: ETHERNET_O TO OFFLINE

28-FEB-01 23:55:24 CDCH 28-FEB-01 23:55:21 CDCH 28-FEB-01 23:55:21 CDCM 28-FEB-01 23:53:22 CDCM 28-FEB-O1 23:53:19 CDCH
DCM1 STATUS CHANGE: STANDBY $\rightarrow$ RUNNING DCHI LINK STATUS CHANGE: ETHERNET_O TO ONLINE DCM1 STATUS CHANGE: OFFLINE $\rightarrow$ STANDBY DCHO STATUS CHANGE: STANDBY $\rightarrow$ RUNNING DCHO STATUS CHANGE: RUNNING $\rightarrow$ STANDBY 


$\begin{array}{ll}1 & \text { A244 } \\ 2 & \text { HVC244 } \\ 3 & \text { WASTE } \\ 4 & \text { A350 } \\ 5 & \text { FEED } \\ 6 & \text { CA1 } \\ 7 & \text { PB1 } \\ 8 & \text { PB2 } \\ 9 & \text { EA1 } \\ 10 & \text { EC1 } \\ 11 & \text { RWATER } \\ 12 & \text { URW } \\ 13 & \text { VVENT } \\ 14 & \text { PC } \\ 15 & \text { IX } \\ 16 & \text { SC } \\ 17 & \text { BASINS } \\ 18 & \text { UTIL } \\ 19 & \text { ROOMS } \\ 20 & \text { AMU } \\ 21 & \text { LERF }\end{array}$

SHORTO 204 FALMON 207 ACK SHORTE 204 FALMON 207 ACK SHORTO 204 FALMON 207 ACK SHORTO 204 FALMON 207 ACK PRCESS $3 E 4$ FALMON 357 ACK PRCESS 364 FALMON 367 ACK PRCESS 364 FALMON 367 ACK PRCESS 364 FALMON 367 ACK PRCESS 364 FALMON 367 ACK PRCESS 364 FALMON 367 ACK PRCES5 364 FALMON 357 ACK PRCESS 364 FALMON 367 ACK PRCESS 364 FALMON 367 ACK PRCESS 364 FALMON 367 ACK PRCESS 354 FALMON 367 ACK PRCESS 364 FALMON 357 ACK PRCESS 364 FALMON 367 ACK PRCESS 364 FALMON 367 ACK PRCESS 364 FALMON 367 ACK PRCESS 364 FALMON 357 ACK PRCESS 364 FALMON 367 ACK

2A4BATCH PGM STARTINE 244-A EXH 5TK FLO LO

WSTXFR PGM STARTINE

35DBATCH DGM STARTING

\section{PROGRAM}

\section{DIAGNOSTIC}

(13es

STEAM CNDSE DIVERTED TO IMRAW

BASINEAT , SEG START

TK-E-104 WT FACTOR LO-LO

450

449

452

452

447

450

449

451

447

449

449

450

AY-AZFRM TNKFRM 450

5 BLDNG

25 BLANKO

TNKFRM 492 FALMON 495 FLGACK

BLANKK 1EB FSLO

BLANKK IEB

\author{
TIME \\ ON . Q四四:32 \\ FHOLD \\ ด 2612 \\ HR MN SEC \\ DATE ${ }_{\text {DD MMM }}{ }_{Y Y}^{1}$ \\ DAY OF WEEK 4
}

RNK

ACK 
INHIBITED ALARM SUMMARY PAGE $\oslash$ *MORE

1 PI-CA1-11 EUAP UACUUM O-30 IN HG

2 PIC-CA1-7 EUAP ABSOLUTE

01-MAR-01 00:27:08

3 LIC-CA1-1 EUAP CA1-1 LEUEL CONTROLR

4 LIC-CA1-2 EUAP CA1-2 LEUEL CONTROLR

5 LI-CA1-3 EUAP CA1-3 CORRECTD

6 FIC-CA1-6 UPPER DE-ENTRN

7 FI-CA1-7 PB-1 PUMP RECIRC FLOW

8 UI-PB1-2A PB-1 PUMP VERTICAL

$g$ UI-PB1-1A PB-1 PUMP HORIZONT

10 UI-PB1-3A PB-1 PUMP LATERAL

11 FI-CA1-1 PB-1 SEAL HATER FLOH

12 PI-CA1-9 PB-1 SEAL HATER PRESSURE

13 FI-CA1-3 RECTRC BYPASS SLURRY FLOW

14 PI-CAI-20 CONDSATE

15 SIC-PB2-1 SLURRY PUMP SPEED CONTROLR

16 UI-PB2-1A PB-2 PUMP LATERAL

17 FI-CA1-2 PB-2 SEAL WATER FLOW

18 PI-CA1-10 PB-2 SEAL HATER PRESSURE

19 FIC-CA1-4 EUAP SLURRY FLOW

20 PI-EA1-14 10 PSI STEAM TO DESUP 


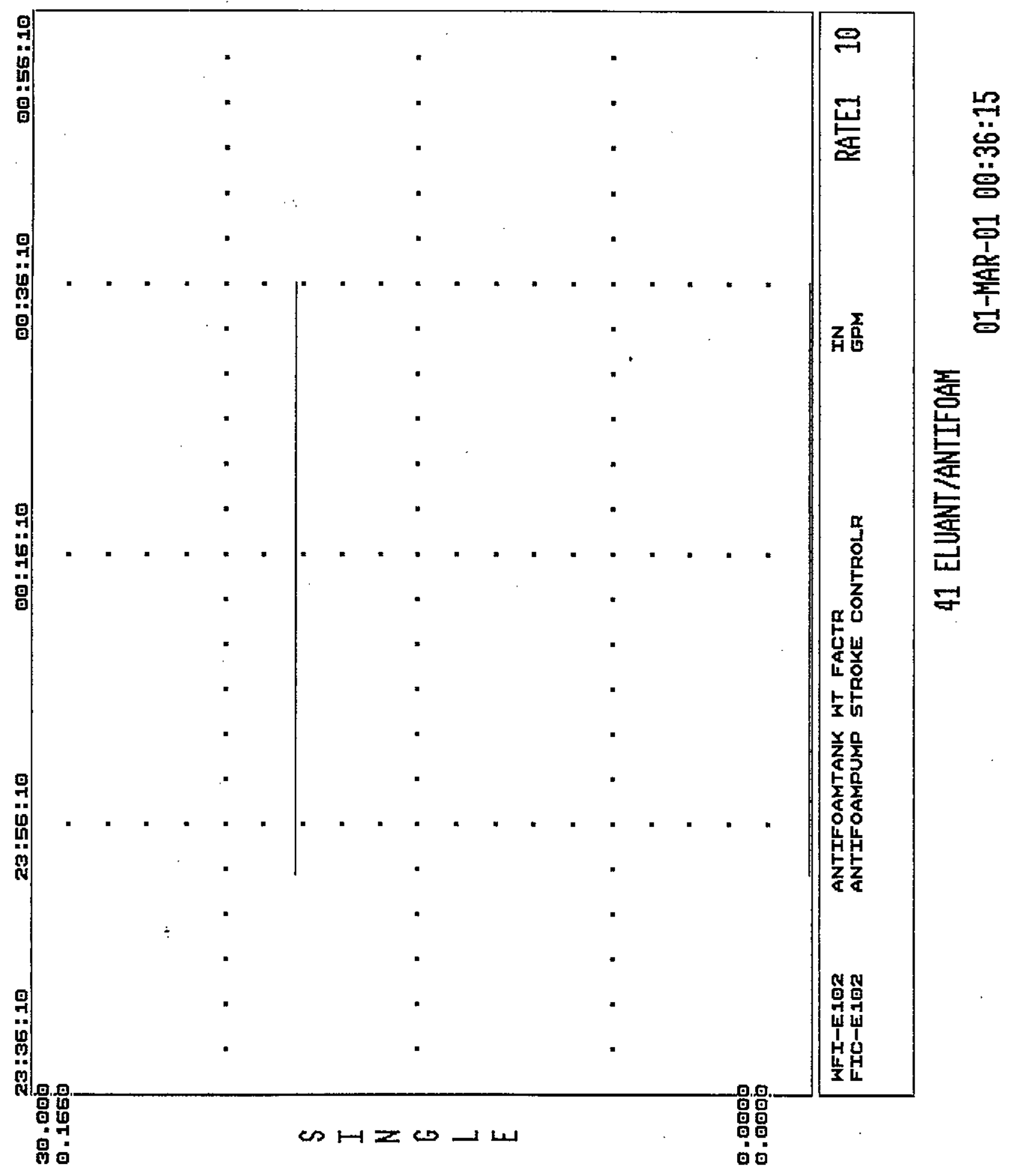




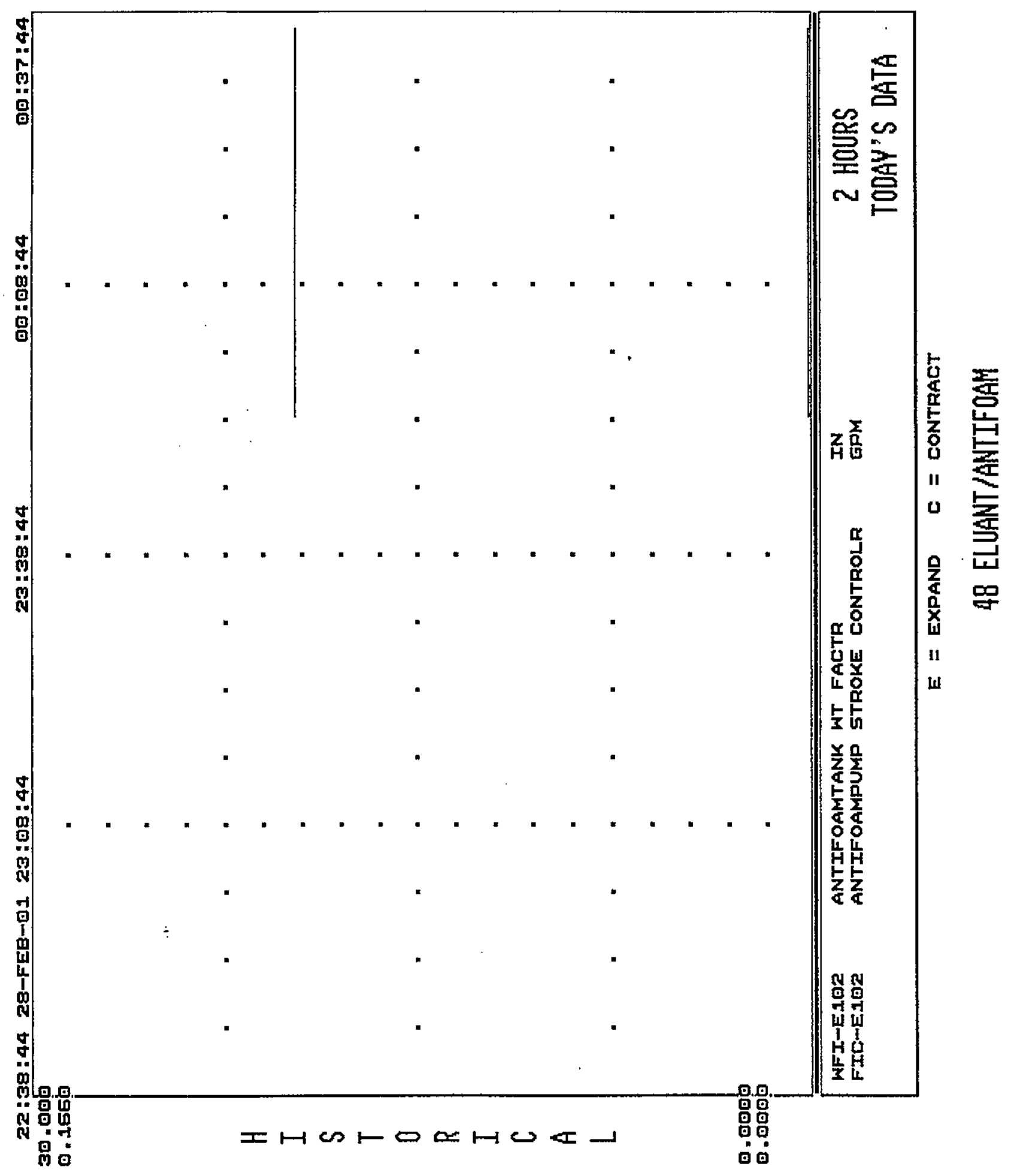




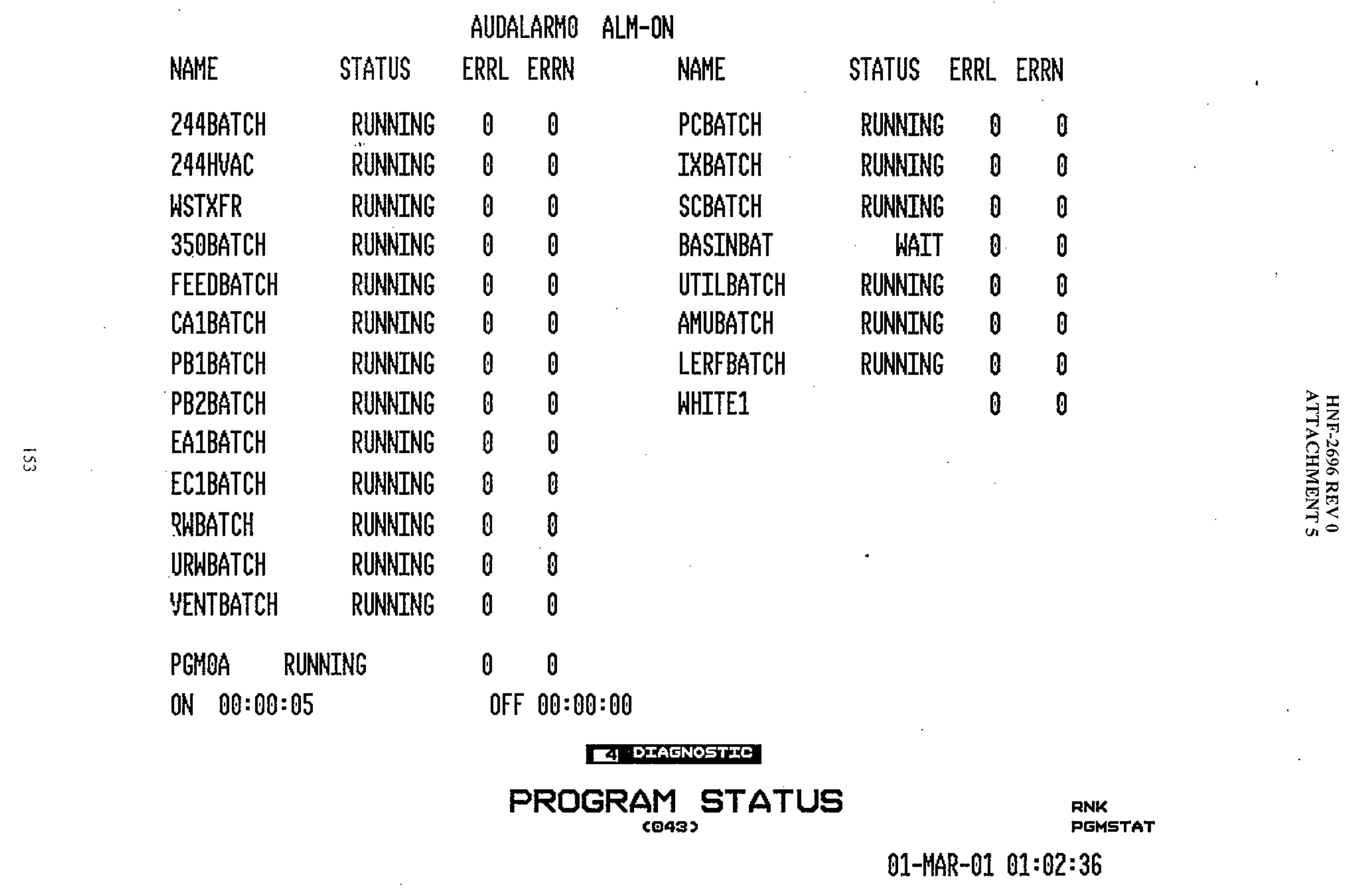




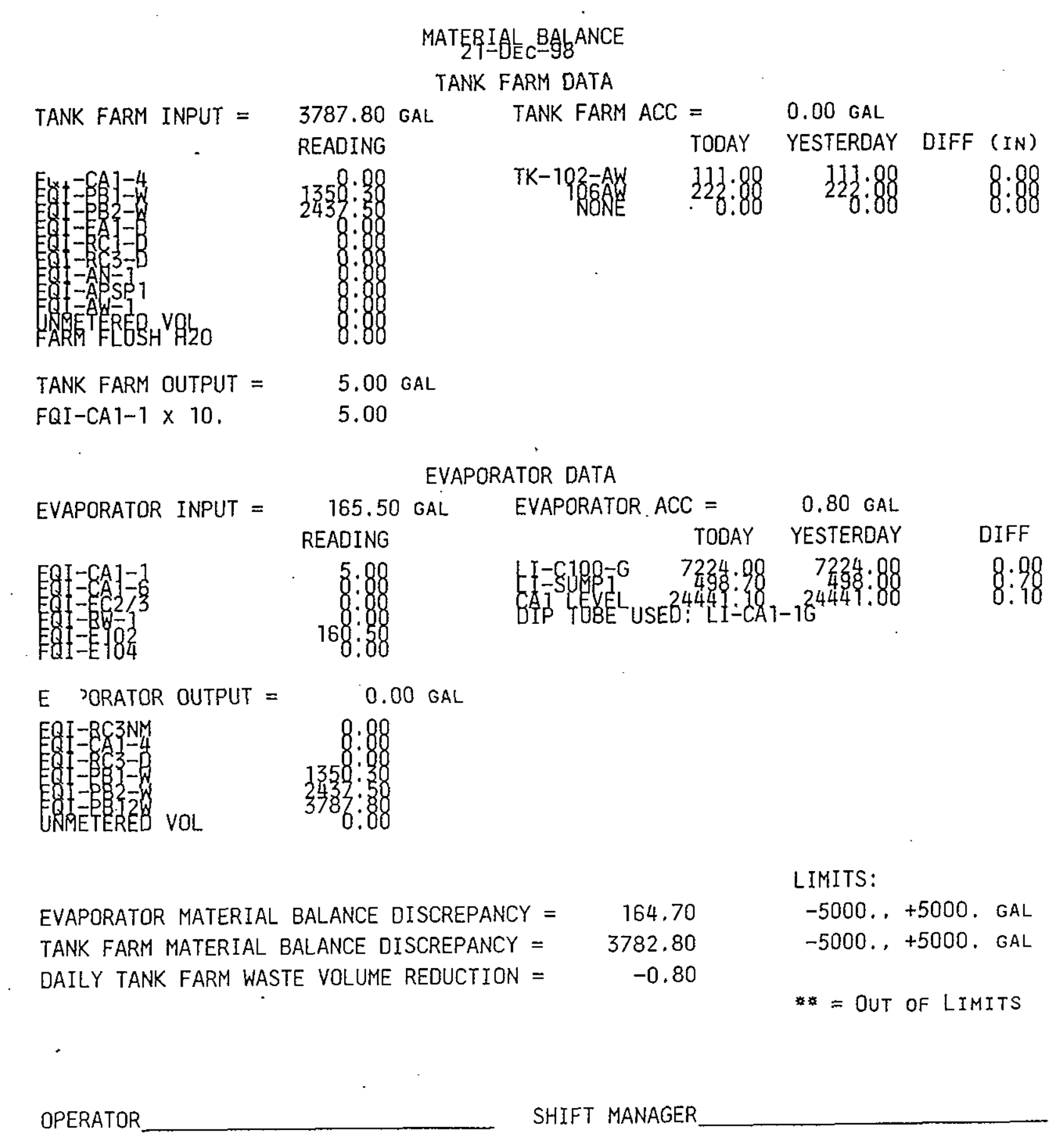


DIRECTORY D3HIS: [HTD]

CDCM001.01C:1

CDCM001.010;1

COCM001.01H;1

CDCM001.01X; 1

CDCMO02. 28C; 1

CDCMO02.280; 1

CDCMO02.28H; 1

CDCM002.28X; 1

CDCM002 2.29C; 1

CDCMO02.29D; 1

CDCMO02.29H; 1

CDCMO02.29X; 1

CDCMO 12.30C; 1

CDCMO 12.30D; 1

COCM012.30H; 1

CDCMO 12.30X; 1

CDCM 102.28C; 1

CDCM 102.28D; 1

CDCM 102.28H: 1

CDCM 102.28X; 1

COCM812.31C; 1

CDCM812.31D; 1

CDCM812.31H; 1

CDCM812.31X; 1

CDCM909.08C; 1

СDCM909.08D; 1

CDCM909.08H; 1

CDCM909.08X; 1

CDCM912.31C; 1

CDCM912.310; 1

CDCM912.31H; 1

CDCM912.31X:1

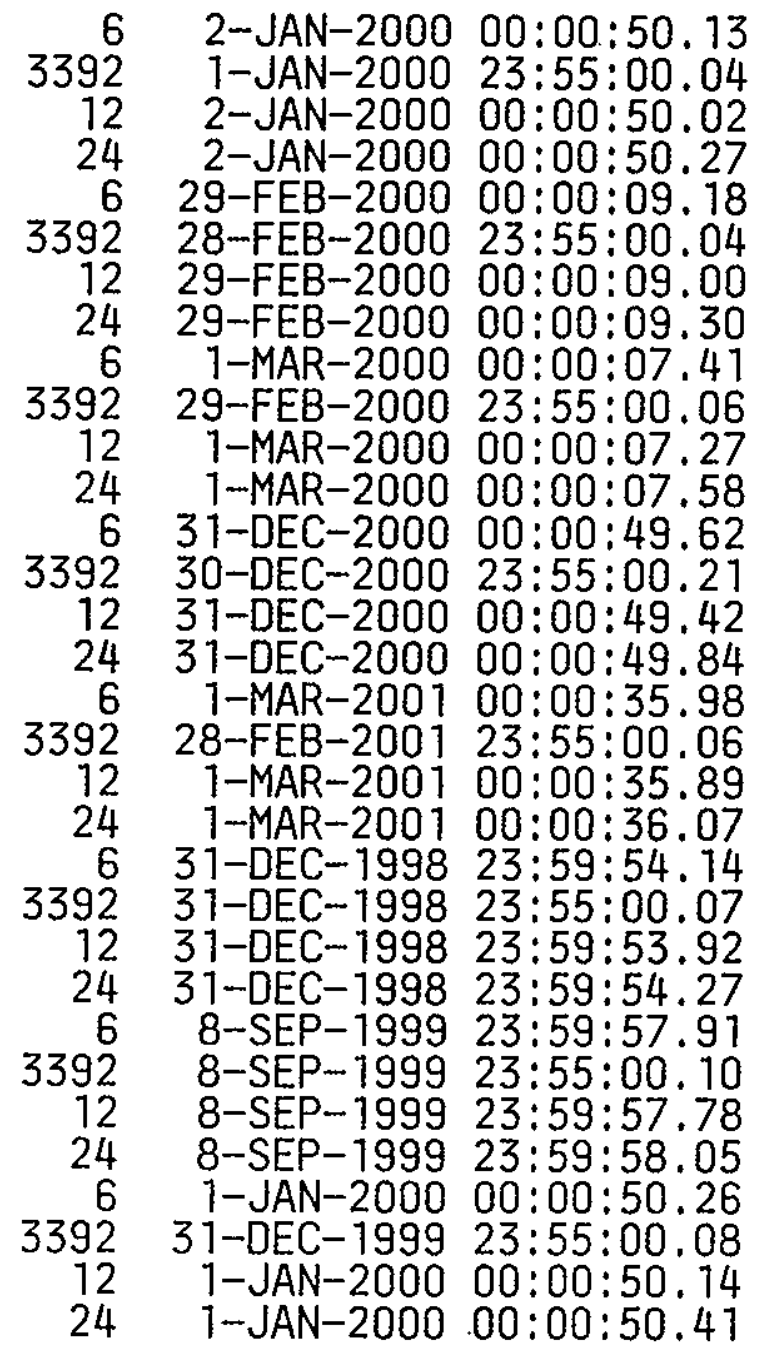

TOTAL OF 32 FILES, 27472 BLOCKS. 
DIRECTORY D3HIS: [AHF]

\begin{tabular}{|c|c|c|}
\hline 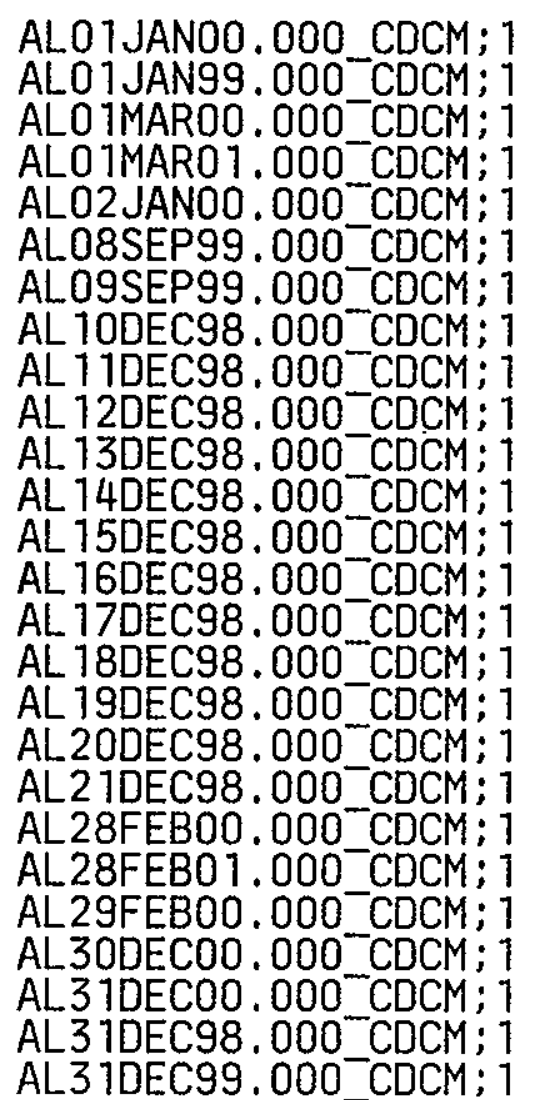 & $\begin{array}{l}76 \\
73 \\
13 \\
34 \\
16 \\
20 \\
58 \\
18 \\
160 \\
6 \\
5 \\
149 \\
552 \\
491 \\
369 \\
19 \\
418 \\
7 \\
13 \\
7 \\
6\end{array}$ & 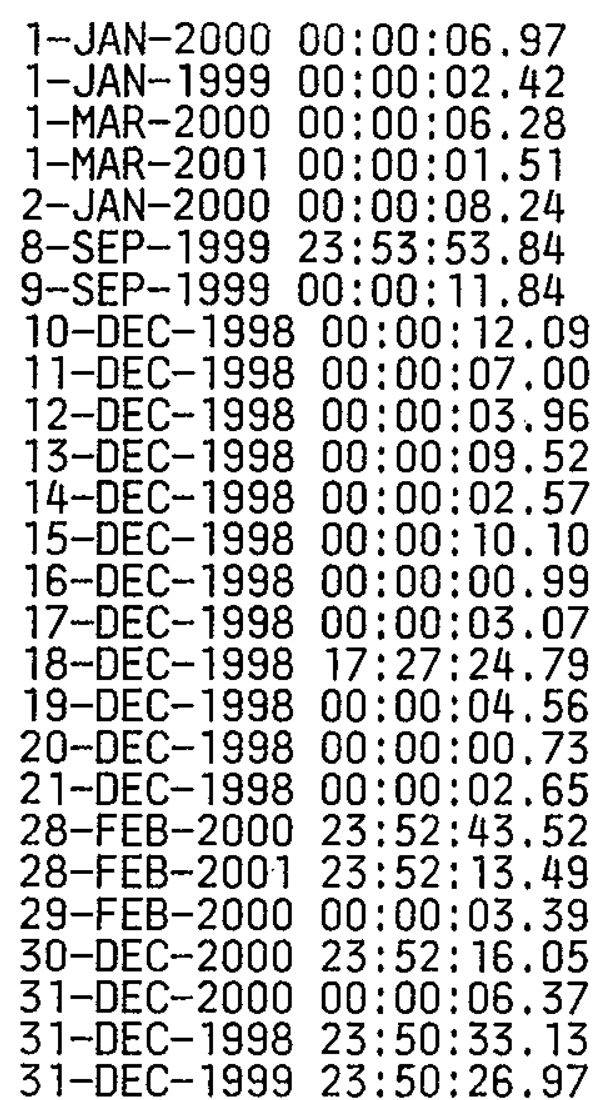 \\
\hline
\end{tabular}

TOTAL OF 26 FILES, 2823 BLOCKS. 


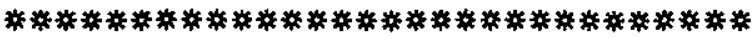
D3APP: [PCMOA. SABL ]DUMMYS. LST ;8

SEquence Instruction COMPILER LISTING 01-MAR-01 01:01:10 DUMMYS

$$
\text { PAGE } 1
$$

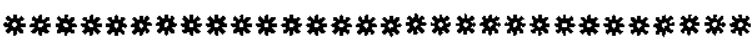

D3APP: [PCMOA. SABL JDUMMYS.LST ;7

SEQUENCE INSTRUCTION COMPILER Listing 31-DeC-00 01:08:47 DUMMYS PAGE 1

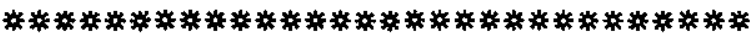
D3APP: [PCMOA. SABL ]DUMMYS. LST ; 6

Sequence Instruction COMpiler Listing 01-MaR-00 01:18:37 DUMMYS PAGE 1

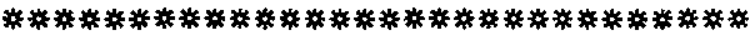
D3APP: [PCMOA. SABL ]DUMMYS.LST ; 5

SEqUENCE INSTRUCTION COMPILER LISTING 29-FEB-00 01:41:52 DUMMYS

$$
\text { PAGE } 1
$$

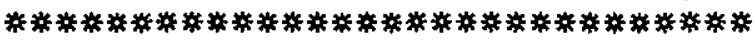

D3APP: [PCMOA. SABL ]DUMMYS. LST ; 4

SEQUENCE INSTRUCTION COMPILER LISTING DUMMYS PAGE 1

02-JAN-00 01:07:15

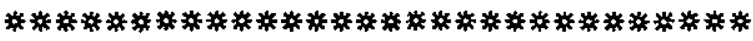

D3APP: [PCMOA. SABL ]DUMMYS. LST;3

SEqUENCE INSTRUCTION COMPILER LISTING 09-SEP-99 01:04:30 DUMMYS PAGE 1

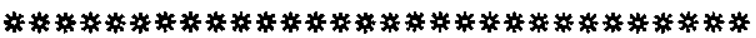

D3APP: [PCMOA. SABL ]DUMMYS.LST ; 2

SEqUENCE InStRUCTION COMPILER LISTING 01-JAN-99 03:23:57 DUMMYS

PAGE 1

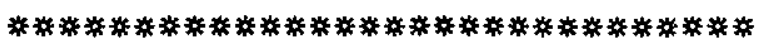

D3APP: [PCMOA. SABL ]DUMMYS. LST ; 1

SEQUENCE InStRUCTION COMPILER LISTING 17-DeC-98 17:00:33 DUMMYS

PAGE 1 


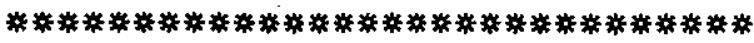

D3APP : [CSPECIALS]DUMMY . LIS ; 2

SOURCE LISTING

16-DEC-1993 17:5\%:19 DEC C V5.5-003

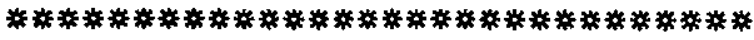

D3APP: [CSPECIALS]DUMMY.LIS;3

SOURCE LISTING T-JAN-1999 03:19:45 DEC C V5.5-003

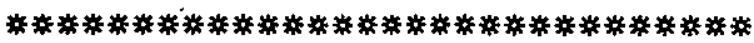

D3APP: [CSPECIALS]DUMMY.LIS ; 4

SOURCE LISTING 9-SEP-1999 00:40:33 DEC C V5.5-003

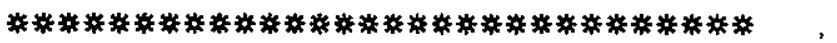

D3APP : [CSPECIALS]DUMMY.LIS ; 5

SOURCE LISTING 2-JAN-2000 00:41:51 DEC C V5:5-003

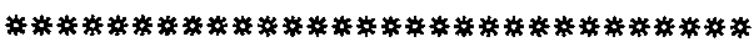

D3APP: [CSPECIALS]DUMMY.LIS; 6

SOURCE LISTING 29-FEB-2000 01:31:20 DEC C V5.5-003

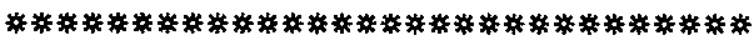

D3APP: [CSPECIALS]DUMMY.LIS ; 7

SOURCE LISTING 1-MAR-2000 00:25:58 DEC C V5.5-003

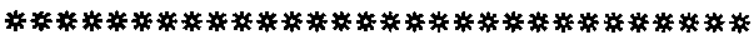

D3APP: [CSPECIALS]DUMMY.LIS ; 8

SOURCE LISTING 31-DEC-2000 00:49:04 DEC C V5.5-003

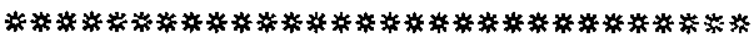

D3APP: [CSPECIALS]DUMMY.LIS ;9

SOURCE Listing 31-DEC-2000 01:08:10 DEC C V5.5-003

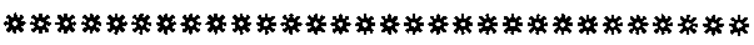

D3APP: [CSPECIALS]DUMMY.LIS ; 10

SOURCE LISTING 1-MAR-2001 01:00:18 DEC C V5.5-003 